\title{
A CATALOGUE.
}

\section{-me}

\section{AdVANCED COLLECTORS$$
-\mathrm{OF}-
$$

\author{
POSTAGE STAMPS,
}

STAMPED ENVELOPES

\section{AND WRAPPERS.}

COMPILED FROM THE MOST RECENT AUTHORITIES AND INDIVIDUAL RESEARCH

$$
-\mathrm{BY}-
$$

\section{Henry Collin and Henry L. Calman.}

$$
P A R T X I .
$$

St. Christopher-South Bulgaria.

NEW YORK :

THE SCOTT STAMP AND COIN CO., LIMITED.

18 EAST 23D STREeT. 



\section{ST, IHRISTOPHER,}

Currency: I2 PENCE $=$ I SHILling; 20 SHILLINGS $=I$ POUND $(£ I)=\$ 4.87$ U. S. Currency.

\section{ADHESIVE STAMPS.}

April Ist, I870.

Typographed on white wove paper, portrait of Queen Victoria. Size I $83 / 4 \times 221 / 2 \mathrm{~mm}$. Watermarked Crown and C. C.

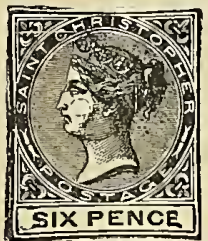

$I^{\circ}$ Perforated $121 / 2$.

Ip rose

Ip lilac rose

Ip violet rose

$6 \mathrm{p}$ green

6p yellow green

$2^{\circ}$ Perforated I 4 .

Ip lilac rose

Ip violet rose

6p green

$6 \mathrm{p}$ yellow green

Varieties:

a. Imperforate vertically.

Io $6 p$ green

b. One penny stamp cut diagonally in two, each half being used as a half-penny stamp. I I $1 / 2 \mathrm{p}$ lilac rose (half of $\mathrm{Ip}$ )

November, 1879 .

Same type, impression and paper as preceding issue. Watermarked Crown and C.C.

Perforated I4.

I2 $21 / 2 \mathrm{p}$ red brown

I3 $4 \mathrm{p}$ blue

End of 1882 .

Same type, impression and paper as preceding issue. Watermarked Crown and C. A.

Perforated I4.

I $4 \quad 1 / 2 \mathrm{p}$ green

I5 IP rose

I6 Ip lilac rose

$72 \frac{1}{2} \mathrm{p}$ red brown

Is $4 \mathrm{p}$ blue

Variety: One penny stamps cut vertically in two, each half being used as a half-penny stamp.

I9 $1 / 2 \mathrm{p}$ lilac rose (half of $\mathrm{IP}$ ), I 883

I 884 .

Same type, impression and paper, as preceding issue. Watermarked Crown and C. A. Periorated I4.

20 Ip pale rose

2 r $2 \mathrm{r} / 2 \mathrm{p}$ ultramarine

224 gray

March, I895.

Provisional issue.

A. One penny stamps of the 1882 issue cut diagonally in two, each half being surcharged "Halfpenny" diagonally. Watermarked Crown and $\mathrm{C} . \mathrm{A}$.

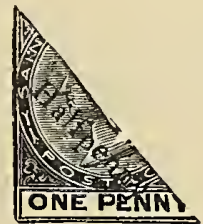

Perforated $\mathbf{I} 4$.

I. Surcharge reading upwards,

$23 \pi / 2 \mathrm{p}$ on half of Ip pale rose, black surcharge, upper half

$24 \quad 1 / 2 p$ on half of Ip pale rose, black sur-

Varieties. charge, lower half

a. Surcharged vertically.

$25 \mathrm{r} / 2 \mathrm{p}$ on half Ip pale rose, black surcharge, upper half

$26 \mathrm{I} / 2 \mathrm{p}$ on half of $\mathrm{IP}$ pale rose, black surcharge, lower half

b. Surcharge inverted.

$27 \quad 1 / 2 p$ on half of Ip pale rose, black surcharge, upper half

$28 \mathrm{I} / 2 \mathrm{p}$ on half of Ip pale rose, black surcharge, lower half

II. Surcharge reading downwards.

$29 \quad 1 / 2 p$ on half of Ip pale rose, black sur. charge, upper half

$30 \quad \mathrm{r} / \mathrm{p}$ on half of Ip pale rose, black surcharge, lower half

Varieties: Surcharge inverted.

3I $1 / 2 \mathrm{p}$ on half of ip pale rose, black surcharge, upper half

$321 / 2 p$ on half of $i p$ pale rose, black surcharge, lower half

B. Sixpenny stamps of the issue of April Ist, I870, surcharged "FOUR PENCE." Watermarked Crown and C. C.

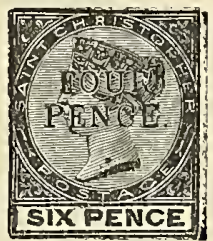

Perforated It

$334 \mathrm{p}$ on $6 \mathrm{p}$ green, black surcharge

Variely: Without period after "Pence."

$34 \quad 4 \mathrm{p}$ on $6 \mathrm{p}$ green, black surcharge

June, 1886.

Sixpenny stamps of the issue of April, I870, surcharged in black with new value and the original value cancelled by a bar. Watermarked Crown and C. C.
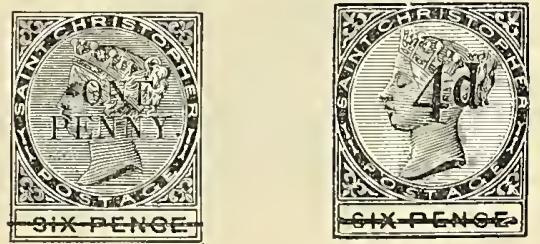

Perforated I4.

35 Ip on $6 \mathrm{p}$ green, black surcharge

$36-4 \mathrm{p}$ on $6 \mathrm{p}$ green

Varietics:

a. Without period after "Penny."

37 Ip on 6p green, black surcharge

b. Without period after "d".

$384 \mathrm{p}$ on $6 \mathrm{p}$ green, black surcharge

c. Surcharge inverted.

39 Ip on $6 p$ green, black surcharge

February, 1887.

Same type, impression and paper, as issues 
of I878-82. Watermarked Crown and C. A. Perforated I4.

40 Ish lilac

May, 1887 .

Provisional issue.

Halfpenny stamps of the issue of $r 882$ surcharged in black with new value, the original value being obliterated $b_{y ̈} a$ bar. Watermarked Crown and C. A.

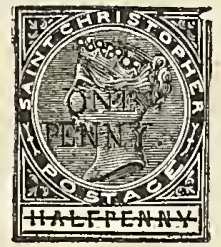

Perforated I4.

4 I IP on $1 / 2 \mathrm{p}$ green, black surcharge

Varieties:

a. Surcharge inverted.

42 Ip on $1 / 2 \mathrm{p}$ green, black surcharge

b. Without period after "penny".

43 I $p$ on $1 / 2$ p green, black surcharge

c. Without bar across original value.

44 Ip on $1 / 2 \mathrm{p}$ green, black surcharge

d. Double surcharge.

45 I $x$ Ip on $1 / 2 \mathrm{p}$ green, black surcharge

There is considerable doubt in regard to the authenticity of variety " $c$ " as the type of the surcharge differs somewhat from that of the normal type; in the variety the top branch of the "E" s is narrower than the lower and the " $y$ " branches out nearer the bottom.

May, I888.

Provisional issue.

Two pence halfpenny stamps of the issue of I 884, surcharged with new value. There are two varieties of the surcharge; one has the letters $3 \mathrm{~mm}$. high and the original value obliterated by a bar; the other has the letters measuring only $2 \mathrm{~mm}$. in height and the original value is not cancelled. Watermarked Crown and C. A.

REVENUE STAMPS USED FOR POSTAGE.

I 885.

I. Postage stamps of St. Christopher surcharged "SAINT KITTS-NEVIS-REVENUE." Watermarked Crown and C. A.

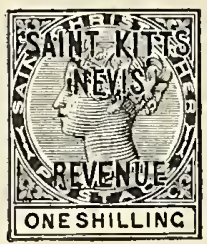

Perforated I4.

$\begin{array}{ll}54 & \text { Ip rose } \\ 55 & 3 \mathrm{p} \text { violet } \\ 56 & 6 \mathrm{p} \text { green } \\ 57 & 6 \mathrm{p} \text { orange brown }\end{array}$

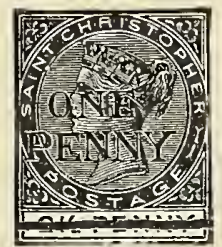

Type I.

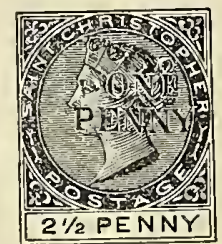

Type II
Perforated 14.

46 Ip on $2 \mathrm{t} / 2 \mathrm{p}$ ultramarine, black surcharge, type I

47 Ip on $21 / 2 \mathrm{p}$ ultramarine, black sur-

Varieties: charge, type 2

a. Surcharge inverted.

48 Ip on $2 \frac{1}{2} \mathrm{p}$ ultramarine, black surcharge, type I

b. Double surcharge.

49 IxIP on $2 \frac{1}{2} \mathrm{p}$ ultramarine, black sur-

I 890 . charge, type I

Same type, impression and paper as previous regular issues. Watermarked Crown and C. A.

Perforated $\mathrm{r} 4$

50 Ip carmine rose (February)

51 6p olive brown (May)

52 Ish violet

February, 1890.

Provisional issue.

One penny stamps of Antigua, issue of I 884 , used in St. Christopher pending the arrival of a supply of one penny stamps from England. Watermarked Crown and $\mathrm{C} A$.

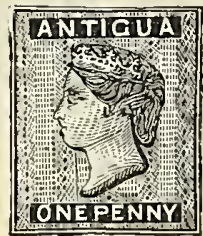

Perforated I 4 .

53 Ip rose red

This provisional can be identified by the St. Christopher postmark, "A I2." $\begin{array}{ll}58 & \text { Ish reseda } \\ 59 & \text { Ish rose }\end{array}$

II. Postage stamps of Nevis surcharged "Saint Christopher Revenue." Watermarked Crown and C. A.

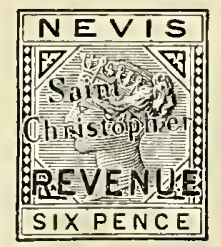

Perforated I 4 .

6o $6 \mathrm{p}$ green, black and lilac surcharge

6I Ish lilac, black surcharge

COUNTERFEITS.

We do not know of any good forgeries of the regular issues of the colony; we have, however seen some very dangerous counterfeits of the provisional I penny on $2 \frac{1 / 2 p}{\mathrm{p}}$ ultramarine, type II, and of the provisional I penny on $1 / 2 \mathrm{p}$ green with inverted surcharge; the surcharges on both of these are soclosely imitated that only experts can distinguish them from the genuine. Cleaned revenue stamps with forged postmarks are pleatiful, a d collectors should be especially careful in purchasing these.

Since October, I89o, this colony has ceased to issue stamps of its own, and is using those of the Leeward Islands. 


\section{ST. HELENA.}

Currency : I2 PENCE $=$ I SHILLING; 20 SHILLINGS $=$ I POUND $-\$ 4.87$, U. S. Currency.

\section{ADHESIVE STAMPS.}

1856.

Engraved in taille douce on white wove paper varying in thickness, sometimes blued by chemical action of the gum. Size $191 / 4 \mathrm{x}$ $25 \mathrm{H} / 2 \mathrm{~mm}$.

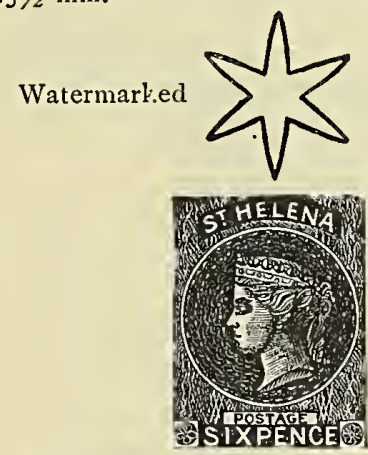

I. White wove paper.

I $6 \mathrm{p}$ blue

II. White wove paper blued.

$26 \mathrm{p}$ blue

1862.

Same type, impression and paper as preceding issue. Watermarked a large six rayed star.

Perforated $I_{4}$ to $I_{5} \mathrm{I} / 2$, single and compound.

I White wove paper.

$36 \mathrm{p}$ blue

II. White wove paper blued.

$46 \mathrm{p}$ blue

1863.

Same type as preceding issue but with original value obliterated by a black line and new value surcharged above it. On the one penny stamp the letters of the surcharge are $21 / 2 \mathrm{~mm}$., in height, DUE PEAMY and on the four penny stamp they are $3 \mathrm{~mm}$. FOUR PENCE In the one penny there are two styles of bars; the first measuring from 16 to $17 \mathrm{~mm}$., and the second $181 / 2$ to I $1 / 2 \mathrm{~mm}$. Watermarked Crown and C.C.

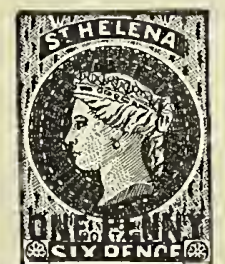

$I^{\circ}$ Surcharge $21 / 2 \times 161 / 2$ to $171 / 2 \mathrm{~mm}$. Bar 16 to $17 \mathrm{~mm}$.

5 Ip red, black surcharge

$2^{\circ}$ Surcharge $21 / 2 \times 181 / 2$ to $19 \mathrm{~mm}$.

Bar $18 \mathrm{r} / 2$ to $\mathrm{I} 9 \mathrm{I} / 2 \mathrm{~mm}$.

6 Ip red, black surcharge

$3^{0}$ Surcharge $3 \times 16 \frac{1}{2}$ to $17 \mathrm{~mm}$.

Bar I6 to $\mathrm{I} 7 \mathrm{~mm}$.

$7 \quad 4$ p rose, black surcharge

Variety: Without surcharge.

8 6p rose

I 864 .

Same type, impression and paper as pre ceding issue. Watermarked Crown and C. C.

Perforated $12 \frac{1}{2}$.

$I^{0}$ Surcharge $21 / 2 \times I 71 / 2 \mathrm{~mm}$.

Bar 16 to $\mathrm{I} 7 \mathrm{~mm}$.

9 Ip red, black surcharge

$2^{\circ}$ Surcharge $3 \times 161 / 2$ to $17 \mathrm{~mm}$.

Bar 16 to $17 \mathrm{~mm}$.

Io $4 \mathrm{p}$ rose carmine, black surcharge

I I 4p carmine, black surcharge

Variety: Double surcharge.

I2 $4 \times 4 \mathrm{p}$ carmine, black surcharge

$3^{\circ}$ Surcharge $3 \times 171 / 2$ to $18 \mathrm{~mm}$.

Bar I6 to $17 \mathrm{~mm}$.

I 3 Ish yellow green, black surcharge

- I868.

Same type, paper and impression as preceding issue. Watermarked Crown and C. C.

Perforated I $21 / 2$.

$\mathrm{I}^{0}$ Surcharge $2 \mathrm{I} / 2 \times \mathrm{I} 7 \mathrm{I} / 2 \mathrm{~mm}$

Bar I4 to $141 / 2 \mathrm{~mm}$.

I4 Ip red, black surcharge

$2^{\circ}$ Surcharge $3 \times 151 / 2 \mathrm{~mm}$.

Bar I4 to $141 / 2 \mathrm{~mm}$.

I5 2P yellow, black surcharge

$3^{\circ}$ Surcharge $3 \times 171 / 2$ to $18 \mathrm{~mm}$.

Bar I4 to $14 \frac{1}{2} \mathrm{~mm}$.

I6 $3 \mathrm{p}$ brown violet, black surcharge

I 7 P violet, black surcharge

$4^{\circ}$ Surcharge $3 \times 18$ to $19 \mathrm{~mm}$.

Bar I 3 to $141 / 2 \mathrm{~mm}$.

$184 \mathrm{p}$ rose, black surcharge

I9 $4 \mathrm{p}$ carmine rose, black surcharge

$5^{\circ}$ Surcharge $21 / 2 \times 161 / 2$ to $17 \mathrm{~mm}$.

Bar I4 to $14 \frac{1}{2} \mathrm{~mm}$.

20 tsh yellow green, black surcharge

$6^{\circ}$ Surcharge $21 / 2 \times 18 \mathrm{~mm}$.

Bar I4 to I $4 \frac{1}{2} \mathrm{~mm}$.

2 I 5 sh orange, black surcharge

I $871-73$.

Same type, impression and paper as preceding issue. Watermarked Ciown and

C. C.

Perforated $121 / 2$.

$I^{\circ}$ Without surcharge.

$226 p$ milky blue (1871)

$236 p$ dull blue (1873)

$2^{\circ}$ Surcharge $3 \times 17 \mathrm{~mm}$.

Bar I $6 \mathrm{r} / 2$ to $\mathrm{I} 7 \mathrm{~mm}$.

$24 \quad$ Ip red, black surcharge

$3^{\circ}$ Surcharge $3 \times 18 \mathrm{~mm}$.

a. Bar $18 \mathrm{~mm}$.

25 2p yellow, black surcharge

b. Bar I6 $1 / 2$ to $171 / 2 \mathrm{~mm}$.

26 3p violet, black surcharge

c. Bar $16 \mathrm{~mm}$.

$273 \mathrm{p}$ brown violet

d. Bar I 7 to $18 \mathrm{~mm}$.

28 Ish deep green, black surcharge

I877.

Same type, as preceding issue, white wove paper, blued. 
Watermarked Crown and C. C.

Perforated I 4 .

Surcharge $2 \frac{1}{2} \times 171 / 2 \mathrm{~mm}$.

Bar?

29 Ip dark red

We catalogue this stamp on the authority of $\mathrm{Mr}$. Moens.

I 882-84.

Same type, impression and paper as pre-

ceding issue. Watermarked Crown and C. A.

I. Perforated I4XI2 $1 / 2$.

$I^{\circ}$ Without surcharge.

$30 \quad 6 \mathrm{p}$ gray blue

$2^{\circ}$ Surcharge $21 / 2 \times 17 \mathrm{~mm}$.

Bar $13 \mathrm{I} / 2$ to $14 \mathrm{~mm}$.

3 I Ip red, black surcharge

$3^{\circ}$ Surcharge $3 \times 151 / 2 \mathrm{~mm}$.

Bar $14 \mathrm{~mm}$.

32 2p yellow, black surcharge

$4^{0}$ Surcharge $3 \times 17$ to $17 \frac{1}{2} \mathrm{~mm}$.

a. Bar I 4 to $15 \mathrm{~mm}$.

$33 \quad 3 \mathrm{p}$ violet, black surcharge

b. Bar I4 to $141 / 2 \mathrm{~mm}$.

$34 \quad 4 \mathrm{p}$ rose carmine, black surcharge

$5^{\circ}$ Surcharge $3 \times 171 / 2$ to $18 \mathrm{~mm}$

Bar $17 \% 2$ to $18 \mathrm{~mm}$.

35 Ish green, black surcharge

II. Perforated I4.

Io Without surcharge.

$36 \quad 6$ p gray blue

$2^{\circ}$ Surcharge $2 \mathrm{I} / 2 \times 17 \mathrm{~mm}$.

Bar I4 to $141 / 2 \mathrm{~mm}$.

37 Ip red, black surcharge

$3^{\circ}$ Surcharge $3 \times 15$ to $151 / 2 \mathrm{~mm}$

Bar 14 to $14 \frac{1}{2} \mathrm{~mm}$.

$3^{8} \quad 2$ yellow, black surcharge

$4^{0}$ Surcharge $2 \frac{1}{2} \times 17 \mathrm{~mm}$.

Bar $13 \frac{x}{2}$ to $14 x / 2 \mathrm{~mm}$.

39 Ish yellow green, black surcharge I 884-90.

Same type, impression and paper as preced ing issue. Watermarked Crown and C. A.

Perforated I4

$I^{0}$ Without surcharge.

406 gray (I 889 )

$2^{\circ}$ Surcharge $3 \times I 7$ to $\mathrm{I} 7 \mathrm{I} / 2 \mathrm{~mm}$.

Bar I $31 / 2$ to $141 / 2 \mathrm{~mm}$.

4 I $1 / 2 \mathrm{p}$ emerald green, black surcharge, (blurred print, I 884)

$42 \quad 1 / 2 \mathrm{p}$ light yellow green, black surcharge

43 1/2 p dark yellow green, black surcharge

Variety: Double surcharge, the bars meas uring respectively $\mathrm{I} 4$ and $\mathrm{I}+\mathrm{I} / 2 \mathrm{~mm}$.

$441 / 2 \times 1 / 2 \mathrm{p}$ emerald green, black surcharge $3^{\circ}$ Surcharge $21 / 2 \times 17$ to $171 / 2 \mathrm{~mm}$.

Bar $131 / 2$ to $15 \mathrm{~mm}$.

45 Ip pale red, black surcharge (I888)

$4^{\circ}$ Surcharge $3 \times 171 / 2$ to $18 \mathrm{~mm}$.

Bar $I 3 \mathrm{I} / 2$ to $\mathrm{I}_{4} \mathrm{I} / 2 \mathrm{~mm}$.

$463 \mathrm{p}$ violet, black surcharge ( 1887 )

$5^{\circ}$ Surcharge $3 \times 17 \mathrm{~mm}$

Bar $13 \frac{1}{2}$ to $14 \frac{1}{2} \mathrm{~mm}$.

474 p brown, black surcharge (1890)

Variety: With thin line, $18 \mathrm{~mm}$. long. below the thick line.

$4^{8} 4 \mathrm{p}$ brown, black surcharge

This is the second stamp from the left in the seventh horizontal row.

June, $r 89$.

Typographed on white wove paper. The name and denomination of value are printed in different colors from the remainder of the stamp. Size $181 / 4 \times 221 / 2 \mathrm{~mm}$. Watermarked Crown and C. A

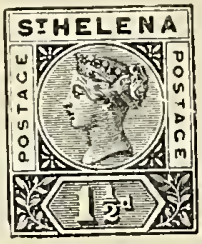

Perforated I4

$49 \mathrm{I} \mathrm{I} / 2 \mathrm{p}$ brown and green

I 893 .

Same type, paper and impression as the issue of $1856-62$, surcharged " $2 \mathrm{I} / 2 \mathrm{~d}$ " and origina! value obliterated with a black line.

Watermarked Crown and C. A.

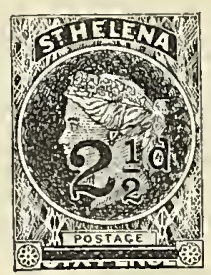

Perforated 14

Bar I $31 / 2$ to $\mathrm{I}_{4} \mathrm{I} / 2 \mathrm{~mm}$.

$50 \quad 2 \mathrm{I} / 2 \mathrm{p}$ ultramarine, black surcharge I 894 .

Same type, paper and impression as issue of r884-00. Watermarked Crown and C. A

Perforated 14 .

Surcharge $3 \times 151 / 2 \mathrm{~mm}$

$\mathrm{I}^{\circ} \mathrm{Bar} \mathrm{I} 4 \mathrm{~mm}$.

5 I $1 / 2 \mathrm{p}$ green, black surcharge

$2^{\circ} \operatorname{Bar} \mathrm{I} 3 \mathrm{I} / 2$ to $14 \mathrm{I} / 4 \mathrm{~mm}$.

52 2p yellow, black surcliarge

I 895 .

Same type, impression and paper as preceding issue. Watermarked Crown and C.A.

Perforated I.4.

Surcharge $3 \times 171 / 2 \mathrm{~mm}$.

Bar $171 / 2 \mathrm{~mm}$.

53 Ish yellow green, black surcharge

The stamps of the preceding issues, No. 49 excepted, are printed in sheets of 240 stamps. in 20 consecutive horizontal rows of 12 each, instead of four panels of 60 slamps each, separated from one another by a border watermarked "Crown Colonies" or "Crown Agents for the Colonies," as is the case with other colonial stamps; this was done on account of the size of the stamps, which is larger than that of the other colonial stamps. As a result the stamps of the seventh vertical and of the tenth horizontal rows show only a very small part of the watermark Crown and C. C. or C. A., but also show parts of the letters forming the marginal watermark; the stamps of the bottom row are generally without any watermark except a horizontal line, a portion of the frame surrounding the watermarks in each panel.

1896.

Same type, impression and paper as issue of June I 890 .

Watermarked Crown and C.A.

Perforated I4.

$54 \quad 1 / 2 \mathrm{P}$ green

55 Ip rose

56 2p yellow

$57 \quad 21 / 2 \mathrm{p}$ ultramarine

$585 \mathrm{p}$ violet

59 Iop brown

COUNTERFEITS.

We do not know of any good forgeries of the stamps of St. Helena. 
ST. LUOIA.

Currency: I 2 PENCE $=$ I SHILling ; 20 SHILLINGS $=\mathrm{I} £=\$ 4.87=U$. S. CuRRENCY. ADHESIVE STAMPS.

December 18 th, I860.

Engraved in taille douce, portrait of Queen Victoria, on white wove paper, watermarked

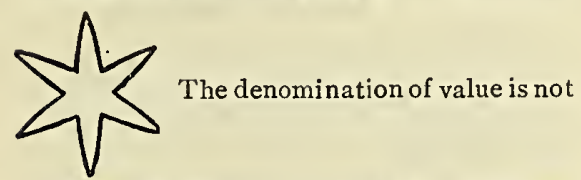

expressed on the stamp. Size $181 / 2 \times 221 / 2 \mathrm{~mm}$.

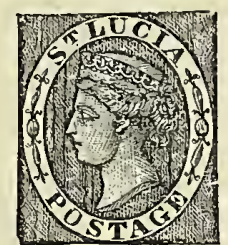

Perforated 14 to $I 6$.

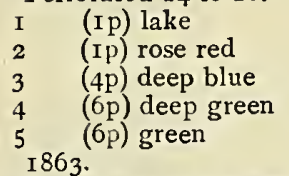

Same type as preceding issue, engraved on white wove paper. Watermarked Crown and C. C.

$$
\begin{aligned}
& \text { Perforated I2 } 1 / 2 \text {. } \\
& 6 \text { (Ip) lake } \\
& 7 \text { (4P) slate blue } \\
& 8 \text { (4p) deep slate blue } \\
& 9 \text { (6p) emerald green } \\
& \text { Varieties: Imperforate. } \\
& \text { Io (4p) slate blue } \\
& \text { I I (6p) emerald green }
\end{aligned}
$$

November Igth, I864.

Same type, paper and impression as preceding issue. Watermarked Crown and C.C. $I^{\circ}$ Perforated $121 / 2$.

$\begin{array}{ll}\text { I2 } & \text { (Ip) black } \\ \text { I3 } & \text { (Ip) gray black } \\ \text { 14 } & \text { (4p) yellow } \\ \text { I5 } & \text { (4p) olive yellow } \\ \text { I6 } & \text { (6p) violet } \\ \text { I7 } & \text { (6p) lilac } \\ \text { I8 } & \text { (6p) mauve } \\ \text { I9 } & \text { (Ish) orange } \\ 20 & \text { (Ish) red orange } \\ & 2^{\circ} \text { Perforated I4. } \\ 21 & \text { (Ip) black } \\ 22 & \text { (Ip) gray black } \\ 23 & \text { (4p) yellow } \\ 24 & \text { (6p) pale lilac } \\ 25 & \text { (6p) deep Iilac } \\ 26 & \text { (Ish) orange } \\ 27 & \text { (Ish) deep orange }\end{array}$

Variety: Vertical half of 4 penny yellow used as 2 penny.

$282 \mathrm{p}$ yellow (half of $4 \mathrm{p}$ )

September, I88r.

Same type, paper and impression as preceding issue, with value surcharged horizontally across the stamp in black. Watermarked Crown and C. C.

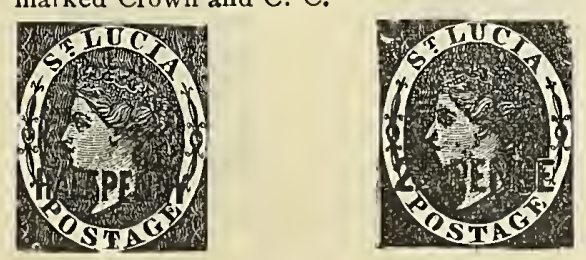

Perforated 14.

$29 \quad 1 / 2$ p green, black surcharge

$30 \quad 21 / 2 \mathrm{p}$ scarlet, black surcharge

3 I $21 / 2 \mathrm{p}$ deep scarlet, black surcharge

April, I882.

Same type, paper and impression as pre. ceding issue. Watermarked Crown and C.C. Perforated $x 4$.

32 xp black, carmine surcharge

V ariety: I penny stamp cut vertically in two, each half being used as $1 / 2$ penny.

$331 / 2 \mathrm{p}$ black, carmine surcharge (half of $\mathrm{Ip}$ ) I883.

A. Provisional issue.

I penny stamp of the $x 864$ issue surcharg. ed in M. S. "rd" in the center and a numeral " $x$ " in each of the four corners in violet ink. Watermarked Crown and C. C.

Perforated I4.

34 Ip black, violet surcharge

Variety: Without the numeral " $\mathrm{I}$ " in the corners.

35 Ip black, violet surcharge

B. Regular issue.

Same type, paper and impression as the issues of I88I-82. Watermarked Crown and C. A.

$I^{0}$ Perforated I4.

$36 \quad 1 / 2 \mathrm{p}$ green, black surcharge

37 Ip gray black, carmine surcharge

38 Ip black, carmine surcharge

$393 \mathrm{p}$ dark blue, carmine surcharge

40 4p yellow, black surcharge

4 I 6p violet "“ “"

42 Ish orange “" “"

Varieties:

a. "ONE" spelt "ONEE."

44 Ip black, carmine surcharge

b. Without surcharge.

45 (3p) dark blue

$46 \quad(6 \mathrm{p})$ violet

Nos. 39 and 45 are probably Revenue stamps from which the surcharge has been removed.

$2^{\circ}$ Perforated i 2.

$474 \mathrm{p}$ yellow, black surcharge

July 6 th, I 883 .

Typographed on white wove paper, portrait of Queen Victoria. Size $183 / 4 \times 221 / 2 \mathrm{~mm}$. Watermarked Crown and C. A.

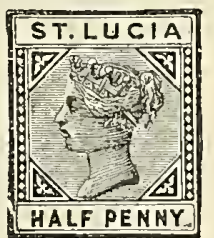

Perforated I4.

$48 \quad 1 / 2 \mathrm{p}$ green

49
50
$2 \mathrm{IP} / 2 \mathrm{p}$ ultramarine

January, 1885 .

Stamps of the issue of 1863 surcharged with new value in black. Watermarked Crown and $C . C$. 


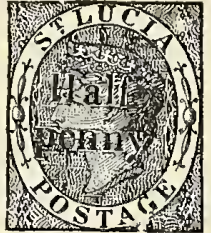

Perforated I $21 / 2$

5 I $\quad 1 / 2 \mathrm{p}$ emerald green, black surcharge

$526 \mathrm{p}$ slate blue, black surcharge

These stamps were prepared for issue, but never went into use

I 885 .

Same type, paper and impression as the issue of July, I883. Watermarked Crown and $C$. A.

Perforated I 4 .

$534 \mathrm{p}$ brown

$546 \mathrm{p}$ lilac

55 Ish orange brown

February, I886.

Same type, impression and paper as preceding issue. The body of all the stamps is printed in lilac and the inscriptions at the top and bottom are printed in green on the $3 p$, blue on the $6 \mathrm{p}$ and carmine on the Ish. Watermarked Crown and C. A.

Perforated $\mathbf{I} 4$.

56 Ip lilac

$57 \quad 3 p$ lilac and green

$586 \mathrm{p}$ lilac and blue

59 Ish lilac and carmine

I $889-93$

Same type as preceding issue, but reengraved. Typographed on white wove paper. The differences between the reengraved and the preceding type are as follows: In the re-engraved, the lines of the groundwork are thinner, the upper part of the second jewel of the band of the crown is like a large white dot, and this jewel does not touch the line below it; the lines of shading in the lower part of the neck are longer than in the first type. Watermarked Crown and C. A.

Perforated I4.

to $\quad 1 / 2 \mathrm{p}$ green

6 I lilac

$62 \quad 2 \mathrm{r} / 2 \mathrm{p}$ ultramarine

$63 \quad 3 \mathrm{p}$ lilac and green

4 prown (1893)

Ish lilac and carmine

5 sh lilac and orange

67 rosh lilac and black

January 29th, I892.

Provisional issue.

I. Four penny stamps of the issue of 1885 surcharged in black with new value. Watermarked Crown and C. A.

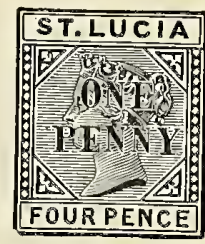

Perforated I 4

68 Ip on $4 \mathrm{p}$ brown, black surcharge

II. Three penny stamps of the issues of I886-89 surcharged with new value in black Watermarked Crown and C. A.

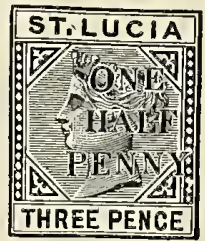

Perforated I4

$69 \quad 1 / 2 \mathrm{p}$ on $3 \mathrm{p}$ lilac and green, black surcharge

$70 \mathrm{r} / 2 \mathrm{p}$ on $3 \mathrm{p}$ lilac and green, black surcharge (re-engraved type)

Variety: Double surcharge and additional surcharge on reverse of stamp.

7 I $1 / 2 \mathrm{P}$ on $3 \mathrm{p}$ lilac and green, black surcharge (re-engraved type)

III. Six penny stamps of the issue of $I 886$ cut vertically in two and each half surcharged with new value in black. Watermarked Crown and C. A.

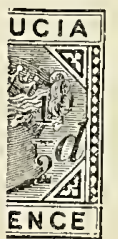

Perforated I4

$721 / 2 \mathrm{p}$ on half of $6 \mathrm{p}$ lilac and blue, blark surcharge (right half)

$731 / 2 \mathrm{p}$ on half of $6 \mathrm{p}$ lilac and blue, black surcharge (left half)

Varieties:

a. Slanting serif.

$74 \quad 1 / 2 \mathrm{p}$ on half of $6 \mathrm{p} \mathrm{lilac}$ and blue, black surcharge (left half)

b. Without the bar of $1 / 2$.

$75 \quad 1 / 2 \mathrm{p}$ on half of $6 \mathrm{p}$ lilac and blue, black surcharge (left half)

c. Without the " 2 " of the $1 / 2$

$761 / 2 \mathrm{p}$ on half of $6 \mathrm{p}$ lilac and blue, black surcharge (right half)

$77 \quad x / 2 p$ on half of $6 p$ lilac and blue, black surcharge (left half)

\section{REVENUE STAMPS USED FOR POSTAGE.}

I 882-84.

Various revenue stamps of the issues of 188 I to 1833.

A. Watermarked Crown and C. C.

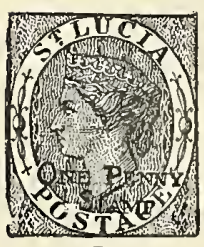

I.

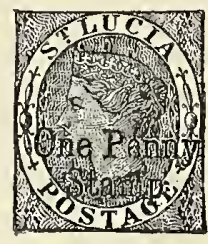

II.

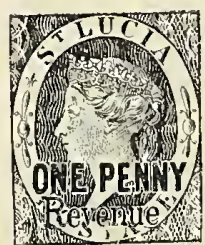

III.

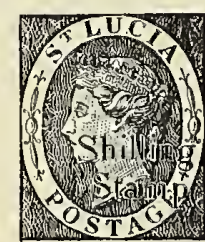

IV. 
Perforated I4.

\begin{tabular}{|c|c|c|c|c|}
\hline IOI & \multicolumn{4}{|c|}{ Ip black, carmine surcharge, type I } \\
\hline IO2 & 4p yellow, & black & $" 1$ & \\
\hline IO3 & $6 \mathrm{p}$ violet & $"$ & “ & “ \\
\hline 104 & (I) sh orange & “6 & " & “ \\
\hline 5 & Ip black, c & armine & “ & type \\
\hline & 4p yellow, & black & “ & \\
\hline 2 & $6 \mathrm{p}$ Iilac & “" & “ & “ \\
\hline & $1 / 2 \mathrm{p}$ green & $" 6$ & "6 & Iype \\
\hline & (I) sh orange & “ & “ & \\
\hline
\end{tabular}
arieties:

a. SHileing instead of SHILliNG.

I IO (I)sh orange, black surcharge, type I b. SHILDING inslead of SHILLING.

I I (I)sh orange, black surcharge, type I

B Watermarked Crown and C. A.

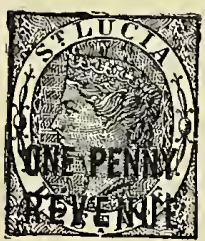

V.

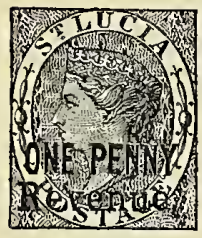

VII.

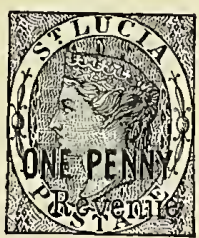

VI.

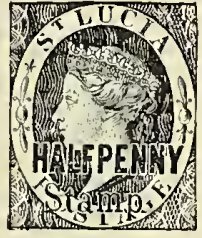

VIII.

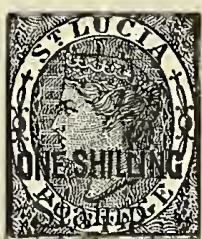

IX.
$I^{\circ}$ Perforated I4.

Ip black, carmine surcharge, type 5

2p pale blue, black

3p deep blue; carmine ". "“

4p yellow, black “، “،

6p violet brine " $\quad$ type 6

Ip black, carmine “ “

$1 / 2 \mathrm{p}$ green, black “" type 8

Ip black, carmine " "

iety: Double surcharge, one inverted

Variety: Double surcharge, one inverted at top.

I22 Ip black, carmine surcharge, type 8

O Perforated I 2.

I23 Ip black, carmine surcharge. type 5

124 3p deep blue ".

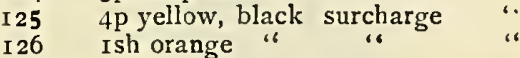

I 26

I 834 .

Revenue stamps of the issue of ${ }^{2} 88_{3}$. Watermarked Crown and C. A.

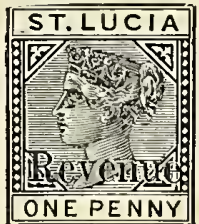

Perforated I4

I 27 Ip rose, black surcharge

I 885 .

Revenue stamps of the same date. Water-marked Crown and C. A.

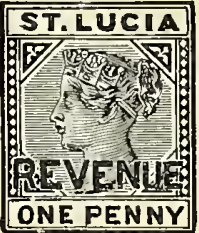

Perforated I 4

I28 Ip slate, carmine surcharge

I29 Ip lilac, black surcharge

REGISTRATION ENVELOPES.

December 2oth, 1887 .

Stamp embossed on right flap. Linen lined envelope.

$I^{\circ}$ Size $152 \times 97 \mathrm{~mm}$.

I5 $\mathrm{I} 2 \mathrm{p}$ ultramarine

$2^{\circ}$ Size $202 \times 127 \mathrm{~mm}$.

$1522 \mathrm{p}$ ultramarine

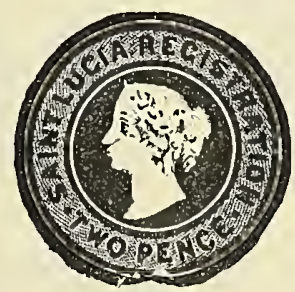

WRAPPERS.

December I 9 th, I 887.

Stamp typographed at right on manila paper.

Size $125 \times 300 \mathrm{~mm}$.
$201 \quad 1 / 2 \mathrm{p}$ green
$202 \quad$ Ip carmine

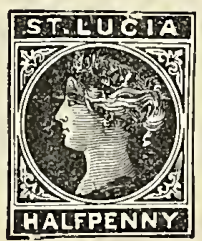

COUNTERFEITS.

We do not know of any good forgeries of the stamps of this colony, but revenue stamps with the revenue cancellation washed off and replaced by a counterfeit postal cancellation are plentiful. 


\section{ST. THOMAS AND PRINCE ISLANDS.}

Currency : IOOO REIS=I MILREIS= $\$ \mathrm{I} .08=\mathrm{U}$. S. CURRENCY.

ADHESIVE STAMPS.

December i4th, I869.

Typographed on thick white wove paper. ize $21 \times 24 \mathrm{~mm}$.

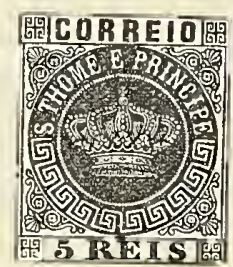

Perforated $121 / 2$.

$5 \mathrm{r}$ black

Ior orange yellow

2or pale bistre

2or deep bistre

$25 \mathrm{r}$ rose

$25 \mathrm{r}$ red

5or green

I $872-8$ I.

Same type as preceding issue ; typographed on ordinary white wove paper, varying in thickness, some appearing on very thin paper. $I^{0}$ Perforated I2 $1 / 2$.

$\begin{array}{cc}9 & 5 \mathrm{r} \text { black } \\ \text { IO } & \text { Ior yellow }\end{array}$

II 20 bistre

I2 $25 \mathrm{r}$ rose

I3 4or blue (1875)

I4 5 or green

I5 Ioor violet

I6 200r orange (1877)

I7 300 brown (1877)

I8 300 deep brown

$2^{\circ}$ Perforated 13.

I9 $5 \mathrm{r}$ black

2o Ior yellow

2120 bistre

$22 \quad 25 \mathrm{r}$ rose

23 4or blue

24 5or green

25 Ioor gray lilac

26 200r orange

273 oor brown

I 88 I- 85 .

Same type, paper and impression as preceding issue. The 5 reis is printed from a new plate. The difference between the new plate and the preceding one consists in the figure " 5 " in the lower label, which, in the new plate, is slanting, instead of straight. There are two plates of the 50 reis, the first one being that used in the preceding issues, in which the figure " 5 " of " 50 " is straight, while in the second plate the " 5 " is slanting, as in the plate for the 5 reis of this issue.

I. Perforated $121 / 2$.

$28 \quad 5 \mathrm{r}$ black, type 2

29 tor green

$30 \quad 20 r \operatorname{red}(1885)$

3 I $25 \mathrm{r}$ violet (I 885 )

32 4or yellow
33 5or blue, type I

345 or deep blue, type 2

II. Perforated 13.

35 5r black, type 2

36 Ior green

$37 \quad 20 r$ red

$38 \quad 25 \mathrm{r}$ violet

39 4or yellow

$40 \quad 5$ or blue, type $r$

4 I 5 or deep blue, type 2

1885.

Same type as preceding issue; typographed on thick smooth white paper ungummed. Perforated 13.

$42 \quad 5 \mathrm{r}$ black

43 Ior light yellow

44 2or light bistre

$45 \quad 25 \mathrm{r}$ light red

46 4or blue

47 5or light green

48 Ioor pale lilac

49 2oor orange

50 30or light brown

5 I Ior green

52 2or light rose

$5325 \mathrm{r}$ light violet

54 4or light yellow

55 or light blue

What we have said in regard to the stamps of Angola, Cape Verde, etc., printed on this paper will also apply to those of St. Thomas and Prince Islands.

I887.

Embossed on thick white paper; portrait of Dom Luiz. S ze $2 \mathrm{IX} 24 \mathrm{~mm}$.

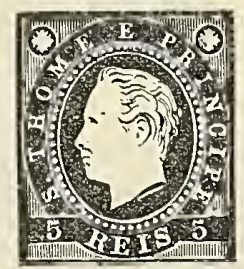

$$
\begin{array}{ll} 
& \text { I }^{\circ} \text { Perforated I21/2. } \\
56 & 5 \mathrm{r} \text { black } \\
57 & 5 \text { or blue } \\
& 2^{\circ} \text { Perforaled } \mathrm{I3} . \\
58 & 5 \mathrm{r} \text { black } \\
59 & \text { IOr green } \\
60 & \text { 20r red } \\
6 \mathrm{I} & 25 \mathrm{r} \text { lilac } \\
62 & \text { 40r chocolate } \\
63 & \text { 50r blue } \\
64 & \text { IOor brown } \\
65 & \text { 20or slate } \\
66 & \text { 30or orange }
\end{array}
$$

August 3Ist, I889.

Provisional issue.

10 reis stamps of the preceding issue surcharged in black with new value. 


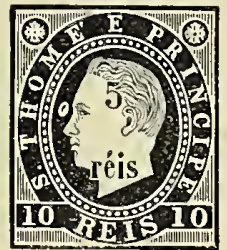

Perforated I 3.

$67 \quad 5 \mathrm{r}$ on Ior green, black surcharge

Variety: Without accent over the "e" of reis.

$68 \quad 5 r$ on Ior green, black surcharge

December roth, I889.

Provisional issue.

20 reis stamps of the issue of 1887 , surcharged in black with new value.

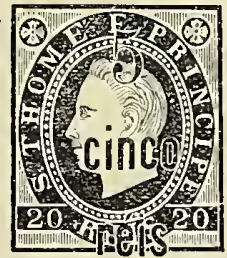

Perforated 13.

$695 \mathrm{r}$ on $20 \mathrm{red}$, black surcharge

Variety: Surcharge inverted.

$70 \quad 5 \mathrm{r}$ on $20 \mathrm{red}$, black surcharge

June 23d, r8gr.

Provisional issue.

40 reis stamps of the issue of 1889 , surcharged in black with new value.

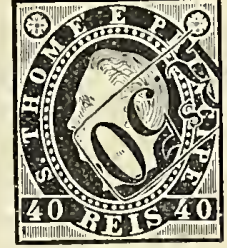

Perforated 13.

7 r 5 Or on 4 or chocolate, black surcharge

Variety: Surcharge inverted.

725 or on 4 or chocolate, black surcharge 1895 .

Typographed on thick smooth white paper portrait of Dom Carlos. Size 20x23 mm.

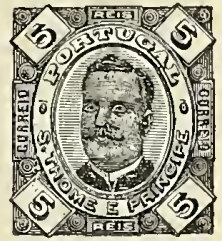

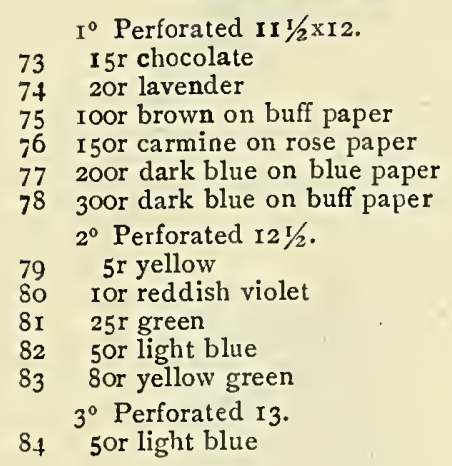

NEWSPAPER STAMPS.

1882.

Typographed on white wove paper. Size $20 \times 22 \mathrm{~mm}$.

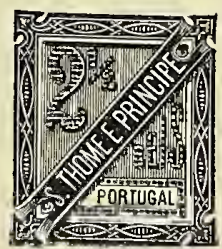

$I^{\circ}$ Perforated II $1 / 2 \times 12$.

$2012 \frac{1}{2} \mathrm{r}$ brown

$2^{\circ}$ Perforated 13.

$2022 \frac{1}{2} \mathrm{r}$ brown

I $\delta 93$.

Provisional issue.

Regular adhesives of the issue of 1887 , surcharged with new value.

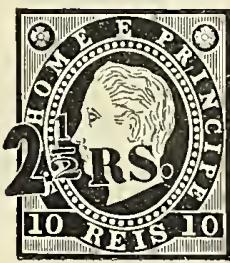

I.

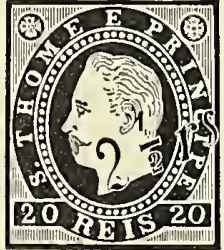

II.
Perforated $\mathbf{I} 3$.

I. Black surchaige.

$20321 / 2 \mathrm{r}$ on ror green, type $\mathrm{I}$

$20421 / 2 \mathrm{r}$ on $20 r$ red, type $\mathrm{I}$

$2052 \mathrm{r} / 2 \mathrm{r}$ on Ior green, type 2

$20621 / 2 \mathrm{r}$ on $20 r$ red, type 2

Varieties: Double surcharge, one in black and the other in green.

$2072 \frac{1}{2} \times 2 \frac{1}{2} \mathrm{r}$ on ror green, type 2

$20821 / 2 \times 21 / 2$ r on $20 r$ red, type 2

II. Green surcharge.

$2092 \mathrm{r} / 2 \mathrm{r}$ on $5 \mathrm{r}$ black, type I

2 ro $21 / 2 \mathrm{r}$ on $20 r$ red, type $\mathrm{I}$

$2 \mathrm{II} 2 \mathrm{r} / 2 \mathrm{r}$ on $5 \mathrm{r}$ black, type 2

$2122 \mathrm{r} / \mathrm{r}$ on ror green, type 2

2 I3 $21 / 2 \mathrm{r}$ on $20 r$ red, type 2

Varieties : Double surcharge

2 I $42 \mathrm{r} / 2 \mathrm{r} \times 2 \mathrm{r} / \mathrm{r}$ on ror green, type 2

$21521 / 2 \mathrm{r} \times 21 / 2 \mathrm{r}$ on $20 r \mathrm{red}$, type 2 


\section{COUNTERFEITS.}

There is a pretty good forgery of the stamps of the first issue. Although it is not a dangerous one, it might deceive anyone who has no genuine stamp to compare with. The counterfeit is a trifle smaller than the genuine, measuring $20 \times 231 / 2 \mathrm{~mm}$. The bottom line of the label containing the word "CORREIO" and the top line of the label containing the value touch the outer line of the frame at the sides in the genuine stamp; in the counterfeit the outer line of the frame is of the same thickness as the inner line, while in the genuine the outer line is much thicker. The counterfeits are either pin perforated I3 or regular perforation II $1 / 2$. We know of no good forgeries of the stamps of the subsequent issues.

\section{ST. VINCENT.}

Currency : I2 PENCE $=$ I SHILling ; 20 SHILLINGS $=I$ POUND $=\$ 4.87=U$ U. S. CURRENCY.

\section{ADHESIVE STAMPS.}

May, I86r.

Engraved in taille douce; portrait of Queen Victoria. White wove paper; no watermark, Size I9 $1 / 4 \times 221 / 4 \mathrm{~mm}$.

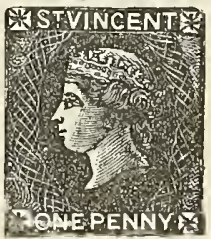

Roughly perforated 14 to $I 61 / 2$.

I Ip rose red

$26 \mathrm{p}$ blue green

Varieties :

a. Imperforate vertically.

$36 \mathrm{p}$ blue green

b. Imperforate.

4 Ip rose red

$56 \mathrm{p}$ blue green

c. Double perforation horizontally.

6 Ip rose red

I 862.

Same type, paper and impression as preceding issue.

Clean cut perforation 14 to $161 / 2$.

$76 p$ yellow green

1863-66.

Same type, paper and impression as preceding issue.

$\mathrm{I}^{\circ}$ Clean cut perforation II to $\mathrm{I} 3$.

8 Ip rose red

$96 \mathrm{p}$ blue green

$2^{\circ}$ Clean cut perforation II to 13 horizontally and rough perforation $I_{4}$ to I 5 vertically. Io Ip rose red

August, I866.

Same type, paper and impression as preceding issue.

$I^{\circ}$ Rough perforation 14 to $I 6 \frac{1}{2}$.

I I Ish dark slate gray

I2 Ish grayish purple

$2^{\circ}$ Clean cut perforation II to I 3

I3 4p deep blue

$3^{\circ}$ Clean cut perforation II to I3 horizontally and rough perforation 14 to $161 / 2$ vertically.

I4 Ish dark slate gray

I5 Ish grayish purple

April, I869.

Same type, paper and impression as preceding issue.

Clean cut perforation I I to I 3

I6 Ish indigo

September, I869.

Same type, paper and impression as preceding issue.
Clean cut perforation II to I3.

I 7 p bright yellow

I 8 Ish bright brown

June, I $87 \mathrm{I}$.

Same type, paper and impression as pre-

ceding issue. Watermarked

$I^{\circ}$ Rough perforation $I 4$ to $I 61 / 2$

I9 Ip black

$20 \quad 6 \mathrm{p}$ blue green

Variety: Imperforate vertically.

2I Ip black

$2^{\circ}$ Clean cut perforation $141 / 2$ to $15 \frac{1}{2}$.

2ra Ip black

$2 \mathrm{Ib} 6 \mathrm{p}$ blue green

$3^{\circ}$ Clean cut perforation II to I 3 horizontally and clean cut perforation $14 \frac{1}{2}$ to $151 / 2$ vertically.

22 Ip black

From this time on all perforations are clean cut.

June, 1872 .

Same type, impression and paper as preceding issue. Watermarked a star.

I 0 Perforated II to I3.

23 Ish rosered

24 Ish dull red

$2^{\circ}$ Perforated II to is horizontally and I $4^{1 / 2}$ to $151 / 2$ vertically.

25 Ish rose red

I 874 .

Same type, paper and impression as preceding issue. Watermarked a star.

I 0 Perforated II to I3.

26 Ish pale violet rose

$2^{\circ}$ Perforated II to I 3 horizontally and I $4^{1 / 2}$ to I $51 / 2$ vertically.

27 Ish pale violet rose

I 875.

Same type, impression and paper as preceding issue. Watermarked a star.

Perforated II to 13 .

28 Ish claret

I $877-80$.

Same type, impression and paper as preceding issue. Watermarked a star.

$I^{\circ}$ Perforated I $41 / 2$ to $151 / 2$.

$296 p$ yellow green (Oct., 1878 )

$2^{\circ}$ Perforated II to I3.

$30 \quad 4 \mathrm{p}$ dark blue (July, I877)

3I Ish vermilion red (June, I880) 
$3^{\circ}$ Perforated II to 13 horizontally and $14 \frac{1}{2}$ to 15 vertically.

32 6p yellow green (Feb., I 877)

33 Ish vermilion (Feb., I877)

May, 1880.

Provisional issue.

Six penny stamps of the issue of June, 1871, divided vertically in two by a line of perforation gauging I2, each being surcharged in red with new value, as per illustration. Watermarked a star.

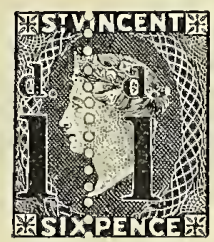

Clean cut perforation $141 / 2$ to $151 / 2$, at three sides and one side clean cut perforation I2.

34 Ip on half of $6 p$ blue green, red surcharge (right half)

35 xp on half of $6 p$ blue green, red surcharge (left half)

Variety: Double perforation $\mathrm{I} 2$.

36 Ip on half of $6 p$ blue green, red surcharge (right half)

June, 1880 .

Same type, paper and impression as preceding regular issue for the one penny and six penny stamps and a new type for the five shillings. Size of the five shillings stamp $251 / 2 \times 30 \mathrm{~mm}$. Watermarked a six rayed star.

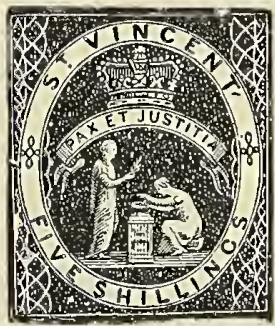

Perforated II 10 I 3.

37 Ip pale gray green

$386 \mathrm{p}$ bright yellow green

395 sh rose red

September, I881.

Provisional issue.

Six penny stamps of the preceding issue divided vertically in two by a line of perforation gauging 12 and surcharged with new value, as per illustration. The top of the figure "I" is curved. Watermarked a six rayed star.

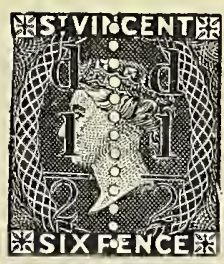

Perforated I I to I 3 at three sides, and I 2 on one side.

$40 \quad 1 / 2 \mathrm{p}$ on half of $6 \mathrm{p}$ yellow green, red surcharge (right half)

$4 \mathrm{I} \quad \mathrm{t} / 2 \mathrm{p}$ on half of $\mathrm{p}$ yellow green, red surcharge (left half)
Varieties:

a. "I" with straight top.

$42 \mathrm{r} / 2 \mathrm{p}$ on half of $6 \mathrm{p}$ yellow green, red surcharge (right half)

b. Surcharged vertically.

$43 \quad 1 / 2 \mathrm{p}$ on half of $6 \mathrm{p}$ yellow green, red surcharge (left half)

November, I88I.

Provisional issue.

One shilling stamps of the issue of February, 1877 , surcharged with new value in black, the original value being obliterated by a black line. Watermarked a star.

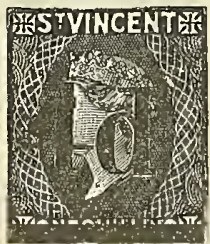

Perforated II to I3.

$444 \mathrm{p}$ on $\mathrm{Ish}$ vermilion red, black surcharge

Variety: Black line at top and bottom of the stamp.

$454 \mathrm{p}$ on Ish vermilion red, black surcharge

December, I88I.

A. Provisional issue.

Six penny stamps of the issue of June, I 880, surcharged in black with new value, the original value being obliterated by a black line. Watermarked a star.

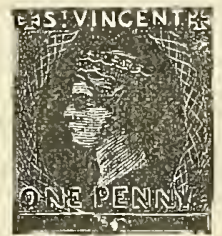

Perforated I I 10 I 3

46 Ip on $6 p$ bright yellow green, black surcharge

B. Regular issue.

Same type as preceding regular issue for the one and four penny stamps and a new type for the half penny stamp. Engraved on white wove paper. Size of the $1 / 2$ penny stamp I $7 \times 20 \mathrm{~mm}$. Watermarked a star.

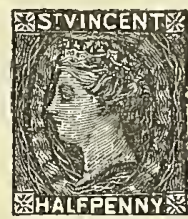

Perforated II to 13.

$47 \quad \mathrm{r} / 2 \mathrm{p}$ orange yellow

48 Ip drab

$49 \quad 4 \mathrm{p}$ bright ultramarine

Variety: Horizontal pair, imperforate between.

49a 4p bright ultramarine

January, 1883 .

Same type, impression and paper as preceding issue. Watermarked Crown and C.A. Perforated I 4

50 Ip drab

$5 \mathrm{I} \quad 4 \mathrm{P}$ light blue 
February, I883.

Same type, impression and paper as one penny stamps of the preceding issue, but printed in rosy lake and surcharged in black with new value, the original value being obliterated by a black line. Watermarked Crown and C. A.

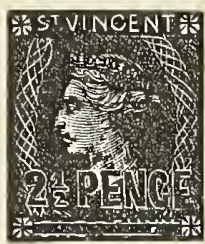

Perforated $\mathrm{I}_{4}$

$522 \frac{1}{2} \mathrm{p}$ on Ip rosy lake, black surcharge

October, I883.

Same type, impression and paper as the issue of January, I883. Watermarked Crown and C. A.

Perforated $\mathrm{x} 2$.

$534 \mathrm{p}$ dull blue

$546 \mathrm{p}$ bright green

55 Ish orange vermilion

September, I 884 .

Same type, impression and paper as the corresponding values of the preceding issues. Watermarked Crown and C. A.

Perforated I 2

$56 \quad 1 / 2 \mathrm{p}$ orange yellow

$57 \quad 1 / 2 \mathrm{p}$ dark green

$58 \quad 4 \mathrm{p}$ ultramarine

The first one was prepared for use, but was never issued.

March, I885.

Provisional issue.

$2 \mathrm{~J} / 2$ penny stamps of the issue of February, I 883 , surcharged in black "Id", the origina value ( $21 / 2$ PENCE) being obliterated in black by double horizontal lines I mm., apart. Watermarked Crown and C. A.

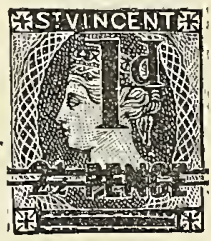

Perforated I4

59 ip on $2 \frac{1}{2}$ p rosy lake, black surcharge April, 1885.

Same type, impression and paper as preceding regular issues. Watermarked Crown and C. A.

Perforated I4.

$60 \quad 1 / 2 \mathrm{p}$ dark green

6 I Ip carmine

$624 \mathrm{p}$ red brown

June, 1886.

Same type, impression and paper as preceding issue. Watermarked Crown and C. A.

Perforated I 4.

63 Ip pink

64 Ip rosy lake

$654 \mathrm{p}$ purple brown

$664 \mathrm{p}$ lake brown

October, I 888.

Same type, paper and impression as corresponding values of preceding regular issues. Watermarked Crown and $\mathrm{C} \mathrm{A}$
Perforated $\mathbf{I}_{4}$.

$67 \quad 6 \mathrm{p}$ dark lilac

68 5sh lake

August, I889.

Same type, impression and paper as the $21 / 2$ penny stamps of the issue of February I883, but printed in blue. Watermarked Crown and C. A.

Perforated $\mathrm{I} 4$

$6921 / 2 \mathrm{p}$ on Ip milky blue, black surcharge August, 18go.

Provisional issue.

Four penny stamps of the issue of June, I886, surcharged in black with new value the original value being obliterated by a black line. Watermarked Crown and C. A.

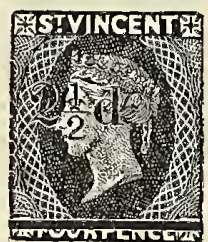

Perforated 14

$70 \quad 21 / 2 \mathrm{p}$ on $4 \mathrm{p}$ lake brown, black surcharge

November, I 890-9I.

Same type, impression and paper as corresponding values of preceding regular issues.

Watermarked Crown and C. A.

Perforated I 4.

$7 \mathrm{I} 2 \mathrm{r} / 2 \mathrm{p}$ on Ip bright blue, black surcharge

$726 \mathrm{p}$ pale red lilac

36 6p deep red lilac

74 Ish vermilion red

November, I892.

Provisional issue.

Four penny stamps of the issue of June, 1886 , surcharged in carmine with new value, the original value being obliterated by a bar. Watermarked Crown and C. A.

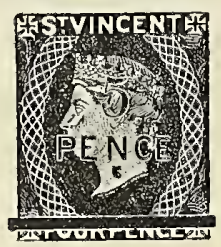

Perforated I4.

$75 \quad 5 \mathrm{p}$ on $4 \mathrm{p}$ lake brown, carmine surcharge March, I 893.

I. Same type, impression and paper as preceding regular issue. Watermarked Crown and C. A.

Perforated I4.

$76 \quad 4 \mathrm{p}$ yellow

II. Same type as the sixpenny stamps of the preceding issue, but printed in carmine and surcharged in black "FIVE PENCE" over the original value. Watermarked Crown and C.A.

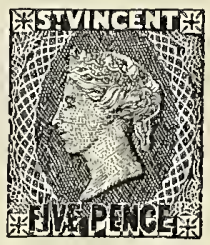

Perforated 44.

$775 \mathrm{p}$ on $6 \mathrm{p}$ crimson lake, black surcharge $785 \mathrm{p}$ on $6 \mathrm{p}$ carmine lake, black surcharge 


\section{REVENUE STAMPS USED FOR POSTAGE.}

Revenue stamps were never allowed to be used for postage in this colony. Nevertheless, numerous revenue stamps are found with postal cancellation, but this, however, is either a forged cancellation or a genuine can. cellation obtained by favor from some obliging official.

\section{REGISTRATION ENVELOPES.}

September, I884.

Stamp typographed on right flap. Linen lined paper.
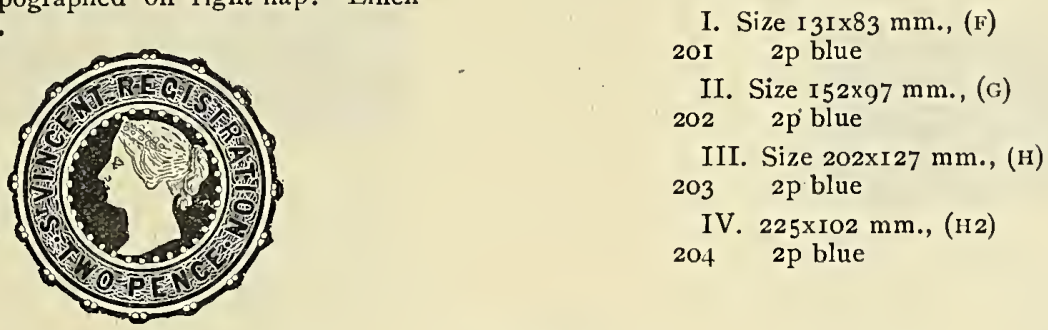

\section{WRAPPERS.}

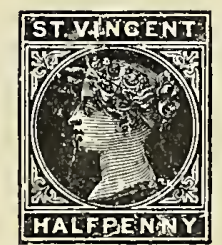

May, 1893.

Stamp typographed at right on manila paper.

Size $125 \times 300 \mathrm{~mm}$.
$301 \quad$ 1 $2 \mathrm{p}$ green
$302 \quad$ Ip carmine

COUNTERFEITS.

We do not know of any good counterfeits of the regular issues of St. Vincent, but the provisional $1 / 2$, I and 4 penny stamps of $1880-8 \mathrm{r}$, especially the last, have been splendidly counterfeited. Below we describe some of the points pertaining to the genuine stamps.

I penny on half of $6 \mathrm{p}$.

The perforation dividing the stamp in two is a clean cut perforation, gauging $\mathrm{I} 2$

The measurements of the surcharge are as follows :

Height of figure, $83 / 4 \mathrm{~mm}$.

Width of figure, $11 / 2 \mathrm{~mm}$.

Length of foot of figure, $3 \frac{1}{2} \mathrm{~mm}$.

Height of " $\mathrm{d}$," $3 \mathrm{~mm}$.

Extreme width of "d," $2 \mathrm{~mm}$.

Space between " $d$ " and figure $I, I y / 2 \mathrm{~mm}$.

Space between the figures on the right and left halves of the stamp, $8 \mathrm{r} / 2 \mathrm{~mm}$.

The figure has a straight top projecting only to the left.

$1 / 2$ penny on half of $6 \mathrm{p}$.

The perforation dividing the stamp is also clean cut, gauging I2

The measurements are as follows:

Height of the figure "I," $4 \mathrm{~mm}$.

Height of the figure " $2, " 4 \mathrm{~mm}$

Height of the letter "d," $4 \mathrm{~mm}$.

The space between the " $\mathrm{I}$ " and the " 2 " is $2 \mathrm{r} / 2 \mathrm{~mm}$.

The extreme height from the top of the " $\mathrm{d}$ " to the bottom of the numeral " 2 " is $161 / 2 \mathrm{~mm}$.

The space between the letter " $\mathrm{d}$ " and the figure " $\mathrm{I}$ " is $2 \mathrm{~mm}$.

4 pence on I shilling.

This stamp has been the favorite of the forgers on account of its great rarity, and some of these counterfeits are extremely dangerous.

The perforation is always the clean cut perforation II to I3, and never the compound perforation. The color of the surcharge is a deep black, heavily impressed, the indentation showing clearly through the back of the stamp. Although heavily impressed, on all the genuine copies seen by us the color of the stamp shows through the surcharge in various spots.

The measurements are as follows

Height of the letter and figure, $81 / 2 \mathrm{~mm}$.

Width of the vertical stroke of the figure " 4 ," I $3 / 4 \mathrm{~mm}$.

Width of the vertical stroke of " 4 " at top, $1 \mathrm{~mm}$.

Extreme width of the "4" at bottom, I $21 / 2 \mathrm{~mm}$.

Extreme width of the " 4 " at top, $81 / 4 \mathrm{~mm}$.

Extreme width of the "4" in the centre, $13 \mathrm{~mm}$.

The top stroke of the "d," $23 / 4 \mathrm{~mm}$. , wide.

The ball of the " $\mathrm{d}$ " measures $51 / 2 \mathrm{~mm}$, high.

The distance between the vertical stroke of the " 4 " and the vertical stroke of the "d" is $6 \mathrm{~mm}$.

The distance between the bar and the bottom of the " 4 " and "d" is $5 \mathrm{~mm}$ 


\section{SALVADOR.}

Currency, 8 REALES $=\mathrm{I}$ PESO $=\mathrm{IOO}$ CenTAVOS $=\mathrm{I}$ PESO $=\$ 0.60$ U. S. CuRRENCY

ADHESIVE STAMPS.

1867.

Engraved on white wove paper, size $241 / 2$ $\mathrm{xI} 8 \mathrm{I} / 2 \mathrm{~mm}$
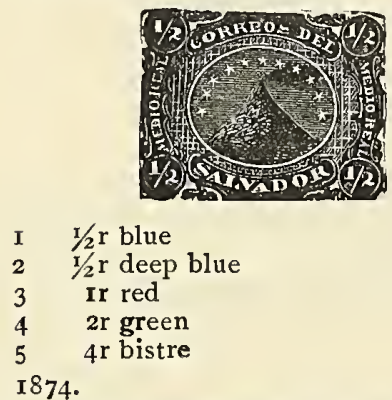

Same as preceding issue, surcharged in black with circular seal. There are three types of this seal; in type I the letters are double lined and the branches are close to the shield; in type II the letters are also double lined but the branches are further away from the shield : in type III the letters are single lined.

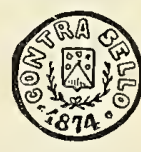

II.

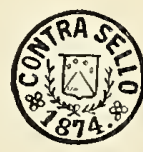

III.
Perforated I2.

$6 \quad 1 / 2 \mathrm{r}$ blue, black surcharge, seal $\mathrm{I}$

$7 \quad 1 / 2$ r blue " " " "

$8 \quad 1 / 2$ r blue “" “ " " 3

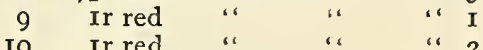

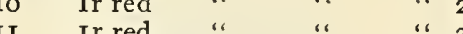

I2 2 green “ ". ".

I3 2 green " $\quad$ “ $\quad$ "

I4 2 green “" “

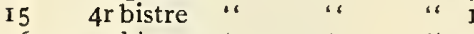

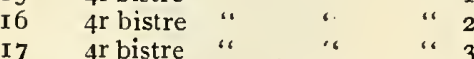

1879 .

Lithographed on white wove paper. There are ten varieties of the I centavo and five of each of the other values, all differing from one another in minor details. Sizes: Ic $18 \times 22 \mathrm{~mm}$.; $2 \mathrm{c}$ and $20 \mathrm{c}, \mathrm{I} 8 \times 22^{1 / 2} \mathrm{~mm}$.; $5 \mathrm{c}$ I $81 / 2 \times 221 / 2 \mathrm{~mm}$.; IOc, $19 \times 221 / 2 \mathrm{~mm}$.
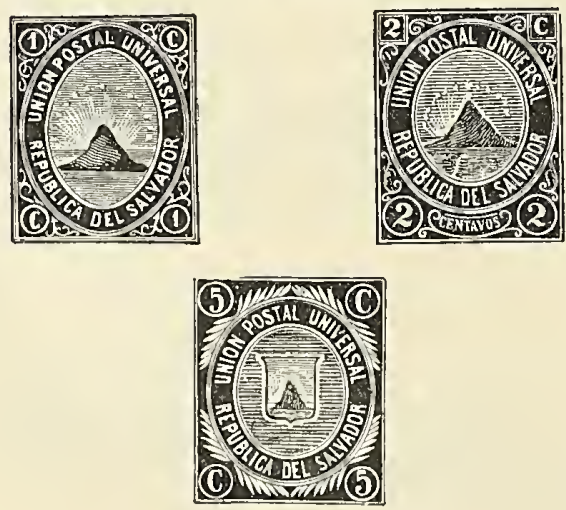
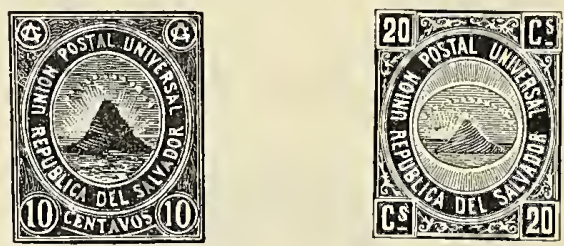

Perforated I2.

\begin{tabular}{|c|c|c|c|}
\hline I 8 & Ic green & & arieties \\
\hline & Ic pale green & Io & \\
\hline & Ic yellow green & Io & “" \\
\hline & 2c carmine & 5 & “ \\
\hline & 2c deep carmine & 5 & "“ \\
\hline & $5 \mathrm{c}$ dull blue & 5 & " \\
\hline & $5 \mathrm{c}$ ultramarine & 5 & “ \\
\hline & $5 \mathrm{c}$ deep ulramarine & 5 & “" \\
\hline & IOc black & 5 & ““ \\
\hline & $20 c$ violet & 5 & “" \\
\hline
\end{tabular}

These stamps are found surcharged with a seal similar to that printed on the stamps of the preceding issue, but in this case they are nothing but telegraph stamps.

I $88 \mathrm{I}$

Same type as preceding issue, but re engraved. There are fifteen varieties of each of the Ic and $2 c$ stamps, and twenty-five varieties of the $5 \mathrm{c}$ stamp.

Perforated 12.

$\begin{array}{lll}28 & \text { Ic green } & \text { I5 varieties } \\ 29 & \text { 2c carmine } & \text { I5 “ } \\ 30 & \text { 5c blue } & 25\end{array}$

April Ist, $\mathrm{x} 887$.

Engraved on white wove paper, size $21 \times 28$ $\mathrm{mm}$.
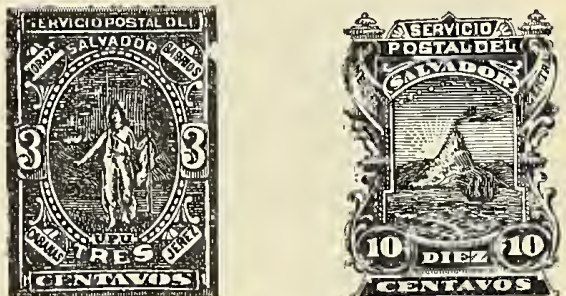

Perlorated I 2.

3I $3 \mathrm{c}$ brown

32 Ioc orange

Variety: Imperforate.

$333 \mathrm{c}$ brown

September, $\mathrm{x} 888$.

Engraved on white wove paper, size $21 \times 28$

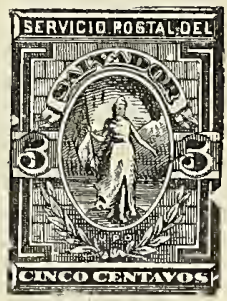

Rouletted.

$34 \quad 5 \mathrm{c}$ ultramarine 
I889.

I. Provisional issue.

3c stamps of the issue of 1887 surcharged in black with new value horizontally, across the centre of the stamp.

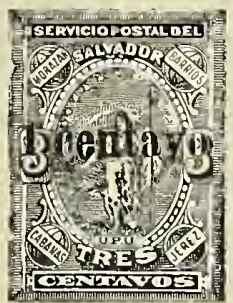

Perforated I2.

35 Ic on $3 \mathrm{c}$ brown, black surcharge

II. Regular issue.

Engraved on white wove paper, size $21 \times 28$ $\mathrm{mm}$.

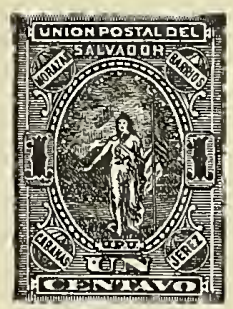

Perforated 12.

\section{$36 \quad$ Ic green}

$36 \mathrm{a} 2 \mathrm{c}$ scarlet

These stamps, on account of an error in the inscription "Union Postal del Salvador." instead of "Servicio Postal del Salvador," were not used.

III. Same as II, with the inscription in the upper label obliterated by a heavy black I ine.

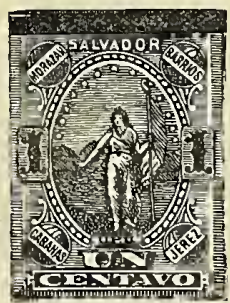

Perforated I 2
$37 \quad$ Ic green and black
$3^{8} \quad 2 \mathrm{c}$ scarlet and black
November 21st, I889.

I, 3, 5 and roc stamps of the preceding issues surcharged 1889 .

I. Black surcharge.

$I^{\circ}$ Perforated I2.

39 Ic on $3 \mathrm{c}$ brown, black surcharge

40 Ic green "“ "“

4 I 3 c brown "“ "“

42 Ioc orange

a. Double surcharge.

43 Ic green, black surcharge

$443 \mathrm{c}$ brown "

b. Surcharge inverted.

45 Ic green, black surcharge

c. With additional surcharge "8g."

$46 \quad 3 \mathrm{c}$ brown, black surcharge d. "I88" instead of "I 889 ."

47 Ic green, black surcharge

483 brown ". ".

49 I "I 8 " instead of "I889."

50 Ic green, black surcharge

f. "I I 888" instead of "I889."

5I 3c brown, black surcharge

g. With additional surcharge " $9 . "$

$523 \mathrm{c}$ brown, black surcharge

h. "889" instead of "I 889."

53 IOc orange, black surcharge

i. " 89 " instead of "I889."

54 IOc orange, black surcharge

$2^{\circ}$ Rouletted.

$555 \mathrm{c}$ ultramarine, black surcharge

Varieties :

a. Double surcharge.

${ }_{5} 65 \mathrm{c}$ ultramarine, black surcharge

b. Surcharge inverted.

$57 \quad 5 \mathrm{c}$ ultramarine, black surcharge

c, "I88" instead of "I 880 ."

58 5c ultramarine, black surcharge

d. "889" instead of "I889."

59 " $5 \mathrm{c}$ ultramarine, black surcharge

e. " 880 " inverted.

$60 \quad 5 \mathrm{c}$ ultramarine, black surcharge

II. Red surcharge.

${ }^{\circ}$ Perforated I2.

6I Ic green, red surcharge

$623 \mathrm{c}$ brown, red surcharge

Varielies:

a. Treble surcharge.

63 Ic green, red surcharge

b. " 889 ," instead of " $1889 . "$

64 Ic green, red surcharge

$653 \mathrm{c}$ brown, red surcharge

c. "I88" instead of "I889."

66 Ic green, red surcharge

d. "I 8 " instead of " I 889 ."

67 Ic green, red surcharge

e. " 18899 " instead of " I 889."

68 Ic green, red surcharge

f. Surcharge inverted.

$693 \mathrm{c}$ brown, red surcharge

$2^{\circ}$ Rouletted.

$70 \quad 5 \mathrm{c}$ ultramarine, red surcharge

Varieties:

a. Double surcharge.

7 I $5 \mathrm{c}$ ultramarine, red surcharge

b. Inverted surcharge.

72 "5c ultramarine, red surcharge

c. " 889 " instead of " 1889 ."

73 " $5 \mathrm{c}$ ultramarine, red surcharge

d. " 89 " instead of "I 889 ."

$74 \quad 5 \mathrm{c}$ ultramarine, red surcharge

III. Violet surcharge.

I ${ }^{\circ}$ Perforated $\mathbf{I} 2$.

75 Ic green, violet surcharge

$763 \mathrm{c}$ brown “" “"

77 Ioc oran

a. Treble surcharge.

78 Ic green, violet surcharge

b. Double surcharge.

79 Ic green, violet surcharge

8o 3c brown ".

c. " 889 " instead of "I 889 ."

8 I Ic green, violet surcharge

82 3c brown " "

83 IOc orange " " 89 " instead of "I 889 ."

8f Ic green, violet surcharge

85 3c brown " "

e. "I8" instead of "I889."

86 Ioc orange, violet surcharge

$f$. Surcharge inverted.

87 3c brown, violet surcharge 
g. With additional surcharge "I8." $3 \mathrm{c}$ brown, violet surcharge

h. Double surcharge " 889 ."

88 a $3 \mathrm{c}$ brown, violet surcharge

$2^{\circ}$ Rouletted.

89 5c ultramarine, violet surcharge Varieties:

a. Double surcharge.

$90 \quad 5 \mathrm{c}$ ultramarine, violet surcharge

b. With additional surcharge "889."

9I $5 \mathrm{c}$ ultramarine, violet surcharge

c. " 889 " instead of " 1880 ."

$925 \mathrm{c}$ ultramarine, violet surcharge

d. "I89" instead of "I889."

93 5c ultramarine, violet surcharge

December, 1889 .

Typographed on white wove paper. Size 2 i $\times 281 / 2 \mathrm{~mm}$.

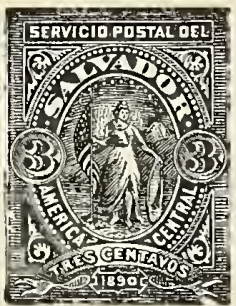

Perforated I2.

$\begin{array}{rl}94 & \text { Ic green } \\ 95 & 2 \mathrm{c} \text { brown } \\ 96 & \text { 3c yellow } \\ 97 & 5 \mathrm{c} \text { blue } \\ 98 & \text { IOC violet } \\ 99 & 20 \mathrm{C} \text { orange } \\ \text { IOO } & 25 \mathrm{C} \text { rose } \\ \text { IO1 } & 50 \mathrm{C} \text { brown violet } \\ \text { IO2 } & \text { IP rose }\end{array}$

Varieties: Vertical pair, imperforate between.

I02a Ic green

IO2b $50 \mathrm{c}$ brown violet

January Ist, I8gI.

Typographed on white wove paper. Size $201 / 2 \times 25 \mathrm{~mm}$.

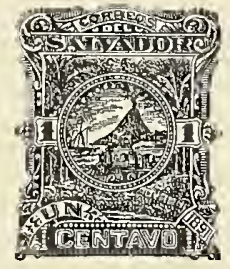

Perforated I2.

IO3 Ic vermilion

I04 2c light green

I05 3c violet

Io6 $5 \mathrm{c}$ red brown

I07 Ioc blue

I08 IIc violet

$10920 c$ green

I IO $25 \mathrm{c}$ light brown

I I $50 c$ dark blue

I2 Ip dark brown

May, I891.

Provisional issue.

2 and $3 c$ stamps of the preceding issue surcharged in black with new value. There are two types of the surcharge of the Ic; in the first one the surcharge is in small letters and the value in figures; in the second the letters of the surcharge are capitals and the value in letters.
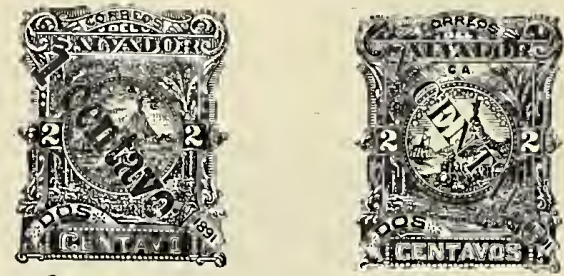

Perforated I2.

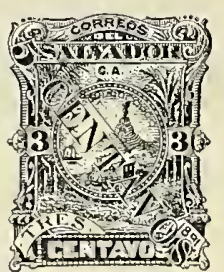

I 3 Ic on $2 \mathrm{c}$ light green, black surcharge

II 4 Ic (Un) on $2 c$ light green, black surcharge

II $55 \mathrm{c}$ on $3 \mathrm{C}$ violet, black surcharge

Variety: Surcharge inverted.

I 16 Ic on 2c light green, black surcharge

January Ist, I 892 .

Typographed on white wove paper, size $21 \times 27 \mathrm{~mm}$.

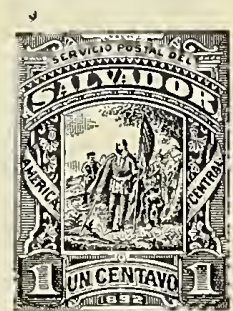

Perforated I 2.

II 7 IC green

II 8 2c light brown

II9 3c ultramarine

I $20 \quad 5 \mathrm{C}$ gray

I2I IOC vermilion

I 22 IIC brown

I23 $20 \mathrm{c}$ orange

I $2425 \mathrm{C}$ maroon

I 25 50c yellow

I20 Ip carmine

Varieties:

a. Vertical pair imperforate between.

I $275 \mathrm{c}$ gray

b. Imperforate horizontally at top and bottom.

I $28 \quad 5 \mathrm{c}$ gray

October, I 892

Provisional issue.

$5 \mathrm{c}$ stamps of the preceding issue surcharged with new value.

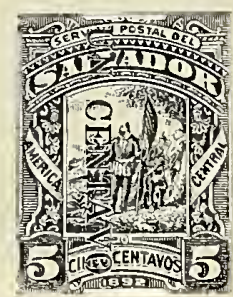


Perforated $\mathbf{I} 2$.

I29 Ic on 5c gray, black surcharge, reading upwards

I 30 Ic on $5 \mathrm{c}$ gray, black surcharge, reading downwards

I3 I IC on $5 \mathrm{C}$ gray, red surcharge, reading upwards

December, 1892 .

Provisional issue.

$20 \mathrm{c}$ and $25 \mathrm{C}$ stamps of the issue of January Ist, I892, surcharged with new value.

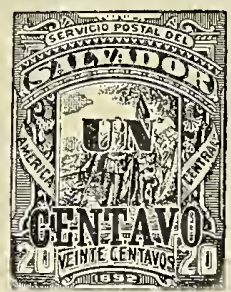

Perforated I2.

I32 Ic on $20 \mathrm{Oc}$ orange, black surcharge

r 33 Ic on $25 \mathrm{c}$ maroon, yellow surcharge

I34 Ic on $25 \mathrm{c}$ maroon, blue surcharge Varieties:

a. "UN CENTANO."

I35 Ic on $20 \mathrm{c}$ orange, black surcharge

b. Surcharge inverted.

I36 xc on $20 \mathrm{c}$ orange, black surcharge

I37 Ic on 25c maroon, yellow surcharge

January Ist, 1893 .

Typographed on white wove paper. Size I $9 \times 22 \frac{1}{2} \mathrm{~mm}$.

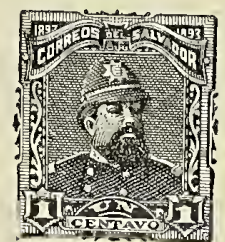

Perforated I 2.

138 Ic blue

I39 2c red brown

I $40 \quad 3 \mathrm{c}$ purple

I4 I $5 \mathrm{c}$ deep brown

I42 Ioc yellow brown

I43 IIC vermilion

I44 $20 \mathrm{c}$ green

I45 $25 \mathrm{C}$ olive brown

I 46 5oc orange

I47 xp black

July, 1893 .

Typographed on white wove paper, a different type for each value. Sizes: 2 pesos, $27 \times 28 \mathrm{~mm}$.; 5 pesos $27 \times 33 \mathrm{~mm}$.; IO pesos, $25 \frac{1}{2} \times 33 \mathrm{~mm}$.
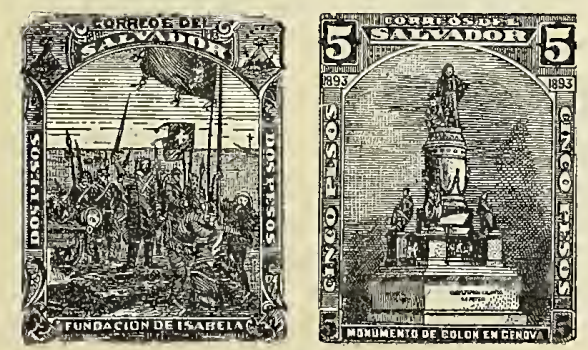

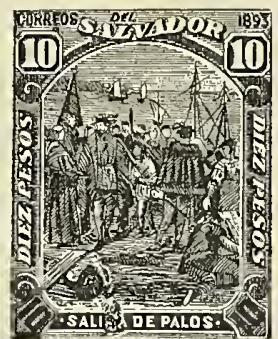

Perforated I2.

r 48 2p green

I49 5p mauve

I50 Iop orange

December, 1893.

Provisional issue.

2 centavos stamps of the issue of January, I 893 , surcharged with new value.

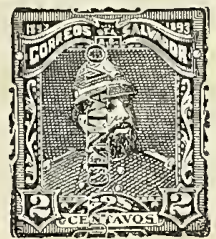

I. Surcharged vertically.

I 5 I Ic on $2 \mathrm{c}$ red brown, black surcharge Variety: "CENTNVO."

I52 Ic on 2c red brown, black surcharge

II. Surcharged diagonally from left lower to right upper corner.

Perforated 12.

I53 Ic on $2 \mathrm{c}$ red brown, blue surcharge

January Ist, I 894 .

Typographed on white wove paper. There are four types: one for the values from I centavo to I peso, inclusive, and one for each of the three other values. Sizes: Ic to I peso, 19 $22 \mathrm{r} / 2 \mathrm{~mm}$., 2 pesos, $32 \mathrm{r} / 2 \times 25 \mathrm{~mm}$. 5 pesos, $32 \times 251 / 2 \mathrm{~mm}$., IO pesos, $33 \times 243 / 4 \mathrm{~mm}$.
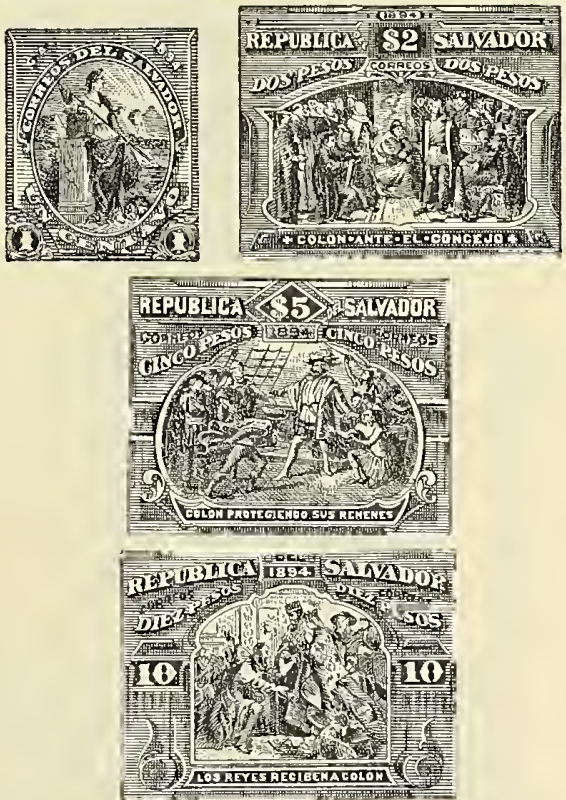

Perforaled $\mathbf{I} 2$.
154 ic brown
155 2c sky blue 


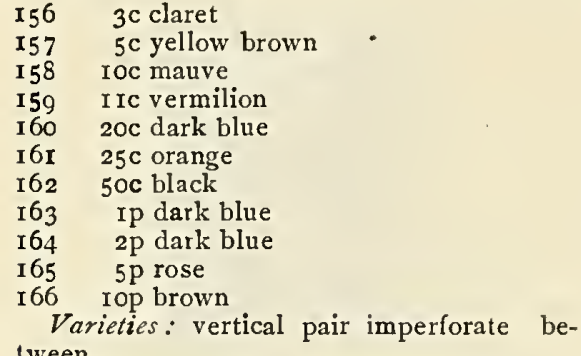
tween.

I67 Ic brown

I67a 2 c sky blue

December, I 894

Provisional issue.

I I centavos stamps of the preceding issue surcharged with new value in black.

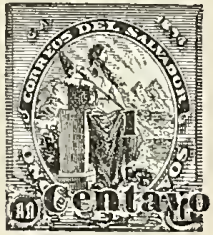

Perforated I2.

I68 Ic on I Ic vermilion, black surcharge Varieties:

a. "CCNTAvo."

I69 Ic on I Ic vermilion, black surcharge b. "CE TAvo."

Ic on IIc vermilion, black surcharge

c. Quod below E and N of CENTAvo.

I7I. Ic on I Ic vermilion, black surcharge

January Ist, I895.

I. Provisional issue.

Typographed on white wove paper. Portrait of ex-President Ezeta. The portrait is obliterated by the coat of arms of Salvador. Size $19 \times 231 / 2 \mathrm{~mm}$.

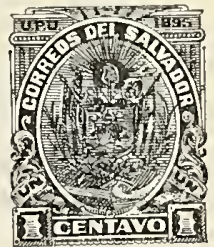

Perforated I2.

Ic brown, green surcharge

2c dark green, blue surcharge

$3 \mathrm{c}$ brown, brown surcharge

$5 c$ blue, brown surcharge

Ioc orange, brown surcharge

I2c claret, brown surcharge

I $5 \mathrm{C}$ vermilion, brown surcharge

$20 c$ yellow, brown surcharge

$24 \mathrm{c}$ purple, black surcharge

3oc deep blue, blue surcharge

$50 \mathrm{c}$ red, brown surcharge

Ip black, brown surcharge

These stamps were engraved during the administration of President Ezeta, but by order of the new government a new set of stamps was prepared: however, for fear that these should not be ready in time, the series with the head of President Ezeta was surcharged with the coat of arms and sold for a few days at the beginning of 1895 .
II. Regular issue,

Typographed on white wove paper, a different design for each value. Size $19 \frac{1}{2} \times 23^{1 / 2}$ $\mathrm{mm}$.
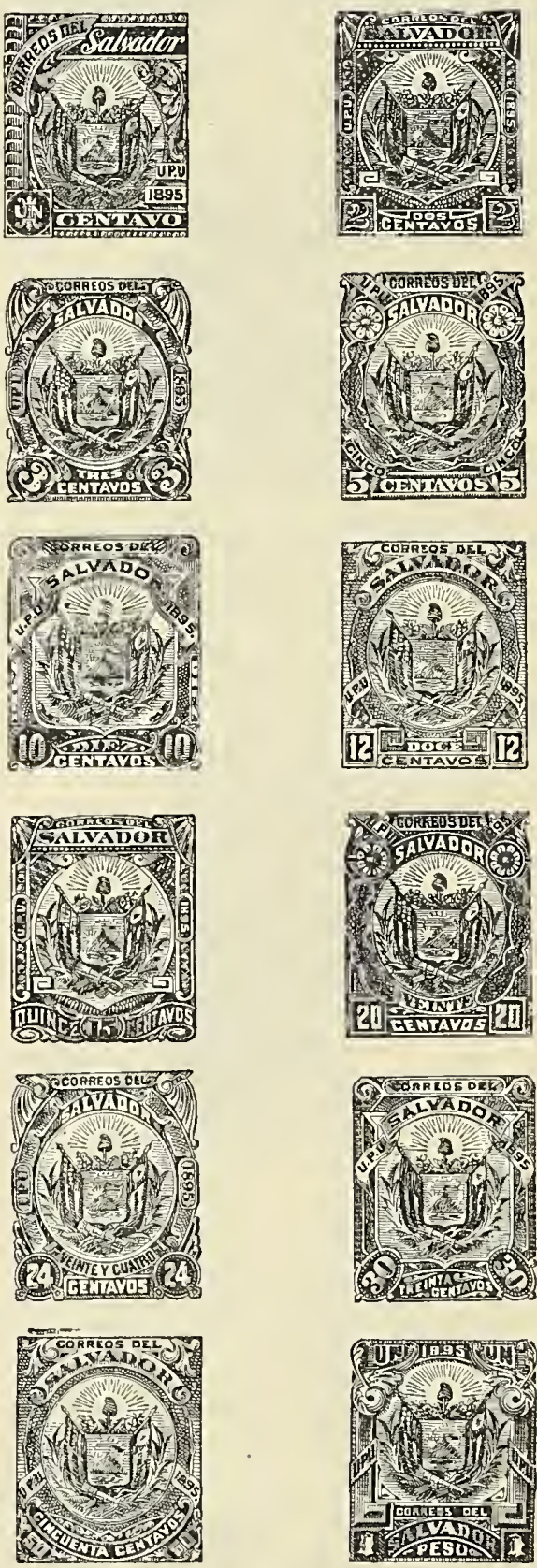

Perforated I 2

I84 Ic slate brown

I85 2c dark green

I 86 3c brown

I $87 \quad 5 \mathrm{c}$ blue

I 88 IOC orange

I 89 I2c red

I9O I $5 \mathrm{C}$ vermilion

IOI 20c dark slate green

I92 $24 \mathrm{C}$ mauve

I93 3oc deep blue

1945 5oc rose red

I95 Ip black 
End of 1895 .

Provisional issue.

Stamps of preceding issue surcharged with new value.

Perforated I2.

I. Black surcharge.

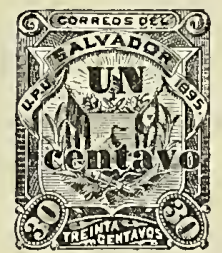

r96 Ic on I2c red, black surcharge

II. Red surcharge.

I97 Ic on $24 \mathrm{C}$ mauve, red surcharge

I98 Ic on $30 \mathrm{Oc}$ deep blue " "

$1992 \mathrm{2c}$ on $20 \mathrm{OC}$ slate green "

$2003 \mathrm{c}$ on $30 \mathrm{c}$ deep blue " '

January Ist. 18,6 .

I. Typogräphed on white wove paper Size $19 \times 221 / 2 \mathrm{~mm}$.
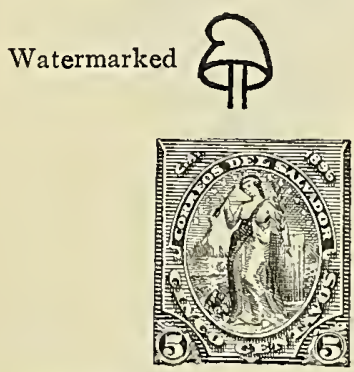

Perforated 12.

201 Ic blue

202 2c dark brown

203 3c deep green

$2045 \mathrm{c}$ olive brown

205 IOc yellow

206 I 2c Prussian blue

207 I5c lilac

$20820 \mathrm{c}$ magenta

$20924 \mathrm{C}$ vermilion

$21030 c$ orange

21 5Oc dark brown olive

212 Ip rose

II. Typographed on white wove paper, a different type for each value. Size I $922 \mathrm{~mm}$

Watermarked a Liberty Cap on a pole.
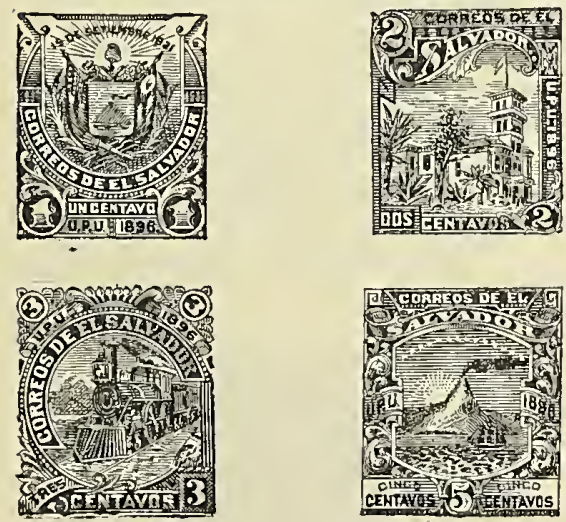
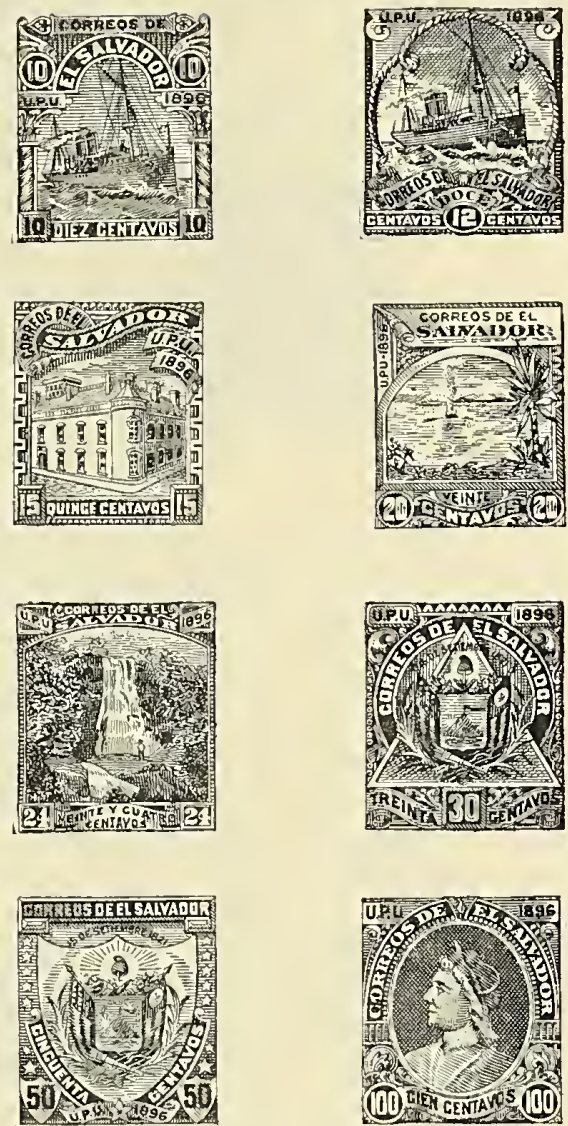

Perforated I2.

213 Ic emerald green

214 2c lake

$2153 \mathrm{c}$ yellow brown

2I $65 \mathrm{c}$ blue

217 roc brown

218 I 2c slate

219 I5c blue green

220 20c carmine rose

221 24c purple

222 30c dark yellow green

$22350 \mathrm{c}$ orange

224 IOOc dark blue

End of 1896 .

Provisional issue.

24 centavos stamps of preceding issue surcharged with new value in black.

Watermarked a Liberty cap on a pole.

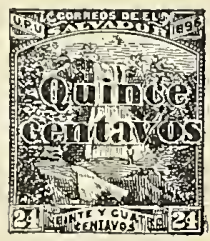

Perforated I2.

225 I $5 \mathrm{C}$ on $24 \mathrm{c}$ purple, black surcharge 
UNPAID LETTER STAMPS。

I 895:

Typographed on white wove paper. Size $181 / 2 \times 221 / 2 \mathrm{~mm}$

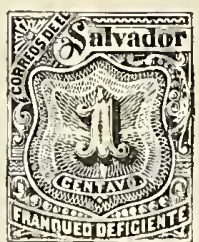

Perforated I2

$30 \mathrm{I}$ Ic olive

$302 \quad 2 \mathrm{c}$ olive

303 3c olive

$3045 \mathrm{C}$ olive

305 Ioc olive

306 I5c olive

$30725 \mathrm{c}$ olive

$308 \quad 50 c$ olive

I896.

Same type, impression and paper as preceding issue.

Perforated 12

$\begin{array}{ll}309 & \text { Ic red } \\ 310 & 2 c \text { red } \\ 311 & 3 c \text { red } \\ 312 & 5 c \text { red } \\ 313 & \text { Ioc red } \\ 314 & \text { I5c red } \\ 315 & 25 c \text { red } \\ 316 & 50 c \text { red }\end{array}$

POSTAL PACKET STAMPS.

I895.

Typographed on white wove paper. Size $221 / 2 \times 231 / 2 \mathrm{~mm}$.

Perforated 12.

35 I $5 \mathrm{C}$ orange brown

352 Ioc dark blue

353 I $5 \mathrm{C}$ red

$35420 \mathrm{c}$ orange yellow

355 50c green

OFFICIAL STAMPS.

I 896 .

I. Regular issue of 1896 surcharged

in black

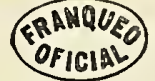

Watermarked a Liberty Cap on a pole.

Perforated I 2 .

40I Ic emerald green, black surcharge

$402 \quad 2 \mathrm{clake}$

403 3c yellow brown ". ".

$4045 \mathrm{c}$ blue "، ".

405 IOc brown " " "

406 I2c slate "“ “"

407 I $5 \mathrm{C}$ blue green “" “,

408200 carmine rose " " "

$40924 c$ purple "،

4 IO 3 Oc dark yellow green " " "

4 II $50 \mathrm{Oc}$ orange

II. Regular issues of 1896 surcharged

in black

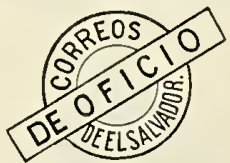

Watermarked a Liberty Cap on a pole.

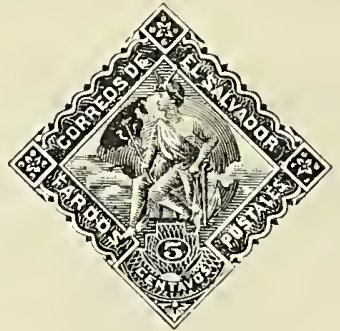




\section{ENVELOPES.}

July, $\mathbf{1 8 8 7}$.

Stamp embossed in upper right corner and the word "PROVISIONAL" printed in black above the stamp on the $5 \mathrm{c}$ and Ioc envelopes.
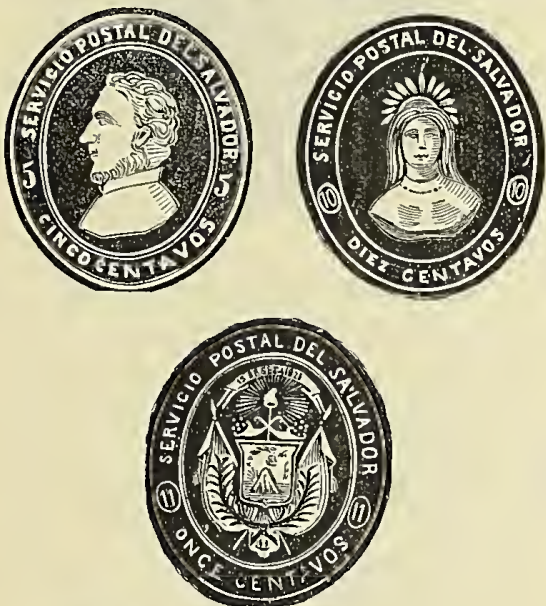

I. White wove paper. $\mathrm{I}^{\circ}$ Size $143 \times 8 \mathrm{Im}$.

55 I $5 \mathrm{C}$ ultramarine and black

552 IOc red and black

553 Irc lilac

554 IIc blue lilac

$2^{\circ}$ Size $152 \times 86 \mathrm{~mm}$.

555 roc red and black

556 IIc lilac

557 I Ic blue lilac

$3^{\circ}$ Size 15 IXII $5 \mathrm{~mm}$.

558 IIC violet

$4^{\circ}$ Size I23×95 mm.

559 II lilac

$5^{\circ}$ Size $146 \times 90 \mathrm{~mm}$.

560 Ioc lilac

II. White laid paper, colored inside.

Size $143 \times 81 \mathrm{~mm}$.

56I 5c ultramarine and black, inside blue

$5625 \mathrm{c}$ ultramarine and black, inside rose

563 5c ultramarine and black, inside green

$5645 \mathrm{c}$ ultramarine and black, inside yellow

$5655 \mathrm{c}$ ultramarine and black, inside lavender

$5665 \mathrm{c}$ ultramarine and black, inside ochre

$5675 \mathrm{c}$ ultramarine and black, inside violet

568 Ioc red and black, inside blue

569 roc red and black, inside rose

570 roc red and black, inside yellow

$57 \mathrm{I}$ roc red and black, inside violet

572 IIc yellow, inside blue

573 IIC gray lilac, inside violet

574 Irc gray lilac, inside rose

575 IIc gray lilac, inside blue

Varieties:

a. Without stamp, but " PROVISIONAL" printed in the correct place.

576 black, inside lavender

b. Double impression of "PROVISIONAL."

$5775 \mathrm{C}$ ultramarine, inside violet

III. Yellowish white laid paper.

Size I 43 XI ro $\mathrm{mm}$.

$578 \quad 5 \mathrm{c}$ ultramarine and black

579 IOc red and black
IV. White wove paper.

${ }^{\circ}$ Size $137 \times 106 \mathrm{~mm}$.

$580 \quad$ Ioc red and black

$2^{\circ}$ Size $152 \times 122 \mathrm{~mm}$.

581 IIc gray lilac

582 IIc lilac

V. Orange wove paper.

$\mathrm{I}^{\circ}$ Size $\mathrm{I} 37 \times 106 \mathrm{~mm}$.

583 Ioc red and black

$2^{\circ}$ Size I $43 \times 1$ ro $\mathrm{mm}$.

584 Ioc red and black

VI. Cream wove paper.

Size $137 \times 106 \mathrm{~mm}$.

585 Ir lilac

VII. Yellow laid paper.

$\mathrm{I}^{\circ}$ Size $137 \times 78 \mathrm{~mm}$.

$5865 \mathrm{C}$ ultramarine and black

$2^{\circ}$ Size II $2 \times 73 \mathrm{~mm}$.

$587 \quad 5 \mathrm{C}$ ultramarine and black

I 887 .

Same type as preceding issue, but printed

in a different color.

White laid paper.

$I^{\circ}$ Size $137 \times 106 \mathrm{~mm}$

588 I Ic olive yellow

$2^{\circ}$ Size $146 \times 82 \mathrm{~mm}$.

$589 \quad$ II olive yellow

I 888

Envelopes of the preceding issues embossed on flap " CONTAD. MYOR. 5(YO or I I)c."

I. White laid paper.

$I^{\circ}$ Size I $43 \times 81 \mathrm{~mm}$.

$590 \quad 5 \mathrm{C}$ ultramarine and black

$59 \mathrm{I}$ Ioc red and black

592 Irc lilac and black

593 I Ic olive yellow

$2^{\circ}$ Size I $43 \times 110 \mathrm{~mm}$

594 roc red and black

Variety: Double surcharge.

595 IOc red and black

$3^{\circ}$ Size $152 \times 122 \mathrm{~mm}$

596 roc red and black

$4^{\circ}$ Size $146 \times 82 \mathrm{~mm}$.

597 I Ic olive yellow

II. White laid paper, colored inside.

Size $143 \times 81 \mathrm{~mm}$.

$598 \quad 5 \mathrm{C}$ ultramarine and black, inside blue

$5995 \mathrm{c}$ ultramarine and black, inside rose

$6005 \mathrm{c}$ ultramarine and black, inside green

60I 5c ultramarine and black, inside yellow

$6025 \mathrm{c}$ ultramarine and black, inside lavender

603 5c ultramarine and black, inside ochre

$6045 \mathrm{c}$ ultramarine and black, inside violet

605 roc red and black, inside blue

606 Ioc red and black, inside rose

$60-$ roc red and black, inside green

608 roc red and black, inside yellow

609 Ioc red and black, inside lavender

6 10 IOc red and black, inside ochre

6I I IOc red and black, inside violet

$6 \mathrm{I}_{2}$ IIc olive yellow, inside blue

6I 3 IIc olive yellow, inside rose

6I4 I Ic olive yellow, inside green

6 I5 I Ic olive yellow, inside yellow

6I6 IIc olive yellow, inside lavender

6I 7 I Ic olive yellow, inside ochre

6I 8 IIc olive yellow, inside violet 
January, I 889.

Stamp embossed in upper right corner.

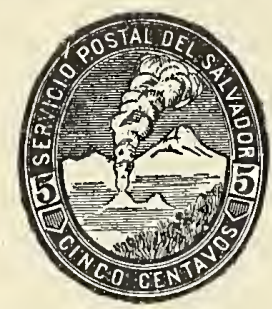

I. White wove paper.

Size $160 x 90 \mathrm{~mm}$.

6 I 9 c blue

II. Amber laid paper.

Size $150 \times 85 \mathrm{~mm}$.

$620 \quad 5 \mathrm{c}$ blue

III. Blue laid paper.

Size $160 \times 90 \mathrm{~mm}$.

$621 \quad 5 \mathrm{c}$ blue

December 3d, I889.

Stamp embossed in upper right corner on wove paper.

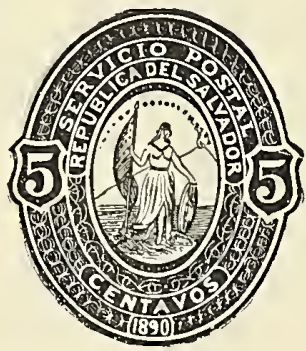

I. White paper.

Size $160 \times 90 \mathrm{~mm}$.

\begin{tabular}{ll}
622 & 5 c blue \\
623 & IOc red \\
624 & I Ic yellow \\
625 & $20 c$ rose \\
626 & $22 c$ yellow \\
\multicolumn{2}{c}{ II. Amber paper. } \\
Size I60x9o mm. \\
$627 \quad 5 \mathrm{c}$ blue \\
628 IOc red \\
$629 \quad$ I Ic yellow \\
630 & $20 c$ rose \\
631 & $22 c$ yellow \\
III. Blue paper.
\end{tabular}

III. Blue paper.

Size $160 x 90 \mathrm{~mm}$.

$\begin{array}{ll}632 & 5 \mathrm{c} \text { blue } \\ 633 & \text { IOc red } \\ 634 & \text { IIc yellow } \\ 635 & \text { 20c rose } \\ 636 & 22 c \text { yellow } \\ \text { IV. } & \text { Cream paper } \\ \text { Size } & \text { I60 x 9omm. } \\ 637 & 5 \mathrm{c} \text { blue } \\ 638 & \text { IOc red } \\ 639 & \text { IIc yellow } \\ 640 & 20 c \text { rose } \\ 641 & 22 c \text { yellow }\end{array}$

January Ist, I89I,

Stamp typographed in upper right corner on wove paper.

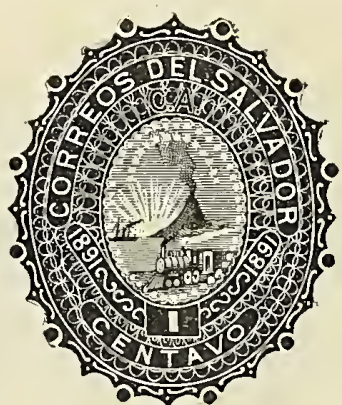

I. Amber paper.

$I^{\circ}$ Size $150 \times 85 \mathrm{~mm}$.

642 Ic lilac

643 2c red

$2^{\circ}$ Size $160 x 90 \mathrm{~mm}$.

$6445 \mathrm{c}$ brown

645 Ioc green

646 IIC orange

647 2oc carmine

$64822 \mathrm{c}$ brown

II. White paper.

$I^{\circ}$ Size $150 \times 85 \mathrm{~mm}$.

649 Ic lilac

650 2c red

$2^{\circ}$ Size $160 \times 90 \mathrm{~mm}$.

$65 \mathrm{I} 5 \mathrm{c}$ brown

652 IOc green

653 IIC orange

654 2oc carmine

$65522 \mathrm{c}$ brown

III. Salmon paper.

$I^{\circ}$ Size $150 \times 85 \mathrm{~mm}$.

656 Ic lilac

657 2c red

$2^{\circ}$ Size $160 x 90 \mathrm{~mm}$.

$658 \quad 5 \mathrm{c}$ brown

659 IOc green

660 I Ic orange

$66 \mathrm{I} 20 \mathrm{c}$ carmine

662 22c brown

IV. Blue paper.

$I^{\circ}$ Size I $50 \times 85 \mathrm{~mm}$.

663 Ic lilac

$6642 \mathrm{c}$ red

$2^{\circ}$ Size $160 x 90 \mathrm{~mm}$.

$665 \quad 5 \mathrm{c}$ brown

666 Ioc green

667 I Ic orange

668 20c carmine

$66922 \mathrm{c}$ brown

January Ist, I892.

Stamp typographed, with embossed center, in upper right corner, on wove paper.

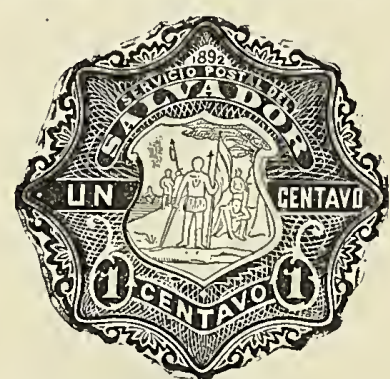

I. White paper.

Size $152 \times 90 \mathrm{~mm}$. $670 \quad$ Ic green 
II. Blue paper.

Size $152 \times 90 \mathrm{~mm}$.

67 I $5 \mathrm{c}$ blue

Variety: Salmon laid paper.

$672 \quad 5 \mathrm{c}$ blue

III. Amber paper.

Size $152 \times 90 \mathrm{~mm}$.

673 Ioc carmine

674 2oc orange

Varieties:

a. Without embossing,

675 Ioc carmine

b. Center inverted.

676 Ioc carmine

IV. Salmon paper.

$I^{\circ}$ Size $152 \times 90 \mathrm{~mm}$.

677 IIc brown

$2^{\circ}$ Size $160 x 90 \mathrm{~mm}$.

$678 \quad 22 \mathrm{c}$ dark blue

January, I893.

Stamp typographed in upper right corner on blue wove paper.

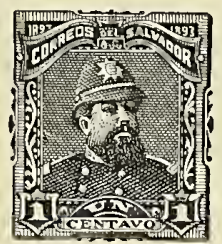

Size $\mathrm{r} 60 x 9 \mathrm{Imm}$

679 Ic blue

$680 \quad 3 \mathrm{c}$ purple

68I 5c deep brown

682 IOc chocolate

683 IIC vermilion

684 20c green

$68522 \mathrm{c}$ carmine

January Ist, I 894.

Stamp typographed, with center embossed, in upper right corner on white wove paper.

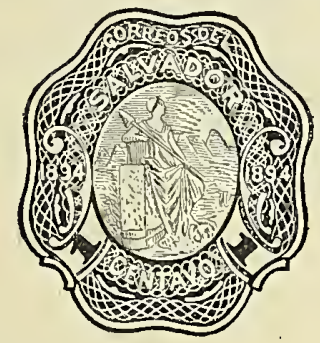

$$
\begin{aligned}
& \mathrm{I}^{\circ} \text { Size } 153 \times 88 \mathrm{~mm} \\
& 686 \text { Ic brown } \\
& 687 \text { 3c rose } \\
& 688 \text { 5c brown } \\
& 2^{\circ} \text { Size } 158 \times 9 \mathrm{rmm} \text {. } \\
& 689 \text { Ioc mauve } \\
& 695 \text { IIc red } \\
& \text { 9I } 20 c \text { deep blue } \\
& 69222 \mathrm{c} \text { sea green }
\end{aligned}
$$

Provisional issue.

IIc envelopes of the preceding issue surcharged with new value in black.

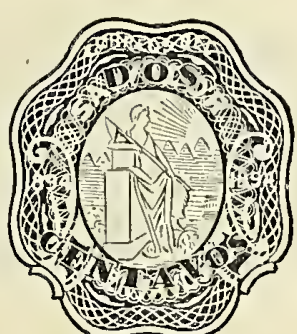

White wove paper.

Size' $158 \times 91 \mathrm{~mm}$.

693 2c on IIc red, black surcharge

January Ist, I895.

Stamp typographed, with center embossed in upper right corner on white wove paper.

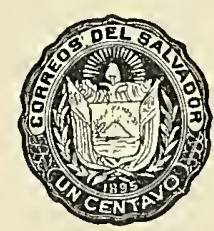

Size $158 \mathrm{xg} \mathrm{mm}$.

694 Ic olive

$695 \quad 3 \mathrm{c}$ slate green

$606 \quad 5 \mathrm{c}$ blue

697 I2c lilac brown

698 I5c vermilion

End of 1895 .

Same type as preceding issue ${ }^{-}$with ad ditionsl inscription in semicircle above stamp.

White wove paper.

Size $158 \times 91 \mathrm{~mm}$.

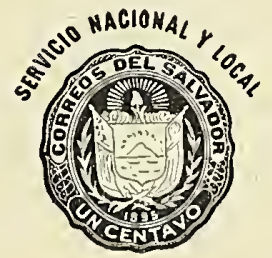

$699 \quad$ Ic olive

$700 \quad 2 \mathrm{C}$ dark green

I 896 ,

Stamp same type as second series adhesives of corresponding date, typographed in upper right corner.

White wove paper.
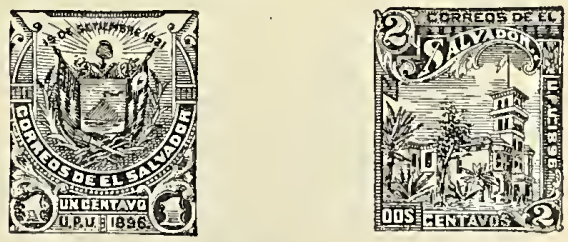

$I^{\circ}$ Size $153 \times 89 \mathrm{~mm}$.

701 Ic olive green

$7022 \mathrm{cred}$ 


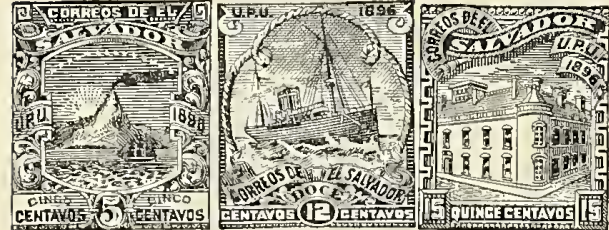

$2^{\circ}$ Size $160 \times$ gomm.

$7035 \mathrm{c}$ ultramarine

704 I2c slate

705 I $5 \mathrm{c}$ blue green

December 3d, I889.

Stamp same type as envelopes of corresponding date, embossed on wove paper.

I. Blue paper.

Size $195 \times 260 \mathrm{~mm}$.

$801 \quad 3 \mathrm{c}$ brown

802 6c brown

$80425 \mathrm{c}$ brown

II. White paper.

$I^{\circ}$ Size $195 \times 260 \mathrm{~mm}$.

$805 \quad 3 \mathrm{c}$ brown

$806 \quad 6 \mathrm{c}$ brown

$2^{\circ}$ Size $198 \times 294 \mathrm{~mm}$

807 I $2 \frac{1}{2} \mathrm{c}$ brown

$808 \quad 25 \mathrm{c}$ brown

January Ist, I89x.

Stamp same type as envelopes of corresponding date, typographed on salmon wove paper.

Size 2 I0x265 $\mathrm{mm}$.

$809 \quad 2 \mathrm{c}$ red

8Io 3c dark blue

8II $6 \mathrm{c}$ green

8 I 2 I $21 / 2 \mathrm{c}$ brown

January Ist, I892.

Stamp same type as envelopes of same date typographed, with center embossed, on blue wove paper.

$\mathrm{I}^{\circ}$ Size $150 \times 295 \mathrm{~mm}$

8I3 2c brown

$2^{\circ}$ Size $165 \times 254 \mathrm{~mm}$

$8 \mathrm{I} 43 \mathrm{C}$ brown
803 I $21 / 2 \mathrm{c}$ brown

End of 1896

Provisional issue.

I5 centavos envelopes of preceding issue, surcharged in black with new value over the stamp.

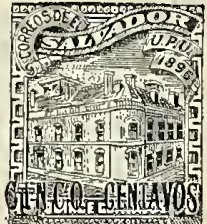

White wove paper.

Size I6oxgomm.

$7065 \mathrm{C}$ on $\mathrm{I} 5 \mathrm{c}$ blue green, black surcharge

\section{WRAPPERS.}

$$
\begin{gathered}
3^{\circ} \text { Size } 172 \times 254 \mathrm{~mm} . \\
6 \mathrm{c} \mathrm{brown} \\
8 \mathrm{I} 64^{\circ} \mathrm{Size} \mathrm{I}_{40 \times 303} \mathrm{~mm} . \\
\mathrm{I} 2 \mathrm{1} / 2 \mathrm{c} \text { brown }
\end{gathered}
$$

January, I 893 .

Stamp same type as envelopes of corresponding date, typographed on blue wove paper.

$$
\begin{aligned}
& \text { Size } 204 \times 265 \mathrm{~mm} \text {. } \\
& \text { 817 2c red } \\
& 818 \text { 3c purple } \\
& 819 \text { Ioc brown } \\
& 820 \text { IIC vermilion } \\
& \text { January Ist, I894. }
\end{aligned}
$$

Stamp same type as envelopes of corresponding date, typographed, with center embossed, on white vertically laid paper, batonné horizontally.

$\begin{array}{ll}\text { Size } & \text { I68 } \times 252 \mathrm{~mm} . \\ 82 \mathrm{I} & \text { 2c deep blue } \\ 822 & \text { 3c rose } \\ 823 & \text { IOc mauve } \\ 824 & \text { I Ic red }\end{array}$

Jauuary Ist, I 895 .

Stamp same type as envelopes of corresponding date, typographed, with center em. bossed, on blue wove paper.

\begin{tabular}{ll}
\multicolumn{2}{c}{ Size $170 \times 255 \mathrm{~mm}$} \\
825 & 2c green \\
826 & 3c brown \\
827 & 4c blue \\
828 & $6 \mathrm{c}$ rose
\end{tabular}

COUNTERFEITS.

We do not know of any good forgeries of the stamps of this country.

\section{SAMOA.}

CURRENCY : I2 PENCE=I SHILLING ; 20 SHILLINGS $=$ I POUND $=\$ 4.87$ U. S. CURRENCY.

\section{ADHESIVE STAMPS.}

October, I877.

Lithographed on white wove paper, varying in thickness. The I and 6 penny stamps were printed in sheets of twenty stamps, in four horizontal rows of five stamps each. The other values were printed in sheets of ten, in two horizontal rows of five each. All the sheets were imperforale at the edges. Size $20 \times 231 / 2 \mathrm{~mm}$,

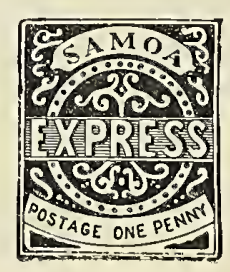


Perforated $121 / 2$.

Ip ultramarine

Ip pale ultramarine

$3 \mathrm{p}$ red

$3 p$ scarlet

$6 \mathrm{p}$ purple

6p mauve

I878.

Same type, paper and impression as preceding issue.

Perforated I2 $1 / 2$.

7 Ish yellow

8 Ish orange yellow

92 sh brown

Io 2 sh violet brown

II 2sh carmine brown

I2 5 sh emerald green

May, I88I.

Same type, paper and impression as preceding issue.

Perforated I2.

I3 Ip blue

I4 Ip dark ultramarine

I5 $3 \mathrm{p}$ red

I6 $3 \mathrm{p}$ red

I7 6p purple

I8 9p yellow brown

I9 $9 \mathrm{p}$ orange brown

20 Ish yellow

2 I 2 sh brown

Reprints.

1882.94.

Perforated 12 and $121 / 2$.

$1 p$ dull blue

$1 p$ cobalt blue

3p vermition

$6 p$ purple

Gp violet

9p yellow brown

op orange brown

gp orange

Ish yellow

1 sh orange yellow

$2 s h$ brown

ssh carmine brown

5 sh emerald green

5sh yellow green

The reprints were printed in sheets of 40 , in five rows of eight. Some of the sheets have the edges trimmed, others have not.

The reprints can be distinguished from the originals by the colors and also by the perforation, which, in the originals, is generally very ragged, the perforating machine having very often made holes without removing any of the paper.

I 882.

Same type, paper and impression as preceding issue.

Perforated 12.

$36 \quad 2 p$ lilac rose

This stamp, although prepared for issue, was never put in use, as the post-office was discontinued about the time of the supply of this stamp reaching the islands. Messrs. Whitfield, King \& Co. state that when they bought up the remainders frcm Mr. Griffith. the late postmaster, they included a lot of the 2 penny ones.

Reprints.

1882.94.

Perforated 12 and $121 / 2$.

37 2p bright rose

38 2p lilac rose
There were at least four printings of the $\mathrm{I}$, 3, 6 pence and I, 2 and 5 shillings, while there was only one printing of the 2 and 9 pence stamps. The first printing took place previous to October, 1877 , and is easily distinguished from the subsequent printings by the top frame of the tablet containing the word "Express" being unbroken. The second printing, which probably took place the latter part of 1878 , since the earliest postmark which we have seen is November, I878, is recognized by a break in the frame above the letter "X" of the word "Express." In the third printing, of which the earliest postmark seen by us is January 26 th, 1880 , this break has been repaired, but in so bungling a manner that it looks worse than the break itself. All the stamps of the first three printings were perforated $12 \frac{1}{2}$. The fourth printing is identical with the third, except that the perforation is I 2. All the reprints have the characteristics of the third and fourth printings.

Some of the stamps are watermarked with portions of double lined letters and numerals, which however are only the papermaker's trade-mark and date of manufacture. The reprints have a similar watermark which we have been able to reconstruct, and is "J. Whatman" and date, of which we have seen I885, I89o and I8gr.

I 887.

Typographed on white wove paper. Water marked<smiles>C1CC2CCC(C1)CC2</smiles>
Size $173 / 4 \times 22 \frac{1}{2} \mathrm{~mm}$.

\section{N Z}

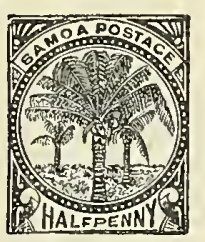

PerforatedII, I $21 / 2$, I 2XI I $1 / 2$.

$\begin{array}{ll}39 & \mathrm{I} / 2 \mathrm{p} \text { brown viol } \\ 40 & \text { Ip green } \\ 4 \mathrm{I} & 2 \mathrm{p} \text { orange } \\ 42 & 4 \mathrm{p} \text { blue } \\ 43 & 6 \mathrm{p} \text { brown } \\ 44 & \text { Ish rose }\end{array}$

52 sh $6 \mathrm{p}$ violet

Variety: I shilling stamp cut diagonally in two, each half being used as a 6 penny stamp.

$45 \mathrm{a} 6 \mathrm{p}$ rose, (half of $\mathrm{Ish}$ ), 1895

I 892.

Typographed (portrait of King Malietoa) on white wove paper, watermarked a small Star and N. Z. Size $173 / 4 \times 22 \mathrm{~mm}$.

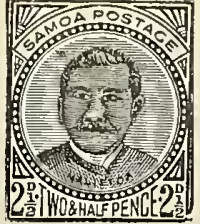

Perforated $121 / 2$

$46 \quad 21 / 2 \mathrm{p}$ pink 
End of I 893 .

Provisional issue.

4 penny stamps of the issue of 1887 , sur. charged with new value and the original value obliterated by a bar. There are three different types of this surcharge: the first and second are similar, but in type $I$ the words and surcharge measure respectively 6 and $8 \mathrm{r} / 2 \mathrm{~mm}$. in length, while in the second type they measure $41 / 2$ and $6 \mathrm{~mm}$. In the first and second types the original value is obliterated by two lines-a heavy one above a thin one; in the third type the original value is obliterated by a single thick line. Watermarked, a small Star and N. Z.

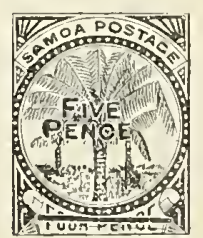

I.

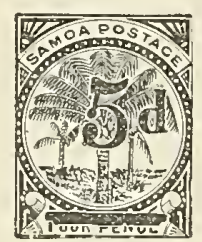

7II.

Perforated II, I $21 / 2$, I 2 XII $1 / 2$.

$475 \mathrm{p}$ on $4 \mathrm{p}$ blue, black surcharge, type I

$485 \mathrm{p}$ on $4 \mathrm{p}$ blue " " " " II

$495 \mathrm{p}$ on $4 \mathrm{p}$ blue, red surcharge, type III Varieties:

a. Without bar.

$50 \quad 5 \mathrm{p}$ on $4 \mathrm{p}$ blue, black surcharge, type I

b. With thick line only.

5 I $5 \mathrm{p}$ on $4 \mathrm{p}$ blue, black surcharge, type I

c. Thin line above the heavy line.

$525 \mathrm{p}$ on $4 \mathrm{p}$ blue, black surcharge, type II

d. Double surcharge.

$535 \mathrm{p}$ on $4 \mathrm{p}$ blue, red surcharge, type III

The Samoan stamps prepaid postage to any part of the world, if forwarded via New Zealand. Since I 89I, the Samoan stamps also prepay postage on letters sent direct to any part of the United States.

\section{COUNTERFEITS.}

There is one very dangerous forgery of the stamps of the first issue. The principal differences between this forgery and the genuine are as follows: In the genuine there are ten horizontal lines in the tablet containing the word "Express," these lines being at an equal distance one from another. In the counterfeits there are only nine lines, and the 6th and 7 th from the top, between the " $\mathrm{E}$ " and "X," are further apart than the others. In the genuine, the first dot from the left in the lower semi-circle does not touch the line above, which it does in the counterfeit.

There is a second counterfeit which, although very fine, is not so dangerous, the principal differences being as follows: In the genuine, the 8th, gth and Ioth dots in the upper semi-circle are nearer one another than the others, two of them being under the "M" of SAMOA. In the counterfeit, these dots are about equidistant and there is only one under the " $M$ "- - exactly under the center of this letter.

\section{SAN MARINO.}

CURRENCY : IOO CENTESIMI $=\mathrm{I}$ LIRA $=\mathrm{I} 9$ Cents, U. S. Currency.

\section{AIHHESIVE STAMPS.}

August Ist, I 877 .

Typographed on white wove paper. There are two types: one for the 2 centesimi stamps and another for the higher values. Size $22 \mathrm{r} / 2 \times 18 \mathrm{r} / 2 \mathrm{~mm}$.
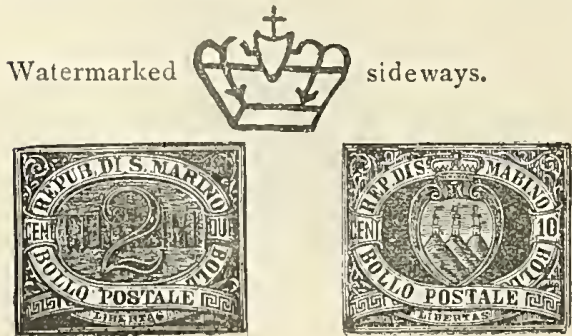

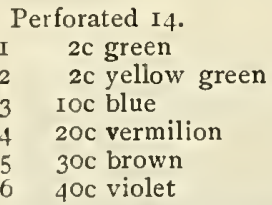

Variety : 2 centesimi stamp cut diagonally in two, each half being used as a I centesimo stamp.

7 Ic green (half of 2c)

April, I8go.

Same type as Io centesimi of preceding issue. Typographed on white wove paper. Watermarked a Crown sideways. 
Perforated I4.

$85 \mathrm{c}$ orange.

$9 \quad 25 \mathrm{c}$ magenta

June, I 892.

Provisional issue.

IO, 20 and 30 centesimi stamps of the issue

of 1877 surcharged with new value in black.

There are several types of each surcharge.

Watermarked a Crown sideways.

Perforated $\mathbf{I}_{4}$.

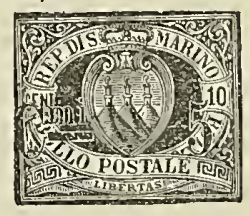

I.

Io $5 \mathrm{c}$ on Ioc blue, black surcharge, type I

I I $5 \mathrm{c}$ on $30 \mathrm{c}$ brown " " " "II

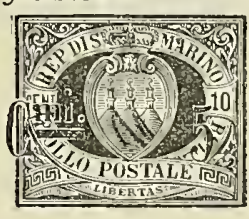

I $5 \mathrm{c}$ on roc blue, black surcharge, type II I 3 c on $30 \mathrm{c}$ brown "“

Varieties:

a. Thin line under " $\mathrm{mi}$."

I 4 5c on Ioc blue, black surcharge, type II

. Double line under " $\mathrm{mi}$."

I6 5c on Ioc blue, black surcharge, type II

I $7 \mathrm{c}$ on $30 \mathrm{oc}$ brown "

c. "ini" instead of " $\mathrm{mi}$."

I $85 \mathrm{c}$ on roc blue, black surcharge, type II

I $5 \mathrm{c}$ on $30 \mathrm{c}$ brown " " " "

d. Dotted line below " mi."

$5 \mathrm{c}$ on Ioc blue, black surcharge, type II

2 I $5 \mathrm{c}$ on $30 \mathrm{c}$ brown

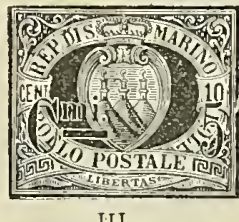

III.

$225 \mathrm{c}$ on Ioc blue, black surc'ge,type III

$235 \mathrm{c}$ on $30 \mathrm{c}$ brown " " " III

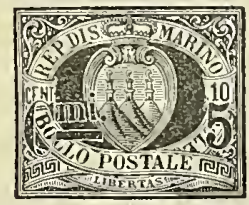

IV.

$245 \mathrm{c}$ on roc blue, black surcharge, typeIV

25. $5 \mathrm{c}$ on $30 \mathrm{c}$ brown

Varieties:

a. Comma after "mi".

$26 \quad 5 \mathrm{c}$ on IOc blue, black surcharge, typeIV

275 c on $30 \mathrm{c}$ brown "

b. Wavy line under "mi".

28 5c on Ioc blue, black surcharge, ty peIV

$295 \mathrm{c}$ on $30 \mathrm{oc}$ brown "

c. " $i$ " of "mi" inverted.

$305 \mathrm{c}$ on Ioc blue, black surcharge, typeIV

3 t 5 c on $30 \mathrm{c}$ brown "

d. Double line under "mi".

$325 \mathrm{c}$ on roc blue, black surcharge, type IV

33

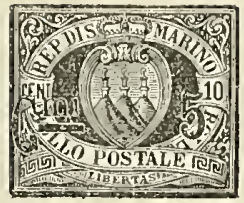

v.

$345 \mathrm{c}$ on Ioc blue, black surc'ge, type $\mathrm{V}$ $355 \mathrm{c}$ on $30 \mathrm{c}$ brown " " " "V

Varieties: Double line under "mi".

$365 \mathrm{c}$ on roc blue, black surc'ge, type V

$375 \mathrm{c}$ on $30 \mathrm{c}$ brown "،

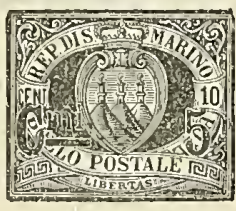

VI.

385 c on roc blue, black surc'ge, type VI

$5 \mathrm{c}$ on $30 \mathrm{c}$ brown " " "

arieties:

a. Wavy line under "mi."

40 $5 \mathrm{c}$ on IOc blue, black surc'ge, type VI

4 I 5 c on $30 \mathrm{c}$ brown "

b. Double line under " $\mathrm{mi}$."

$425 \mathrm{c}$ on Ioc blue, black surc'ge, type VI

435 con $30 \mathrm{c}$ brown " " " VI

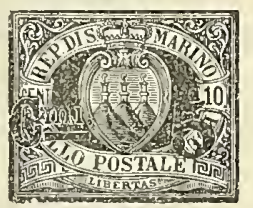

VII.

4.

$5 \mathrm{c}$ on roc blue, black surch'ge, ty peVII

$5 \mathrm{c}$ on $30 \mathrm{c}$ brown " " "

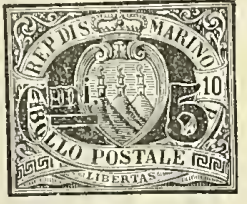

VIII.

$5 \mathrm{c}$ on roc blue, black surc'ge, typeVII

47

$5 \mathrm{c}$ on $30 \mathrm{c}$ brown "

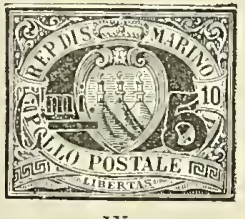

$485 \mathrm{c}$ on roc blue, black surch'ge, type IX

$495 \mathrm{c}$ on $30 \mathrm{c}$ brown " " " " " IX

Varieties: Dotted line under "'mi."

$50 \quad 5 \mathrm{c}$ on roc blue, black surcharge, typeIX

5 I 5 c on 3 oc brown "

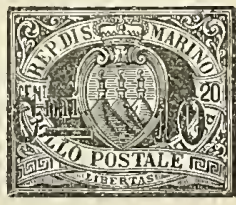

52 Ioc on $20 c$ vermilion, bl'k surc'ge,type $\mathrm{X}$ 
Varieties:

a. "mi" on a level with the bottom of "C" (Cmi), instead of with the top of "C" (C $\mathrm{mi}$ ).

53 I Oc on $20 c$ vermilion, bl'k surc'ge, type X

b. Same as "a" with broad "o" in "Io." 54 IOc on 200 vermilion, b'lk surc'ge,type X

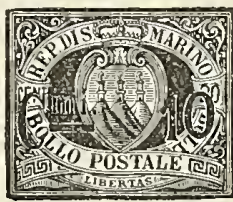

$\mathrm{XI}$.

55 IOc on $20 c$ vermilion, bl'k sur'ge, type XI Varieties :

a. " $\mathrm{i}$ " of " $\mathrm{mi}$ " inverted.

56 Ioc on $20 c$ vermilion, bl'k sur'ge, type XI

b. Comma after "mi."

57 IOc on $20 \mathrm{c}$ vermilion, bl'k sur'ge, type XI

c. Broad "o" in " 10 ."

$5^{8}$ IOc on $20 c$ vermilion, bl'k sur'ge, ${ }_{\mathrm{b}}^{\mathrm{t}} \mathrm{type} \mathrm{XI}$

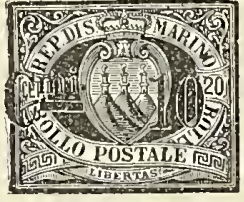

XII.

59 Ioc on $20 c$ vermilion, bl'k sur'ge, type XII Varieties :

a. Thick broad "o."

6o Ioc on $20 c$ vermilion, bl'k sur'ge, ty pe XII

b. Thick broad "o" and comma after " $i$ " of " mi."

6 I IOC on $20 c$ vermilion, bl'ksur'ge, type XII

c. Thin broad "o."

62 IOC on' 2 Oc vermilion, bl'ksur'ge, type XII

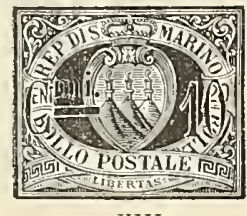

XIII.

63 IOc on $20 c$ vermilion, bl'k sur'ge, typeXIII Varieties:

a. Broad thin " o,"

64 IOc on $20 c$ vermilion, bl'k sur'ge, typeXIII

b. Narrow thick "o."

65 Iocon $20 \mathrm{c}$ vermilion, bl'k sur'ge, typeXIII

c. No period after "mi."

66 IOc on $20 c$ vermilion, bl'k sur'ge, typeXIII

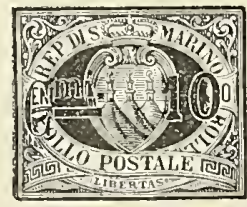

XIV.

67 IOc on $20 \mathrm{Ocvermilion,} \mathrm{bl'k} \mathrm{sur'ge,} \mathrm{typeXIV}$

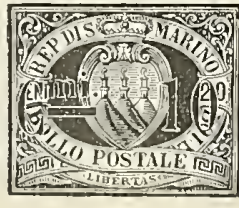

$\mathrm{XV}$
68 Ioc on $20 c$ vermilion, bl'k surc'ge, typeXV Variety: Broad thick "o."

69 IOc on $20 \mathrm{c}$ vermilion, bl'k sur'ge,typeXV

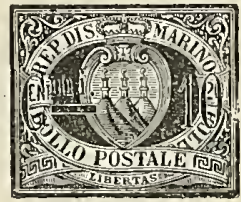

YVI.

70 Ioc on $20 c$ vermilion, bl'k sur'ge, typeXVI Variety: Broad thick "o""

$7 \mathrm{I}$ IOc on $20 \mathrm{oc}$ vermilion, bl'k sur'ge, typeXVI

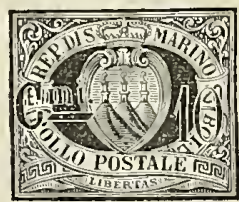

XVII.

72 Ioc on Ioc vermilion, bl'k sur'ge,typeXVII Variety: Narrow "o" and space between " $\mathrm{C}$ " and " $\mathrm{mi}$."

73 I Ioc on 2 Oc vermilion, bl'k sur'ge,typeXVII July I 5 th, 1892.

Same type, impression and paper as issue of April, I 800 . The I lira stamp is printed with yellow groundwork, and has the numerals of value in the upper corners. Watermarked a Crown sideways.

Perforated $\mathbf{I} 4$.

$745 \mathrm{c}$ olive green

75 3oc yellow

$7640 c$ brown

$7745 \mathrm{c}$ pale green

78 I 1 red, yellow groundwork

September 9 th, I 892 .

Provisional issue.

20 centesimi stamps, of the issue of August Ist, 1877 , surcharged with new value. Watermarked a Crown sideways.

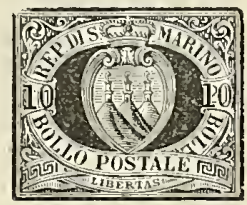

Perforated I 4

79 IOC on $20 \mathrm{C}$ vermilion, black surcharge

March, I 894.

Same type, impression and paper as preceding regular issues. The 2 and 5 lire stamps are of the same type as the I lira. Watermarked a Crown sideways.

Perforated I4.

80 2c blue

8 I IOc blue gray

82 I $5 \mathrm{c}$ carmine

$8365 \mathrm{c}$ red brown

$84 \quad 21$ brown; yellow groundwork

855 l dark violet, blue green groundwork September $20 t h$, I894.

Celebration issue on the occasion of the inauguration of the new palace and the installation of the new regents. Lithographed in two colors on white wove paper. Sizes: 25 centesimi, $24 \frac{1}{2} \times 29^{1 / 2} \mathrm{~mm}$; 50 centesimi $24 \times 30 \mathrm{~mm}$; I lira, $29 \mathrm{I} / 2 \times 241 / 2 \mathrm{~mm}$ 

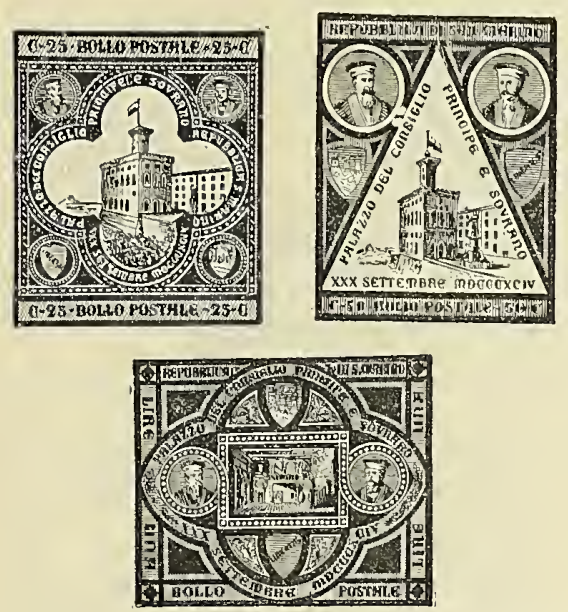

Perforated $15 \mathrm{I} / 2 \times 1 \mathrm{x}$.

$86 \quad 25 \mathrm{c}$ blue and dark brown

87 5oc old rose and dark brown

$88 \quad \mathrm{rl}$ green and dark brown

The issue lasted only from September zoth to October gth. These stamps, although issued under cover of a celebration issue, are merely of a speculative nature.

End of 1894 .

Same type as corresponding values of preceding issues, White wove paper. Watermarked a Crown sideways.

Perforated I 4 .

$\begin{array}{ll}89 & 2 \mathrm{c} \text { red } \\ 90 & 20 \mathrm{c} \text { lilac } \\ 9 \mathrm{I} & \text { xl sky blue }\end{array}$

REGISTRATION ENVELOPE.

September 2oth, r894,

Issued especially for the forwarding of the stamps of the celebration issue in quantities of not less than 500 lire. The stamp is lithographed in 6 colors on the face of the envelope. The size of the stamp is $\mathrm{r}_{45} \mathrm{x}$ 20omm. On the back of the envelope are the following inscriptions; at top: "REPUBRLICA DI SAN MARINO," below are five dotted lines for the address, at the left side: "COMmizzione DEL PALAzZo DEL consigLio."

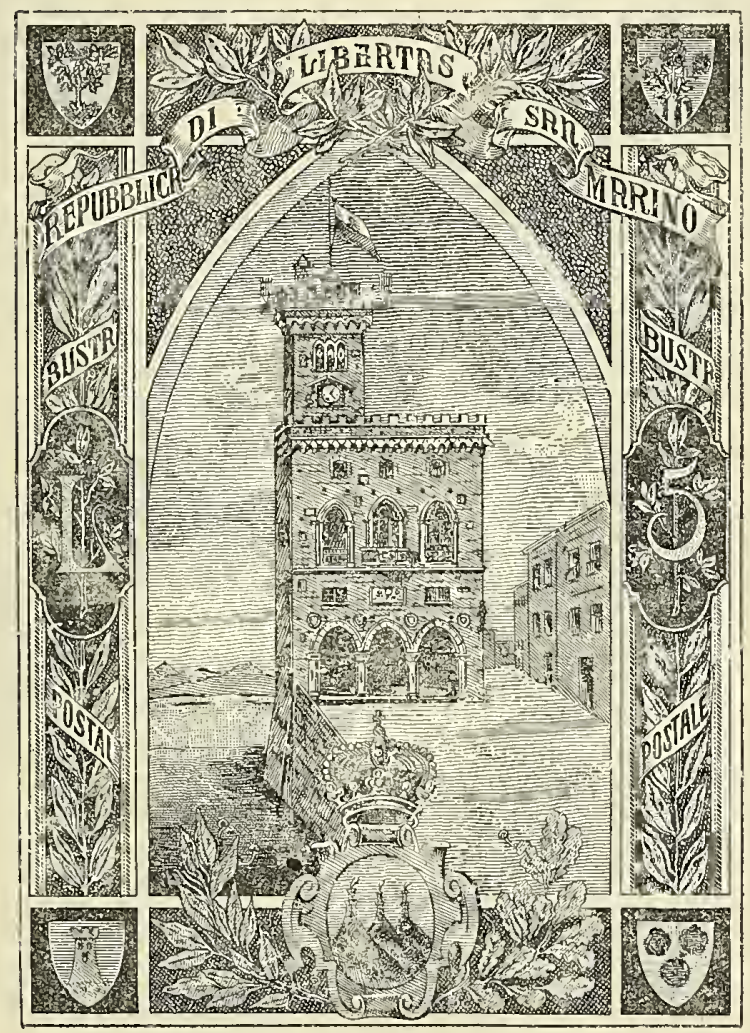

Size $150 \times 260 \mathrm{~mm}$.

White wove paper.

30 I $5 l$ brown, blue, red, yellow, green, and gold

Only 2000 of these were issued.

\section{COUNTERFEITS.}

We know of no good forgeries of the stamps of this Republic. 
SARAWAK.

CURRENCY: IOO CENTS $=$ I DOLLAR $=55$ Cents U. S. Currency.

ADHESIVE STAMPS.

May Ist, I869.

Lithographed (portrait of Rajah James Brooke) on yellow wove paper. Size Igx $26 \mathrm{I} / 2 \mathrm{~mm}$.

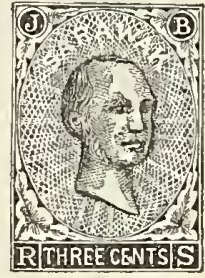

Perforated II.

I 3 c brown on yellow

Vanety: Imperforate.

$23 \mathrm{c}$ brown on yellow

I87I.

Lithographed (portrait of Charles Brooke) on yellow wove paper Size $20 \times 221 / 2 \mathrm{~mm}$.

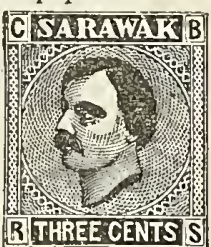

Perforated II.

$33 \mathrm{c}$ brown on yellow

Variety: Imperforate.

$43 \mathrm{c}$ brown on yellow

June, 1877 .

Same type as preceding issue. Lithographed on colored wove paper. There are five varieties of each value, differing in the letters of the denomination of value in the lower tablet.

Perforated I 2.

$5 \quad 2 \mathrm{c}$ mauve on lilac

64 c brown on yellow

7 6c green on greenish

8 8c deep blue on blue

9 I2c red on bluish

Varieties:

a. Laid paper.

ro $12 \mathrm{c}$ red on bluish 5 varieties 5 “"

5 “"

Imperforate.

I I 2 mauve on lilac

I2 $4 \mathrm{c}$ brown on yellow

I3 $6 \mathrm{c}$ green on greenish

I4 $8 c$ deep blue on blue

I5 I2c red on bluish

c. The vertical bar of the " $\mathrm{T}$ " goes beyond the horizontal bar, giving it the appearance of a cross.

I6 $4 \mathrm{c}$ brown on yellow

d. Same as "c" but imperforate.

77 4c brown on yellow

e. Pin perforated.

I8 $6 \mathrm{c}$ green on greenish 5 varieties

I9 $8 c$ deep blue on blue 5 ".

These were pin perforated unofficially.

August, 1876 .

Provisional issue.

3 cent stamps of the $187 \mathrm{I}$ issue surcharged in black with new value.

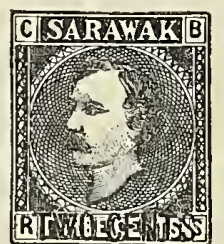

Perforated I I.

$202 \mathrm{c}$ on $3 \mathrm{c}$ brown on yellow, black surcharge

January, 1889 .

Typographed on white wove paper; the 2 3, 4 and 6 cent stamps are printed in lilac and the tablet containing the value is printed in a different color. In the higher values the body of the stamp is printed in green and the tablet also in a different color. Size $181 / 2 \times 221 / 2 \mathrm{~mm}$.

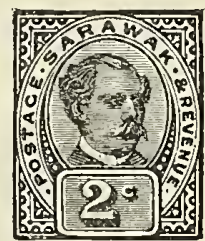

Perforated I4.

$2 c$ lilac and red

$3 c$ lilac and blue

$4 \mathrm{clilac}$ and yellow

$6 \mathrm{c}$ lilac and brown

$8 c$ green and red

I $2 c$ green and blue

$25 \mathrm{C}$ green and brown

I 889 .

Provisional issue.

8 cent stamps of the preceding issue surcharged with new value in black.

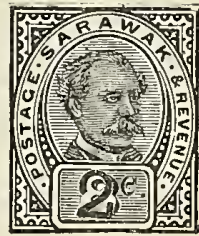

Perforated I4.

$282 \mathrm{c}$ on $8 \mathrm{c}$ green and red, black sur charge

Varieties:

a. Double surcharge.

$292 \mathrm{c}$ on $8 \mathrm{c}$ green and red, black surcharge

b. A pair, one of which is without surcharge.

$302 \mathrm{c}$ on $8 \mathrm{c}$ green and red, black sur charge

I89I

Provisional issue.

I 2 cent stamps of the issue of January, $188 \mathrm{~g}$, surcharged with new value in black. There are two different types of the surcharge, one with small " $c$ " and the other with a large " $c$ " as per illustrations. 
SARAWAK.

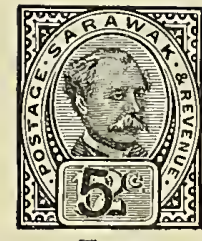

Type I.

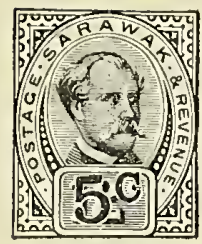

Type II.
Perforated $\mathrm{I} 4$

$3 \mathrm{I} 5 \mathrm{C}$ on I $2 \mathrm{c}$ green and blue, black surcharge, type I

$325 \mathrm{C}$ on I2c green and blue, black surVarieties: charge, type II

a. Double surcharge.

$335 \mathrm{C}$ on $\mathrm{I} 2 \mathrm{c}$ green and blue, black surb. No period after c.

3t $5 \mathrm{c}$ on I $2 \mathrm{c}$ green and blue, black surcharge, type I

$355 \mathrm{c}$ on $\mathrm{rac}$ green and blue, black surcharge, type II

c. A pair, one without surcharge.

$365 \mathrm{C}$ on I2c green and blue, black sur-

July, I891. charge, type I

Same type, impression and paper as issue

of January, $188 \mathrm{~g}$.

Perforated I4.

$37 \quad 5 \mathrm{c}$ lilac and green

38 Ioc green and mauve

January, I 892 .

Provisional issue.

3 cent stamps of the issue of January, I 889 , surcharged with new value in black. There are two types of this surcharge; on one the initial letter of each word of the surcharge is plain ; in the others these initials are printed in capitals.

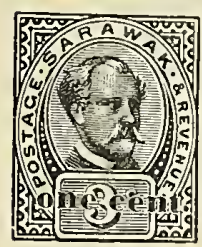

Type I.

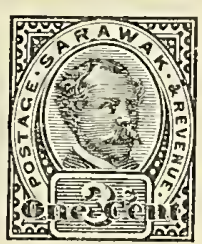

Type II.
Perforated 14

39 Ic on $3 \mathrm{c}$ lilac and blue, black surcharge, type I

40 Ic on $3 c$ lilac and blue, black surcharge, type II

Varieties :

a. No period after "cent."

4 I Ic on 3c lilac and blue, black surcharge, type I b. "Ccnt," instead of "Cent."

42 Ic on $3 \mathrm{c}$ lilac and blue, black sur-

March, 1892. charge, type II

Provisional issue.

3 cent stamps of the $187 \mathrm{r}$ issue surcharged with new value in black and the original value obliterated by black lines.

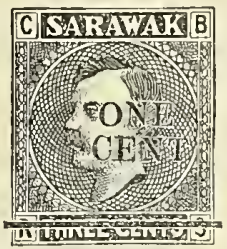

Perforated II.

43 Ic on $3 \mathrm{c}$ brown on yellow, black surcharge

Varieties

a. Without lines.

44 Ic on $3 \mathrm{c}$ biown on yellow, black surcharge

b. Imperforate horizontally.

45 Ic on 3c brown on yellow, black surcharge

May, I 892.

Same type, impression and paper as issue of January, 1889.

Perforated I4.

46 Ic lilac and slate

January, I 895 .

Typographed on white wove paper. Different design for each value. Size Igx24 $\mathrm{mm}$.
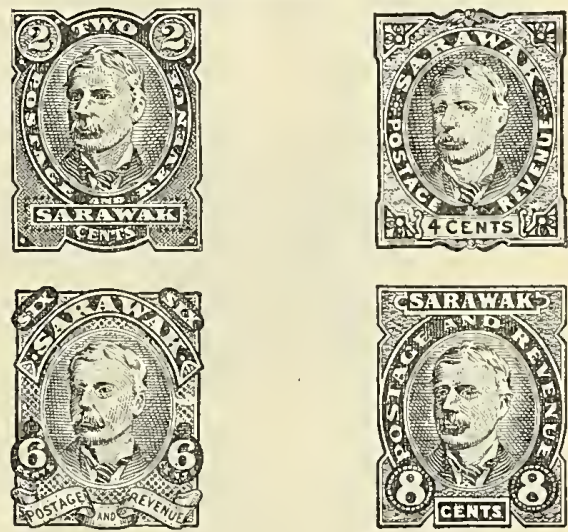

Perforated 12.

$47 \quad 2 \mathrm{c}$ red brown

$48 \quad 4 \mathrm{c}$ black

49 6c violet

$50 \quad 8 \mathrm{c}$ deep green

COUNTERFEITS.

We know of no good counterfeits of the stamps of Sarawak. 


\section{SAXONY.}

CURRENCY : IO PFENNIGE $=$ I NEUGROSCHEN ; 30 NEUGROSCHEN $=1$ THALER $=72$ cents, U. S. Currency. IOO PFENNIGE $=$ I MARK $=24$ cents, U.S. Currency.

\section{ADHESIVE STAMPS.}

July Ist, I $85^{\circ}$.

Typographed on white wove paper. Size, I $81 / 4 \times 181 / 4 \mathrm{~mm}$, to I $9 \times 19 \mathrm{~mm}$.

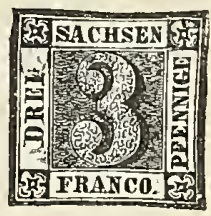

I 3 pf red

23 pf dark red

August Ist, I850.

I. Typographed (coat of arms) on white wove paper. Size $183 / 4 \times 23^{1 / 2} \mathrm{~mm}$.

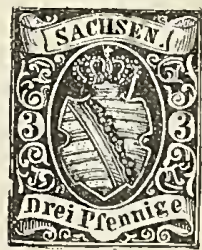

33 pf green

$4 \quad 3$ pf yellow green

II. Typographed (portrait of King Friedrich August) in black on colored wove paper. Size $183 / 4 \times 231 / 2 \mathrm{~mm}$.

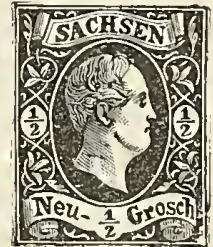

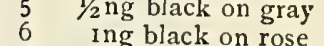 \\ 7 Ing black on deep rose \\ 8 2ng black on pale blue \\ 92 2ng black on dark blue \\ Io 3 ng black on yellow \\ I 3 ng black on deep yellow}

Variety: Error- $1 / 2$ neugroschen printed on paper of the 2 neugroschen.

$121 / 2 \mathrm{ng}$ black on pale blue

June Ist, I 855 .

Typographed (portrait of King Johann) in black on colored wove paper. Size I9x $24 \mathrm{~mm}$.

There are three different types of the $1 / 2$ neugroschen and two yypes of the I neugros chen, the differences being in the numeral at the sides and in the lower label. The three types of the $1 / 2$ neugroschen are distinguished as follows: In type $I$, the $1 / 2$ in the lower label is perfectly straight ; in type 2 , the $1 / 2$ leans towards the left ; in type 3 it leans towards the right. In type I of the I neugroschen stamps, the $I$ at the sides is about $2 \mathrm{~mm}$. high ; in lype 2 , it is $21 / 2 \mathrm{~mm}$.
There are also two printings of these stamps, the first one is a heavy and rather coarse impression, and the second is of a much finer impression. The former are generally printed on naper of a deeper shade than the latter.

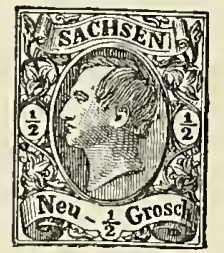

$\mathrm{I}^{\circ}$ Heavy impression.

I 3 1/2ng black on gray,

I4 Ing black on deep rose type I

I5 Ing black on deep rose " 2

I6 2 ng black on blue

I 7 ng black on yellow

I 8 ng black on deep yellow

$2^{\circ}$ Fine impression.

$19 \quad 1 / 2$ ng black on gray, type 2

$20 \quad 1 / 2 \mathrm{ng}$ black on gray " 3

2 Ing black on rose “ I

22 Ing black on rose "

23 2ng black on blue

$24 \quad 3$ ng black on yellow

April 24th, I856.

Same type as preceding issue. Typographed in color on white wove paper. Size $19 \times 24 \mathrm{~mm}$.

I. Yellowish white wove paper

$\begin{array}{ll}25 & \text { 5ng red } \\ 26 & \text { 5ng vermilion } \\ 27 & \text { 5ng red brown } \\ 28 & \text { Iong blue }\end{array}$

II. Thin bluish white paper.

$29 \quad 5 \mathrm{ng}$ vermilion

30 Iong blue

July Ist, I 863.

Typographed, with coat of arms embossed on white wove paper. There are two types one for the 3 pfennige and $1 / 2$ neugroschen stamps and another for the ligher values. Sizes: 3 pfennige and $1 / 2$ neugroschen, $19 \times 221 / 2$ $\mathrm{mm}$.; $\mathrm{I}, 2,3$ and 5 neugroschen, $19 \times 22 \mathrm{~mm}$.
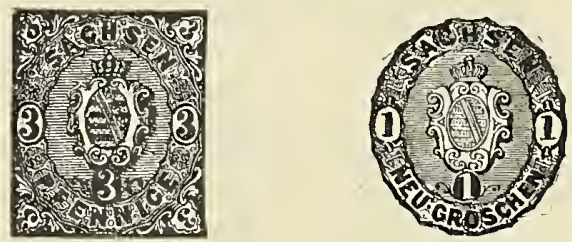

Perforated 13

3 pf green

$3 \mathrm{pf}$ yellow green

$3 \mathrm{pf}$ blue green

$1 / 2 \mathrm{ng}$ vermilion

$1 / 2 \mathrm{ng}$ orange

Ing rose 


$\begin{array}{ll}\text { 37 } & \text { Ing deep rose } \\ 38 & \text { 2ng blue } \\ 39 & \text { 2ng Prussian blue } \\ 40 & \text { 2ng ultramarine } \\ 4 \mathbf{I} & \text { 3ng brown }\end{array}$

$\begin{array}{ll}42 & \text { 3ng red brown } \\ 43 & \text { 3ng bistre brown } \\ 44 & \text { 5ng gray violet } \\ 45 & \text { 5ng blue gray } \\ 46 & \text { 5ng red violet }\end{array}$

ENVELOPE STAMPS USED AS ADHESIVES.

I 859 .

Envelope stamps of the issue of 1859 cut either square or to shape.
47 Ing rose
$48 \quad 5$ ng lilac
49 Iong green
I 862-63.

Envelope stamps of the issues of 1862 and beginning of I 863 cut either square or to shape. 50 eng ultramarine

\section{$51 \quad 3$ ng orange yellow \\ $525 \mathrm{ng}$ red violet \\ I863-65.}

Envelope stamps of the issues of July, 1863 , and July, 1865 , cut either square or to shape.

$53 \quad 1 / 2 \mathrm{ng}$ orange

54 ing rose

55 2ng ultramarine

$56 \quad 3$ ng brown

$57 \quad 5$ ng violet

\section{ENVELOPES.}

TRESSES.

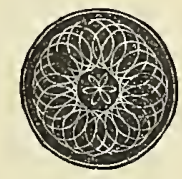

$\mathrm{H}$

July Ist, 1859 .

Stamp embossed in the upper left corner on yellowish white paper, with two lines of inscriptions in small capitals printed in green across the upper left corner: "EIN (ZWEI, DREI, FUNF, ZEHN) NEUGROSCHEN-FRANCO COUVERT."

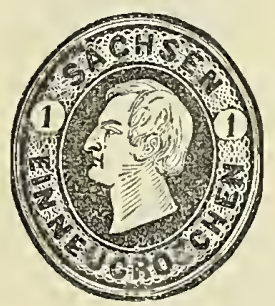

'Tress Q.

Short gum.

$I^{\circ}$ Size $147 \times 84 \mathrm{~mm}$.

58 Ing rose

59 Ing pale rose

59 ing pale rose

6I 2ng deep Prussian blue

62 2ng ultramarine

$63 \quad 3$ ng orange yellow

643 3ng deep yellow

$65 \quad 3$ ng pale yellow

$66 \quad 5$ ng deep lilac

$67 \quad 5$ ng gray lilac

$68 \quad 5 \mathrm{ng}$ violet

$69 \quad 5$ ng red violet

$70 \quad$ Iong green

71 Iong pale green

Varieties: Stamp embossed without color.

$72 \quad$ Ing

$73 \quad 3 n$

$2^{\circ}$ Size $149 \times 115 \mathrm{~mm}$.

74 Ing rose

75 Ing carmine

76 2ng dull Prussian blue

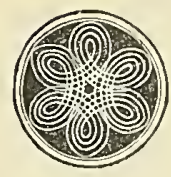

Q

$77 \quad 2 n g$ deep Prussian blue

78 3ng orange yellow

$79 \quad 3 n g$ pale yellow

Eo $\quad 5 n g$ deep lilac

8 r $\quad 5 n g$ gray lilac

$82 \quad 5 n g$ slate

I 862 .

Stamp of the same type as the preceding issue, embossed in upper right corner on yellowish white wove paper. As in the preceding issue, the inscription is printed in green across the upper right corner.

Tress Q.

Short gum.

$I^{\circ}$ Size $147 \times 84 \mathrm{~mm}$.

83 Ing carmine

$8+\quad 2 n g$ ultramarine

85 3ng orange yellow

$86 \quad 5 \mathrm{ng}$ red violet

Varieties: Stamp embossed without color.

87 Ing

$88 \quad 2 n g$

$89 \quad 3 n g$

$2^{\circ}$ Size I 49xi $15 \mathrm{~mm}$.

go Ing carmine

9I $3 n g$ orange

Beginning of $186_{3}$.

Same type, paper, etc. as preceding issue.

Tress Q.

Long gum.

$I^{0}$ Size $147 \times 84 \mathrm{~mm}$.

92 Ing carmine

93 2ng ultramarine

94 3ng orange yellow

Variety: Stamp embossed without color.

95 2ng 
$2^{\circ}$ Size I $49 \times 1$ I $5 \mathrm{~mm}$.

96 Ing carmine

97 3ng orange yellow

July Ist, I863.

Stamp embossed in upper right corner on white wove paper. As in the preceding issue, the inscription is printed in green in the upper left corner.

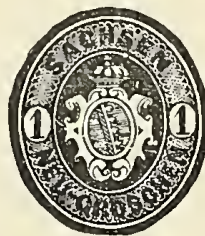

A. Tress Q.

Long gum.

I. Yellowish white wove paper.

$I^{\circ}$ Size $147 \times 84 \mathrm{~mm}$.

98 Ing rose

$99 \quad$ Ing pale rose

Ioo Ing carmine

Ing deep carmine

2ng ultramarine

2ng dull sky blue

2ng pale ultramarine

2ng bright ultramarine

2ng bright Prussian blue

3 ng brown

3ng deep brown

3ng yellow brown

3ng red brown

$5 \mathrm{ng}$ pale lilac

5 ng red lilac

$5 \mathrm{ng}$ violet

II3 5ng violet

Varieties: Stamp embossed without color,

Ir 5 Ing

II 6 2ng

II $\quad 3^{\text {ng }}$

II $5 \mathrm{ng}$

$2^{\circ}$ Size I 49 XII $5 \mathrm{~mm}$.

I I9 Ing carmine

120 Ing pale carmine

I2I 2ng ultramarine

I22 3 ng red brown

123 nng violet

Variety: Stamp embossed without color. I $24 \quad 2 \mathrm{ng}$

II. Bluish white wove paper.

Size $147 \times 84 \mathrm{~mm}$.

I25 Ing carmine

I26 Ing bright carmine

I 27 2ng ultramarine

I28 3ng red brown

I29 3ng deep red b:own

I $30 \quad 5 \mathrm{ng}$ violet

I3I 5 ng mauve

B. Tress H.

I. Yellowish white wove paper.

$I^{\circ}$ Size ${ }_{4} 4 \times 84 \mathrm{~mm}$.

Ing pale carmine

Ing deep carmine

2ng deep ultramarine

2ng pale ultramarine

2ng pale Prussian blue 3ng pale brown

3ng yellow brown

3ng red brown

I40 5 ng mauve
I4I 5 ng violet

Variety: Stamp embossed without color.

I 42 Ing

$2^{\circ}$ Size I $49 x$ I $5 \mathrm{~mm}$

Ing carmine

Ing pale carmine

2ng ultramarine

2ng pale ultramarine

$3^{\text {ng }}$ brown

3ng yellow brown

5ng mauve

II. Bluish white wove paper.

$I^{\circ}$ Size $147 \times 84 \mathrm{~mm}$

Ing carmine

Ing pale carmine

2ng ultramarine

3ng red brown

5 ng mallve

$2^{\circ}$ Size $149 \times 115 \mathrm{~mm}$.

I55 Ing carmine

I 56 2ng ultramarine

1573 ng red brown

July Ist, I865.

Stamp embossed in upper right corner on white or bluish white wove paper. $A s$ in the preceding issues, the inscription is print ed in green across the upper left corner.

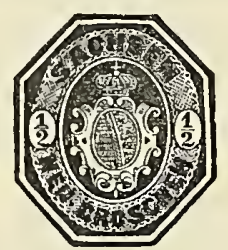

A. Tress Q.

Long gum.

I. White wove paper.

Size $147 \times 84 \mathrm{~mm}$.

I58 $1 / 2 \mathrm{ng}$ orange

I $59 \quad 1 / 2 \mathrm{ng}$ pale orange

I60 $\quad 1 / 2$ ng red orange

Varieties :

a. Stamp embossed without color.

I6I $1 / 2 \mathrm{ng}$

b. No stamp.

I62 I $1 / 2 \mathrm{ng}$

II. Bluish white wove paper.

Size $147 \times 84 \mathrm{~mm}$.

$163 \quad 1 / 2 \mathrm{ng}$ orange

I64 $1 / 2 \mathrm{ng}$ pale orange

B. Tress $\mathrm{H}$.

Long gum.

I. Yellowish white wove paper.

Size $147 \times 84 \mathrm{~mm}$.

I $65 \quad 1 / 2$ ng orange

$1661 / 2 \mathrm{ng}$ pale orange

II. Bluish white wove paper.

Size $147 \times 84 \mathrm{~mm}$.

I67 $1 / 2 \mathrm{ng}$ orange

I68 $1 / 2$ ng pale orange 


\section{COUNTERFEITS.}

There are some very fine counterfeits of the 3 pfennige of the 1850 issue and of the 5 and ro neugroschen of the 1856 issue, as well as of the ro neugroschen envelope.

I850, 3 pfennige red.

Genuine.

Each corner rosette contains a sort of a star with four points.
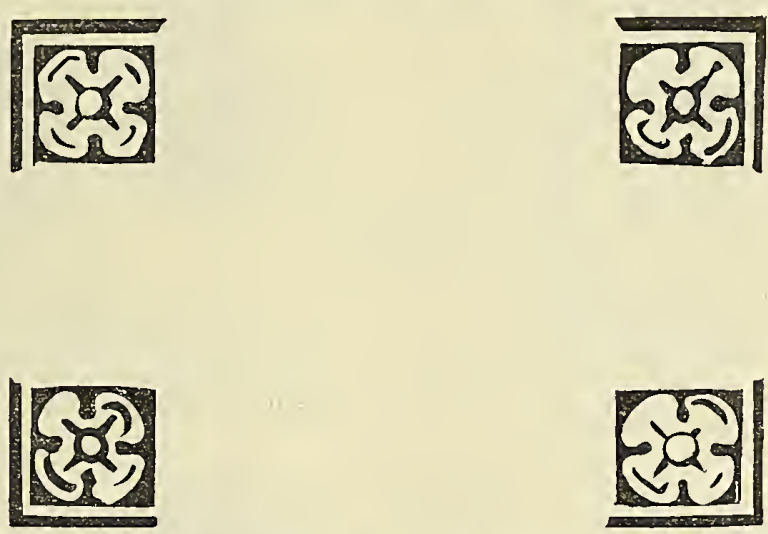

In the upper left rosette there is a curved line opposite each of the points of the star. In the upper right rosette there is a curved line opposite each of the two lower points; in the lower corner rosettes there is no curved line opposite the upper left point. The star of the upper left rosette has the lower left point shorter than the three others. In the upper right rosette the lower left point is the shortest and the upper right point the longest. In the lower right rosette the upper and lower right points are exceedingly short and the upper left one very long. The " $R$ " and " $E$ " of DREI almost join. The top branch of the " $\mathrm{E}$ " of DREI is shorter than the bottom one. The " $\mathrm{S}$ " and " $\mathrm{A}$ " of SACHSEN almost join. The top branch of the last " $E$ " of PFENNIGE slants a trifle upwards.

There is a break in the left frame of the inner rectangle opposite the "I" of DREI.

We do not describe any of the counterfeits of this stamp, as there are too many of them.

I856, 5 neugroschen red.

Genuine,

The left oval containing the numeral 5 does not touch the frame at the left, and the right oval with the numeral 5 does not touch the frame of the oval containing the head. The right fold of the bandrol containing the denomination of value does not touch the frame below it. There are five lines of shading to the left of the " $N$ " of Neu-Grosch, and there is a line of shading between the "c" and "h" of the same word. The leaves of the interleaved vine below the oval with the numerals of value have three small ornaments each.

Counterfeit.

The left oval containing the numeral of value touches the frame at the left, and the left side is very flat. The right oval touches the oval frame containing the head at the left. The right fold of the bandrol touches the frame below it. There are six lines of shading to the left of the "N" of Neu-grosch, and there is no line of shading between the "c" and " $h$ " of the same word. The leaves below the oval with the numeral of value have only two small ornaments; the one at the outside of each leaf is missing.

Io Neugroschen blue.

Genuine.

The third line of shading to the right of the oval containing the head touches the hair. The two lines of shading at the bottom of the oval run into the neck. The $8 \mathrm{th}$ line of shading at the right touches the lower part of the neck. "There are two thin lines of shading to the left of the first "s" of SACHSEN. The third line of shading to the left in the oval touches the nose. The inner line of the frame at the right is a double line.

Counterfeit.

The 4 th line of shading to the right touches the hair. None of the lines of shading at the bottom run into the neck. The 7th line of shading at the right touches the lower part of the neck. There are no lines of shading to the left of the first " $s$ " of SACHSEN. The $4^{\text {th }}$ line of shading at the left touches the nose. The inner line of the frame to the left and the outer one to the right are single lines.

The diagonal stroke of the " $\mathrm{N}$ " of NEU instead of being exactly in the centre of the uprights is closer to the left than to the right one.

Envelope, ro neugroschen green.

Genuine.

The green inscription in diamond capitals crosses the upper right corner. The figures of the numerals Io in the ovals are well formed. The " $\mathrm{G}$ " of NEUGRoschen is a perfect" $\mathrm{G}$," and the " $\mathrm{O}$ " and " $\mathrm{C}$ " of the same word are rounded. There are three colored dots between the " $N$ " and "E" of NEUGROSCHEN, two between the " $E$ " and " $U$ " and one between the " $U$ " and " $G$ " of the same word. There is one colored dot in the center of the "O" of NEUGROSCHEN. Between the "N" of ZEHN and the "N" of NEUGROSCHEN the network is horizontal.

Counterfeit.

There is no inscription across the upper right corner. The figures of the denomination of value are badly formed, expecially those at the right. The "G" of NEUGroschen resembles a "C." The "O" and " $\mathrm{C}$ " of NEUGROSCHEN are square. Between the " $N$ " of ZEHN and the " $N$ " of NEUGROSCHEN the network is vertical. 


\section{SEHLESWIG HOLSTEIN.}

Currency : 16 Schillings $=$ I Mark $=24$ Cents U. S. Currency.

\section{ADHESIVE STAMPS}

\section{Revolutionary Governmept.}

November I5th, I850.

Lithographed on white wove paper, with arms embossed without color in the center of the stamp, and a blue silk thread running vertically down the center of the stamp. The principal part of the design is a spread eagle which is overprinted with a similar design in greenish blue ink on the $\mathbf{I}$ schilling and a delicate pink on the 2 schillinge. This was probably done as a safety check against counterfeiting. Size $181 / 2 \times 21 \mathrm{~mm}$.

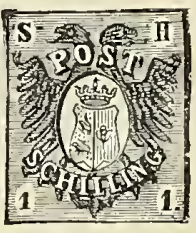

Isch blue and greenish blue Isch deep blue and greenish blue 2sch rose and pink 2sch deep rose and pink

These stamps were in use for only a few months, when they were superseded by the stamps of Denmark.

\section{Austro-Prussian Oocupation.}

March Ist, 1865.

Embossed on white wove paper. There are two designs-one for the $1 / 2, I 1 / 4$ and 2 schillinge, and the other for the $I 1 / 3$ and 4 schillinge stamps. Size I $9 \times 2 \mathrm{I} 3 / 4 \mathrm{~mm}$.

Rouletted.

$5 \quad 1 / 2$ s rose (March Ist)

$6 \mathrm{I} 1 / \mathrm{s}$ green (June Ist)

7 I $1 / 3 \mathrm{~s}$ mauve (August 2oth)

82 2s blue (August 20th)

94 bistre (September I 5 th)
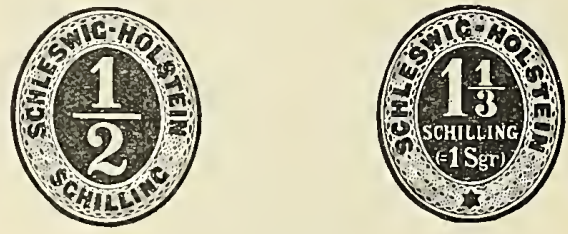

Folstein and Lauenours.

March Ist, I864.

Lithographed on white wove paper covered with a gray network and showing a large capital "P" in white in the center of the stamp. Size Igxig $\mathrm{mm}$. There are three types of this stamp, their principal characteristics being as follows:

1. The wavy lines between the wreath of oak leaves and the frame are close togeher.

There is a period after each of the letters H R Z G L in the frame at the left.

The " 4 " of $1 / 4$ has a vertical bar at the end of the horizontal one.

The " $\mathrm{H}$ " of schilling has no bar.

II. The wavy lines between the wreath of oak leaves and the frame are close together. There is no period after the "L" of $\mathrm{HR} \mathrm{Z} \mathrm{G}$ $\mathrm{L}$ in the frame at the left.

The " 4 " of $1 / 4$ has a vertical bar at the end of the horizontal one.

The " $\mathrm{H}$ " of SCHILLING is barred.

The "G" of sCHILLING is smaller than the other letters.

III. The wavy lines between the wreath of oak leaves and the frame are further apart from one another.

There is no period after any of the letters H R Z G L in the left frame.

There is no period after " $\mathrm{S} \mathrm{R}$ " in the lower label.

The " $\mathrm{H}$ " of SCHILLING is barred.

There are no dots over the "I's" of SCHILLING.

The " 4 " of $1 / 4$ has no vertical bar at the end of the horizontal one.
The " 4 " in the lower label is more open and has a horizontal darh at the bottom.

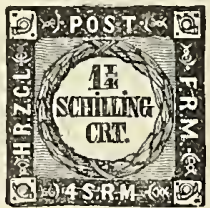

Io I $1 / 4 \mathrm{~s}$ blue and gray, type I

I I I $1 / \mathrm{s}$ pale blue and gray, type I

I2 I $1 / 4$ s blue and gray, type 2

I3 I $1 / 4$ s bright blue and gray, type 2

I4 I $1 / 4 \mathrm{~s}$ blue and gray, type 3

I 5 I I/4s light blue and gray, type 3

May, I864.

Lithographed on white wove paper with a rose background formed of diagonal lines crossing each other and with a large letter " $\mathrm{p}$ " in the center. Size 1 $81 / 2 \times 181 / 2 \mathrm{~mm}$.

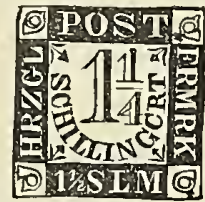

Rouletted.

I6 I $1 / 4$ s blue and rose

I7 II $1 / 4$ deep blue and rose

Varieiy: I $1 / 4 \mathrm{~s}$ stamp cut diagonally in two each half being used as $1 / 2$ schilling.

is $1 / 2 \mathrm{~s}$ blue and rose (half of $1 / 1 / 4$ ) 
March 15th, 1865, to November, 1865 .

Embossed on white wove paper. There is one type for he $1 / 2, I 1 / 4,2$ and 4 schillinge, and another for the $\mathrm{I} 1 / 3$ schilling. Size $19 \times 213 / 4 \mathrm{~mm}$.
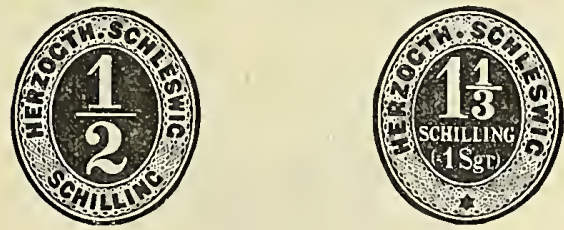

November Ist, $\mathrm{I}_{6} 4$.

Embossed on white wove paper. The $1 / 2$, $\mathrm{I} 1 / 4$ and 2 schillinge are of one type, and the $\mathrm{r} 1 / 3$ and 4 schillinge are of another. Size I $91 / 2 \times 22 \mathrm{~mm}$.
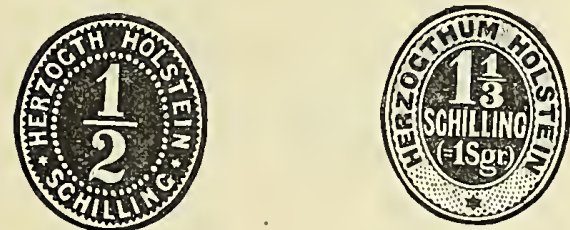

Rouletted.

$27 \quad 1 / 2$ s green

$28 \mathrm{I} 1 / 4 \mathrm{~s}$ violet
Sohleswis.

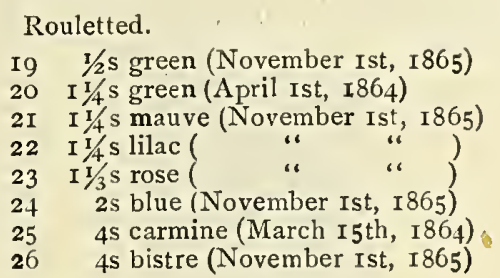

Holsteip.

$$
\begin{aligned}
& 29 \text { I } 1 / 3 \text { s carmine } \\
& 30 \quad 25 \text { blue } \\
& 3 \text { I } 4 \text { s bistre } \\
& \text { March and Augu }
\end{aligned}
$$

Embossed on white wove paper. Size $191 / 2 \times 22 \mathrm{~mm}$.

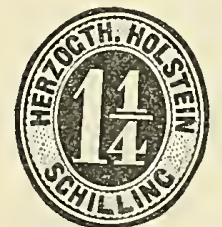

$$
\begin{aligned}
& \text { Rouletted. } \\
& 32 \text { I I } / 4 \mathrm{~s} \text { mauve } \\
& 332 \text { s blue }
\end{aligned}
$$

There are some good forgeries of the stamps of the first issue of Schleswig-Holstein. These, however, are easily distinguished by the absence of the secret over-printing, principally discernible in the " $\mathrm{O}$ " and " $\mathrm{s"}$ of " $\mathrm{POST}$, ," $\mathrm{n}$ which, on the genuine, the vertical lines of the safety print are plainly visible, while they are absent from the forgeries. This test is easily applied to the I schilling stamp, but is not so easy with the 2 schillinge, on which the safety print is generally very faint. In this case, the following points pertaining to the genuine may also be considered:

The "H" and "I" of schilling are joined. One of the claws of the eagle shows below the bottom of the first stroke of the "N" of SCHILIING. The four corner ovals have no border line. The genuine s'amps are printed on a paper with a sllk thread running vertically down the stamp; this thread is in the paper. In the forgeries, to obtain the same appearance, the stamp has been made of two pieces of very thin paper pasted one against the other and a silk thread pasted between. By immersing the counterfeits in hot water for a short time, the back and the silk thread will easily be removed and thus show the fraud.

There is also a good forgery of the I I/4 schilling, with close network, of the issue of March Ist I864, which

for years has been considered a fourth type of the genuine stamp; it answers to the following description:

The wavy lines between the wreath of oak leaves and the frame are furher apart from one another.

There is no period after each of the letters $\mathrm{H} \mathrm{R} \mathrm{Z} \mathrm{G} \mathrm{L.}$

There is a period after each of the letters S R M in the lower label.

The " $\mathrm{H}$ " of SCHILLING is barred.

The "I's" of SCHILLING are dotted.

The " 4 " of $1 / 4$ has no vertical bar at the end of the horizontal one.

The "4" in the lower label has no horizonlal dash at the bottom.

The forgeries of the subsequent issues are rather poor and, consequently, not dangerous.

\section{SERVIA.}

CURRENCY: IOO PARAS=I DINAR=2O Cents U. S. CURRENCY.

\section{ADHESIVE STAMPS.}

October Ist, I866.

Lithographed in color on various papers in sheets of 12 stamps, composed of three horizontal rows, showing slight variations in the figures of value. Size $18 \times 21 \frac{1}{2} \mathrm{~mm}$.

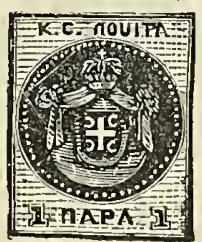

I. Wove paper, colored on the surface. Ip yellow green on rose, I 2 varieties Ip green on rose, I2 varieties Ip olive green on rose, I2 varieties Ip bright green on rose, I2 varieties $2 \mathrm{p}$ dark brow $\mathrm{n}$ on lilac, $\mathrm{I} 2$ varieties 2P pale brown on lilac, I2 varieties $2 \mathrm{p}$ red on lilac, I 2 varieties.

Variety: Error of impression. 2p green on rose, 12 varieties

II. Wove paper, colored through.

9 Ip green on rose violet, I2 varieties

Io Ip deep green on rose violet, I2 " 
October, 1866.

Typographed (portrait of Prince Michael Obrenowitch III.) on white wove paper. Size $2 I_{1} / 2 \times 25^{1 / 4} \mathrm{~mm}$. This issue was printed in Vienna.

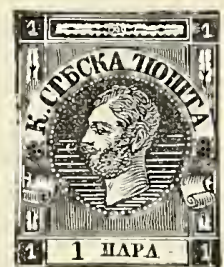

Perforated I2.

$$
\begin{array}{ll}
\text { I I } & \text { Iop orange } \\
\text { I } 2 & \text { 2op rose } \\
\text { I3 } & \text { 20p deep rose } \\
\text { I4 } & 40 p \text { dull blue }
\end{array}
$$

November, 1866.

I. Ordinary white wove paper.

Perforated $9 \frac{1}{2}$.

$\begin{array}{ll}\text { I5 } & \text { Ip green } \\ \text { I6 } & \text { Ip yellow }\end{array}$

I6 Ip yellow green

I 7 Ip pale green

I8 $2 \mathrm{p}$ brown

I9 $2 \mathrm{p}$ deep brown

$20 \quad 2 \mathrm{p}$ bistre brown

2 I 2 op rose

22 2op deep rose

23 4op ultramarine

24 4op deep ultramarine

Varieties:

a. IIAPF instead of IIAPE.

$252 \mathrm{p}$ deep brown

26 2p bistre brown

b. Dash after IIAPA.

27 Ip green

c. Imperlorate horizontally.

$28 \quad 20$ deep rose

d. Horizontal pair, imperforate between.

28 a 4 op ultramarine

Varieties a and $b$ are caused by defective printing.

II. Yellowish white wove paper.

Perforated $9 \mathrm{~T} / 2$.

2920 rose

III. Pelure paper.

Perforated $91 / 2$.

30 Iop deep orange

3I Iop yellow orange

32 2op rose

33 2op deep rose

34 4op ultramarine

35 4op deep ultramarine

The principal difference between the stamps printed in Vienna and those printed in Belgrade is the perforation. The impression of those printed at Belgrade is much coarser than of those printed in Vienna.

I868.

Same type and impression as preceding issue.

I. White wove paper.

Imperforate.

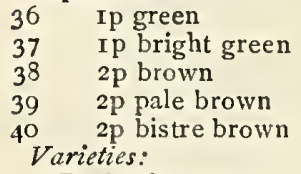

Varieties:

a. Dash after IIAPA.

b. "A"s of IIAPA" smaller than the other letters.
42 Ip green

c. IIAPF instead of IIAPE.

$432 \mathrm{p}$ brown

II. Yellowish wove paper.

Imperforate.

44 Ip olive green

$45 \quad 2 \mathrm{p}$ yellow bistre

July, 1869.

Typographed (portrait of Prince MilanIV). on white wove paper varying in thickness. Size $191 / 2 \times 231 / 4 \mathrm{~mm}$.

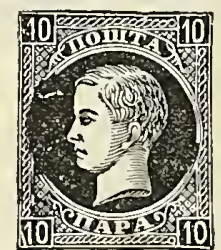

I ${ }^{\circ}$ Perforated 9 $1 / 2$.

Ip yellow

Ip deep yellow

Iop brown

Iop bistre brown

I $5 \mathrm{p}$ orange yellow

2op ultramarine

2op bright ultramarine

$25 \mathrm{p}$ rose

$25 \mathrm{p}$ red

$40 \mathrm{p}$ violet

4op bright violet

5op deep green

5 op emerald green

Varieties: Imperforate.

59 Iop bistre brown

2op ultramarine

$2^{\circ}$ Perforated 12.

6I Ip yellow

62 Ip deep yellow

63 2op ultramarine

$6435 \mathrm{p}$ green

65 4op violet

66 40p bright vio'et

67 5op deep green.

Varieties :

a. Double perforation.

68 Iop brown

b. Imperforate vertically.

69 Ip yellow

$3^{\circ}$ Perforated $9 \mathrm{r} / 2 \times 12$, or vice versa.

Ip yellow

I5p orange yellow

2op ultramarine

$25 \mathrm{p}$ rose

$35 \mathrm{p}$ green

400 violet

$75 \quad$ 5op deep green

$4^{\circ}$ Perforated $91 / 2 \times 121 / 2$, or vice versa

$77 \quad 4$ op violet

$5^{\circ}$ Perforated $121 / 2 \times 12$, or vice versa.

78 Ip yellow

79 2op ultramarine

$80 \quad 25 \mathrm{p}$ rose

8 I 4 op bright violet

$6^{\circ}$ Perforated I I $1 / 2 \times 12$, or vice versa.

$82 \quad 2$ op ultramarine

The above list of perforations comprises only those seen by us, probably there are more.

August, 1872 .

Sxme type, impression and paper as preceding issue. 


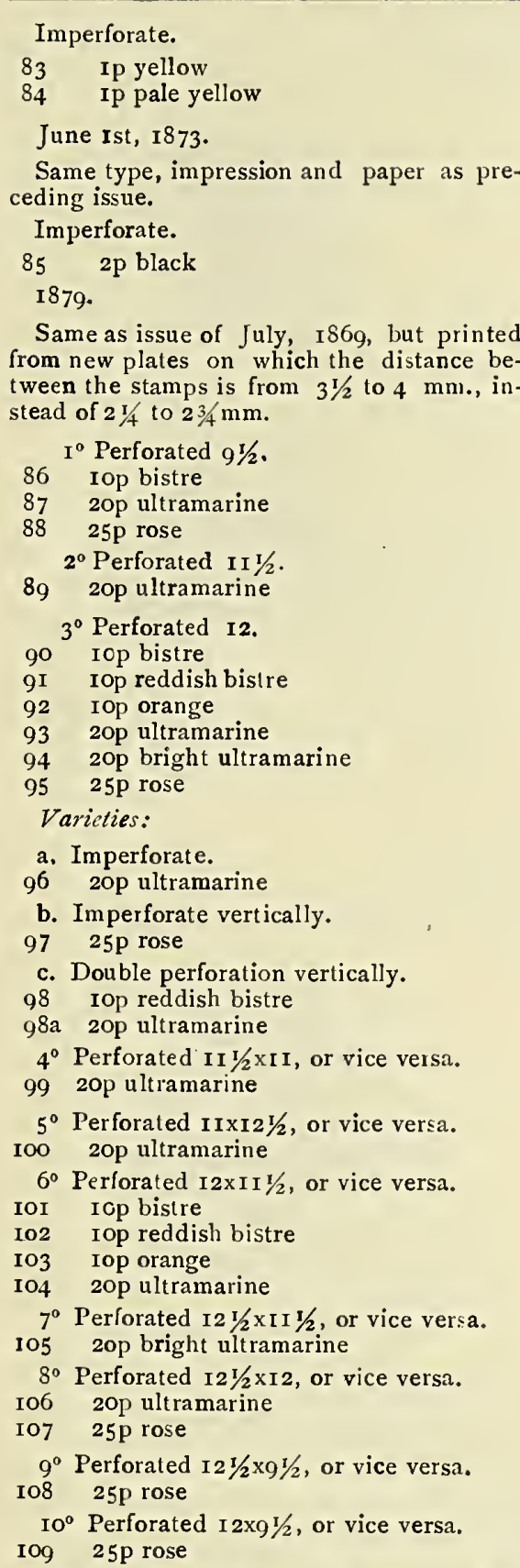

Variety: Vertical pair, imperforate between.

IIO $25 \mathrm{P}$ rose

Janualy Ist, I88I.

Typographed on white wove paper. Size I $71 / 2 \times 211 / 2 \mathrm{~mm}$.

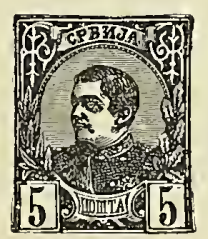

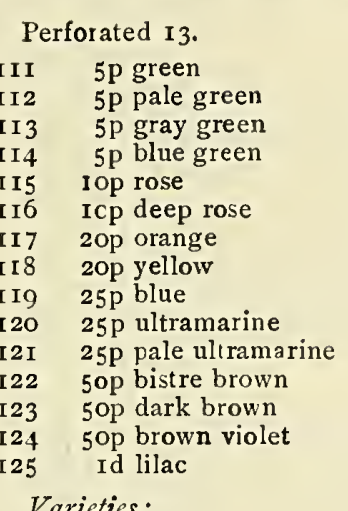

Varieties:
a. Imperforate.
I26 $25 \mathrm{p}$ blue
b. Perforated horizontally across center of stamp.
I27 Iop rose

February, I89o.

Typographed (portrait of King Alexander I) on white wove paper varying in thickness. Size $171 / 2 \times 21 \frac{1}{2} \mathrm{~mm}$.

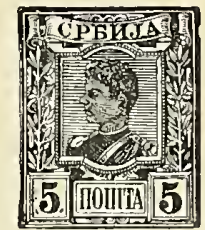

Perforated 13.

$\begin{array}{ll}\text { I28 } & \text { 5P green } \\ \text { I29 } & 5 \mathrm{p} \text { blue green } \\ \text { I30 } & \text { IOp rose } \\ \text { I3 } & \text { IOp deep rose } \\ \text { I32 } & \text { I 5p violet } \\ \text { I33 } & \text { 20p orange } \\ -34 & 20 p \text { yellow orange } \\ \text { I35 } & 25 \mathrm{p} \text { ultramarine } \\ \text { I36 } & 50 p \text { brown } \\ \text { I37 } & \text { Id lilac }\end{array}$

1894.

Typographed on thin white wove paper with fragments of silk threads (granite paper). Size $\mathrm{I} 63 / 4 \times 2 \mathrm{I} / 4 \mathrm{~mm}$.

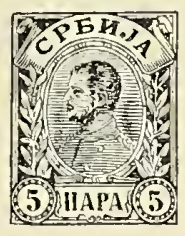

Perforated 13.

$\begin{array}{ll}138 & 5 \mathrm{P} \text { green } \\ \text { I39 } & \text { IOp rose } \\ \text { I40 } & \text { I } 5 \mathrm{P} \text { violet } \\ \text { I4I } & 20 \mathrm{Op} \text { orange } \\ \text { I42 } & 25 \mathrm{p} \text { blue } \\ \text { I43 } & 50 \mathrm{O} \text { bistre } \\ \text { I44 } & \text { Id blue green }\end{array}$




\section{UNPAID LETTER STAMPS.}

I894.

Typographed on granite paper. Size $181 / 2$ X2I $\mathrm{mm}$.

Perforated 13

$3015 \mathrm{p}$ lilac rose

302 Iop dark blue

303 2op orange brown

304 3op dark green

305 50p rose

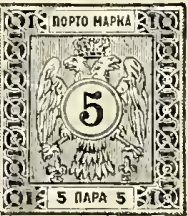

\section{COUNTERFEITS}

The only dangerous forgeries of the stamps of Servia which we have seen are the 1 and 2 Paras of the issue of November, I 866 (perforated and imperforate), and all the values of the issue of July, I 869 .

November, $\mathbf{r} 866$

I para. In the genuine, the small dash below the scroll in the frame at the left is crossed, which it is not in the counterleit. The three parts of the ornament with three dots in the upper label are of equal width in the genuine, while in the forgeries the central one is much wider than those at the sides. In the counterfeits, there are four vertical lines of shading to the left of the head, close to the pearl frame.

2 paras. In the genuine, the first letter (II) of para is not crossed, which it is in the counterleit. In the forgeries, the central part of the ornament in the upper border is wider than in those at the sides, and the line below the scroll in the frame at the left is not crossed.

Issue of July, 1869 I, IO, I5, 20, 25, 35, 40 and 50 paras. In the counterfeits, there is a distinct white line at the outline of the base of the neck, and the last link of the chainwork at the right side is a perfect circle.

\section{SEYOHELLES ISLANDS.}

CURRENCY : TOO CENTS $=\mathrm{I}$ RUPEE $=32$ Cents, U. S. CURRENCY.

\section{ADHESIVE STAMPS.}

April 15th, I89o.

Typographed on white wove paper, the name of the colony in the upper label and the tablet with figure of value in the lower label are printed in a different color from the remainder of the stamp. Size $181 / 2 \times 22 \frac{1}{2}$ $\mathrm{mm}$. Watermarked Crown and $\mathrm{CA}$.

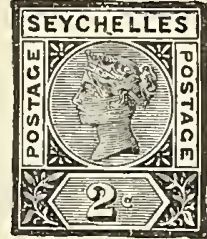

Perforated 14 .

$2 c$ green and carmine

$4 c$ carmine and green

$8 \mathrm{c}$ brow $\mathrm{n}$ violet and blue

IOc blue and brown

12c blue gray and black

I6c orange brown and blue

$48 \mathrm{c}$ yellow and green

$96 \mathrm{c}$ violet and carmine

February, 1892 .

Provisional issue.

Stamps of the preceding issue surcharged

in black with new value. Watermarked Crown and CA.

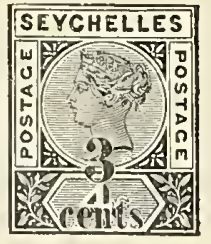

Perforated 14.

$9 \quad 3 \mathrm{c}$ on $4 \mathrm{C}$ carmine and green, black surcharge
I0 I2c on I6c orange brown and blue, black surcharge

II $15 \mathrm{c}$ on $16 \mathrm{c}$ orange brown and blue, black surcharge

I2 $45 \mathrm{c}$ on $48 \mathrm{c}$ yellow and green, black surcharge

I3 $90 \mathrm{c}$ on $96 \mathrm{c}$ violet and carmine black surch arge

Valieties.

a. Surcharge inverted,

I4 $3 \mathrm{c}$ on $4 \mathrm{c}$ carmine and green, black surcharge

I5 I5c on $16 \mathrm{c}$ orange brown and blue black surcharge

b. Double surcharge.

I6 $3 \mathrm{cx} 3 \mathrm{c}$ on $4 \mathrm{c}$ carmine and gre en, black surcharge

c. "cents" omitted.

I $72 \mathrm{c}$ on $4 \mathrm{c}$ carmine and green, black surcharge

I8 I2c on I6c orange brown and blue, black surcharge

d. Horizontal pair, one with and the other without surcharge.

I9 $3 \mathrm{C}$ on $4 \mathrm{C}$ carmine and green, black surcharge

e. "cents" above the value.

$20 \quad 3 \mathrm{c}$ on $4 \mathrm{c}$ carmine and green, black

f. "s" above the line (cents)

2I $3 \mathrm{C}$ on $4 \mathrm{C}$ carmine and green, black surcharge

g. "c" above the line (ents)

$223 \mathrm{c}$ on $4 \mathrm{c}$ carmine and green, black surcharge

h. "ce" above the line ( ${ }^{c e}$ nts)

$233 \mathrm{c}$ on $4 \mathrm{c}$ carmine and green, black surcharge

i. "ce" and "s" above the line $\left({ }^{(\mathrm{e}} \mathrm{nt}^{\mathrm{s}}\right)$
$24 \quad 3 \mathrm{c}$ on $4 \mathrm{c}$ carmine and green, black surcharge 


\section{893.}

Same type, paper and impression as issue of April, r89o. Watermarked Crown and CA.

Perforated 14.

$253 \mathrm{c}$ violet and orange

26 I $2 c$ olive brown and blue green

27 I5c olive and purple

$2845 \mathrm{c}$ brown and carmine

I 896.

Provisional issue.

45 cent stamps of preceding issue, surcharged with new value in black.

Watermarked Crown and CA.

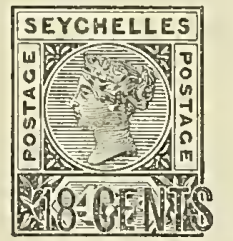

Perforated 14

29 I $8 \mathrm{c}$ on $45 \mathrm{c}$ brown and carmine, black surcharge

$30 \quad 36 \mathrm{c}$ on $45 \mathrm{c}$ brown and carmine, black surcharge

Variety: Surcharged "8 cents."

3t $8 \mathrm{c}$ on $45 \mathrm{c}$ brown and carmine, black surcharge

This variety is caused by negligent feeding of the paper in the press, the missing " $I$ " being printed on the next stamp.

I 897.

Same type, paper and impression as issue of $\mathbf{1} 893$.

Walermarked Crown and CA.

Perforated I 4

32 I $8 \mathrm{c}$ blue

$3336 \mathrm{c}$ brown and carmine

34 Ir deep lilac and carmine

\section{REVENUE STAMP USED FOR POSTAGE.}

I893.

Postage stamps of the issue of April, r 890 , surcharged in black "Revenue" and new value. Watermarked Crown and CA.
Perforated $\mathbf{I} 4$

$30 \mathrm{r} 4 \mathrm{c}$ on $8 \mathrm{c}$ brown violet and blue, black surcharge

I895.
Stamp typographed in upper right corner on thick white wove paper. The stamp on the I 5 cent envelope is of the same type as that on the 8 cent envelope.

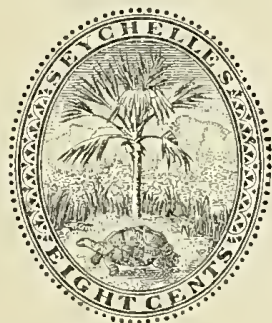

$$
\begin{aligned}
& 2^{\circ} \text { Size } 120 \times 94 \mathrm{~mm} \text {. } \\
& 402 \text { I } 5 \mathrm{c} \text { blue }
\end{aligned}
$$

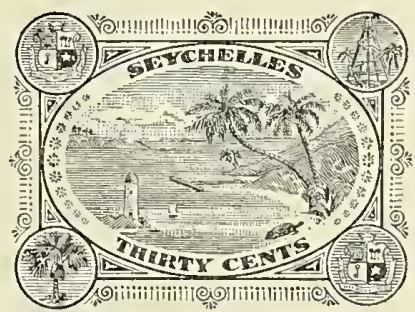

$1^{\circ}$ Size $140 \times 78 \mathrm{~mm}$.

$40 \mathrm{I} \quad 8 \mathrm{c}$ rose

$3^{\circ}$ Size I $40 x$ I $10 \mathrm{~mm}$.

$40330 \mathrm{c}$ brown

I 896.

Provisional issue.

3o cent envelopes of preceding issue surcharged in black with new value.

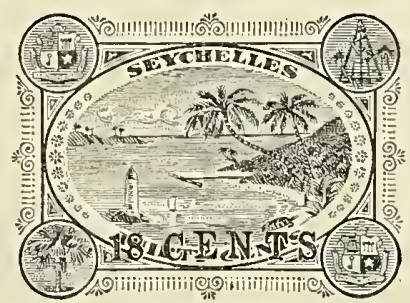

Thick white wove paper. Size I $40 x$ romm. 404 I $8 \mathrm{c}$ on $30 \mathrm{c}$ brown, black surcharge

\section{COUNTERFEITS}

We do not know of any forgeries of the stamps of the Seychelles Islands. 
SHANGHAI.

Currency: I6 CASH=I CANDAREEN; IOO CANDAREENS=I MACE; IO MACE=I TAEL=9O CENTS, U.S. Currency.

IOO $\mathrm{CENTS}=\mathrm{I}$ DOLLAR=60 CENTS, U. S. Currency,

\section{ADHESIVE STAMPS.}

I $864-65$.

Type set, hand printed on various papers. Size about $27 \times 30 \mathrm{~mm}$. There are several printings of these stamps, differing only in the relative positions of the inscriptions and of the compartment lines, the center piece (dragon) being the same for all the values in all the printings.

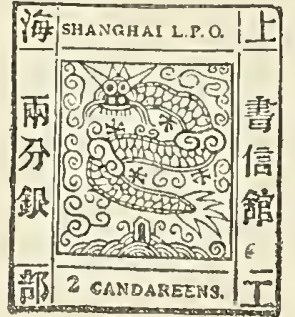

On the 2 candareens stamps, in groups I to IX inclusive, the first of the Chinese characters in the left-hand panel is the character Liang (雨).

\section{Group I.}

Very clear, early impressions. The central block is separated by a wide space from the horizontal lines above and below it, and is equally distant from them. These lines are moderately thick and quite straight. The top and bottom frame lines overlap the ends of the side frame lines. The lines under the characters in the upper corners are in a straight line with that under SHANGHAI L. P. $O$. The corresponding lines in the lower part of the stamp are also in a straight line.

The line under the Chinese character Hai, in the upper left corner, curves upward at both ends. The line above the character $P u$, in the lower left corner, curves upward at the left end. The " $\mathrm{s}$ " of SHANGHaI is close to the vertical line at its left, but the "s" of CANDAREENS is not close to the vertical line at its right. The figures of value on the 2 . 8 and 16 candareens are above the line of the word.

Candareens in the plural.

Numerals: Antique on the 2, 4 and $8 c$; the $16 c$ has a Roman I and an antique 6 .

Paper: Thin white wove.

2 cands gray black

4 cands yellow

8 cands green

8 cands yellow-green

I6 cands scarlet

Variety: Double impression.

64 cands yellow

\section{Group II}

Much the same as group I. The impressions are blurred by too liberal use of ink. On the 2 and 8 candareens the lines above and below the central block are a little nearer to it than in the preceding group. SHANGHAI L. P. O. is nearer the line above it than that below it. The " $s$ " of SHANGHAI is far from the vertical line at its left and the "s" of CANDAREENS close to the vertical line at its right The letters "CA" of CANDAREENS have dropped below the line of the word.

Candareens in the plural.

Numerals : As in group I.

Paper: Thin white wove.

$7 \quad 2$ cands deep rusty black

88 cands green

916 cands scarlet

\section{Group III.}

Impressions nearly as clear as in group I. The lines above and below the centre piece are close to it and very thin. The upper line has the left end turned upward and the right end turned down ward. The three horizontal lines in the upper part of the stamps are still in a straight line but the lower three are not, the left end of the middle one being considerably higher than the short line over the character in the lower left corner. The frame lines at the sides now overlap the ends of the top and bottom frame lines. SHANGHAI L. P. O. occupies about the same position as in group II. CANDAREENS is far from the line at the left and the numerals are below the line of the word but nearer to it than before.

Candareens in the plural.

Numerals : Antique.

Paper: Thin white wove.

Io 2 cands deep black

II 4 cands yellow

I 8 cands bright green

GROUP IV.

Very like group 1II. The line above CANDAREENS shows a slight depression above the letters "ND." This depression is a feature of groups IV to XII inclusive. The numerals are on a line with CANDAREENS, but further from it than in the preceding group; the final "s" of the word is close to the vertical line at its right.

Candareens in the plural.

Numerals: As in group I.

Paper: Thin wove and pelure.

A. Thin wove paper.

I3 2 cands greenish black, yellowish white paper

I4 2 cands dull black, bluish white paper

I5 I6 cands scarlet

B Pelure paper.

I6 2 cands dull black

Group V.

Impressions blurred by excess of ink. The horizontal lines above and below the central block are further from it, especially the lower one, than in group IV, and about on a level with the smaller lines at the sides. The English inscription at the bottom occupies about the same position as in group IV, but that at the top was not securely fastened and the letters slipped out of place more or less on the various stamps.

Candareens in the plural.

Numerals : As in group I.

Paper: Pelure.

I 2 cands black 
184 cands orange

I9 8 cands bright grass green

20 I 6 cands scarlet

Variety: The "P" of "L. P. O." is above the line of the other letters.

21 I 6 cands scarlet

Group VI.

Almost identical with group $V$. The central cut is nearer the line above it than that below it, and the left end of the latter is very slightly higher than the line over the character in the lower left corner.

Candareens in the plural.

Numerals : As in group I.

Paper: Pelure.

224 cands orange

23 I6 cands scarlet

Group VII.

Clear impressions but the central cut begins to show signs of wear at the edges. It is very close to the line below and correspondingly removed from the line above it. The latter line has been slightly damaged and shows a trifling elevation below the space between the letters "I" and " $L$ " of SHANGHAI L. P. o. The three horizontal lines in the upper part of the stamp are not in a straight line. The one at the left is higher and that at the right lower than the centre line. The three lines in the lower part are almost in line with one another The one at the left has been reversed and now turns downward at the right-hand end. The " $\mathrm{s}$ " of SHANGHAI is close to the line at the left and the " $\mathrm{s}$ " of CANDAREENS is far from the line at the right.

Candareens in the plural.

- Numerals : Antique.

Paper : Pelure and thin wove.

A. Pelure paper.

$24 \quad 2$ cands rusty black

254 cands ochre yellow

The Chinese value reads 4 mace (錗)

silver instead of 4 candarcens ( 7 ) silver

268 cent deep green

The Chinese value reads 8 mace (\$ 9 ) silver instead of 8 candareens (分) silver.

B. Thin wove paper.

272 cands greenish black

\section{Group VIII.}

On No. 28 the position of the central device is about the same as in the preceding group and we think it quite possible the stamp belongs in that group. On the other stamps of group VIII the block is about equally distant from the lines above and below it. The relative position of the three horizontal lines at the top varies. The line above CANDAREEN is lower than the short lines at the sides except on No. 28. The final " $N$ " of CANDAREEN is far from the vertical line at the right and the numeral is usually much below the line of the word. The end letters of SHANGHAI L. P. O. are close to the vertical lines, and all the letters seem to have had considerable vertical play.

Candareen in the singular.

Numerals : Antique.

Paper: Horizontally laid, white or toned.

28 r cand dark blue

I cand pale blue

I cand blue

I cand dull blue

Varieties:

a. The letters "L. P." of "L. P. O." are above the line.
32 I cand dull blue

b. The letters "P. O." of "L. P. O." are above the line.

33 I cand dull blue

c. The letters "L. P. o." are poorly printed and read "I. P. C.," "т P. r", etc.

37 I cand dull blue

d. The letters "L. P. o." are belew the level of sHANigHAI.

35 I cand blue

e. The letters "L. P." are below the level of SHANGHAI.

36 I cand blue

f. The letters "sH" of SHANGHaI are above the line of the rest of the word.

37 I cand blue

\section{Group IX}

Impressions fairly clear, except Nos. 39 and 40. The central cut is widely separated from the lines above and below it, a trifle more from the former than from the latter. The short lines between the left-hand pane and the corner characters have both been re versed. The ends of the upper line now turn downward and the left end of the lower line turns upward. The line over CANDAREEN is lower than the short lines at the sides, except on Nos. 4I and 48. The relative positions of the three horizontal lines at the top change somewhat on the various stamps. The " $\mathrm{s}$ " of SHANGHAI is close to the line at the $l \in \mathrm{ft}$. The final " $N$ " of CANDAREEN is about 4 $\mathrm{mm}$. from the line at the right, which is further than in any other group. The numerals are close to the left vertical line and usually below the level of CANDAREEN. In all the stamps of this group the " $D$ " of CANDAREEN is more or less below the line of the word.

Candareen in the singular.

Numerals : Antique.

Paper: Thin wove and horizontally laid.

A. Thin white wove paper.

38 I cand pale biue

39 I cand bright blue

40 I cand dark blue

4 I 2 cands gray black

424 cands yellow

Varieties:

a. Final " $N$ " of CANDAREEN above the line of the word.

432 cand gray black

b. Final " $N$ " of CANDAREEN below the line of the word.

$44 \quad 2$ cand gray black

c. "CAND" below the line of "AREEN."

454 cand yellow

d. A dot of color below the "D" of CANDAREEN.

464 cand yellow

e. A dot of color below the first " $N$ " of CANDAREEN

474 cand yellow

B. Laid paper.

482 cand gray black

494 cand yellow

Varieties:

a. A dot of color below the second " $A$ " of CANDAREEN.

504 cand yellow

b. A dot of color below the "D" of CANDAREEN.

5 I 4 cand yellow

Group X.

Impressions poor, either blurred by too much ink or indistinct from too little. Position of central device about as in group IX. The three lines at the top are nearly in line 
with one another. The left end of the line over CANDAREEN is about on a level with the short line over the character in the lower left corner. The final " $N$ " of CANDAREEN is still far from the vertical line at the right, though not as far as in group IX. Except on No. 52 the letters "CAND" slope slightly down ward toward the right.

Candareen in the singular.

Numerals: Antique.

Paper: Thin white wove.

52 I cand pale blue

538 cand dark olive green

54 I6 cand scarlet

55 I 6 cand orange vermilion

Variety: The Chinese value reads 16 CANDAREENS, but the "I" of the English value has failed to print except a minute speck of color.

$56 \quad 6$ cand scarlet

GRouP XI.

Somewhat blurred impressions. Setting very similar to the last group. The three lines at the top are in a straight line.

The line over CANDAREENS is higher than the side line at the left and lower than that at the right. The word CANDAREENS is set up very crookedly, being almost in a curve. The final "s" seems larger than before and the period following it is lower than the letter. There are two small dots of color in the upper character of the Chinese value.

Candareens in the plural.

Numerals : Antique.

Paper: Thin white wove.

576 cands red brown

586 cands dull red brown, much blurred

596 cands pale red brown

\section{GRoup XII.}

Colors blurred and washy. Setting almost identical with group XI, the cut being a trifle further from the line over the value. The period after the "o" of "L. P. O." is at the top instead of the bottom of the letter except, perhaps, on No. 6o. In this group the compartment rules usually cut deeply into or through the paper and the stamps frequently have to be backed to keep them together. No. 62 is usually found cut with a penknife along the frame lines.

Candareens in the plural.

Numerals: Roman I and antique 2 on the I2c, antique on the other values.

Paper: Laid and thin wove.

A. Horizontally laid paper.

$60 \quad 3$ cands carmine-brown

B. Thin white wove paper.

6I 6 cands pale terra cotta

626 cands dark terra cotta

63 I2 cands pale terra cotta

GRoup XIII.

Impressions heavily inked and blurred. Setting very like that of group X1I, but on some of the stamps the center block is a littie nearer the line below it. The period after the "O" of "L.P.O." is still misplaced. 'The line over CANDAREENS, which has so long shown a depression over the letters "ND", has been replaced by a new one, quite straight and slightly thicker. The line over the character in the lower left corner has also been changed. It lacks the pronounced hook of its predecessor, though it is by no means a straight line. CANDAREENS is set up very crookedly.

Beginning with this group the 2 candareens stamps bear the Chinese character Erh (-)
Candareens in the plural except on the Ic.

Numerals: Roman I, antique 2 and 4. Paper: Thin wove and laid.

A Thin white wove paper.

64 I cand bright blue

652 cands deep black

664 cands chrome yellow

Varieties:

a. "CA" above the line of " NDAREEN."

67 I cand bright blue

b. " $C$ " above and " $D$ " below the line.

68 I cand bright blue

B. Laid paper.

69 I cand blue

$70 \quad 2$ cands deep black

Group XIV.

The impressions are at first fairly clear but gradually become less distinct and finally excessively blurred.

The central cut is widely separated from the lines above and below it, particularly the former. The arrangement of the three horizontal lines at the top is the same as in group XIII but on the $\mathbf{I} 2$ candareens stamps the middle line at the bottom is lower than the lines at the sides. The period after the "O" of " L. P. O." is now slightly below the line of the letters. The final " $\mathrm{s}$ " of CANDAREENS is a little nearer the vertical line at the right. The large letter "s", used in the last three groups, has been replaced by the smaller one used in the earlier groups.

The letter " $D$ " is below the line of CAN DAREENS, as in several preceding groups.

Candareens in the plural.

Numerals: As in group XII.

Paper: Thin white wove.

7 I 3 cands red brown

726 cands scarlet

736 cands orange vermilion

74 I2 cands light chocolate brown

75 I2 cands chocolate brown

76 I2 cands dark chocolate brown

Varieties:

a. The top of the " 3 " is on a line with CANDAREENS.

$77 \quad 3$ cands red brown

b. "CAN" and "s" above the other letters of CANDAREENS.

786 cands scarlet

796 cands orange vermilion

GRoup XV.

Poor impressions, the cut showing many signs of wear. The setting is identical with the last stamps of group XIV. On the I candareen stamps the Chinese character " $I$ " is now very thin and looks like an English "l" without a foot.

Candareen in the singular except on the 2c.

Numerals: Modern.

Paper: White wove and toned.

A. Thin yellowish white wove paper.

8o I cand pale blue

8 I r cand dark blue

82 I cand gray blue

83 I cand slate blue

$84 \quad 2$ cands gray black

2 cands full black

3 cand carmine brown

3 cand dark red brown

883 cand red brown

Variety: "s" below the line of CANDAREENS

$89 \quad 2$ cands full black

B. Deeply toned paper

go I cand dark blue 
Group XVI.

Clear impressions though worn. Position of the central cut and lines above it the same as in group XV. The line above the value slopes downward from left to right. The left end is usually as high or higher than the line above the character in the lower left corner and the right end is lower than the line above the character in the lower right corner. The " $s$ " of SHANGHAI is not quite as close to the line at the left.

Candareens in the plural.

Numerals : Modern for the $3 \mathrm{c}$, antique for the other values.

Paper: Pelure, thin wove, toned and porous.

A. Pelure paper.

9I 2 cands dull black

B. Thin white wove paper.

$92 \quad 2$ cands dull black

933 cands red brown

4 cands yellow

4 cands orange yellow

6 cands red brown

6 cands pale red brown

Varieties:

a. Without period after CANDAREENS.

$98 \quad 3$ cands red brown

996 cands pale red brown

b. The " $\mathrm{C}$ " is above the line of CAN-

DAREENS.

IOO 4 cands yellow

C. Toned paper.

IOI 2 cands dull black

IO2 4 cands orange yellow

I03 6 cands red brown

D. Coarse porous paper.

IO4 6 cands red brown

Variety: Without period after CANDAREENS.

I05 6 cands red brown

GROUP XVII.

The setting of the upper part of the stamps is as in group XVI, but the line above the value is lower than the short lines at the sides.

Candareens in the plural except on the Ic.

Numerals : Antique.

Paper : Pelure, thin wove and porous.

A. Pelure paper.
I06 I cand pale blue
Io 7 I cand blue
Io8 I cand dark blue
I09 I cand indigo
B. Thin yellowish white wove paper.
I IO I cand dull blue
III 4 cands ochre yellow
I 28 cands dull gray green
C. Coarse porous paper.
I 138 cands dull gray green
GROUP XVIII.

Most of the stamps are better printed than in the preceding group. The setting is very much like that of group XVI, the line above the value being higher than the short line at the left and lower than the corresponding line at the right. The numerals of value are usually not on a level.

Candareens in the plural.

Numerals: Antique.

Paper: Thin wove, toned and cardboard.

A. Thin yellowish white wove paper.

I 4 I2 cands orange brown

II5 I6 cands scarlet

II6 I6 cands vermilion
Varieties.

a. No top stroke to character fen.

II 72 cands orange brown

II 8 I2 cands vermilion brown

II9 I6 cands carmine

b. Figure I of English value has failed to print.

I20 6 cands carmine

I2I 6 cands vermilion

c. Dot of color between the bars of char-

acter Erh.

I22 I 2 cands pale orange brown

I23 I2 cands orange brown

d. Same as " $c$ " but the "A" of CANDA-

REENS is above the line.

I24 I2 cands pale orange brown

e. The " $\mathrm{C}$ " of CANDAREENS is above the line.

I25 I2 cands pale orange brown

B. Thin toned wove paper.

I26 I2 cands vermiliou brown

I27 I6 cands scarlet

C. Thin toned cardboard.

I 28 I 2 cands vermilion brown

Variety: Dot of color in character Erh.

I 29 I 2 cands orange brown

Group XIX.

The central device is very much worn. Impressions light and in spots indistinct. The setting resembles that of group XVII, especially the position of the line above the value, which is lower than the short lines at the sides.

Candareens in the plural.

Numerals: Antique.

Paper: Thin wove and pelure.

A. Thin white wove paper.

I30 3 cands pale red brown

I3I 3 cands dark red brown

Variety: "I. P. O." instead of " L. P. O."

1323 cands dark red brown

B. Pelure paper.

The two succeeding stamps are usually cut with a pen knife along the frame lines, as was No. 62. The impressions are faint and imperfect.

I33 3 cands red brown

I 343 cands pale red brown

GROUP XX.

Impression blurred and worn. The outer line has nearly disappeared from the central block and the lines above and below it are set further away than in any other group.

The period after the "O" of "L. P. O." is opposite the middle of the letter. CANDAREENS is set up very crookedly, the "C" and " $\mathrm{D}$ " being below the line and the " $\mathrm{s}$ " above it.

Candareens in the plural.

Numerals : Antique.

Paper: Thin white wove.

I35 4 cands pale yellow

I36 4 cands olive yellow

I37 8 cands yellow green

I38 8 cands deep green

Group XXI.

Impression fairly good. New type is used for the characters in the corners, except that in the lower left, and also for some of those at the sides. The line above the value is near the central cut.

Candareen in the singular.

Numerals : Antique.

Paper: Toned and thicker than heretofore.

I39 I cand blue 
Group XXII.

The character in the lower left corner has been replaced by a new one, quite unlike its predecessor in some of the details. There is much in the appearance of the stamps of this group to warrant the conclnsion that they are printed from electrotypes, in which only the Chinese numerals of value and the English inscription in the bottom label are movable. There is no period after the value except on the I candareen stamps. The large final " $s$ " of CANDAREENS, used in groups XI to XIII, appears once more.

Candareens in the plural except on the rc.

Numerals: Modern on the $3 c$, antique on the other values.

Paper: As in group XXI.

I40 I cand deep blue

I4 I 2 cands black

I42 3 cands red brown

I 433 cands dark red brown

I 444 cands chrome yellow

Varieties:

a. " $\mathrm{C}$ " of CANDAREEN is below the line.

I45 I cand blue

b. Figure " $I$ " is above the line of CANDAREEN.

I46 I cand blue

GRoup XXIII.

The setting appears to be the same as that of group XXII, but the English value, except the numeral and the final "s" of "CANDAREFNS," has now become part of the electrotype. Large modern numerals of value are introduced. They are, except the I, 2 and 3 , entirely different from any hitherto used. There are slight shades of most of the colors. The numerals, paper and colors make extended description of the stamps of this group unnecessary.

Candareens in the plural except on the Ic.

Numerals : Modern.

Paper: Coarse porous wove.

I47 I cand ultramarine

I48 2 cands gray black

I49 3 cands red brown

I5O 4 cands chrome yellow

I5I 6 cands olive green

I52 8 cands emerald green

I53 I2 cands orange red

I54 I 6 cands rose red

I55 I6 cands scarlet

I56 I6 cands carmine brown

I57 I6 cands red brown

Group XXIV.

A new setting, also apparently electrotyped.

The lines above and below the central device and those separating the corner characters from the inscriptions at the sides are all new. The final " $N$ " and " $\mathrm{S}$ " of CANDAREENS are new and the former is always broken.

Candareens in the plural.

Numerals : Modern.

Paper: Grayish white porous wove. I5 2 cands gray black

It is claimed by some weriters that groups $X X I$ to XXIV are reprints; this howerer is an unsettled question.

Reprints.

1869.

Typographed on thin grayish roove paper, printed in pairs, the center piece being different on each; Candareens in the plural, except the 1 candareen.

I. Modern numerals of value, same size as in group $X V$.
1591 cand blue, 2 types

160 2 cands black, 2 types

1613 cands brown, 2 types

II. Modern numerals of value, smaller than preceding.

162 1 cand blue, 2 types

1632 cands black, 2 types

These reprints which are virtually counterfeits are easily disting uished from the originals by the paper and by the center piece; in type $I$ of the reprints each side of the dragon's mous. tache is formed of two hairs ending in a point like a horn, and the dragon has nine teeth, the first one from the right being much smaller than the others.

Type II is a closerimitation of the genuine type, the dragon has, also nine teeth, but shorter than those of type $I$; in the genuine type the dragon has only seven teeth.

June, I 866.

Typographed on white wove paper. Sizes: 2 cents, I9 $1 / 4 \times 223 / 4 \mathrm{~mm}$; 4 cents, $193 / 4 \times 231 / 2$ mm.; 8 cents, 20x231/2 mm.; I6 cents, 20x $23 \frac{3}{4} \mathrm{~mm}$.
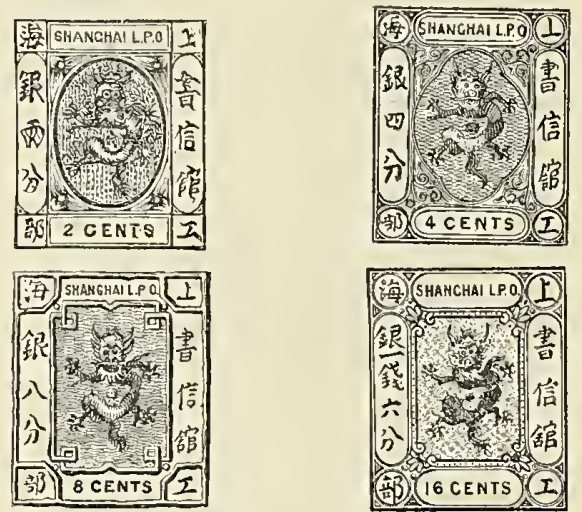

Perforated 12.

I65 4 cts lilac

I66 4 cts gray lilac

I67 8 cts blue

I68 $8 \mathrm{cts}$ pale blue

I69 I6 cts yellow green

Variety: Numeral 3 instead of 8 .

I70 3 cts blue

This variety is probably caused by defective printing.

December, I866.

Typographed on white wove paper. Size $20 \times 23 \mathrm{~mm}$.
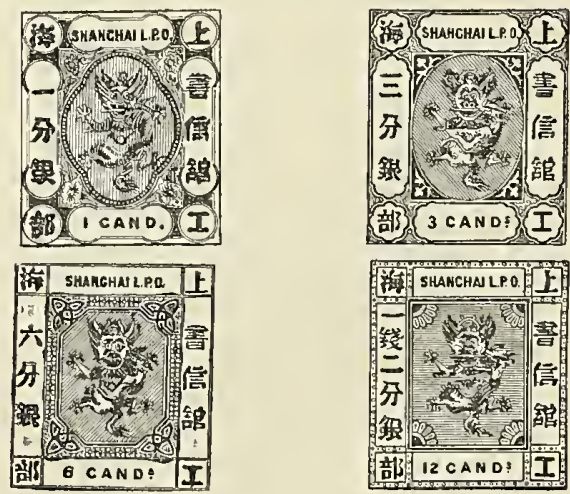

Perforated 15

I7I I cand brown 


I72 I cand light brown
I73 3 cands yellow
I74 6 cands slate
I75 I 2 cands olive brown
Varieties.

a. Blotch after "CAND," having the appearance of an "s."

I 6 I cand brown

b. Numeral 6 instead of 3 .

I77 6 cands yellow

Both of these varieties are caused by defective printing.

I872.

Same type, paper, etc. as the issue of June, I 866.

Perforated $\mathrm{I} 5$.

I $78 \quad 2$ cts rose

January, I873.

Provisional issue.

Stamps of preceding issues surcharged diagonally in blue with new value, the surcharge reading from the left bottom to the upper right corner.

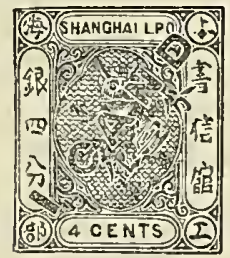

Perforated I2.

I 79 I cand on $4 \mathrm{cts}$ lilac, blue surcharge

I80 I cand on 4 cts gray lilac, blue sur-

Varieties: charge

a. Surcharge inverted, reading from right top to lefi bottom corner.

I8I I cand on 4 cts lilac, blue surcharge

b. Surcharge inverted, reading from the right bottom to the left top corner.

I82 I cand on $4 \mathrm{cts}$ lilac, blue surcharge

c. Surcharge reading from the left top to the right bottom corner.

I 83 I cand on 4 cts lilac, blue surcharge

I84 I cand on 4 cts gray lılac, blue surcharge

d. Double surcharge.

I85 I cand on 4 cts lilac, blue surcharge

e. Original value obliterated with blue pencil.

I 86 I cand on 4 cts lilac, blue surcharge

October, 1873

Provisional issue.

Stamps of the preceding regular issues surcharged diagonally with new value, the surcharge reading from the left bottom to the right top corner, as in the preceding provisional issue.

I. Black surcharge.

Perforated I 2.

I87 I cand on $4 \mathrm{cts}$ lilac, black surcharge

Variety: No period after "CAND."

I 88 I cand on 4 cts lilac, black surcharge

II. Blue surcharge.

$\mathbf{I}^{\circ}$ Perforated $\mathbf{I} 2$.

I89 I cand on 2 cts rose, blue surcharge

Igo I cand on 8 cts blue " "

I9I I cand on I6 cts green "

Variety: Numeral 3 instead of 8

I92 I cand on $3 \mathrm{cts}$ blue, blue surcharge $2^{\circ}$ Perforated 15.

I93 I cand on 2 cts rose, blue surcharge Variety: Original value obliterated by blue pencil.

I94 I cand on 2 cts rose, blue surcharge
III. Red surcharge.

Perforated I 2 .

I95 I cand on $4 \mathrm{cts}$ gray lilac, red surcharge

I96 I cand on $8 \mathrm{cts}$ blue, red surcharge

I97 I cand on I6 cts green, red surcharge

We are very suspicious of the stamps with red surcharge, the surcharge differing materially from the blue and black surcharge. In these the "D" of "CAND" is always broken except in the very earliest printing of the January 1873 issue, and the distance between " $I$ " and " $D$ " is $33 / 4 \mathrm{~mm}$., while in the red surcharge the " $D$ " is unbroken and the distance between the " $I$ " and " $D$ " is only $3 \frac{1}{4} \mathrm{~mm}$. on all specimens that we have seen.

January, 1875 .

Provisional issue.

Stamps of the preceding regular issues surcharged in the same manner as the provis. ional issue of January, I873.

I. Blue surcharge.

I $^{0}$ Perforated I2.

I9 83 cands on 2 cts rose, blue surcharge

I99 3 cands on I 6 cts yellow green, blue surcharge

$2^{\circ}$ Perforated I 5 .

200 I cand on 3 cand yellow, blue surcharge

$20 I$ I cand on 6 cand slate, blue surch'ge

202 I cand on I 2 cand olive brown, blue surcharge

2033 cands on I 2 cands olive brown, blue surcharge

2043 cands on 2 cts rose, blue surcharge

II. Red surcharge.

Perforated I 5 .

205 I cand on 6 cand slate, red surch'ge

206 I cand on 12 cand olive brown, red surcharge

July, I875.

Same type as the regular issue of December, I866, typographed on tinted wove paper.

Perforated I 5 .

207 I cand yellow on pale yellow

2083 cands carmine on pink

Variety: Perforated II $1 / 2$.

209 I cand yellow on pale yellow

February, I876.

Same type, impression and paper as the regular issue of December, I866.

Perforated I 5 .

2 ro I cand yellow

2 I 3 cands rose carmine

2I2 6 cands deep green

2 I3 9 cands pale blue

I 4 I cands light brown

Variety: I. P. O., instead of I. P. O.

2 I 53 cands rose carmine

This variety is undoubtedly caused by

defective printing.

I 877 .

Same type as preceding issue, typographed on tinted wove paper.

Perforated I $21 / 2$

2 I6 I cand carmine on pink

March, I877.

Provisional issue.

Stamps of the preceding regular is`ues surcharged with new value in the same manner as the preceding provisional issues.

Perforated I 5 .

I. Blue surcharge.

217 I cand on 3 cands carmine on pink, blue surcharge 
2 I 8 I cand on 3 cands rose carnine, blue surcharge

2 I9 I cand on 6 cands green, blue surcharge

220 I cand on 9 cands pale blue, blue surcharge

22 I I cand on I 2 cands light brown, blue surcharge

II. Red surcharge.

222 I cand on I2 cands light brown, red surcharge

We also doubt the authenticity of this stamp on the same grounds on which we suspect the stamps with red surcharge of the issue of October, I8 73 .

April I4th, I877.

Typographed on white wove paper. The types are similar to the preceding regular issues, but the currency has been changed from Candareens to Cash; the roo Cash stamp is of the same type as the 80 Caslı stamp.
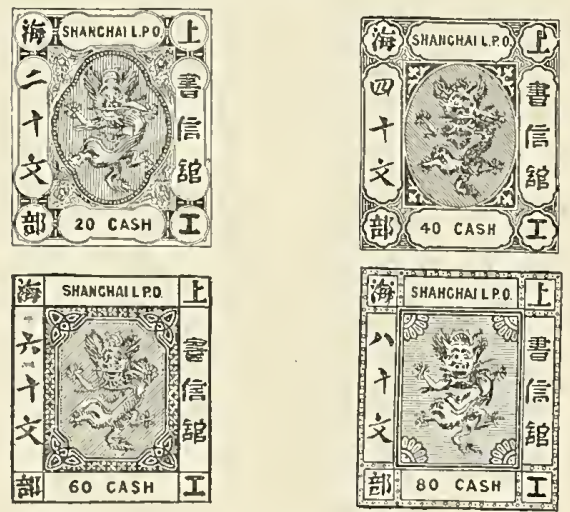

Perforated $\mathrm{I}_{5}$.

22320 cash lilac

22420 cash gray

22540 cash rose

22660 cash bright green

22780 cash blue

228 8o cash light blue

229 Ioo cash light brown

The 20 cash blue given in certain catalogues is due merely to discoloration through exposure.

$$
\text { July, I879. }
$$

Provisional issue.

Stamps of the preceding issues surcharged in blue with new value, the surcharge reading diagonally from the left bottom to the right top corner.

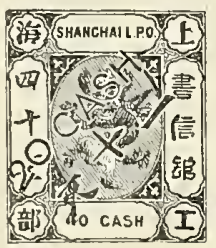

Perforated I5.

$23020 \mathrm{cash}$ on 40 cash rose, blue surcharge

23 I 60 cash on 80 cash blue, blue surcharge

23260 cash on Ioo cash light brown, blue surcharge

July 20 h, I880.

Same type, paper and impression as preceding issue.

$$
I^{0} \text { Perforated II } 1 / 2 \text {. }
$$

23320 cash lilac
23420 cash dark lilac

$23540 \mathrm{cash}$ rose

$236 \quad 60$ cash bright green

23780 cash dark blue

238 I0o cash light brown

Varieties:

a Grayish paper.

23920 cash lilac

b. Horizontal pair, imperforate between.

24020 cash dark lilac

24 I 40 cash rose

$2^{\circ}$ Perforated I 5 XII $1 / 2$.

24220 cash lilac

End of I884.

I. Provisional issue.

Stamps of the preceding issue surcharged with new value in the same manner as the provisional issue of July, I879.

Perforated II $1 / 2$.

24320 cash on 40 cash rose, blue surcharge

24460 cash on 80 cash dark blue, blue sur

charge

24560 cash on Ioo cash light brown, blue surcharge

II. Regular issue.

Same type, impression and paper as preceding regular issue.

Perforated II $\mathrm{I} / 2$.

24620 cash green

I88 5-86.

Same type, impression and paper as pre ceding regular issue.

Perforated 15 .

24720 cash green (beginning of I885)

248 20 cash dark green "“ (March 28th, I886)

$250 \quad 40$ cash dark brown
25 I 60 cash lilac (I885)

25260 cash red lilac “"

253 8o cash flesh (September, I885)

254 Ioo cash yellow

Varieties:

a. Perforated II $1 / 2$ at top and $I 5$ at bottom and sides.

25520 cash green

b. Perforated II $1 / 2$ at bottom and $I_{5}$ at top and sides.

25620 cash green

c. Perforated II $1 / 2 \times 15$

25720 cash green

25860 cash red lilac

January 29th, I886.

Provisional issue.

Stamps of the issue of $1885-86$ surcharged in blue with new value in the same manner as the provisional issue of 1884 .

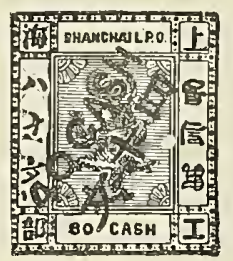

Perforated I 5 .

25940 cash on 80 cash flesh, blue sur 259

26060 cash on I00 cash yellow, blue sur Varieties:

a. Surcharge reading from left top to right bottom corner.

26I 40 cash on 80 cash flesh, blue surcharge 
26260 cash on Ioo cash yellow, blue surcharge

b. Surcharge inverted.

26360 cash on Ioo cash sellow, blue surcharge

January Ioth, I888.

Provisional issue.

Stamps of the issues of $1885-86$ surcharged with new value.

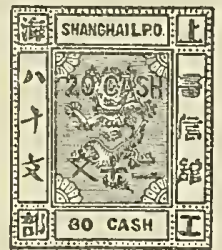

Perforated 15 .

I. Blue surcharge.

26420 cash on 40 cash brown, blue surcharge

26520 cash on 80 cash flesh, blue surcharge

Varieties :

a. Surcharge inverted.

26620 cash on 40 cash brown, blue surcharge

26720 cash on 80 cash flesh, blue surcharge

b. Surcharge in double line frame with rounded corners.

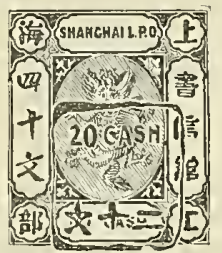

26820 cash on 40 cash brown, blue surcharge

II. Red surcharge.

26920 cash on 40 cash brown, red surcharge

27020 cash on 80 cash flesh, red surcharge

These two are supposed to be essays.

March and July, I888.

Same type, impression and paper as preceding regular issue.

Perforated I5.

27 I 20 cash gray (March)

27240 cash black (July)

$27360 \mathrm{cash}$ rose (March)

27480 cash yellow green ( $\mathrm{July}$ )

275100 cash bright blue (July)

Varicty: The top stroke of the third

Chinese character in the left label is missing.

27660 cash pale rose

June, I888.

Provisional issue.

Stamps of the issues of I885-86 surcharged with new value in the same manner as the provisional issue of January $29 t h, \mathbf{I} 886$.

Perforated I 5.

I. Blue surcharge.

27740 cash on Ioo cash yellow, blue sur-

$$
\text { charge }
$$

Varieties:

a. Surcharge reading from left top to right bottom corner.

27840 cash on Ioo cash yellow, blue surcharge

b. Surcharge inverted,

27940 cash on IOO cash yellow, blue sur. charge c. Double surcharge.

28040 cash on IOO cash yellow, blue surcharge

II. Red surcharge.

28 I 40 cash on 60 cash red lilac, red surcharge

28240 cash on 80 cash flesh,red surcharge

28340 cash on Ioo cash yellow, red surcharge

28440 cash on Ioo cash yellow, red surcharge

Varieties:

a. Surcharge reading from left top to right bottom corner.

28540 cash on Ioo cash yellow, red sur-

charge
b. Surcharge inverted.

28640 cash on Ioo cash yellow, red surcharge

Surcharges Nos. 28I, 282, 28+ are supposed to be essays.

April, 1889.

Provisional issue.

Stamps of Ioo cash of the issue of $1885-86$ surcharged horizontally " 20 cash" in a double line frame in black and diagonally "IOO cash" in red.

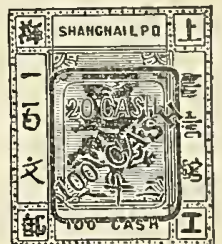

Perforated I5.

287 IOO cash on 20 cash on Iou cash yellow; black and red surcharge

Variety: Without the surcharge of Ioo cash. 28820 cash on Ioo cash yellow, black surcharge

May, I889.

Provisional issue.

80 and roo cash stamps of the issue of July, I888, surcharged in red with new value in the same way as the provisional issue of January Ioth, I888.

Perforated 15 .

28920 cash on 80 cash green, red surcharge

29020 cash on 100 cash blue, red surcharge

Variety: Surcharge inverted.

29 I 20 cash on 80 cash green, red surcharge I889.

Same type as preceding regular issue, typographed on white wove paper; water-

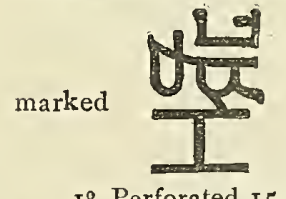

I 0 Perforated I 5

29220 cash gray (May Ioth)

29340 cash black (July I 8th)

2946 cash rose (December 9 th)

Variety: The third Chinese character in the left label has the top stroke missing.

29560 cash rose

$2^{\circ}$ Perforated I 2.

$29680 \mathrm{cash}$ green (August I4th)

297 I00 cash dark blue "6 
January Ist, I89o, and May, I89I.

Typographed on various papers. Size, $\mathrm{I} 8 \mathrm{x}$ $22 \mathrm{~mm}$.

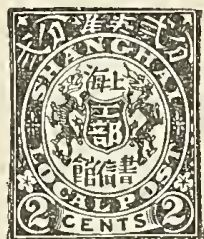

A. Thick opaque white or yellowish wove paper.

Unwatermarked.

I. White paper.

Perforated 15.

$298 \quad 2 \mathrm{cts}$ brown (I89o)
$299 \quad 5 \mathrm{cts}$ rose

$300 \quad$ I 5 cts blue

II. Yellowish paper.

Perforated I5.

$30 \mathrm{I} 5 \mathrm{cts}$ rose (I89I)

302 I5 cts blue

B. Thin hard semi-transparent, white wove paper.

Watermarked Chinese characters, as preceding issue.

$I^{0}$ Perforated I5

303 Io cts black (I 890$)$

$30420 \mathrm{cts}$ violet

$2^{\circ}$ Perforated 12.

3052 cts brown (I $89 \mathrm{I})$

3065 cts rose

C. Thin hard semi-transparent yellowish wove paper.

Watermarked Chinese characters

$I^{0}$ Perforated I 2.

$307 \quad 2$ cts brown (I 89 I)

$308 \quad 5 \mathrm{cts}$ rose

$2^{0}$ Perforated I5.

309 Io cts black (I89I)

3 IO I5 cts blue "“

3I I 20 arieties. Unwatermarked.

3 I2 IO cts black

$3 \mathbf{r} 2 \mathrm{a}$ I 5 cts blue

31320 cts violet

On some sheets of this issue, the stamps in the outer vertical row either at the right or at the left have no watermark or so little of it as to make it invisible on a single specimen.

September, I 892 .

Same type and impression as preceding issue, watermarked Chinese characters.

I. Yellowish wove semi-transparent paper. Perforated I 2.

3I4 Io cts orange

II. White wove semi-transparent paper.

Perforated I 2 .

3 I 4 a 2 cts green

3 I5 $5 \mathrm{cts}$ red

$3 I 5$ a Io cts orange

3 I 6 I 5 cts violet

31720 cts light brown

End of 1892 .

Provisional issue.

Five cent stamps of the $189 \mathrm{I}$ issue surcharged with new value in blue.
Unwatermarked.

Yellowish wove opaque paper.

Perforated I 5 .

$318 \quad 2$ cts on 5 cts rose, blue surcharge

Variety: Surcharge inverted.

3 I9 $2 \mathrm{cts}$ on $5 \mathrm{cts}$ rose, blue surcharge

May to August, I 893 .

A. Provisional issue.

I. Stamps of the issues of I 89 I-92 divided vertically in two by a perforation gauging 12 and surcharged with new value. There are two types of the surcharge $1 / 2$. In type $I$ the bottom stroke of the 2 is straight $\frac{1}{2}$ Ct in

type 2 it is curved $\frac{1}{2} \mathrm{Ct}$. Watermarked Chinese characters.

Yellowish or white wove, semi-transparent paper.

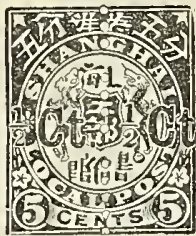

Perforated I2.

$320 \mathrm{I} / 2 \mathrm{ct}$ on 5 cts rose, blue surcharge, type I, right half

$32 \mathrm{I} 1 / 2 \mathrm{ct}$ on $5 \mathrm{cts}$ rose, blue surcharge, type I, left half

$3221 / 2$ ct on 5 cts rose, blue surcharge, type 2 , right half

$3231 / 2$ ct on 5 cts rose, blue surcharge, type 2, left half

$3241 / 2 \mathrm{ct}$ on $5 \mathrm{cts}$ red, blue surcharge, type I, right half

$3251 / 2 \mathrm{ct}$ on $5 \mathrm{cts}$ red, blue surcharge, type I, left half

$326 \mathrm{~J} / 2$ ct on $5 \mathrm{cts}$ red, blue surcharge, type 2 , right half

$327 x / 2$ ct on 5 cts red, blue surcharge, type 2 , left half

328 I ct on 2 cts brown, blue surcharge, right half

329 I ct on $2 \mathrm{cts}$ brown, blue surcharge, left half

330 I ct on $2 \mathrm{cts}$ green, red surcharge, right half

33 I I ct on 2 cts green, red surcharge, left half

a. Period after " $\mathrm{Ct}$ " above the line.

$332 \quad 1 / 2 \mathrm{ct}$ on $5 \mathrm{cts}$ rose, blue surcharge, type I

$333 \mathrm{t} / 2 \mathrm{ct}$ on $5 \mathrm{cts}$ rose, blue surcharge, type 2

$3341 / 2 \mathrm{ct}$ on $5 \mathrm{cts}$ red, blue surcharge, type I

$3351 / 2 \mathrm{ct}$ on $5 \mathrm{cts}$ red, blue surcharge,

$335 \quad 1 / 2$ ct on 5 cts red, blue surcharge, I ct on 2 cts brown, blue surcharge, left half

I ct on 2 cts brown, blue surcharge, right half

b. Surcharge inverted.

$33^{8} \quad 1 / 2 \mathrm{ct}$ on $5 \mathrm{cts}$ rose, blue surcharge, type $I$, right half 
$339 \quad 1 / 2$ ct on 5 cts rose, blue surcharge, type I, left half

$340 \quad 1 / 2 \mathrm{ct}$ on $5 \mathrm{cts}$ rose, blue surcharge, type 2 , right half

$34 \mathrm{I} 1 / 2 \mathrm{ct}$ on $5 \mathrm{cts}$ rose, blue surcharge, type 2 , left half

342 I ct on 2 cts brown, blue surcharge, right half

343 I ct on 2 cts brown, blue surcharge, left half

c. Surcharge inverted, with period above the line.

$344 \quad 1 / 2$ ct on 5 cts rose, blue surcharge, type I

$345 \mathrm{r} / 2 \mathrm{ct}$ on $5 \mathrm{cts}$ rose, blue surcharge, type 2

346 I ct on 2 cts brown, blue surcharge, right half

347 I ct on 2 cts brown, blue surcharge, left half.

d. With additional surcharge "I $\mathrm{Ct}$ " in green.

348 I ct $\times$ I ct on 2 cts brown, blue and green surcharge, right half

349 I ct $x$ I ct on 2 cts brown, blue and green surcharge, left half

e. With additional surcharge "I ct" in black.

350 I ct $\times$ I ct on 2 cts brown, blue and black surcharge, right half

35I I ct X I ct on 2 cts brown, blue and black surcharge, left half

f. Double surcharge, one inverted.

352 I ct on 2cts brown, blue surcharge, right half

353 Ict on 2 cts brown, blue surcharge, left half

g. Double surcharge one with period above the line.

354 I ct on 2 cts brown, blue surcharge, right half

355 I ct on 2cts brown, blue surcharge, left half

II. I5 and 20 cent stamps of the issue of I892 surcharged in blue with new value. Watermarked Chinese characters.

White wove, semi-transparent paper.

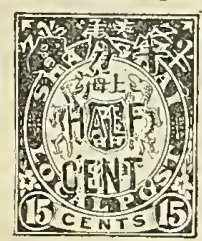

Perforated 12.

$356 \mathrm{I} / 2 \mathrm{ct}$ on $\mathrm{I} 5 \mathrm{cts}$ violet, blue surcharge 357 I ct on 20 cts brown, blue surcharge Variety: Error in the sheet of I cent stamps the IIth and I2th stamps being surcharged "Half Cent."

$358 \mathrm{r} / 2 \mathrm{ct}$ on $20 \mathrm{cts}$ brown, blue surcharge May to December, 1893 .

Typographed in color on ordinary white wove paper. The inscriptions in the labels at top, bottom and sides are printed in black. Size, $20 \times 251 / 2 \mathrm{~mm}$.

Watermarked Chinese characters.

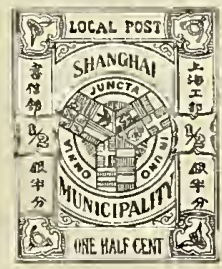

Perforated $131 / 2 \times I_{4}$.

$359 \quad 1 / 2$ ct orange and black

$360 \quad$ I ct brown and black

$36 \mathrm{I} \quad 2 \mathrm{cts}$ vermilion and black

$3625 \mathrm{cts}$ blue and black

363 Io cts green and black

$364 \quad$ I5 cts yellow and black

$36520 \mathrm{cts}$ Iilac and black

End of 1893 .

Jubilee issue.

A. Stamp typographed in color on white wove paper; the date, the value, the words "Local Post" and the Chinese characters are printed in black. Size, $241 / 2 \times 3 \mathrm{Imm}$.

Watermarked Chinese characters.

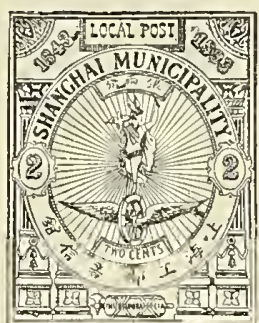

Perforated $13 \mathrm{l} / 2$

$366 \quad 2 \mathrm{cts}$ vermilion and black

B. Stamps of the preceding regular issue surcharged diagonally in black " $x 843$-Jubilee -1893 " in three lines.

Watermarked Chinese characters.

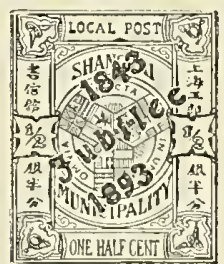

Perforated $\mathrm{I} 3 \mathrm{~T} / 2 \times \mathrm{I} 4$.

$367 \quad 1 / 2$ ct orange and black, black surcharge

368 I ct brown and black " "

3692 cts vermil'n and black “" “"

$370 \quad 5 \mathrm{cts}$ blue and black " “ "

$37 \mathrm{I}$ Io cts green and black “" “ “"

372 I5 cts yellow and black .، “

373 20 cts lilac and black
Variety: Surcharge inverted.

374 2cts vermilion and black, black surcharge

May, I896.

Provisional issue.

I5 and 20 cent stamps, of the issue of May I893, surcharged in black with new value.

Watermarked Chinese characters.

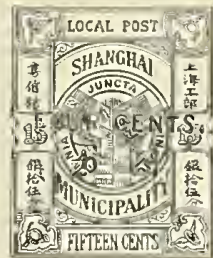

Perforated $131 / 2 \times$ I4.

$3754 \mathrm{cts}$ on I 5 cts yellow and black, black surcharge

$3766 \mathrm{cts}$ on $20 \mathrm{cts}$ violet and black, black surcharge 
End of 1896 .

Same type and impression as issue of May 1893, the 4 and 6 cent stamps are printed on a tinted paper.

Watermarked Chinese characters.

\section{UNPAID LETTER STAMPS.}

January, 1892.

Regular adhesive stamps of the issues of 1890-92 surcharged horizontally "Postage Due."

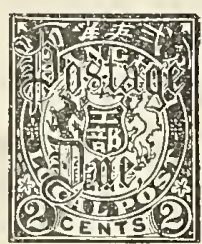

A. Unwatermarked.

I. White wove opaque paper.

Perforated 15.

$40 \mathrm{I} 2 \mathrm{cts}$ brown, black surcharge

$4025 \mathrm{cts}$ rose “" “"

$403 \quad \mathrm{r} 5 \mathrm{cts}$ blue

II. Yellowish wove opaque paper.

Perforated I5.

$404 \quad 5$ cts rose black surcharge

B. Watermarked Chinese characters.

I. Yellowish wove semi-transparent paper. $I^{\circ}$ Perforated I2.

4052 cts brown, black surcharge

$2^{\circ}$ Perforated I5.

406 ro cts black, red surcharge

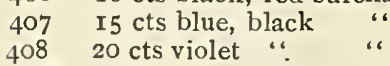

Varieties:

a. Surcharge inverted.

$4092 \mathrm{cts}$ brown, black surcharge

4IO I5 cts blue

b. Unwatermarked.

4II ro cts black, red surcharge

$4 \mathbf{1 2}$ I 5 cts blue, black "“

4I3 $20 \mathrm{cts}$ violet "

II. White wove semi-transparent paper.

Perforated I2.

4I4 $2 \mathrm{cts}$ brown, black surcharge

End of 1892.

Stamp and surcharge same as in the pre-

\section{ENVELOPES.}

I 893.

A. Provisional issue.

Diagonally laid white paper or buff wove paper with the inscription "Postage paid I cent" on the upper part of the envelope; oval seal embossed without color over the inscription.

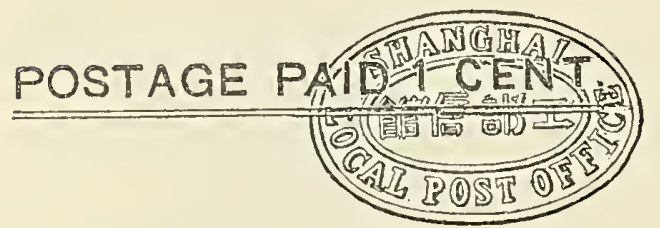

I. White laid paper.

Size $120 \times 82 \mathrm{~mm}$

501 Ict black

Variety: Inscription reads "Postage $\mathbf{r}$ cent."

502 Ict black

II. Buff wove paper.

Size $145 \times 95 \mathrm{~mm}$ 503 Ict black
Perforated $13 \frac{1}{2} \times I_{4}$,

$377 \quad 2$ cts red and black

$378 \quad 4$ cts orange and black on yellowish

$3796 \mathrm{cts}$ carmine and black on pinkish

Variety: Black inscription inverted.

$380 \quad 2$ cts red and black

ceding issue. Watermarked Chinese characters.

White wove, semi-transparent paper.

Perforated I2.

4I5 2 cts brown, blue surcharge

4 I6 5 cts rose "، “"

4 I 7 Io cts orange

I 892-93.

Regular adhesives of the issue of the end of 1892 surcharged as in the preceding issue. Watermarked Chinese characters.

White wove, semi-transparent paper.

Perforated I2.

4I 8 Io cts orange, blue surcharge

4 I9 Io cts orange, ultramarine surcharge

420 I 5 cts violet, red surcharge

42 I 20 cts brown "“

r 892.

Typographed in color on ordinary white wove paper. The inscriptions in the upper, lower and side labels, as well as the value in the center, are printed in black. Size, 22x $28 \mathrm{~mm}$.

Watermarked Chinese characters.

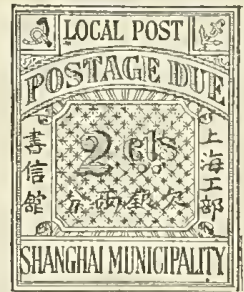

Perforated I 4 XI $31 / 2$

$422 \quad 1 / 2$ ct orange and black
$423 \quad$ I ct brown and black

$424 \quad 2$ cts vermilion and black

$425 \quad 5 \mathrm{cts}$ blue and black

426 Io cts green and black

427 I 5 cts yellow and black

$42820 \mathrm{cts}$ lilac and black

B. Regular issue.

Stamp embossed in color in upper right corner. The inscriptions in the upper, lower and side labels are in black.

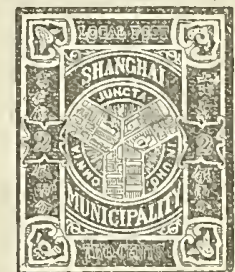

I. White laid batonne paper.

Size I25x7 Imm

$504 \quad$ I ct brown and black

II. Creamish laid batonne paper.

I $^{\circ}$ Size $\mathrm{r}_{45} \times 83 \mathrm{~mm}$

$5052 \mathrm{cts}$ vermilion and black

$2^{\circ} \quad$ Size $152 \times 94 \mathrm{~mm}$.

5065 cts blue and black

C. Jubilee issue.

Envelopes of the regular issue surcharged diagonally "r843-93-Jubilee" in two lines. 


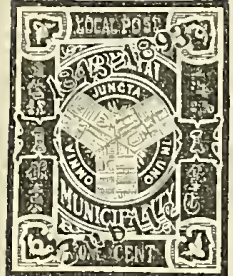

I. White laid batonne paper

Size i $25 \times 71 \mathrm{~mm}$.

507 I ct brown and black, black surcharge

II. Creamish laid batonne paper.

I $^{\circ}$ Size I $45 \times 83 \mathrm{~mm}$.

5082 cts vermilion and black, violet surcharge

$2^{\circ} \quad$ Size $152 \times 94 \mathrm{~mm}$

$5095 \mathrm{cts}$ blue and black, violet surcharge

\section{WRAPPERS.}

I 893.

A. Provisional issue.

Thin wove paper. Inscription in the upper part "Local Post Newspaper Wrapper-Postage paid 1/2 cent" in two lines, and oval seal embossed without color over the inscription.

\section{LOCAL. POST NEWSPAPER WRAPPER.}

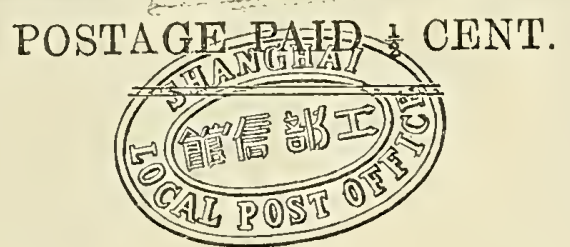

Size, II $7 \times 258 \mathrm{~mm}$.

55 I $\quad 1 / 2$ ct black

B. Regular issue.

Stamp of the same type as on the regular envelopes of the corresponding issue, embossed in color at the right side. The inscriptions in the upper, lower and side labels are printed in black.

I. White laid batonne paper.

Size I0 $2 \times 280 \mathrm{~mm}$.

$552 \quad 1 / 2 \mathrm{ct}$ orange and black

II. Creamish laid batonne paper.

Size $102 \times 280 \mathrm{~mm}$.

553 I ct brown and black

5542 cts vermilion and black
C. Jubilee issue

Wrappers of the regular issue with the stamp surcharged diagonally " I843-93Jubilee" in two lines;

I. White laid batonne paper.

Size $102 \times 280 \mathrm{~mm}$.

$555 \mathrm{I} / 2$ ct orange and black, violet sur charge

II. Creamish laid batonne paper.

Size $102 \times 280 \mathrm{~mm}$

556 I ct brown and black, black surcharge

$5572 \mathrm{cts}$ violet and black, violet surcharge

COUNTERFEITS.

As the forgeries of the first issues are numerous, we shall describe some of the points of the genuine stamps.

The four thick lines forming the frame do not touch one another in all the four corners-very seldom more than one, and quite often in none at all. The dragon has seven teeth. Each side of the dragon's moustache is formed of three hairs, the two lower ones being close together and much shorter than the top one. In the lower part of the dragon's body, between the gth and Icth upper scales from the right and the 7th, 8th

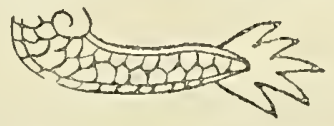

and gth lower ones, there is a small triangular scale. The line separating the $\mathrm{I} 2$ th upper and Ioth lower scales from the right is broken and does not touch the I Ith lower scale.

Of the subsequent issues we do not know of any good forgeries, except of the surcharges of the issue of $1873^{-}$ 77. Of the I candareen surcharge, almost all the specimens seen by us, of whose genuineness we have no doubt, had the D of "CAND" broken at the top. The only stamps with a perfect "D" were a few of the "I CAND" surcharged in blue on the 4 cent stamps of January, 1873.

We believe that all surcharges on other stamps and in any color other than blue, with a perfect "D," are forgeries.

There is a pretty good forgery of the surcharges of the 20,40 and 60 cash of the provisional issues of I879, I884 and I886. In the forgeries, the letters of the surcharge measure only $3 \mathrm{~mm}$. in height, instead of $3 \frac{1}{4}$. The height of the two lines of surcharge from the top of the "s" to the bottom of the Chinese character below it is $7 \mathrm{~mm}$. in the forgery, and $73 / 4 \mathrm{~mm}$. in the genuine. 


\section{SIAM}

Currency: 128 LOTTE $=64$ ATTS $=32$ PYNUNG $=16$ SONGPY $=4$ SALUNG $=I$ TICAL $=40$ CENTS U. S. Currency.

ADHESIVE STAMPS.

July I6th, I 883 .

Engraved (portrait of King Chula Longkorn) on white wove paper. The designs of the I sungpy and the I salung are different from the three lower values. Sizes: I lotte, I att and I pynung, 20x25 I/2 mm. ; I songpy, If $\times 22 \mathrm{~mm}$.; I salung, $221 / 2 \times 27 \mathrm{~mm}$.
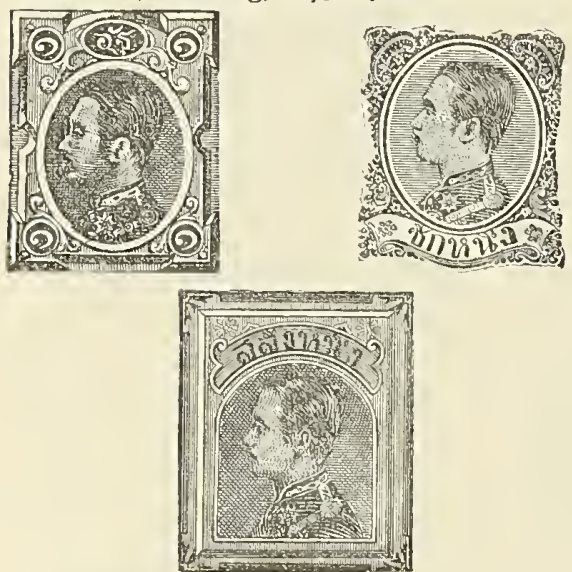

Perforated $\mathbf{1 5}$

I Il dark blue

2 Ia carmine

3 Ip vermilion

4 Iso yellow

1885 .

Isa orange

Provisional issue.

I lotte stamps of the preceding issue surcharged in red with new value. There are three types of this surcharge: in type I all the letters of the surcharge are capitals; in types II and III only the initial letter is a capital. In type II the surcharge measures $3 \times 131 / 2 \mathrm{~mm}$.; in type III it measures $3 \frac{1}{2} \mathrm{x}$ I $3 \frac{1}{2} \mathrm{~mm}$.

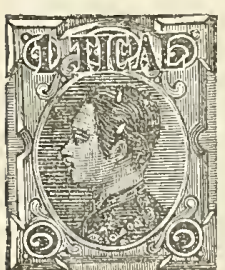

I.

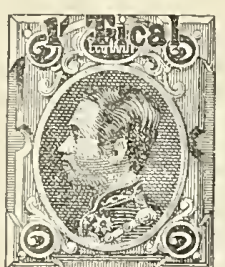

II.

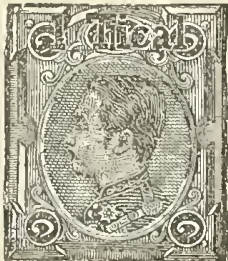

III.

Perforated I 5

6 It on $\mathrm{xl}$ dark blue, red surcharge, type I

7. It on Il dark blue, red surcharge, type 1I

$\delta$ It on Il dark blue, red surcharge, type III
Varieties:

a. Surcharge in verted.

It on Il dark blue, red surcharge, type II

b. Double surcharge

Io It on Il dark blue, red surcharge, type II

c. Double surcharge, one in red the other in black.

II Itxit on Il dark blue, red and black surcharge, type II

Moens catalogues a number of varieties of type II differing in the figure " $x . "$ We think these differences are simply caused by defective printing, and only deserve passing notice.

April Ist, 1887.

Typographed on white wove paper (portrait of King Chula Longkorn). The 2, 3, 4 and 8 atts stamps are printed in green, with the upper corner ornaments and tablet containing the value printed in a different color.

In the higher values the body of the stamp is printed in lilac and the corner ornaments and tablet also in different colors. Size $181 / 2 \times 221 / 2 \mathrm{~mm}$

Watermarked a flower
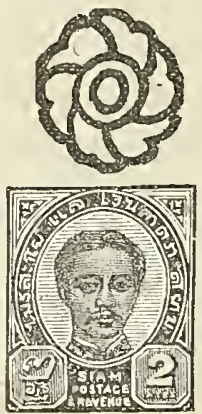

Perforated I4.

I2 2 a green and carmine

I3 3 a green and blue

I4 4 a green and red brown

I5 8a green and yellow

I6 I 2a lilac and carmine

I7 24a lilac and blue

I8 64 a lilac and orange brown

I889.

Provisional issue.

A. Stamps of the issue of July, $\mathrm{I} 88_{3}$, surcharged with new value in black.

Unwatermarked.

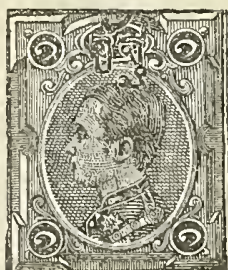

Perforated I5.

I9 Ia on Ip vermilion, black surcharge

B. Stamps of the issue of April, I887, surcharged in black with new value. There are three types of the numeral "I." In 
type I, the figure " $I$ " has the top stroke almost horizontal and has no bottom stroke. In type II, the "I" has the top stroke decidedly slanting and has a bottom stroke. In types I and II, the "I" measures $6 \mathrm{~mm}$. in height and about $3 / 4 \mathrm{~mm}$, in thickness. Type III is similar to type $I$, but the figure is $7 \mathrm{~mm}$. high and about $\mathrm{Imm}$. think.

Watermarked a flower.

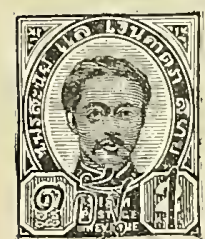

I.

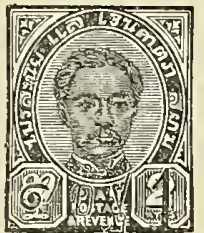

II.
Perforated 15.

$20 \quad$ Ia on $2 a$ green and carmine, black surcharge, type I

21 Ia on 2 a green and carmine, black surcharge, type II

22 Ia on 2 a green and carmine, black surcharge, type III

23 Ia on 3 a green and blue, black sur-

Varieties: charge, type II

a. Horizontal pair, one of which is without surcharge.

24 Ia on 2 a green and carmine, black surcharge, type II

b. Numeral "I" omitted.

25 Ia on 2 a green and carmine, black surcharge

End of 1890 .

Provisional issue.

3 atts stamps of the issue of 1887 surcharged in black with new value. There are three types of this surcharge. In type $I$, the numeral " 2 " measures $61 / 2 \mathrm{~mm}$. in height and the first Siamese character is lower than the one following. In type II, the numeral " 2 " measures $6 \mathrm{~mm}$. high and the first Siamese character is on a level with the one following. In type III, the numeral measures $4 \mathrm{~mm}$. in height and the first Siamese character is on a level with the one following.

Watermarked a flower.

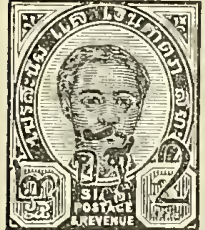

I.

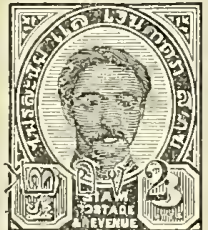

III.
Perforated I4.

262 on $3 a$ green and blue, black surcharge, type I

$272 \mathrm{a}$ on $3 \mathrm{a}$ green and blue, black surcharge, type II

282 a on $3 a$ green and blue, black surcharge, type III

I 89 I.

Same type and paper as the issue of April

Ist, I887, but printed in one color.

Watermarked a flower.

Perforaled I 4 .

29 Ia green

I893.

Provisional issue.

8 and $2+$ atts stamps of the issue of April
Ist, I887, surcharged in black with new value.

Watermarked a flower.

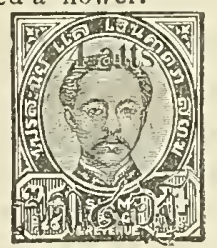

A. Surcharged with Siamese characters only.

Perforated I4.

$30 \quad 4 \mathrm{a}$ on $24 \mathrm{a}$ lilac and blue, black sur-

3 I $4 \mathrm{a}$ on $8 \mathrm{a}$ green and yellow, black surcharge

$326 \mathrm{a}$ on $8 \mathrm{a}$ green and yellow, black

surcharge
These last two were used in June in the Praket district during the Franco-Siamese difficulties.

B. Surcharged in Siamese and English, the latter measuring Iomm., including the period. The second Siamese character measures $3 \mathrm{l} / 2 \mathrm{~mm}$. and the distance between the English and Siamese surcharges is about I $3 \mathrm{~mm}$.

Perforated I4.

$334 \mathrm{a}$ on $24 \mathrm{a}$ lilac and blue, black surVarieties: charge

a. English surcharge printed twice.

$34 \quad 4^{a}$ on $24 a$ lilac and blue, black surcharge

b. Siamese surcharge omitted.

35 4a on 24a lilac and blue, black surcharge

C. Same as B, but the distance between the English and Siamese surcharge is about $8 \mathrm{~mm}$-sometimes only $6 \mathrm{~mm}$.

Perforated 14.

364 a on $24 a$ lilac and blue, black surcharge

D. Same as B, but the English surcharge measures II $1 / 2 \mathrm{~mm}$, including the period.

Perforated I 4 .

$37 \quad 4$ a on 24 a lilac and blue, black sur-

Varieties: charge

a. Horizontal pair, one of which is sur. charged in Siamese only.

38 4a on $24 a$ lilac and blue, black sur. charge

b. "s" of atts inverted.

394 a on 24 a lilac and blue, black surcharge

Variety: Double Siamese surcharge.

$40 \quad 4$ a on $24 a$ lilac and blue, black surcharge

E. Same as D but the second Siamese character measures $4 \mathrm{~mm}$ in height.

Perforated 14 .

4 I 4 a on 24 a lilac and blue, black surcharge

F. Same as B; but the English surcharge measures $9 \mathrm{~mm}$, and has no period after atts.

Perforated I4.

424 a on 24 a lilac and blue, black surch arge

G. Same as D, but the English surcharge measures Iomm. and has no period after atts.

Perforated $I_{4}$.

$434 \mathrm{a}$ on $24 \mathrm{a}$ lilac and blue, black surcharge 
Variety: Double Siamese surcharge.

$44 \quad 4 \mathrm{a}$ on $24 \mathrm{a}$ lilac and blue, black sur-

1894.

$$
\text { charge }
$$

Provisional issue.

64 atts stamps of the issue of April rst, I887, surcharged in black with new value in English and Siamese. There are a number of minor varieties, consisting in the spacing between the English and Siamese surcharges and between the numerals of value and the word "atts" in the English surcharge.

Watermarked a flower.

A. "atts" measures 9mm., including the period, There is only one type of the numeral $r$, but there are six types of the numeral 2, as per illustration. "atts" is spelt in the plural in all the values.

\section{$\begin{array}{llllll}2 & 2 & 2 & 2 & 2 & 2\end{array}$ \\ I. II. III, IV. V. VI.}

Perforated 14

45 Ia on 64 a lilac and orange brown, black surcharge

46 2a on 64a lilac and orange brown, black surcharge, type I

$472 \mathrm{nn} 64 \mathrm{a}$ lilac and orange brown, black surcharge, type II

$482 \mathrm{a}$ on 64a lilac and orange brown, black surcharge, type III

$2 \mathrm{a}$ on $64 \mathrm{a}$ lilac and orange brown, black surcharge, type IV

2a on 64a lilac and orange brown,

black surcharge, lype $V$.
5 2a on 64 a lilac and orange brown, black surcharge, type VI

Variety: Inverted period after atts.

52 Ia on 6 ta lilac and orange brown, black surcharge

I895.

Inscriptions embossed in white on colored ground on white wove paper. Size, $42 \times 37 \mathrm{~mm}$. period, and is in the singular.

Perforated I4. black surcharge $51 / 2$ and $7 \mathrm{~mm}$., including the period.

Perforated 14 black surcharge black surcharge stamp. black surcharge

I 895.

Provisional issue. $7 \mathrm{~mm}$., including the period.

Watermarked a flower.

Perforated $x 4$ charge

Variety: "s" of " atts" inverted. charge

Beginning of 1896 .

Provisional issue. cluding period.

Watermarked a flower.

Perforated I 4 . charge

OFFICIALLY SEALED.

B. "att" measures $8 \mathrm{~mm}$, including the

53 ra on 64a lilac and orange brown,

C. " att" and "atts" measure respectively

54 Ia on 64a lilac and orange brown,

$552 \mathrm{a}$ on $64 \mathrm{a}$ lilac and orange brown.

Variety: Surcharged on back and face of

$562 a$ on $64 a$ lilac and orange brow $n$

24 atts stamps of the issue of April Ist, I887, surcharged with new value in English and Siamese. The word "attts" measures

57 Ioa on 24 a lilac and blue, black sur-

58 Ioa on $24 a$ lilac and blue, black sur-

I2 at ts stamps of the issue of April Ist, 1887 surcharged with new value in English and Siamese, " 4 atts" measures $12 \mathrm{~mm}$. in-

594 4a on I2a lilac and blue, black sur-

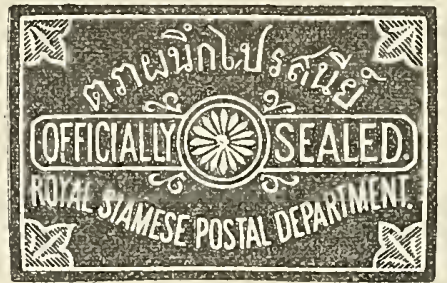

501 (no value) $\mathrm{r} \in \mathrm{d}$

COUNTERFEITS.

We do not know of any good forgeries of the stamps of Siam. But I lotte stamps with a forged surcharge of I tical are plentiful. Some of these are quite dangerous, and we advise collectors to be very cautious and to purchase these stamps from reliable firms only.

\section{SIERRA LEONE.}

Currency: I2 PENCE=I SHILling; 20 SHILLINGS=I POUND $(£ I)=\$ 4,87$ U.S. Currency.

\section{ADHESIVE STAMPS.}

I86r.

Typographed (portrait of Queen Victoria) on bluish or white nove paper, Size $18 \%$ $\mathrm{x} 22^{1} \mathrm{r} / \mathrm{mm}$.

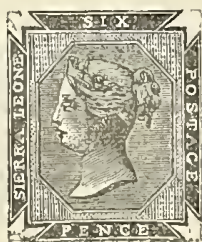

I. Bluish wove paper.

I' Imperforate.

I $6 \mathrm{p}$ deep violet

$2^{\circ}$ Perforated I 4 .

$26 \mathrm{p}$ deep violet

II. White wove paper.

Perforated I4.

$36 \mathrm{p}$ violet

$46 \mathrm{p}$ mauve $(\mathbf{1} 867)$ 
1872.

Same type as preceding issue, typographed on bluish or white wove paper.

I. Bluish wove paper.

Perforated I2 $1 / 2$.

$56 \mathrm{p}$ mauve

II. White wove paper.

Perforated $\div 21 / 2$.

$66 \mathrm{p}$ mauve

April 1872 .

Typographed on white wove paper. Size, $\mathrm{I} 8 \mathrm{~T} / 2 \times 22 \mathrm{~T} / 2 \mathrm{~mm}$.

Watermarked Crown and CC sideways.

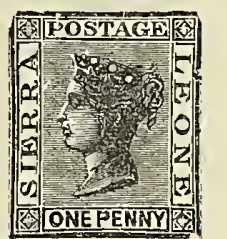

Perforated $12 \mathrm{r} / 2$.

7 Ip rose

$8 \quad$ Ip yellow buff

$94 \mathrm{p}$ blue

Io Ish pale yellow green

I873-76.

Same type, paper and impression as preceding issue. Watermarked Crown and CC pláced normally.

Perforated I $21 / 2$

I I Ip rose (October, I873)

I2 Ip dark rose “"

I3 2p magenta “"

I4 3p yellow buff

I5 : 3p golden yellow (February, I876)

I6 4p blue (October, I873)

January, 1876, to July, I877.

Same type, paper and impression as preceding issue.

Watermarked Crown and CC.

Perforated I4.

I8 $1 / 2 \mathrm{p}$ bistre

I9 Ip rose

20 Ip carmine

I I $1 / 2 \mathrm{p}$ violet ( $\mathrm{July}, \mathrm{I} 877$ )

$22 \quad 2 \mathrm{p}$ magenta

233 yellow buff

$24 \quad 4 \mathrm{p}$ blue

25 Ish yellow green

26 Ish blue green

June, 1883.

Same type, paper and impression as preceding issue.

Watermarked Crown and CA.

Perforated $\mathrm{I}_{4}$

$27 \quad 1 / 2 \mathrm{p}$ bistre

$28 \quad 2 \mathrm{p}$ magenta

$z_{9} \quad 4 \mathrm{p}$ blue

1884.

Same type, paper and impression as preceding issue.

Watermarked Crown and CA.

Perforated I 4 .

$30 \quad \mathrm{t} / 2 \mathrm{p}$ green (June)

$3 \mathrm{I}$ Ip rose (September)

$32 \quad 2 p$ slate (June)

$334 \mathrm{p}$ bistre (July)

Variety: 2 penny stamp cut in two, each half being used as I penny.

34 Ip slate (half of $2 p$ )
I885-90.

Same type as the issue of I86I, typographed on white wove paper.

Watermarked Crown and $\mathrm{CC}$

Perforated I4.

$356 \mathrm{p}$ mauve (1885)

$36 \quad 6 \mathrm{p}$ violet brown ( 1890$)$

Variety: 6 penny stamp cut in two, each

half being used as 3 pence.

$37 \quad 3 \mathrm{p}$ mauve (half of $6 \mathrm{p}$ )

November, I888.

Same type, impression and paper as the

I shilling stamp of the issue of $\mathrm{r} 876$.

Watermarked Crown and CA.

Perforated I 4

38 Ish red brown

I8gI-92.

Same type, paper and impression as preceding issue.

Watermarked Crown and CA.

Perforated $\mathrm{I} 4$

$39 \quad \mathrm{I} 1 / 2 \mathrm{p}$ violet $(\mathrm{I} 892)$

$40 \quad 21 / 2 \mathrm{p}$ blue (April, I89I)

4 I $3 \mathrm{p}$ yellow

End of 1892 .

Provisional issue.

I $1 / 2$ penny stamps of the issues of 1877 and 1892 surcharged in black with new value the original value being obliterated by two black lines.

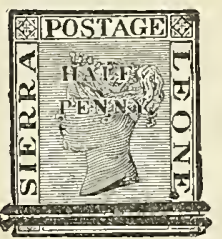

A. Watermarked Crown and CC. Perforated 14

$42 \quad 1 / 2 \mathrm{p}$ on I $1 / 2 \mathrm{p}$ violet, black surcharge Variety: PFNNY instead of PENNY:

$43 \quad 1 / 2 \mathrm{p}$ on $\mathrm{I} / 2 \mathrm{p}$ violet, black surcharge It is said that only 2 or 3 sheets of these stamps were issued.

B. Watermarked Crown and CA.

I. Original value obliterated by two black lines of equal thickness close together.

Perforated I4.

$441 / 2 \mathrm{p}$ on $\mathrm{I} 1 / 2 \mathrm{p}$ violet, black surcharge

Varieties:

a. Surcharge inverted.

$45 \quad 1 / 2 \mathrm{p}$ on $\mathrm{I} 1 / 2 \mathrm{p}$ violet, black surcharge

b. Double line across the value and across "Postage."

$46 \quad 1 / 2 \mathrm{p}$ on $\mathrm{I} 1 / 2 \mathrm{p}$ violet, black surcharge c. PFiNY.

$471 / 2 \mathrm{p}$ on $\mathrm{I} 1 / 2 \mathrm{p}$ violet, black surcharge

d. With one additional line in ink across the original value, the printed ones being placed either too high or too low.

$48 \quad 1 / 2 \mathrm{p}$ on $\mathrm{I} 1 / 2 \mathrm{p}$ violet, black surcharge e. Same as "d" and PFNNY instead of PENNY.

$49 \quad 1 / 2 \mathrm{p}$ on $\mathrm{I} 1 / 2 \mathrm{p}$ violet, black surcharge

f. Same as "c" but surcharge inverted.

$50 \quad \mathrm{I} / 2 \mathrm{p}$ on $\mathrm{I} 1 / 2 \mathrm{p}$ violet, black surcharge

II. Original value obliterated by two black lines of equal thickness not close together.

Perforated I4.

5 I $\quad 1 / 2 \mathrm{p}$ on I $1 / 2 \mathrm{p}$ violet, black surcharge 


\section{Varieties:}

a. With two additional lines close together over the value, the two others being below the value.

$521 / 2 \mathrm{p}$ on $\mathrm{I} / 2 \mathrm{p}$ violet, black surcharge b. With additional lines in ink across the original value, the printed ones being placed too high or too low.

$531 / 2 \mathrm{p}$ on I $1 / 2 \mathrm{p}$ violet, black surcharge

III. Original value obliterated by two lines-a thick one and a thin one-the thin one above the thick one.

Perforated I4.

$541 / 2 \mathrm{p}$ on $\mathrm{I} / 2 \mathrm{p}$ violet, black surcharge

Varieties:

a. With additional line in ink across the original value, the printed one being placed either too high or too low.

$55 \mathrm{I} / 2 \mathrm{p}$ on I $1 / 2 \mathrm{p}$ violet, black surcharge

b. With two additional lines in ink, the printed ones being placed either too high or too low.

$56 \quad 1 / 2 \mathrm{p}$ on I $1 / 2 \mathrm{p}$ violet, black surcharge

IV. Same as III, but the thick line is above the thin one.

$57 \quad \mathrm{I} / 2 \mathrm{p}$ on $\mathrm{I} / 2 \mathrm{p}$ violet, black surcharge

V. Original value obliterated by one thick line.

$58 \mathrm{I} / 2 \mathrm{p}$ on I $1 / 2 \mathrm{p}$ violet, black surcharge

Varieties.

a. PFNNY instead of PENNY.

$59 \quad \mathrm{I} / 2 \mathrm{P}$ on $\mathrm{I} \mathrm{I} / 2 \mathrm{P}$ violet, black surcharge

b. Single thick line across upper and lower labels.

$60 \quad 1 / 2 \mathrm{p}$ on $\mathrm{I} / 2 \mathrm{p}$ violet, black surcharge

c. Same as "b" and PFNNY instead of PENNY.

6I $1 / 2 \mathrm{p}$ on $\mathrm{I} 1 / 2 \mathrm{p}$ violet, black surcharge

The so-called errors HAIF, HALP, etc. are merely caused by defective printing and are not errors of setting.

End of 1895 .

Same type, impression and paper as 6 penny stamps of preceding issues.

Watermarked Crown and CC.

Perforated I4

$626 \mathrm{p}$ red violet

I 896 .

Typographed on white wove paper; the name of the colony and the denomination of value are printed in a different color from the remainder of the stamp which is lilac for the penny values and green for the shilling stamps; the $I f$ stamp is printed in one color on colored paper; on the penny values the tablet containing the figures of value has a lined background. Size, I $81 / 2 \times 221 / 2 \mathrm{~mm}$.

Watermarked Crown and CA.

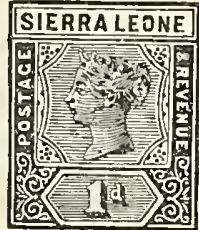

Perforated I4.

63 Ip lilac and rose

$642 \mathrm{p}$ lilac and orange

$652 / 2 \mathrm{p}$ lilac and blue

$665 \mathrm{p}$ lilac and gray

67 Ish green and black

68 2sh green and ultramarine
$69 \quad 5$ sh green and carmine

7o $\quad$ \& brown on red

Beginning of 1897 .

Provisional issue.

I. One penny Revenue Stamps surcharged "Postage and Revenue" in black. Size, $22 \mathrm{r} / 2 \times 38 \mathrm{r} / 2 \mathrm{~mm}$

Watermarked Crown and CA.

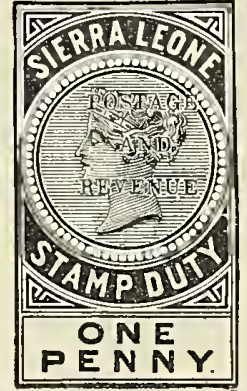

Perforated I4

7 I I lilac and green, black surcharge

II. 3 and 6 penny Revenue stamps surcharged "Postage and Revenue" and " $21 / 2 \mathrm{~d}$ " in black, the original value being obliterated by 6 black lines.

There are three types of this surcharge as per illustrations below.

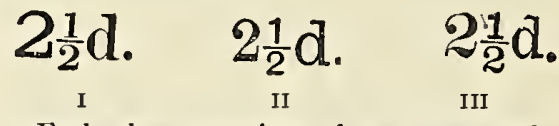

Each sheet collsists of 30 stamps, the various types being made up as follows:

22 stamps of type I.

5 stamps of type II.

3 stamps of type III.

Arranged as per following diagram.

\begin{tabular}{l|l|l|l|l|l|l|l|l|l|} 
I & I & I & I & I & I & I & I & I & I \\
\hline I & I & I & I & I & I & I & I & I & I \\
\hline
\end{tabular}

\begin{tabular}{l|l|l|l|l|l|l|l|l|l|} 
& 2
\end{tabular}

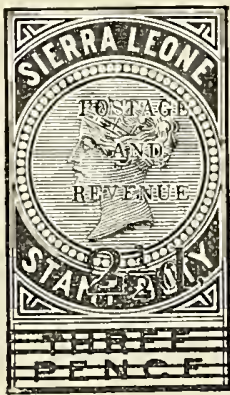

Watermarked Crown and CA

Perforated I4.

$722 \frac{1}{2} \mathrm{p}$ on $3 \mathrm{p}$ lilac and green, black surcharge, type I

$732 \frac{1}{2} \mathrm{p}$ on $3 p$ lilac and green, black surcharge, type II

$742 \frac{1}{2} \mathrm{p}$ on $3 \mathrm{p}$ lilac and green, black sur charge, type III

$752 \frac{1}{2} \mathrm{p}$ on $6 \mathrm{p}$ lilac and green, black surcharge, type I

$7621 / 2 \mathrm{p}$ on $6 \mathrm{p}$ lilac and green, black surcharge, type II

$772 \frac{1}{2} \mathrm{p}$ on $6 \mathrm{p}$ lilac and green, black surcharge, type III 
REVENUES USED FOR POSTAGE.

I 887.

A. Typographed on white wove paper, the denomination of value in lower label is printed in green; size $22 \mathrm{I} / 2 \times 38 \mathrm{r} / 2 \mathrm{~mm}$.

Watermarked Crown and CA.

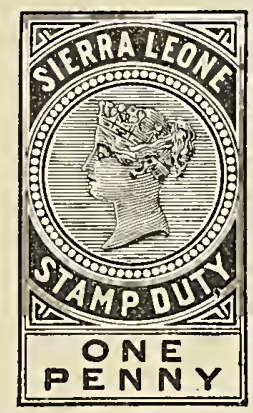

Perforated I4.

$$
\begin{aligned}
& 201 \quad \text { Ip lilac and green } \\
& 202 \quad 3 p \text { lilac and green }
\end{aligned}
$$

B. Same type as postage stamps of corresponding date surcharged "REVENUE;" the I, $3 p$ and Ish have the denomination of value printed respectively in carmine, red brown and blue; the word "PostAGE" is obliterated by a black line.

\section{REGISTRATION ENVELOPES.}

I894.

Stamp embossed on flap on linen lined envelope.

$I^{\circ}$ Size $132 \times 88 \mathrm{~mm}$.

$501 \quad 2 p$ ultramarine

$2^{\circ}$ Size $150 \times 90 \mathrm{~mm}$

$502 \quad 2 p$ ultramarine

$3^{\circ}$ Size $227 \times$ roomm.

$5032 p$ ultramarine

\section{COUNTERFEITS.}

I. Unwatermarked.

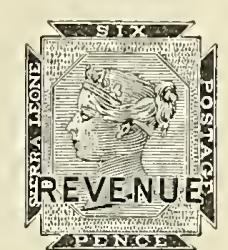

$36 \mathrm{p} \mathrm{lilac}$, black surcharge

II. Watermarked Crown and CC.

Perforated $\mathrm{I} 4$.

2046 p lilac, black surcharge

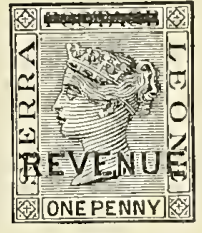

III. Watermarked Crown and CA.

Perforated 14 .
205
3p lilac and red brown “" "“

We do not know of any good forgeries of the stamps of Sierra Leone

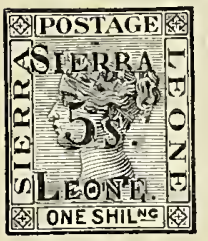

This illustration represents a stamp which is given in some catalogues as a provisional postage stamp, it is however only a revenue stamp which was never put into use.

\section{SOUTH AFRICAN REPUBLIC.}

Currency: $\mathrm{I} 2 \mathrm{PENCE}=\mathrm{I}$ SHILling, 20 SHILI.INGS $=\mathrm{I}$ POUND $(£ \mathrm{I})=\$ 4.87$ U. S. Currency.

\section{ADHESIVE STAMPS.}

\section{FIRST REPUBLIC.}

End of 1869.

Typographed on thin white wove paper. Printed in sheets of 80 stamps, from two plates of 40 stamps each. On the left hand plate of the 6 penny stamps the last stamp from the left, in the fourth horizontal row, is inverted, and in the left hand plate of the I shilling stamps the first stamp from the left in the first horizontal row is inverted. Size $2 \mathrm{I} 1 / 2 \times 241 / 2 \mathrm{~mm}$.

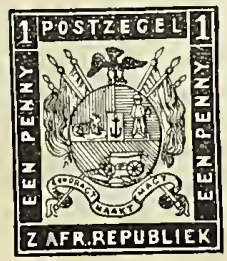

Mecklenburg print, clear impression.

Rouletted $151 / 2$.

I Ip red

2 Ip vermilion red

$36 \mathrm{p}$ blue

4 Ish green

Varieties :

a. Tête bềche.

$56 \mathrm{p}$ blue

6 Ish green

b. Imperforate.

7 Ip red

$6 \mathrm{p}$ blue

Ish green

c. Same as "b" Tête bêche.

Io $6 \mathrm{p}$ blue

I Ish green 
These stamps were printed in Gustrow, Mecklenburg-Schwerin and were received in Pretoria in August, I869. They were to have been issued to the public on January Ist, 1870. Meanwhile, the European dealers sent orders for these stamps, and the entire supply was exhausted before the Ist of January. As the plates had not reached the South African Republic at this time, and arrived there only about the month of February, I870, the issue was postponed until May Ist, and new stamps were printed in Pretoria by the Treasurer General of the Republic himself.

We have never seen any of the imperforates but catalogue them on the authority of Messrs. Moens, Tamsen and others.

Reprints.

There are no reprints of the stamps of this issue, the so-called reprints being merely for. geries made by Adolf Otto, the Gustrow printer. These forgeries have the frame exactly like the genuine, duplicates of the frames having been kept by the printer, but the center piece is a downright forgery and differs from the genuine in the following points: In the gemuine, the flagstaff at the right of the eagle consists of a single thick line, whereas in the forgery it is formed of two thin lines In the genuine, the flagstaff never touches the oval containing the arms; in the counterfeits it usually touches, In the genuine, the horizontal lines in the upper right portion of the oval generally touch the vertical line dividing the left compartment from the right one. In the counterfeits, these horizontal lines seldom touch the vertical one. In the genuine, neither of the staves crossing the bandrol inscribed "Eendragt maakt Magt" touches the oval containing the arms, except in very blurred specimens. In the counterfeits, at least one of these staves always touches the oval. In the genuine, the outsides of the fukes form a continuous line with the arms of the anchor, while in the counterfeits they are arrow shaped. In all the genuine stamps seen by us there are two thin white diagonal scratches in the lower half of the oval containing the coat of arms, a trifle to the left of the prairie wagon; these scratches are specially plain in the 6 penny stamps. In the local issue these scratches do not always show on aciount of the blurred printing.

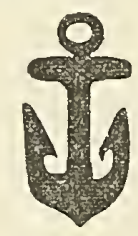

ORIGINAL.

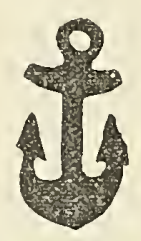

COUNTERFEIT.
May Ist to September, I87o.

Same type as preceding issue. Typographed on white wove paper.

Local (Pretoria) print-Coarse impression.

I. Thin white wove paper, varying in texture.

$I^{\circ}$ Imperforate.

Ip carmine red

Ip red

$6 \mathrm{p}$ ultramarine

$6 \mathrm{p}$ indigo

Ish green
Varieties: Tête bêche.

I7 6p ultramarine

I $6 \mathrm{p}$ indigo

I9 Ish green

$2^{\circ}$ Rouletted I5 $1 / 2$. Ip red

Ip carmine red

$6 \mathrm{p}$ ultramarine

Ish green

Varieties: Tête bêche.

$246 \mathrm{p}$ ultramarine

25 Ish green

II. Thick hard yellowish white wove paper, varying in texture.

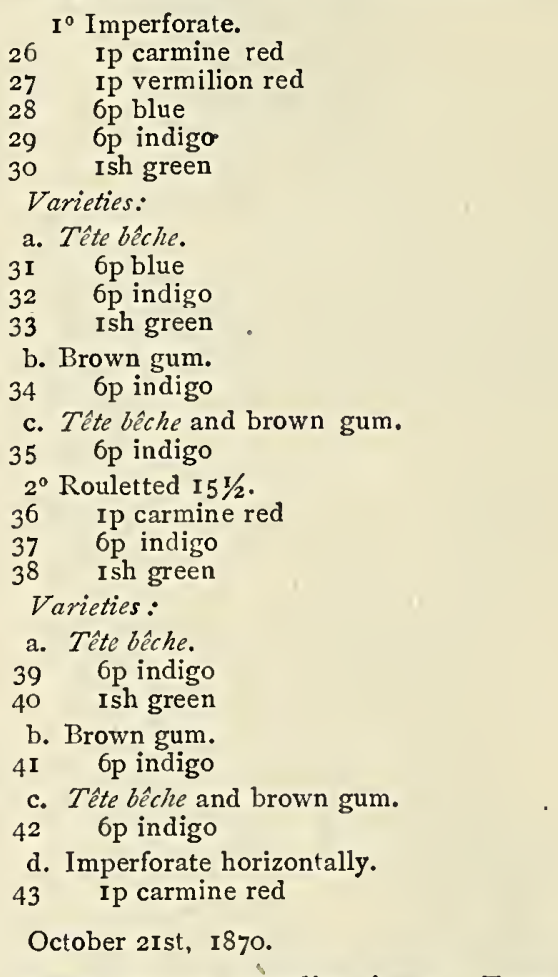

Same type as preceding issue. Typographed on thin or thick white or yellowish white wove paper.

Printed in Potchefstrooom-medium impression.

I. Soft porous white wove paper.

I $^{\circ}$ Imperforate.

44 Ip intense black

45 Ip gray black

$2^{\circ}$ Rouletted $15 \mathrm{I} / 2$.

46 Ip intense black

47 Ip gray black

II. Soft porous yellowish white wove paper.

$I^{\circ}$ Imperforate.

48 Ip intense black

49 I

$2^{\circ}$ Rouletted I5 $1 / 2$.

50 Ip intense black

5 I Ip gray black

III. Thin white wove paper.

I $^{\circ}$ Imperforate.

52 Ip intense black

53 Ip gray black 


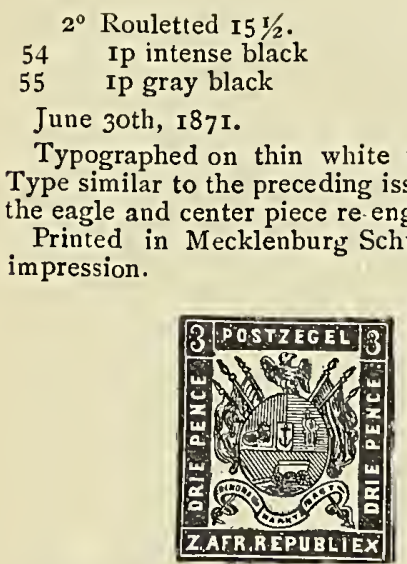

Rouletted $\mathbf{I}_{5} \mathrm{I} / 2$.

$56 \quad 3 p$ lilac

Reprints.

187 (?).

I. Thin white wove paper.

$1^{\circ}$ Imperforate.

$573 p$ red violet

$58 \quad 3 p$ gray lilac

$593 p$ red lilac

20 Rouletted $15 \mathrm{r} / 2$.

603 3p red violet

613 s gray lilac

$623 p$ red lilac

II. Ordinary white wove paper.

$1^{\circ}$ Imperforate.

$6.33 p$ red violet

$643 p$ red lilac

20 Rouletted $15 \mathrm{r} / 2$.

$653 p$ red violet

66 .3p red lilac

III. Yellowish wove paper.

$1^{\circ}$ Imperforate.

67 3p rea violet

20 Rouletted $15 \mathrm{I} / 2$.

$683 p$ red violet

It is very difficult to distinguish these reprints from the originals. The color of the orioinals is a cold bluish lilac without any reddish tint, while the reprints have either a reddish or a grayish tint. The reprints are either on thinner or on thicker paper than the originals, that is to say, the impression showes very plainly on the back or reverse of the stamp, or not at all, while in the originals the impression shows on the back, but not so clearly as on the reprints.

July, I87I to I874.

Same type as corresponding values of preceding issues. Typographed on white or yellowish white wove paper. Printed in Potchefstroom. Medium impression.

I. Thin white wove paper.

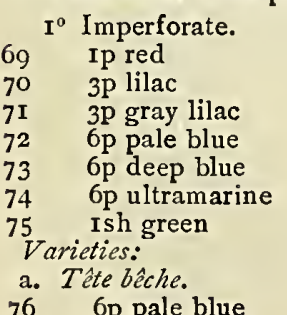

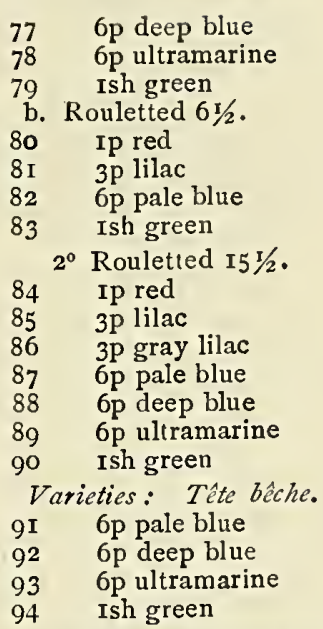

II. Ordinary white wove paper.

$I^{\circ}$ Imperforate.

95 Ip red

$96 \quad 6 \mathrm{p}$ blue

$97 \quad 6 \mathrm{p}$ dull blue

98 Ish green

Varieties : Téte-bêche.

I00 $6 \mathrm{p}$ blue

IOI $6 \mathrm{p}$ dull blue

I02 $6 \mathrm{p}$ indigo

I03 Ish green

$2^{\circ}$ Rouletted I5 $5 / 2$.

IO4 Ip red

I05 $6 \mathrm{p}$ ultramarine

I06 6p blue

I07 $6 \mathrm{p}$ indigo

I08 Ish green

Varieties:

a. Tête-bếche.

Iog 6p ultramarine

IIO $6 \mathrm{p}$ blue

III $6 \mathrm{p}$ indigo

II 2 Ish green

b. Rouletted $6 \mathrm{I} / 2$.

II 3 IP red

II4 $6 \mathrm{p}$ blue

II5 Ish green

III. Yellowish white wove paper.

$I^{\circ}$ Imperforate.

I $16 \quad 6 \mathrm{p}$ blue

Variety: Tête bêche.

I $76 \mathrm{p}$ blu

$2^{\circ}$ Rouletted I $5 \mathrm{I} / 2$.

I $86 \mathrm{p}$ blue

I 19 6p indigo

Varieties : Tête bêche.

I20 $6 \mathrm{p}$ blue

I2I $6 \mathrm{p}$ indigo

September, 1874 .

Same type as preceding issue, typographed on thin yellowish white wove paper. Printed in Natal ; fair impression.

Perforated $12 \mathrm{r} / 2$.

I22 Ip vermilion red

I23 Ip carmine red

I24 6p light blue

I $256 \mathrm{p}$ blue

$126 \quad 6 \mathrm{p}$ indigo

Varieties:

a. Tête bếche.

$1276 \mathrm{p} \mathrm{light} \mathrm{blue}$

128 6p blue

I29 $6 \mathrm{p}$ in digo 
b. Imperforate vertically.

I30 $6 \mathrm{p}$ blue

October Ist, 1874 .

Same type as issue of June 3oth, I87I.

Typographed on thin white wove paper.

Printed in Mecklenburg-Schwerin ; clear impression.

Rouletted $151 / 2$.

I3I 6p pale ultramarine

Reprints.

187 (?).

Thin white wove paper.

Rouletted $15 \mathrm{1} / 2$.

133 6p blue

It is very difficult to distinguish the reprints from the originals. The orisinals are all printed in pale ultramarine while the reprints, when not printed in the reguilar blue, are in a dull chalky or milky blue. The paper of the reprints is thinner and more transparent and the impression is generally more blurred, especially so in the flags and eagle.

I 875 .

Same type as preceding issue, the 6 penny stamp being of the same type as the I penny. Typographed on pelure paper. Printed in Potchefstroom.

I0 Imperforate.

Ip red

$3 \mathrm{p}$ violet

6p pale biue

$6 \mathrm{p}$ indigo

Varieties:

a. Tête bếche.

I38 6p pale blue

$1396 \mathrm{p}$ indigo

b. Pin perforated (unofficial).

I40 Ip red

I4 I $6 \mathrm{p}$ pale blue

$1426 \mathrm{p}$ indigo

c. Same as "b" but Tête bîche.

I43 6p pale blue
132 6p chalky blue

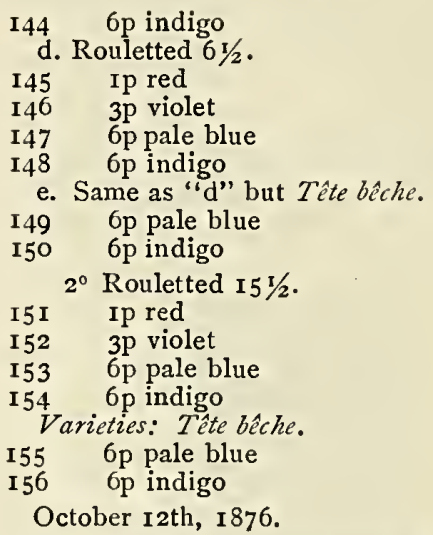

Same type as preceding issue, typographed on thick hard white wove paper, slightly glazed.

$I^{\circ}$ Imperforate.

I 57 Ip vermilion red

$2^{\circ}$ Rouletted $15 \%$.

I58 Ip vermilion red

May (?) 1877 .

Same type as preceding issue, typographed on soft porous white wove paper.

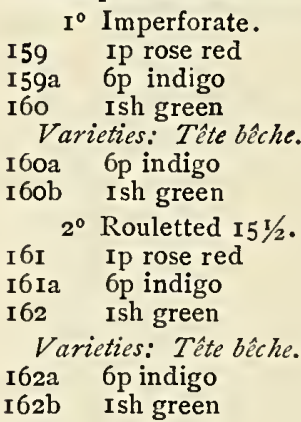

BRITISH OCCUPANCY.

May to July, I877.

Provisional issue.

A. 3 penny stamps of the 1875 issue (pelure

V. R.

paper) surcharged in red

TRANSVAAL.

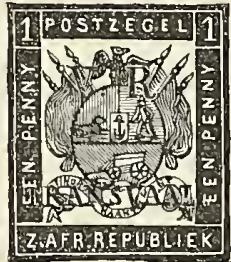

Imperforate.

$163.3 p$ lilac, red surcharge

Varieties:

a. Surcharge printed on the back, instead of on the face of the stamp.

I64 3p lilac, red surcharge

b. Rouletted $61 / 2$

I65 3p lilac, red surcharge

B. Same type as preceding issue. Typographed on soft porous white wove paper and surcharged in red "v. R. TRANSVAAL."

$I^{0}$ Imperforate.

I66 3p lilac, red surcharge
I67 6p blue, red surcharge
I68 6p dark blue "،

I69 Ish green

Varieties :

I70 $3 p$ lilac, red surcharge

I7I 6p blue "“ "

I 72 Ish green"

b. The first and second lines of the surcharge $4 \frac{1}{2} \mathrm{~mm}$. wider a part.

$1733 \mathrm{p}$ lilac, red surcharge

c. Surcharge inverted.

I74 $6 \mathrm{p}$ blue, red surcharge

I 75 Ish green " " "

d. Tête bếche.

I76 6p blue, red surcharge

I77 6p dark blue “" “

178 Ish green “" ،

$796 \mathrm{p}$ green, red surcharge (half of Ish)

f. Vertical half of Ish used as $6 p$.

I $806 p$ green, red surcharge (half of Ish)

$2^{\circ}$ Rouletted I5 $1 / 2$

I8I 3p lilac, red surcharge

$1826 \mathrm{p}$ blue "“ "

183 6p dark blue “" “

$184 \quad$ Ish green

Varieties:

a. Surcharge inverted.

I85 6p blue, red surcharge

I 86 Ish green" a. Rouletted $6 / 2 / 2$. 
b. Tête bềche.

I87 6p blue,

I88 6p dark blue red surcharge

I89 Ish green

c. The first and second lines of the surcharge $4 \frac{1}{2} \mathrm{~mm}$. wider apart.

I9o $3 p$ lilac, red surcharge

d. Diagonal half of Ish used as 6p.

I9I 6p green, red surcharge (half of Ish)

C. Same as B, but surcharged in black.

I. Pelure paper.

$\mathrm{I}^{\circ}$ Imperforate.

I92 Ip red, black surcharge

$2^{\circ}$ Rouletted I5 $1 / 2$.

I93 Ip red, black surcharge

II. Soft porous white wove paper.

$I^{\circ}$ Imperforate.

I94 Ip red, black surcharge

I95 3p lilac “" “"

I96 6p blue blue “، “.

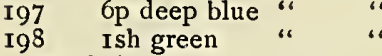

Varieties:

a. Diagonal half of $\mathrm{ish}$ used as $6 \mathrm{p}$.

I99 6p green, black surcharge (half of Ish)

b. Surcharge inverted.

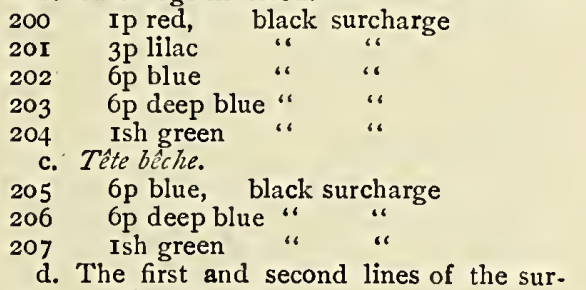

charge $4 \frac{1}{2} \mathrm{~mm}$. wider apart.

\begin{tabular}{|c|c|c|}
\hline $208^{\circ}$ & Ip red, & black surcharge \\
\hline 209 & $6 \mathrm{p}$ blue & " " \\
\hline 210 & $6 \mathrm{p}$ deep blue & “ \\
\hline & Ish green & " " " \\
\hline e. & Same as "d" & Tête bêche. \\
\hline 12 & 6p blue, bla & ack surcharge \\
\hline I3 & 6 p deep blue " & " \\
\hline I4 & Ish green “ & “" \\
\hline
\end{tabular}

f. Same as "d" but surcharge inverted.

215 6p blue, black surcharge

216 6p deep blue “"

2 I7 6p blue, black surcharge

h. Rouletted $61 / 2$.

2 I 8 Ip red, black surcharge

2 I9 3p lilac “" “"

220 Ish green "

i. No period after TRANSVAal.

22I Ish green, black surcharge

j. No period after " $R$ " of $V$, $R$.

222 Ip red, black surcharge

k. TRANSAAAL (with $\mathrm{V}$ inverted).

223 Ip carmine red, black surcharge

2 Rouletted I $51 / 2$

224 Ip red, black surcharge

$\begin{array}{lll}225 & 3 p \text { lilac } \\ 226 & 6 \mathrm{p} \text { blue } & \text { “. }\end{array}$

227 Ish green " "

Varieties:

a. Surcharge inverted.

228 IP red, black surcharge

229 3p lilac "“ "“

$230 \quad 6 p$ blue “" “"

b. Tête bếche.

$2326 \mathrm{p}$ blue, black surcharge

233 Ish green "“ "“

c. The first and second lines of the sur-

charge $41 / 2 \mathrm{~mm}$. wider apart.

234 Ip red, black surcharge

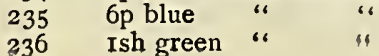

d. Same as "c" but Tête bêche.

$2376 \mathrm{p}$ blue, black surcharge

238 Ish green " "

III. Thick hard white wove paper.

I' Imperforate.

239 Ip carmine red, black surcharge

240 Ip vermilion red "

Varieties:

a. Surcharge inverted.

24I Ip carmine red, black surcharge

242 Ip vermilion red

b. The first and second lines of the sur-

charge $4 \mathrm{~T} / 2 \mathrm{~mm}$. wider apart.

243 Ip carmine red, black surcharge

$2+4$ Ip vermilion red "“

c. Rouletted $61 / 2$

245 Ip carmine red, black surcharge

d. No period after " $R$ " of $V$. $R$.

246 Ip carmine red, black surcharge

247 Ip vermilion red

e. TRANSAAAL ( $v$ inverled).

248 Ip carmine red, black surcharge

249 Ip vermilion red "

$2^{\circ}$ Rouletted I5 $1 / 2$

250 Ip vermilion red, black surcharge

Varieties:

a. Surcharge inverted.

25I Ip vermilion red, black surcharge

b. The first and second lines of the sur-

charge $4 \frac{1}{2} \mathrm{~mm}$. wider apart.

252 Ip vermilion red, black surcharge

August 3Ist, I 877.

Provisional issue.

Same type as the 6 penny stamps of the issue of 1875 . Typographed on thick colored wove paper and surcharged in black " $v$. R. TRANSVAAL," as in the preceding issue.

I' Imperforate.

$2536 \mathrm{p}$ blue on rose, black surcharge

253 a 6p indigo on rose "

Varieties:

a. Tête bềche.

$2546 \mathrm{p}$ blue on rose, black surcharge

6p indigo one, bla

b. Surcharge inverted.

$2556 \mathrm{p}$ blue on rose, black surcharge

c. Without surcharge.

$256 \quad 6 \mathrm{p}$ blue on rose

d. Diagonal half of $6 \mathrm{p}$ used as $3 \mathrm{p}$

$2573 \mathrm{p}$ blue on rose, black surcharge (half of $6 \mathrm{p}$ )

e. Rouletted $6 y / 2$.

$2586 \mathrm{p}$ blue on rose, black surcharge $2^{\circ}$ Rouletted I5 512

$2596 \mathrm{p}$ blue on rose, black surcharge

Varieties:

a. Tête bếche.

260 $6 \mathrm{p}$ blue on rose, black surcharge

b. Surcharge inverted.

26I $6 \mathrm{p}$ blue on rose, black surcharge

October and December, 1877.

Provisional issue.

Same types as the corresponding values of the I87I issue. Typographed on thick colored wove paper and surcharged in black V. R.

\section{Transvaal}

$I^{\circ}$ Imperforate.

262 Ip red on blue, black surcharge

2633 p lilac on buff "“ "“

264 6p blue on green “" “

Varieties:

a. Transvral ( $r$ instead of a).

265 Ip red on blue, black surcharge 
b. No period after "v".

266 Ip red on blue, black surcharge

c. No period after " $R$ ".

267 Ip red on blue, black surcharge

d. Surcharge inverted.

268 Ip red on blue, black surcharge

2693 p lilac on buff " " "

$2706 \mathrm{p}$ blue on green " "

e. Tête bếche.

$2716 \mathrm{p}$ blue on green, black surcharge

f. Two periods between " $V$, and

none after " $R$ ".

272 Ip red on blue, black surcharge

273 3p blue on green "“

g. Diagonal half of $6 \mathrm{p}$ stamp used as 3 pence.

$2743 p$ blue on green, black surcharge (half of $6 \mathrm{p}$ )

h. Rouletted $61 / 2$.

275 3p lilac on buff, black surcharge

$2^{\circ}$ Rouletted I $5 \mathrm{r}$

Ip red on blue, black surcharge

3p lilac on buff "“ “"

Varicties:

a. Transvral ( $r$ instead of a).

280 Ip red on blue, black surcharge

b. No period after " $v$ ".

28 I Ip red on blue, black surcharge

c. No period after " $R$ ".

282 Ip red on blue, black surcharge

d. Surcharge inverted.

283 Ip red on blue, black surcharge

284 3p lilac.on buff "“ ‘

$2856 \mathrm{p}$ blue on green "

e. Tête bêche.

$286 \quad 6 \mathrm{p}$ blue on green, black surcharge

$f$. Two periods between " $v$ " and " $R$ " and none after "R".

287 Ip red on blue, black surcharge

$2886 \mathrm{p}$ blue on green "

g. Unsurcharged.

2896 blue on green

h. Diagonal half of $6 \mathrm{p}$ stamp used as 3 pence.

$2903 p$ blue on green, black surcharge (half of $6 \mathrm{p}$ )

January I 8 th and March 22d, I878.

Provisional issue.

Same type, paper, impression and surcharge as preceding issue.

I0 Imperforate.

29 I Ip red on orange, black surcharge (January)

2926 p blue on blue, black surcharge

Varieties. (March)

a. No period after " $v$ ".

293 Ip red on orange, black surcharge

b. No period after " $R$ ".

294 Ip red on orange, black surcharge

c. No period after either " $V$ " or " $R$ ".

295 Ip red on orange, black surcharge

d. Two periods between " $V$ " and " $R$ " but

none after " $R$ ".

296 Ip red on orange, black surcharge

$2076 \mathrm{p}$ blue

e. Tête bêche.

$2986 \mathrm{p}$ blue on blue, black surcharge

f. Surcharge inverted.

$2096 \mathrm{p}$ blue on blue, black surcharge

g. Diagonal half of $6 \mathrm{p}$ used as 3 pence. $300 \quad 3 \mathrm{p}$ blue on blue, black surcharge

h. Without surcharge.

$3016 \mathrm{p}$ blue on blue i. Rouletted $61 / 2$.

302 Ip red on orange, black surcharge

$3036 \mathrm{p}$ blue on blue

$2^{\circ}$ Rouletted I $51 / 2$.

304 Ip red on orange, black surcharge

$3056 \mathrm{p}$ blue on blue

$\checkmark$ arieties :

a. No period after " $v$ ".

306 Ip red on orange, black surcharge

b. No period after " $R$ ".

307 Ip red on orange, black surcharge

c. No period after " $V$ " or " $R$ ".

308 Ip red on orange, black surcharge

d. Two periods between " $V$ " and " $R$ "

and none after " $R$ ".

309 Ip red on orange, black surcharge

310 $6 \mathrm{p}$ blue on blue

e. Tête bêche.

3 I $6 \mathrm{p}$ blue on blue, black surcharge

f. Surcharge inverted.

3 I $6 \mathrm{p}$ blue on blue, black surcharge

g. Without surcharge.

$3136 \mathrm{p}$ blue on blue

h. Imperforate vertically.

31 4 6p blue on blue, black surcharge

i. Diagonal half of $6 p$ used as 3 pence.

3 I5 3p blue on blue, black surcharge (half of 6p)

April $\mathrm{r}_{5}$ th and May $\mathrm{r} 3 \mathrm{th}, \mathrm{I} 878$.

Provisional issue.

Same as preceding issue, but on 27 stamps of the left pane the "V. R." is in slanting capitals (italics), instead of straight capilals.

\section{V. $R$.}

Transvaal

$\mathrm{I}^{\circ}$ Imperforate.

316 Ip red on orange, black surcharge (April 15 th)

$3173 p$ lilac on buff, black surcharge (April I5th)

3 I $6 \mathrm{p}$ blue on blue, black surcharge

$\checkmark$ arieties : (May I 3 th)

a. No period after " $R$ ".

3I9 Ip red on orange, black surcharge b. Tête bêche.

$3206 \mathrm{p}$ blue on blue, black surcharge

c. Surcharge inverted.

32I $6 \mathrm{p}$ blue on blue, black surcharge

d. Rouletted $6 \mathrm{r} / 2$.

322 Ip red on orange, black surcharge

3233 lilac on buff

$3246 \mathrm{p}$ blue on blue

e. Unsurcharged.

$3256 \mathrm{p}$ blue on blue

$2^{\circ}$ Rouletted I $5 \mathrm{I} / 2$.

326 Ip red on orange, black surcharge

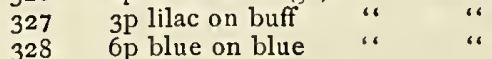

Varieties :

a. No period after " $R$ ",

329 Ip red on orange, black surcharge b. Tête bêche.

$3306 \mathrm{p}$ blue on blue, black surcharge

c. Surcharge inverted.

33I $6 \mathrm{p}$ blue on blue, black surcharge

d. Imperforate vertically.

33 I a Ip red on orange, black surcharge

e. Imperforate horizontally.

$3323 p$ lilac on buff, black surcharge

f. Unsurcharged.

$332 \mathrm{a} 6 \mathrm{p}$ blue on blue 
August 26th to November 25th, 1878.

Typographed (portrait of Queen Victoria) on grayish white wove paper. Size $18 \mathrm{I} / 2 \mathrm{x}$ $231 / 2 \mathrm{~mm}$.

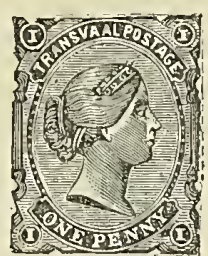

Perforated I4.

333 Ip red biown (August 26th)

333 a 3p claret (November 25th)

334 4P olive green (August 26th)

335 6p slate (November 25 th

336 Ish green (November $25, \mathrm{~h}$ )

$337 \quad 2$ sh blue

The sheets of these stamps have no outside perforations.

April I8th, I879.

Provisional issue.

Same type, paper, impression and surcharge as provisional issue of April I5th, 1878 .

A. Straight "v, R."

$I^{\circ}$ Imperforate.

338 3p lilac on green, black surcharge Varieties:

a. Inverted surcharge.

3393 lilac on green, black surcharge b. Without surcharge.

$3403 p$ lilac on green

c. "Transvaal" above, "v. R." below.

$34 \mathrm{I} 3 \mathrm{p}$ lilac on green, black surcharge

d. Period after " $R$ " inverted.

$3423 p$ lilac on green, black surcharge

e. Periods after " $V$ " and " $R$ " inverted.

$3433 p$ lilac on green, black surcharge

f. Rouletted $61 / 2$.

$3443 p$ lilac on green, black surcharge

$2^{\circ}$ Rouletted $151 / 2$.

345 3p lilac on green, black surcharge

Varieties :

a. Surcharge inverted.

$3463 p$ lilac on green, black surcharge

b. Period after " $R$ " inverted.

$3473 p$ lilac on green, black surcharge

c. Periods after " $V$ " and " $R$ " inverted.

$34^{8} 3 \mathrm{p}$ lilac on green, black surcharge

B. Slanting "v, R."

$I^{\circ}$ Imperforate.

$3493 \mathrm{p}$ lilac on green, black surcharge

Varieties:

a. Surcharge inverted.

$3503 p$ lilac on green, black surcharge

b. "Transvaal" above and "V. R." below.

$35 \mathrm{I} 3 \mathrm{p}$ lilac on green, black surcharge

c. Rouletted $61 / 2$.

$3523 \mathrm{p}$ lilac on green, black surcharge

d. Pair, one with "v. R." slanting and the

other with "v. R." straight.

$3533 \mathrm{p}$ lilac on green, black surcharge

e. Unsurcharged.

$353 \mathrm{a} 3 \mathrm{p}$ lilac on green

$2^{\circ}$ Rouletted $15 \%$.

$3543 p$ lilac on green, black surcharge

Varieties:

a. Surcharge inverted.

$3553 p$ lilac on green, black surcharge

b. Unsurcharged.

$355^{2} 3 \mathrm{p}$ lilac on green

c. Pair, one with "V.R." slanting and the

other with " v. R." straight.

$356 \quad 3 p$ lilac on green, black surcharge
April 22d, I879.

Provisional issue.

6 penny slamps of the issue of November 25 th, 1878, surcharged with new value in black or red, There are seven types of this surcharge, six of which we illustrate, the other one being only a sub-variety of type II in which the curved end of the $\mathrm{Y}$ is missing.

\section{Penny 1 Penny 1 Penny}

I.

II.

IV.

\section{Penny 1 Penny ern Penne}

$\mathrm{v}$.

vi

vir.

The following diagram shows how these seven types were arranged on the sheet.

\begin{tabular}{|l|l|l|l|l|l|l|l|l|l|l|}
\hline 2 & 2 & 2 & 2 & 2 & 2 & I & I & I & I \\
\hline 2 & 2 & 2 & 2 & 2 & 3 & 3 & 2 & 4 & 4 & 4 \\
\hline 5 & 5 & 5 & 5 & 5 & 5 & 5 & 5 & 5 & 5 & 5 \\
\hline 7 & 7 & 7 & 7 & 7 & 6 & 6 & 6 & 6 & 6 \\
\hline 7 & 7 & 7 & 7 & 7 & 7 & 7 & 7 & 7 & 7 \\
\hline 7 & 7 & 7 & 7 & 7 & 7 & 7 & 7 & 7 & 7 \\
\hline
\end{tabular}

Thus giving :

\begin{tabular}{|c|c|c|}
\hline \multicolumn{3}{|c|}{4 stamps of type 1} \\
\hline I & 64 & " \\
\hline & " & \\
\hline 3 & " & $\because 4$ \\
\hline IO & “" & $\because 6$ \\
\hline & “ & \\
\hline
\end{tabular}

Perforated I4.

A. Black surcharge.

357 Ip on $6 \mathrm{p}$ slate, black surcharge, type I

$357 \mathrm{a}$ Ip on 6p slate " " " "

358 Ip on 6p slate " " " " "

359 Ip on 6 slate “ $\quad$ “ $\quad$ “"

360 Ip on 6p slate " “ “ “" “5

361 Ip on 6p slate “" “ “ “ “

I arieties.

a. Surcharge inverted.

363 Ip on 6p slate, black surcharge, type I

364 Ip on 6p slate " " " "

365 Ip on 6p slate " " " " "

Ip on 6p slate " " 6 " 63

Ip on 6p slate "“

Ip on 6p slate “ " " "

Ip on 6p slate " " " "

b. Pair, one with surcharge type 4 , and the other without surcharge.

370 Ip on $6 p$ slate, black surcharge

B. Red surcharge.

37 I Ip on $6 \mathrm{p}$ slate, red surcharge, type $\mathrm{I}$

372 Ip on 6p slate " " " "

373 Ip on 6p slate "“ “ " " “

374 Ip on 6p slate “ “ “ “" “4

375 Ip on 6p slate “ $\quad$ “ 345

377 Ip on 6p slate " " "

Varieties: Surcharge inverted.

378 Ip on 6p slate, red surcharge, type $\mathbf{I}$

379 Ip on 6p slate " " " "

380 Ip on 6p slate “" “ " "

38 I IP on 6p slate “" “ “ “

382 Ip on 6p slate “" “ “ “

383 Ip on 6p slate " “ " "

384 Ip on 6p slate " " " "

August 26th to September 5th, I879.

Provisional issue.

Stamps of same type as provisional issue of April and May, 1878 , with v. R. in small capitals close together. Typographed on colored wove paper. 
V. R.

\section{Transvaal}

$I^{\circ}$ Imperforate.

385 Ip red on yellow, black surcharge

386 Ip red on orange, black surcharge (August 26th)

$3873 p$ lilac on green, black surcharge (September 5 th)

$3883 \mathrm{p}$ lilac on blue, black surcharge (September $5^{\text {th }}$ )

Varieties:

a. Rouletted $61 / 2$.

389 Ip red on yellow, black surcharge

390 Ip red on orange "، ".

391 3p lilac on green " " 392 " "

b. "Transvaal" with small capital " $\mathrm{T}$ "

placed above the line.

393 Ip red on yellow, black surcharge

394 Ip red on orange " " "

$\begin{array}{lll}395 & 3 \text { p lilac on green " " } \\ 396 & \text { 3p lilac on blue }\end{array}$ c. Same as "b" rouletted $6 x / 2$.

397 Ip red on yellow, black surcharge

398 Ip red on orange " " "

399 3P lilac on green “" ،

4003 p lilac on blue

$2^{\circ}$ Rouletted $\mathbf{I}_{5} \mathrm{x} / 2$.

40r Ip red on yellow, black surcharge

402 Ip red on orange " "

403
404 3p lilac on green " "

Variety: "Transvaal" with small capital " $T$ " placed above the line.

405 Ip red on yellow, black surcharge

406 Ip red on orange " " "

$4073 p$ lilac on green "، " "

$4083 \mathrm{p}$ lilac on blue

I880.

Same type as issue of November, 1878. Typographed on grayish white wove paper.

Perforated 14.

$409 \quad 1 / 2 \mathrm{p}$ vermilion

\section{SECOND REPUBLIC.}

August IIth, I882.

Provisional issue.

4 penny stamps of the issue of August, 1878, surcharged in bl ack DEN PENNY

Perforated 14.

4ro Ip on $4 \mathrm{p}$ olive green, black surcharge

$\checkmark$ ariety: Surcharge inverted.

4 I I $\mathrm{P}$ on $4 \mathrm{p}$ olive green, black surcharge

February 2oth to August 3oth, 1883.

Same type as corresponding values of the issue of July, I87I to I874. Typographed on white or colored wove paper.

A. Colored wove paper.

I 0 Perforated II $\mathrm{I} / 2$.

4123 black on lilac rose (Feb. 2oth)

$2^{\circ}$ Perforated 12.

$4133 \mathrm{p}$ black on lilac rose

$3^{\circ}$ Perforated II $1 / 2 \times I 2$.

$4 \mathrm{I}_{4} 3 \mathrm{p}$ black on lilac rose

Variety: Diagonal half used in connection with a 3 p stamp to make the 4 p rate.

4 I 5 Ip black on lilac rose (half of $3 p$ )

B. White wove paper.

I ${ }^{\circ}$ Perforated I I $1 / 2$.

4 I6 Ip black (April 5th)

$4 \mathrm{I} 7 \mathrm{3P}$ red (May 7 th)

4I8 Ish green (Aug. 3d)

lariety: Tête bếche.

4 I9 Ish green

$2^{\circ}$ Perforated 12.

420 Ip black

42 I $3 \mathrm{p}$ red

422 Ish green

Variety: Tête bêche.

423 Ish green

$3^{\circ}$ Perforated II $1 / 2 \times 12$,

424 Ip black

$4253 \mathrm{p} \mathrm{red}$

126 Ish green

Varieties :

a. Tête bêche.

427 Ish green

b. Imperforate.

428 Ip black

c. Imperforate horizontally.

429 Ip black d. Imperforate vertically.

430 Ip black

$43 \mathrm{I} \quad 3 \mathrm{p} \mathrm{red}$

e. Diagonal half of $3 \mathrm{p}$ used in connection with $3 p$ stamp to make the $4 p$ rate.

432 Ip red (half of $3 p$ )

f. Diagonal half of Ish stamp used as $6 \mathrm{p}$. $4336 \mathrm{p}$ green (half of $\mathrm{Ish}$ )

The sheets of the stamps of this issue have no outside perforation.

Reprints.

188 (?)

Perforated 12.

434 sp red

435 sp red on bright rose

The only way to distinguish the reprints from the originals is by the impression, which is generally heavier and more blurred in the originals than in the reprints. The so-called reprints of the one penny and one shilling stamps are merely counterfeits, and what we have said about the so-called reprnts of the first issue also applies to these. No six penny stamps of this issue exist, all of those offered being counterfeits of the same class as the Ip and 1 sh referred to above.

March, I885.

Typographed on white wove paper. Size I $8 \mathrm{r} / 2 \times 22 \mathrm{r} / 2 \mathrm{~mm}$

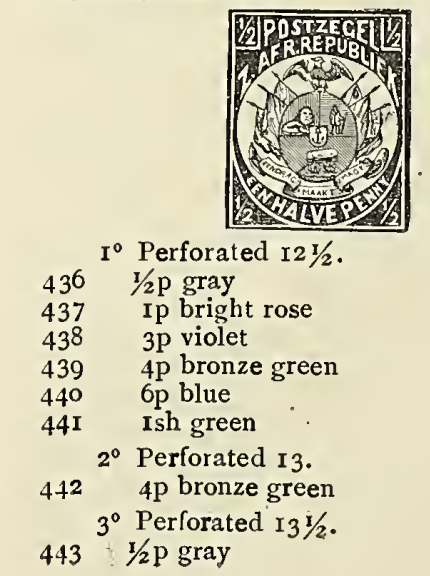




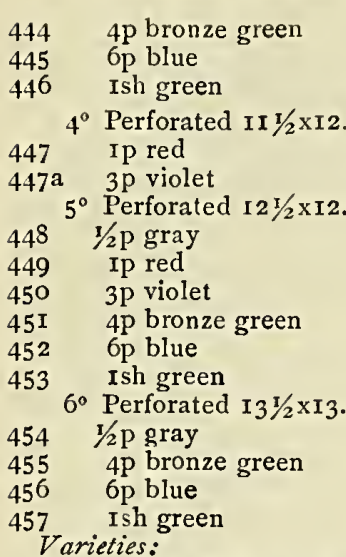

a. Diagonal half of three penny stamp used in connection with another three penny stamp to make up the $4 \mathrm{p}$ rate.

458 Ip violet (half of $3 p$ )

b, Imperforate.

$4596 \mathrm{p}$ blue

May and September, I 885

Provisional issue.

A. Three penny and one shilling stamps of the issue of May and August, I883, surcharged vertically in black "HALVE PENNY" between two parallel lines.

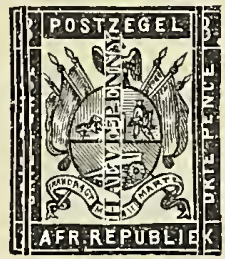

I. Surcharge reading upwards.

$\mathrm{I}^{\circ}$ Perforated II $\mathrm{x} / 2$

$460 \quad \mathrm{~T} / 2 \mathrm{p}$ on $3 \mathrm{p}$ red, black surcharge (May 22nd)

46I $1 / 2 \mathrm{p}$ on Ish green, black surcharge (September 3 rd)

Variety: Tête bêche.

$462 \pi$ t $2 \mathrm{p}$ on Ish green, black surcharge $2^{\circ}$ Perforated I2.

$463 \quad 1 / 2 \mathrm{p}$ on $3 \mathrm{p}$ red, black surcharge $3^{\circ}$ Perforated II $1 / 2 \times 12$

$464 \quad 1 / 2 \mathrm{p}$ on Ish green, black surcharge Variety: Tête bêche.

$4651 / 2 \mathrm{p}$ on Ish green, black surcharge

II. Surcharge reading downwards.

$I^{\circ}$ Perforated II $1 / 2$.

$466 \quad 1 / 2 \mathrm{p}$ on $3 \mathrm{p}$ red, black surcharge

$467 \quad 1 / 2 \mathrm{p}$ on Ish green, black surcharge

Variety: Tête bêche.

$468 \quad \mathrm{t} / 2 \mathrm{P}$ on Ish green, black surcharge $2^{\circ}$ Perforated 12

$469 \mathrm{r} / 2 \mathrm{p}$ on $3 \mathrm{p}$ red, black surcharge

B. Six penny stamps of the issue of 1878 surcharged vertically in red "TWEE PENCEz. A. R." (in two lines) between two parallel lines.

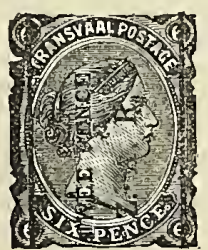

Perforated I4

$470 \quad 2 p$ on $6 \mathrm{p}$ black, red surcharge

Varieties :

a. Imperforate vertically.

$47 \mathrm{I} 2 \mathrm{p}$ on $6 \mathrm{p}$ black, red surcharge

b. Error-surcharged " HALVE PENNYz. A. R." and sold as twopenny stamps. $472 \quad 1 / 2 \mathrm{p}$ on $6 \mathrm{p}$ black, red surcharge

It is said that only 25 sheets were printed with this surcharge, all of these having been sold as twopenny stamps before the error was discovered and corrected.

September 28th, I885.

Provisional issue.

Three penny stamps of the issue of March, I885, surcharged in black vertically "HALVE PENNY" between two parallel lines, the surcharge reading downwards.

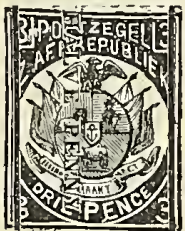

$I^{\circ}$ Perforated II $1 / 2 \times 12$

$473 \quad \mathrm{~T} / 2 \mathrm{p}$ on $3 \mathrm{p}$ violet, black surcharge

Varieties:

a. PRNNY, instead of PENNY.

$474 \quad 1 / 2 \mathrm{p}$ on $3 \mathrm{p}$ violet, black surcharge

b. Second $N$ of PENNY inverted.

$475 \quad 1 / 2 \mathrm{p}$ on $3 \mathrm{p}$ violet, black surcharge

$2^{0}$ Perforated I2 $1 / 2 \times 12$.

$476 \quad 1 / 2 \mathrm{p}$ on $3 \mathrm{p}$ violet, black surcharge

November and December, 1885

Same type, paper and impression as issue of March, I885.

$I^{\circ}$ Perforated $121 / 2$.

$477 \quad 2 p$ brown (November 2 nd)

$478 \quad 2 s h 6 p$ yellow (December 2 nd)

479 5sh dark blue "“

480 Iosh red brown

$2^{\circ}$ Perforated I2 $1 / 2 \times 12$.

48I 2p brown

$482 \quad 2$ sh $6 p$ yellow

$483 \quad 5$ sh dark blue

484 Iosh red brown

January $\mathrm{I}_{5}$ th, 1887 .

Provisional issue.

Three penny stamps of the issue of March, I885, surcharged in black with new value and the original value obliterated by a black line. There are two types of this surcharge. In type I the numeral 2 has a curved foot and in type 2 the numeral 2 has a straight foot.

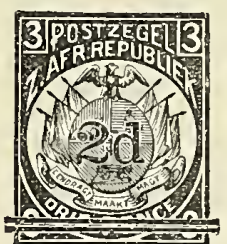

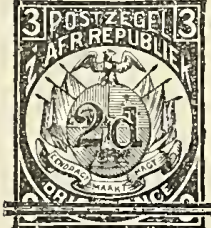

I.

I0 Perforated II $1 / 2 \times 12$

485 2p on 3 p violet, black surch'ge, type I 4862 p on $3 p$ violet 
Variety: Original value not barred.

$4872 \mathrm{p}$ on $3 \mathrm{p}$ violet, black surch'ge, type I

$4882 \mathrm{p}$ on $3 \mathrm{p}$ violet

$2^{0}$ Perforated I2 $1 / 2 \times 12$,

$4892 \mathrm{p}$ on $3 \mathrm{p}$ violet, black surch'ge, type I

$490 \quad 2 p$ on $3 p$ violet

Variety: Original value not barred.

$49 \mathrm{I} 2 \mathrm{p}$ on $3 \mathrm{p}$ violet, black surch'ge, type I

$492 \quad 2 \mathrm{p}$ on $3 \mathrm{p}$ violet

$3^{\circ}$ Perforated I3xi2.

$4932 \mathrm{p}$ on $3 \mathrm{p}$ violet, black surch'ge, type I

494 2p on $3 p$ violet

Variety: Original value not barred.

$\begin{array}{ll}495 & \text { 2p on } 3 p \text { violet, black surch'ge, type I } \\ 496 & \text { 2p on } 3 p \text { violet " }\end{array}$

April I 4 th, I887.

Same type, impression and paper as issue

of November and December, 1885 .

$I^{\circ}$ Perforated $121 / 2$.

4972 2p olive yellow

$2^{\circ}$ Perforated I2 $1 / 2 \times 12$.

$498 \quad 2 p$ olive yellow

March I4th, I889.

Same type, paper and impression as preceding issue.

Perforated I2 $1 / 2$.

$499 \quad 5$ green

January 2nd, I893.

Provisional issue.

One shilling stamps of the issue of March I885, surcharged horizontally in black " $21 / 2$ Pence" between two parallel lines I3 mm. apart.

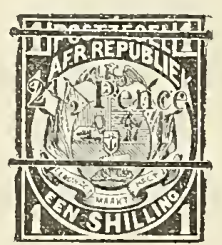

Perforated $121 / 2$.

$5002 \mathrm{t} / 2 \mathrm{p}$ on $\mathrm{Ish}$ green, black surcharge

Varieties:

a. Surcharge inverted.

50I $21 / 2 \mathrm{p}$ on Ish green, black surcharge

b. Fractional line misplaced $\left(2 / I_{2}\right)$

$50221 / 2 \mathrm{p}$ on Ish green, black surcharge

c. Same as " $b$ " but inverted.

$502 a 21 / 2 \mathrm{p}$ on 1 sh green, black surcharge

d. One bar below, none above the surcharge.

$50321 / 2 \mathrm{P}$ on Ish green, black surcharge

e. Two bars below, none above the surcharge.

$50421 / 2$ p on Ish green, black surcharge f. " $1 / 2$ pence" instead of " $21 / 2$ pence." 504 a $1 / 2 \mathrm{p}$ on Ish green, black surcharge

This variety is caused by careless feeding of the sheets in the press.

g. The two bars $14 \mathrm{~mm}$, apart.

$5052 \mathrm{t} / 2 \mathrm{p}$ on Ish green, black surcharge $h$. Surcharge inverted and the bars $14 \mathrm{~mm}$. apart.

$5062 \mathrm{l} / 2 \mathrm{p}$ on Ish green, black surcharge

January 26th, I893.

Provisional issue.

Sixpenny stamps of the issue of March, 1885, surcharged in the same way as the preceding issue, "I Penny" between two parallel bars I $3 \mathrm{~mm}$. apart.

Perforated $121 / 2$.

507 Ip on $6 \mathrm{p} \mathrm{blue,} \mathrm{black} \mathrm{surcharge}$
Varieties:

a. Pair, one without surcharge.

508 Ip on $6 \mathrm{p}$ blue, black surcharge

b. Bottom line of surcharge only.

$5096 \mathrm{p}$ blue, black surcharge

c. No line above the value.

5 I0 Ip on $6 \mathrm{p}$ blue, black surcharge

d. No line above and two lines below the value.

5 II Ip on $6 \mathrm{p} \mathrm{blue,} \mathrm{black} \mathrm{surcharge}$

e. One line above and no line below the value.

$5 \mathbf{I 2}$ Ip on $6 \mathrm{p}$ blue, black surcharge

f. Two lines above and none below the value.

513 Ip on $6 \mathrm{p}$ blue, black surcharge

g. Distance between the bars $14 \mathrm{~mm}$.

5 I4 Ip on $6 p$ blue, black surcharge

h. Double surcharge.

5 I5 IXIp on $6 \mathrm{p}$ blue, black surcharge

i. Surcharge inverted.

5 I6 Ip on $6 \mathrm{p}$ blue, black surcharge

k. Surcharge inverted and bars $14 \mathrm{~mm}$. apart.

517 Ip on $6 p$ blue, black surcharge

1. Same as " $\mathrm{i}$ " but without bar below value.

5I8 Ip on $6 \mathrm{p}$ blue, black surcharge

m. Same as "i" but without bar below value and two bars above.

5 I9 Ip on $6 \mathrm{p}$ blue, black surcharge

May 27th, 1893.

Provisional issue.

Twopenny stamps of the issue of April I4th, I887, surcharged in red "HalvePenny" in two horizontal lines between two parallel lines $13 \mathrm{~mm}$. apart.

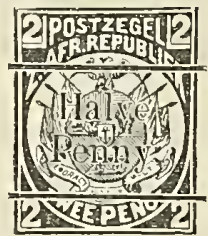

Perforated $121 / 2$.

$520 \quad 1 / 2 \mathrm{p}$ on $2 \mathrm{p}$ olive yellow, red surcharge

Varieties:

a. Surcharge inverted.

$52 \mathrm{I} \quad \mathrm{t} / 2 \mathrm{p}$ on $2 \mathrm{p}$ olive yellow, red surcharge

b. Bars I $4 \mathrm{~mm}$, apart.

$522 \quad 1 / 2 \mathrm{p}$ on $2 \mathrm{p}$ olive yellow, red surcharge c. Surcharge inverted and bars $14 \mathrm{~mm}$. apart.

$523 \quad \mathrm{r} / 2 \mathrm{p}$ on $2 \mathrm{p}$ olive yellow, red surcharge d. Same as "a" but without bar below value.

$52+\quad 1 / 2 \mathrm{p}$ on $2 \mathrm{p}$ olive yellow, red surcharge e. Sáme as "a" but with two bars above value.

$525 \quad 1 / 2 \mathrm{p}$ on $2 \mathrm{p}$ olive yellow, red surcharge

June 24 th, 1893 .

Provisional issue.

One shilling stamps of the issue of March, I 885, surcharged in black " $21 / 2$-Pence" in two horizontal lines between two parallel bars $13 \mathrm{~mm}$. apart.

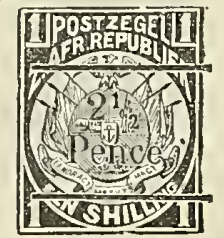


Perforated I $21 / 2$.

$5262 \mathrm{I} / 2 \mathrm{p}$ on Ish green, black surcharge

Varieties:

a. Surcharge inverted.

$52721 / 2 \mathrm{p}$ on Ish green, black surcharge

b. Bars I $4 \mathrm{~mm}$. a part.

$52821 / 2 \mathrm{p}$ on Ish green, black surcharge

c. Surcharge inverted and bars I $4 \mathrm{~mm}$ apart.

$52921 / 2 \mathrm{p}$ on Ish green, black surcharge

July 2nd, 1893 .

Provisional issue.

Same as provisional issue of May 27 th,

I893, but surcharged in black.

Perforated $121 / 2$.

$530 \quad \mathrm{r} / 2 \mathrm{p}$ on $2 \mathrm{p}$ olive yellow, black sur-

Varieties:

a. Surcharge inverted.

$53 \mathrm{I} \quad \mathrm{r} / 2 \mathrm{p}$ on $2 \mathrm{p}$ olive yellow, black sur-

charge

b. Bars $14 \mathrm{~mm}$. apart.

$5321 / 2 \mathrm{p}$ on $2 \mathrm{p}$ olive yellow, black surcharge

c. Surcharge inverted and bars $14 \mathrm{~mm}$. apart.

$533 \quad \mathrm{t} / 2 \mathrm{p}$ on $2 \mathrm{p}$ olive yellow, black surcharge

August Igth, I893.

Same type, impression and paper as regular issue of March, I889.

Perforated I $21 / 2$

$534 \quad 2 \frac{1}{2}$ P purple

I 894 .

Typographed on white wove paper. The prairie wagon has two shafts. Size $181 / 2 \times 22$ $\mathrm{mm}$

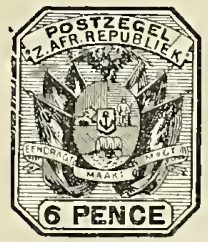

Perforated I $21 / 2$

$535 \mathrm{r} / 2 \mathrm{p}$ gray

536 Ip red

537 2p olive yellow

538 6p light blue

539 Ish green

Beginning of 1895 .

Same type, impression and paper as preceding issue, but the prairie wagon has a pole instead of two shafts.

Perforated $121 / 2$.

$540 \quad 1 / 2 \mathrm{p}$ gray

54 I IP red

$54^{2} \quad 2 \mathrm{p}$ olive yellow

$5433 \mathrm{p}$ violet

$544 \quad 4 \mathrm{p}$ slate

$545 \quad 6 \mathrm{p}$ light blue

546 Ish yellow green

August, 1895 .

Provisional issue.

I. One shilling stamps of the preceding issue (prairie wagon with pole) surcharged in black "Halve-Penny" and original value obliterated by two red lines.

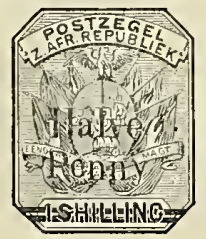

Perforated $\mathrm{I} 2 \mathrm{~T} / 2$

$547 \quad 1 / 2 \mathrm{p}$ on Ish green, red surcharge

Varieties :

a. Surcharge inverted.

$548 \quad 1 / 2 \mathrm{p}$ on Ish green, red surcharge

b. "Pennij" instead of "Penny."

$5491 / 2 \mathrm{p}$ on Ish green, red surcharge

II. Twopence halfpenny stamps of the issue of August Igth, I893, surcharged in green " $1 d$ " and original value obliterated by a thick green bar.

Perforated I $21 / 2$

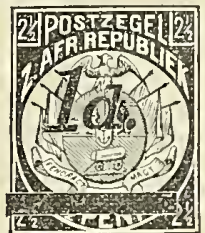

550 Ip on $21 / 2 \mathrm{p}$ purple, green surcharge Varieties:

a. Surcharge inverted.

55 I IP on $2 \frac{1}{2} \mathrm{p}$ purple, green surcharge

b. Surcharge sideways.

552 Ip on $21 / 2 \mathrm{p}$ purple, green surcharge

c. Surcharged on back of stamp.

553 Ip on $21 / 2 \mathrm{p}$ purple, green surcharge

III. Current revenue stamps surcharged in green "POSTZEGEL."

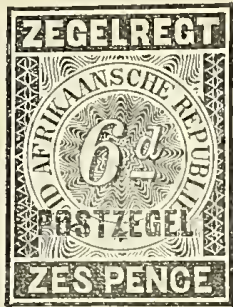

Perforated II $1 / 2$

$5546 p$ red, green surcharge

September, 1895 .

Celebration issue,

Issue to celebrate the reduction of the inland postage to one penny.

Typographed on white wove paper. The inscription in the upper label reads "EERSTE PENNY POSTVERVOER" (First penny post). Size $34 \times 22 \frac{1}{2} \mathrm{~mm}$.

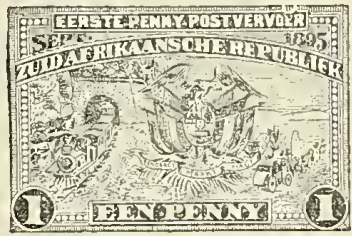

Perforated II $1 / 2$

555 Ip red

I 896.

Same type and paper as regular issue of 1895 ; in all the values, the $1 / 2$ penny, 5 and Io shillings excepted, the denomination of value in the lower label is printed in green.

Perforated $121 / 2$.

$556 \quad 1 / 2 \mathrm{p}$ green

557 Ip red and green

$5582 \mathrm{p}$ brown and green

$5592 \mathrm{r} / 2 \mathrm{p}$ ultramarine and green

$5603 \mathrm{P}$ red violet and green 


$\begin{array}{llll}561 & 4 p \text { olive and green } & 564 & \text { 2sh } 6 \mathrm{p} \text { heliotrope and green } \\ 562 & 6 \mathrm{p} \text { dull lilac and green } & 565 & \text { 5sh slate blue } \\ 563 & \text { Ish yellow bistre and green } & 566 & \text { rosh red brown }\end{array}$

\section{REVENUES USED FOR POSTAGE.}

r 882-84.

Engraved (portrait of Queen Victoria) on grayish white wove paper.

Perforated 14.

$\begin{array}{ll}701 & \text { rp green } \\ 702 & 6 p \text { red } \\ 703 & \text { rsh blue } \\ 704 & \text { Ish } 6 p \text { olive green } \\ 705 & 2 \text { sh brown violet } \\ 706 & 2 \text { sh } 6 \mathrm{p} \text { vermilion } \\ 707 & 5 \text { sh green }\end{array}$

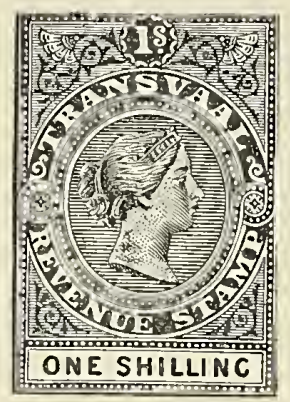

\section{ENVELOPES.}

TRESSES.
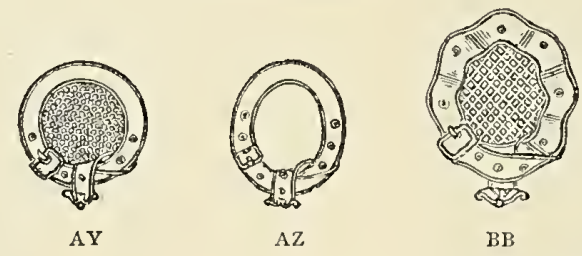

$\mathrm{BB}$

April, r872.

Stamp same type as adhesive of corres. ponding value and date. Typographed in upper right corner on white laid paper.

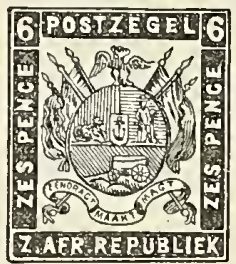

Tress AY.

Size $140 \times 83 \mathrm{~mm}$.

80 r $6 \mathrm{p}$ milky blue

January, I 874 .

Stamp of the same type as the threepenny adhesive of the issue of $r 871$, but with the numerals in the upper corners changed to 6 and the word "DRIE" in the side labels changed to "zES" in colored letters on white ground. Stamp typographed in upper right corner on white laid paper.

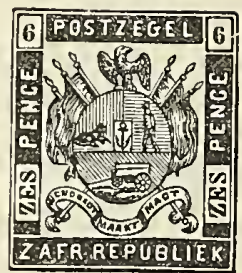

I. Tress AY.

$r^{\circ}$ Size, I24x $76 \mathrm{~mm}$.

$8026 \mathrm{p}$ blue

$2^{\circ}$ Size, $144 \times 80 \mathrm{~mm}$

8036 b blue

II. Tress Az.

$I^{\circ}$ Size, r $24 \times 76 \mathrm{~mm}$.

$8046 \mathrm{p}$ blue

$2^{\circ}$ Size, $I 44 \times 80 \mathrm{~mm}$

$8056 \mathrm{p}$ blue

III. Tress BB.

$I^{\circ}$ Size, $124 \times 76 \mathrm{~mm}$

$806 \quad 6 p$ blue

$2^{\circ}$ Size, $144 \times 80 \mathrm{~mm}$.

$807 \quad 6 p$ blue

\section{COUNTERFEITS}

We do not know of any good forgeries of the stamps of the South African Republic, except those already described and which for a long time were considered as reprints.

The surcharge on the first provisional issues has been extensively forged, especially that with "TRANSVAAL" spelt in capitals. However, the genuine stamps with three exceptions are printed on a soft porous wove paper, which was never used for the unsurcharged stamps, the I shilling of the issue of May, 1877 excepted; however, as this unsurcharged shilling stamp is very rare, the chances of it existing with a forged surcharge are very small.

The three exceptions referred to are the $\mathrm{I}$ penny on hard white wove paper, of the issue of October, 1876 , and the 1 penny and 3 pence on pilure paper of the 1875 issue, and great care should be exercised in the purchase of these; for the purpose of assisting our readers in the identification of these we give lere the measurements of the genuine surcharge:

The first line of the surcharge, "v. R." is $8 \mathrm{~mm}$. wide, including the period. The second line, "TransVAAL," is I $7 \mathrm{~mm}$. wide without period, and the letters $2 \mathrm{~mm}$. high. The height of the two lines together is $131 / 2 \mathrm{~mm}$. and the distance between the top and the bottom lines is $83 / 4 \mathrm{~mm}$. The distance between the " $T$ " and " $R$ " of "TRANSVAAL" is $I / 2 \mathrm{~mm}$. This is quite important, as most of the forgeries seen by us have the " $T$ " and " $R$ " much closer than on the genuine. 
The subsequent provisional issues having been printed on colored paper, no forged surcharge exists, except on forged stamps, the test for which has been described elsewhere. Of the other issues we do no know of any forgeries, with the exception of the surcharged one penny on the six penny Queens head, the forgeries of this surcharge seen by us are rather poor and easily recognized.

The envelopes of the first issue were also counterfeited by the Gustrow printer; but these are easily distinguished as the test given for the adhesives applies to the envelopes as well.
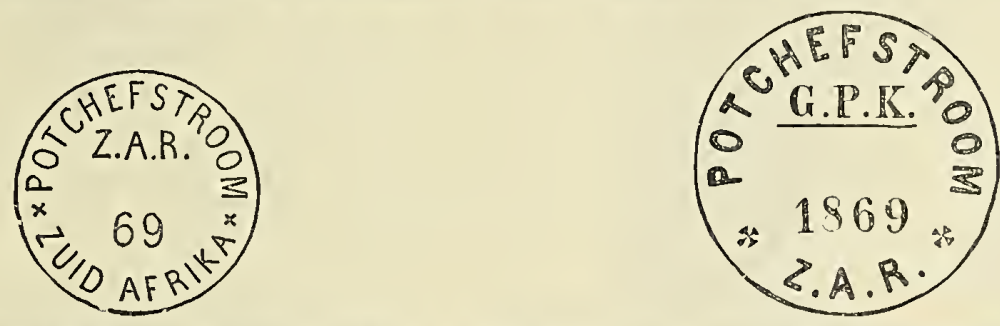

The above cuts represent two fakes which for a long time were catalogued and accepted as bona fide envelopes; these exist on various papers and in different sizes; both are fancy products made by Jeppe the postmaster and his successors and are absolutely of no philatelic value.

Revenue stamps from which the fiscal cancellation has been removed and replaced by either a forged cancellation or by one obtained by favor, are plentiful and collectors should be specially cautious in buying these.

\section{SOUTH AUSTRALIA.}

Currency : I2 PENCE $=\mathrm{I}$ SHILling; 20 SHILLINGS $=\mathrm{I}$ POUND $(£ \mathrm{I})=\$ 4.87, \mathrm{U}$. S. Currency.

\section{ADHESIVE STAMPS.}

1855-59.

Engraved in taille-douce (portrait of Queen Victoria) on white wove paper varying in thickness and rather rough. Size 19x25 $\mathrm{mm}$.

Watermarked a large six rayed star with

long narrow points.
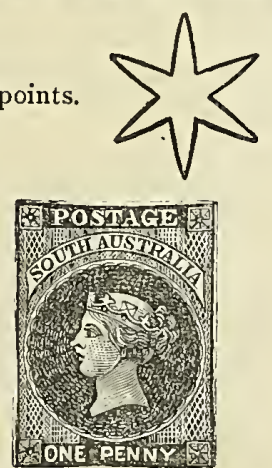

I. London print.

Ip green (October, I855)

$2 \mathrm{p}$ carmine (January Ist, I855)

$6 \mathrm{p}$ dark blue (October, 1855 )

rsh violet (r856)

This last was never put into actual use.

II. Local print.

5 Ip pale yellow green

rp dark yellow green

$2 \mathrm{p}$ blood red

$2 \mathrm{p}$ pale red

6 p slate blue

rsh orange (July 8th, I857)

Variety: Printed on both sides.

II $2 \mathrm{p}$ pale red

Reprints.

1885.

Watermarked Crown and $S A$.

12 ip dark green

ap carmine

2p brownish rose

6p blue

6p dark blue
All the reprints of this and the subsequent issues are surcharged "REPRINT" or "SPECIMEN" in black or red.

Beginning of 1859 .

Same type, paper and impression as preceding issue, Watermarked a large six rayed star with long narrow points.

Rouletted.

r 7 ip pale yellow green

I8 Ip dark yellow green

r9 2p pale red

$20 \quad 6 p$ slate blue

2 I Ish orange

Varieties:

a. Printed on both sides.

22 2p pale red

23 Ish orange

b. Doubly rouletted vertically.

$24 \quad 2 p$ pale red

Reprints.

1885.

Watermarked Crown and SA, letters wide apart.

Rouletted.

$\begin{array}{ll}25 & \text { 1p yellow green } \\ 26 & \text { 2ppale orange } \\ 27 & \text { 2p orange red } \\ 28 & 6 p \text { blue } \\ 29 & 6 p \text { ultramarine } \\ 29 a & 6 p \text { slate blue } \\ 30 & 1 \text { sh yellow }\end{array}$

End of 1859 .

Same type, paper and impression as preceding issue. Watermarked a large six rayed star with long narrow points.

Rouletted.

3 I 6 p purple blue

$\begin{array}{ll}32 & \text { rsh yellow } \\ 33 & \text { rsh olive yellow }\end{array}$

June, I $860-68$.

Same type as corresponding values of preceding issues. The 4,9 , ro pence and 2 shillings are of a new design; the 2 shillings is of the same type as the 4 pence, and the ro pence consists of the 9 penny stamp printed in yellow or orange and sur- 
charged in blue "TEN PENCE." The surcharge "TEN PENCE" is type set, there being six different settings arranged in a group of six in two horizontal rows of three. This group is repeated forty times in the sheet. Sizes : 4 pence and 2 shillings, I9 $1 / 2 \times 24 \mathrm{~mm}$. 9 and Io pence, I $9 \times 22 \mathrm{I} / 2 \mathrm{~mm}$. White wove paper varying in texture. Watermarked a large six rayed star with long narrow points.
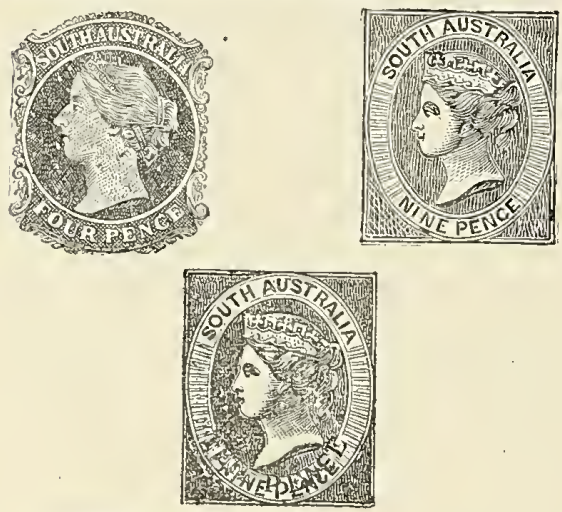

Rouletted.

34 Ip bright yellow green

35 Ip blue green

36 Ip sage green

$37 \quad 2 \mathrm{p}$ bright vermilion (I862)

$3^{8} \quad 2 \mathrm{p}$ pale vermilion (I867)

$394 \mathrm{p}$ dull purple (January 24th, I867)

$40 \quad 6 p$ greenish blue

4 I $\quad 6 \mathrm{p}$ dull blue

$426 \mathrm{p}$ pale ultramarine

$436 \mathrm{p}$ Prussian blue

$449 \mathrm{p}$ brownish lilac (December 24th, I 860)

459 gray lilac

46 Iop on 9p orange red, blue surcharge (July 2oth, I866)

47 Iop on 9p yellow, blue surcharge (I867)

48 Ish gray brown (July, I862)

49 Ish dark red brown

50 Ish bright red brown

5 I Ish chestnut brown

52 2sh rose carmine (January 24 th, I 867 )

a. Imperforate.

$532 \mathrm{p}$ pale vermilion

b. Double rouletting at three sides.

549 9 gray lilac

Reprints.

1885.

Watermarked Crown and $S A$, letters wide apart.

Rouletted.

55 9p gray lilac

$55 a$ 9p gray

$5610 p$ on $9 p$ canary yellow, blue surcharge

5y $10 p$ on 9p browonish orange, blue surcharge

$5 \%$ a $10 p$ on $9 p$ orange brown, blue surcharge 581 1sh brown

December, 1867-68.

Same types as the corresponding values of the preceding issues. Watermarked a large six rayed star with long narrow points.

$I^{\circ}$ Perforated I I $1 / 2$ horizontally and rouletted vertically.

$\begin{array}{ll}59 & \text { Ip blue green } \\ 60 & \text { Ip yellow green } \\ 6 \text { I } & 4 \text { p dull purple } \\ 62 & 6 p \text { sky blue } \\ 63 & 6 p \text { Prussian blue }\end{array}$

64 Ish dark brown

65 Ish chestnut brown

Variety: Printed on both sides.

666 p Prussian blue

$2^{\circ}$ Perforated I $2 / 2$ horizontally, rouletted vertically.

$676 \mathrm{p}$ Prussian blue

68 Ish dark brown

$3^{\circ}$ Perforated II $1 / 2 \times 121 / 2 \times$ rouletted $x$ rouletted.

$696 \mathrm{p}$ Prussian blue

$4^{\circ}$ Perforated I I $1 / 2$.

7o Ip blue green

7 I Ip yellow green

$72 \quad 2 p$ vermilion

73 4p dull purple

$74 \quad 6$ p sky blue

75 Ish dark brown

76 Ish chestnut brown

77 2sh pale rose carmine

Varieties:

a. Rouletted on four sides and perforated

I I $1 / 2$ on four sides.

$78 \quad 2 \mathrm{p}$ vermilion

$796 \mathrm{p}$ Prussian blue

b. Printed on both sides.

80 2 sh pale rose carmine

$5^{\circ}$ Perforated I I $1 / 2 \times 121 / 2$

$8 \mathrm{I}$ Ip blue green

82 Ip yellow green

83 2p vermilion

84 4p dull purple

$85 \quad 6$ p sky blue

86 6p Prussian blue

87 Ish dark brown

88 Ish chestnut brown

89 2sh pale rose carmine

Varieties :

a. Perforated I $2 / 2$ on one side and II $1 / 2$ on the others.

$90 \quad 4 \mathrm{p}$ dull purple

9 I $6 \mathrm{p}$ sky blue

92 Ish dark brown

93 2sh pale rose carmine

b. Rouletted on four sides and perforated I I $1 / 2$ horizontally and I $2 \frac{1}{2}$ vertically.

94 Ip blue green

c. Printed on both sides.

95 2sh deep carmine lake

$6^{\circ}$ Perforated $12 \frac{1}{2}$ horizontally, I I $1 / 2$ vertically.

$96 \quad 6 \mathrm{p}$ sky blue

97 Ish dark green

$7^{\circ}$ Perforated 12 $1 / 2$.

98 Ip yellow green

996 6 sky blue

Reprints.

1885.

Watermarked Crown and SA, letters wide apart.

Perforated 111/2, 121/2 single and compound.

$100 \quad 4 p$ violet

101 4p black violet

$1026 p$ blue

103 1sh red brown

104 2sh dull carmine

September, I 868.

Typographed on white wove paper. Size $181 / 2 \times 23 \mathrm{~mm}$. Watermarked Crown and $S A$, the letters wide apart.

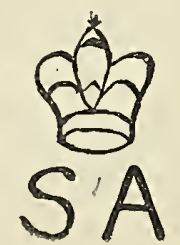




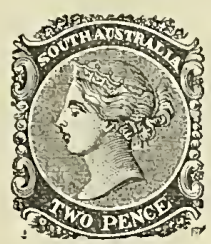

I $^{\circ}$ Rouletted.

I05 $2 \mathrm{p}$ deep orange red

Io6 2p pale orange red

Varieties :

a. Imperforate.

I07 2p pale orange red

b. Printed on both sides.

Io8 2p pale orange red

$2^{\circ}$ Perforated I I $1 / 2$.

Io9 2 p orange red

$3^{\circ}$ Perforated I I $1 / 2 \times 12 \frac{\pi}{2}$,

I 2 p orange red

$4^{\circ}$ Perforated I I $1 / 2$ horizontally and rou-

letted vertically.

I I 2 p orange red

Reprints.

1885.

Watermarked Crown and $S A$, letters wide apart.

Rouletted.

112 2p reddish orange

November, I 868.

Same type, paper and impression as ten penny stamps of the issue of July $20 t h, 1866$.

A. Watermarked a large six rayed star with long narrow points.

$I^{\circ}$ Perforated I I $1 / 2$ horizontally, rouletted vertically.

II3 Iop on 9p yellow, blue surcharge

Variety : Printed on both sides.

I 4 Iop on 9p yellow, blue surcharge

$2^{0}$ Perforated II $\mathrm{I} / 2$

I 5 IOp on 9p yellow, blue surcharge

$3^{\circ}$ Perforated I I $1 / 2 \times 121 / 2$

II6 Iop on 9p yellow, blue surcharge

1 ariety: Perforated $121 / 2$ on one side and I I $1 / 2$ on the others.

I 7 Iop on 9p yellow, blue surcharge

B. Watermarked Crown and SA, the letters wide apart.

Perforated II $1 / 2$.

I 8 Iop on 9p yellow, blue surcharge

Reprints.

1885.

Watermarked Crown and $S A$, letters wide apart.

Perforated $11 \frac{1}{2}, 121 / 2$ single and compound.

$118 a$ 10p on 9p canary yellow, blue surcharge

I 869 .

Same type, paper and impression as preceding issue. Watermarked a large six rayed star with long narrow points.

$I^{\circ}$ Rouletted.

I I Iop on 9p yellow, black surcharge

Varieties:

a. Surcharge inverted on upper part of stamp.

†20 Iop on 9p yellow, black surcharge b. Imperforate.

I 2 I Iop on $9 p$ yellow, black surcharge

c. Stamp printed on both sides.

I22 Iop on 9p yellow, black surcharge

d. Same as c, but rouletted horizontally

and perforated vertically.

I23 Iop on 9p yellow, black surcharge

$2^{\circ}$ Perforated 1 I $1 / 2$.

124 Iop on 9p yellow, black surcharge

$3^{\circ}$ Perforated I I $1 / 2 \times 121 / 2$.

I25 IOp on 9p yellow, black surcharge

July, 1869.

Same type, paper and impression as issue of September, I868. Watermarked a large six rayed star with long narrow points.

$I^{\circ}$ Rouletted.

I $262 \mathrm{p}$ deep orange red

I27 2p pale orange red

$2^{\circ}$ Perforated I I $1 / 2$ horizontally and rou -

letted vertically.

1282 p orange red

$3^{\circ}$ Perforated II $1 / 2$.

$1292 \mathrm{p}$ orange red

Variety: Rouletted on four sides and perforated II $1 / 2$ on four sides.

I30 2p orange red

Reprints.

1885.

Watermarked Crown and $S A$, letters wide apart.

$1^{\circ}$ Rouletted

$130 a$ 10p on 9p yellow, black surcharge

20 Perforated 111/2, $121 / 2$ single and compound.

$130 b 10 p$ on $9 p$ orange yellow, black surcharge

I870.

Same type, impression and paper as corresponding values of the issue of December, I 867-68. Watermarked a large six rayed star with long narrow points.

Perforated Io.

I3 I Ip yellow green

I32 Ip blue green

I $334 \mathrm{p}$ dull purple

I34 4p dull lilac

I35 6p Prussian blue

I36 Ish chestnut brown

May, $\mathbf{1} 870$.

A. Same type as issue of September, 1868; white wove paper varying in texture and either rough or smooth. Watermarked Crown and $\mathrm{SA}$, letters wide apart.

I $^{0}$ Perforated Io horizontally x rouletted vertically.

I37 2p orange red

$2^{\circ}$ Perforated ro.

I38 2p deep orange red

I39 $2 \mathrm{p}$ pale orange red

I $40 \quad 2 \mathrm{p}$ brownish orange

I4I 2p pale yellow

Variety: Printed on both sides.

I42 2p orange red

Reprints.

$1^{\circ} 1885$.

Watermarked Crown and $S A$, letters wide apart.

Perforated 10

143 ap orange vermition

20189 ?

Perforated 111/2.

143 a $2 p$ orange vermiliom 
B. Same type, paper and impression as issue of 1869 . Watermarked a large six rayed star with long narrow points.

I ${ }^{\circ}$ Perforated I I $1 / 2 \times 10$.

I44 Iop on $9 p$ orange yellow, black surcharge

$2^{\circ}$ Perforated Ioxi2 $1 / 2$.

I 45 Iop on 9p orange yellow, black surcharge

$3^{\circ}$ Perforated II $1 / 2 \times 121 / 2 \times 10$.

146 Iop on op orange yellow, black surcharge

Reprints.

1885.

Watermarked Crown and $S A$, letters wide apart.

Perforated 12.
147 10p on $9 p$

147 10p on ip orange yellow, black surcharge

August, I 870.

Four penny stamps of the issue of January $24^{\text {th }}$, I867, printed in blue and surcharged horizontally with new value; white wove paper varying in thickness and rather rough.

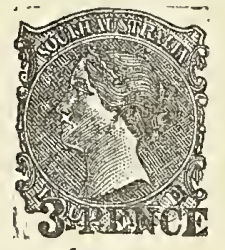

A. Carmine surcharge.

Watermarked a large six rayed star with long narrow points.

Perforated Io.

I $483 \mathrm{p}$ on $4 \mathrm{p}$ slate blue, carmine surReprints.

1885.

Watermarked Crown and $S A$, letters wide apart.

Perforated 111/.121/2 single and compound. 149 3p on $4 p$ ultramarine, red surcharge

$149 a$ 3p on $4 p$ light ultramarine, red sur-

B. Black surcharge.

Watermarked a large six rayed star with long narrow points.

$I^{\circ}$ Perforated ro.

I $50 \quad 3 \mathrm{p}$ on $4 \mathrm{p}$ sky blue, black surcharge (end $\mathrm{I} 870$ )

I 5 I $3 \mathrm{p}$ on $4 \mathrm{p}$ dark blue, black surcharge

$2^{\circ}$ Perforated II $1 / 2$.

I52 $3 \mathrm{p}$ on $4 \mathrm{p}$ sky blue, black surcharge

$3^{\circ}$ Perforated I I $1 / 2 \times 12 \mathrm{I} / 2$.

$\mathrm{r}_{53} 3 \mathrm{p}$ on $4 \mathrm{p}$ sky blue, black surclıarge

Reprints.

1885.

Watermarked Crown and $S A$, letters wide apart.

Perforated $111 / 2,121 / 2$ single and compound.

1543 ipon $4 p$ ultranarine, black surcharge

$154 a$ ip on $4 p$ cobait blue, black surcharge

December, I870-7I.

Same type and impression as corresponding values of preceding issue ; white wove paper varying in texture and either rough or smooth.

Perforated II $1 / 2 \times I O, \quad$ IOXI $2 \frac{1}{2}$ and II $1 / 2 \mathrm{x}$ I $21 / 2 \times 10$, irregularly.

I $^{\circ}$ Watermarked a large six rayed star, with long narrow points.

I55 Ip yellow green
I 56 Ip blue green

I57 3p on $4 \mathrm{p}$ dark blue, black surcharge

I58 4p dull purple

r59 4p dull lilac

I60 6p Prussian blue

I6 I $6 \mathrm{p}$ dark blue

I62 Ish chestnut brown

I63 2sh pale rose carmine

I64 2sh deep crimson lake

Variety: Imperforate vertically.

I65 2sh deep crimson lake

$2^{\circ}$ Watermarked Crown and SA, letters wide apart.

I66 $2 \mathrm{p}$ orange red

Variety: Imperforate vertically.

I67 $2 \mathrm{p}$ orange red

I8 $7 \mathrm{r}$.

I. Same type and impression as preceding issue, white wove paper, varying in thickness and rather rough.

Watermarked a large six rayed star with long narrow points.

I* Perforated II $1 / 2$.

r68 Ip yellow green

r69 Ip blue green

I $70 \quad 3 \mathrm{p}$ on $4 \mathrm{p}$ dark blue, black surcharge

I 7 I 4 p dull lilac

I $724 \mathrm{p}$ dull purple

I73 6p dark blue

I74 6p Prussian blue

I 75 Ish red brown

r 762 sh deep carmine lake

$2^{\circ}$ Perforated I I $1 / 2 \times 121 / 2$.

I77 Ip blue green

I 78 Ip yellow green

I79 $2 \mathrm{p}$ orange red

I80 $3 p$ on $4 \mathrm{p}$ dark blue, black surcharge

I 8 I $4 \mathrm{p}$ dull purple

I $824 \mathrm{p}$ dull lilac

I83 6p Prussian blue

I84 $6 \mathrm{p}$ dark blue

I 85 Ish red brown

I 86 2sh deep carmine lake

Varieties:

a. Without surcharge.

I87 $4 \mathrm{p}$ dark blue

b. Perforated I $2 \frac{1}{2}$ on one side and II $1 / 2$ on the others.

I $88 \quad 3 p$ on $4 p$ dark blue, black surcharge

I89 $4 \mathrm{p}$ dull purple

$3^{\circ}$ Perforated I $21 / 2 \times 111 / 2$.

Igo $4 \mathrm{p}$ dull purple

I9I 2sh deep carmine lake (December, r870)

$4^{\circ}$ Perforated ro at top, II $1 / 2$ at bottom and $121 / 2$ at sides.

I $922 \mathrm{p}$ orange red

Some of the stamps of this issue can only be distinguished from the stamps of the issue of December 1867.68 by the date of the cancellation.

II. Thin white wove paper.

Watermarked V over Crown.

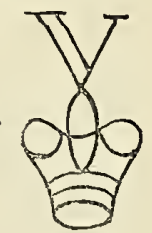

Perforated ro.

I93 2p orange red

I94 4p dull purple

Varieties:

a. Printed on both sides.

I05 4p dull purple 
b. Double perforation.

I $962 \mathrm{p}$ orange red

c. Perforated Io and rouletted all round.

I 972 p orange red

Unwatermarked specimens from the bor-

der of sheets occur in the 4 pence.

June, I872.

Same type, impression and paper as issue

of December 24th, I 860 .

Watermarked a large six rayed star with long narrow points.

I0 Perforated I I $1 / 2 \times$ rouletted.

I98 9p gray lilac

$2^{\circ}$ Rouletted $\mathrm{x}$ perforated II $\mathrm{x} / 2$.

r99 9p gray lilac

$3^{\circ}$ Rouletted and perforated II $1 / 2 \times 121 / 2$.

2009 9 gray lilac

July, I 872 .

Same type, impression and paper as pre-

ceding issue.

Watermarked a large six rayed star with

long narrow points.

$I^{\circ}$ Perforated I I $1 / 2$.

$2019 p$ red lilac

$2^{\circ}$ Perforated I I $1 / 2 \times 121 / 2$.

2029 9p red lilac

July, I 873 .

Same type, impression and paper as preceding issue.

Watermarked a large six rayed star with long narrow points.

I0 Perforated II $1 / 2$.

$2039 \mathrm{p}$ violet

2049 9p mauve

$V$ ariety: Printed on both sides.

$2059 \mathrm{p}$ violet

$2^{\circ}$ Perforated I I $1 / 2 \times 121 / 2$.

$2069 \mathrm{p}$ violet

207 op mauve

Reprints.

1885.

Watermarked Crown and $S A$, letters wide apart

Perforated 111/2,121/2 single and compound. 208 op red lilac

January, I875.

Typographed on white wove paper, varying in texture and either rough or smooth. Size, I $9 \times 221 / 2 \mathrm{~mm}$.

Watermarked Crown and SA, letters wide apart.

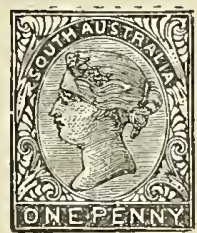

I ${ }^{\circ}$ Perforated ro.

209 Ip blue green

$2^{\circ}$ Perforated II $1 / 2 \times 10$.

2 ro Ip blue green

$3^{\circ}$ Perforated II $1 / 2$

2 I Ip blue green

$V$ ariety: Perforated Io across center.

2 I 2 Ip blue green

$4^{\circ}$ Perforated I I $1 / 2 \times 121 / 2$.

$2 \mathrm{I} 3$ Ip blue green

Reprints.

1885.

Watermarked Crown and $S A$, letters wide apart.

Perforated 10

214 1p green
$189 ?$

Perforated 111/2.

$214 a 1 p$ green

September, I876.

Ninepenny stamps of the issue of 1872 printed in brown and surcharged in black with new value across lower part of stamp; soft white wove paper, rather thin and of uniform thickness.

Watermarked a six rayed star with short

broad points.
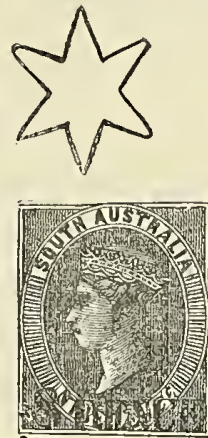

$I^{\circ}$ Perforated II $1 / 2$

$2158 p$ on $9 p$ bistre brown, black surcharge

Variety: Surcharge across the upper part of stamp.

$216 \quad 8 p$ on $9 p$ bistre brown, black surcharge

$2^{\circ}$ Perforated II $1 / 2 \times 121 / 2$.

$2178 \mathrm{p}$ on $9 \mathrm{p}$ bistre brown, black surcharge

I 876-77.

Same type as corresponding values of preceding issues, printed on soft white wove paper, rather thin and of uniform thickness.

Watermarked a six rayed star with short broad poin's.

I0 Perforated Io.

$2186 \mathrm{p}$ dark blue

$2^{\circ}$ Perforated IOXII $1 / 2 \times 121 / 2$ compound.

2 I9 4p dull purple

$2204 \mathrm{p}$ dull lilac

22 I $6 \mathrm{p}$ dark blue

$2226 \mathrm{p}$ bright blue

223 Ish red brown

224 Ish lake brown

2252 sh bright crimson lake

Variety: Imperforate vertically, perforated I I $1 / 2$ at top, ro at bottom.

2262 sh bright crimson lake

$3^{\circ}$ Perforated II $1 / 2$.

$2273 \mathrm{p}$ on $4 \mathrm{p}$ dark blue, black surcharge

$2283 \mathrm{p}$ on $4 \mathrm{p}$ bright blue "“

$229 \quad 4 \mathrm{p}$ dull purple

$230 \quad 4 \mathrm{p}$ dull lilac

23 I 6 p dark blue

$2326 \mathrm{p}$ bright blue

2339 9p lilac rose

234 Ish red brown

235 Ish lake brown

2 sh bright crimson lake

Variety: Imperforate vertically.

2376 p dark blue

$4^{0}$ Perforated I I $1 / 2 \times 1 / 2$.

$2393 \mathrm{p}$ on $4 \mathrm{p}$ dark blue, black surcharge

2 to $3 \mathrm{p}$ on $4 \mathrm{p}$ bright blue, black surcharge

$240 \mathrm{ap}$ dull purple

$24 \mathrm{I} 4 \mathrm{p}$ dull lilac

2 ra $6 \mathrm{p}$ dark blue 


$242 \quad 6 \mathrm{p}$ bright blue
$243 \quad 9 \mathrm{p}$ lilac rose
$244 \quad$ Ish red brown
$245 \quad$ Ish lake brown
$246 \quad$ 2sh bright crimson lake
Varieties:

a Double surcharge.

$2473 P$ on 4 p dark blue, black surcharge

b. Imperforate.

2486 p deep bright blue

$5^{\circ}$ Perforated I $2 \frac{1}{2} \times$ II $1 / 2$.

2496 6 dark blue

250 Ish red brown

$25 \mathrm{I} 2 \mathrm{sh}$ bright crimson lake

Varieties :

a. Perforated II $1 / 2$ on one side, $12 \frac{1}{2}$ on the others.

252 2sh bright crimson lake

b. Perforated $12 \frac{1}{2}$ on one side, I I $1 / 2$ on the others.

2536 6p dark blue

2549 p lilac rose

$6^{\circ}$ Perforated $121 / 2$.

255 Ish red brown

256 2sh bright crimson lake

I 877.

Same type as corresponding values of the issues of December, 1868 and January, 1875 . Typographed on white wove paper slightly surfaced.

Watermarked Crown and SA, letters

close together.

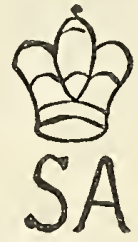

I ${ }^{\circ}$ Perforated Io.

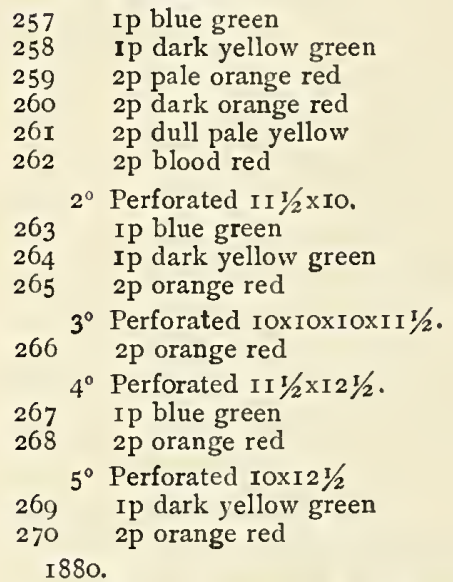

Same type, impression and paper as corresponding values of the issues of $1876-77$.

I. Watermarked a six rayed star with short broad points.

$I^{\circ}$ Perforated Iox II $1 / 2$.

27 4 4 reddish purple

2728 p on 9 p yellow brown, black surcharge

$2^{\circ}$ Perforated Ioxi2 $1 / 2$.

2734 p reddish purple

$3^{\circ}$ Perforated IOxIOXII $1 / 2 \times 121 / 2$.

274 4p reddish purple

$4^{\circ}$ Perforated IOxIOXI2 $1 / 2 \times 1$ I $1 / 2$.

2754 p reddish purple

$5^{\circ}$ Perforated II $\mathrm{I} / 2$.

2764 p reddish purple
$2778 p$ on 9 p yellow brown, black surcharge

$6^{\circ}$ Perforated II $1 / 2 \times 121 / 2$.

278 4p reddish purple

279 8p on 9 p yellow brown, black surcharge

Variety: Perforated $12 \mathrm{t} / 2$ on one side, I I $1 / 2$ on the others.

$280 \quad 4 \mathrm{p}$ reddish purple

$7^{0}$ Perforated $121 / 2$.

$25 \mathrm{I} 4 \mathrm{P}$ reddish purple

$8^{\circ}$ Perforated II $1 / 2 \times 10$.

$2824 \mathrm{p}$ reddish purple

$9^{\circ}$ Perforated $12 \mathrm{r} / 2 \times 1 \mathrm{I} / 2$.

2838 p on 9p yellow brown, black sur Reprints.

1885.

Watermarked Crown and $S A$, letters wide apart.

$1^{\circ}$ Perforated $11 \mathrm{r} / 2,12 \mathrm{l} / 2$ single and compound.

$284 \quad 8 p$ on $9 p$ bistre brown, black surcharge 285 8pon 9p yellow brown, black surcharge

$2^{\circ}$ Perforated 10.

286 sp on 9p brown, black surcharge

II. Watermarked Crown and SA letters close together.

Perforated Io.

287 2p dark brown

January Ist, I882.

Provisional issue.

One penny stamps of the issue of 1877 surcharged in black with new value, the original value being obliterated by a black line.

Watermarked Crown and SA, letters close together.

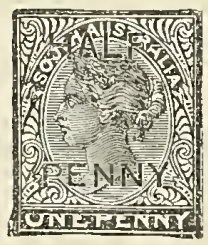

Perforated IO.

$288 \mathrm{I} / 2 \mathrm{p}$ on Ip green, black surcharge Reprints.

1885.

Watermarked Crown and $S A$, letters wide apart.

Perforated 10.

$2891 / 2 p$ on 1p green, black surcharge

March, I 883.

Typographed on white wove paper. Size, IO $\mathrm{t} / 2 \times 18 \mathrm{~T} / 2 \mathrm{~mm}$.

Watermarked Crown and SA, letters close together.

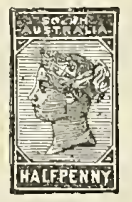

Perforated ro.

$290 \quad 1 / 2$ p chocolate

Reprints.

1885.

Watermarked Crown and $S A$, letters wide apart.

$1^{\circ}$ Perforated 10.

$291 \quad 1 / 2 p$ brown 
$2^{\circ}$ Perforated 111/2,121/2 single and compound.

$291 a \quad 1 / 2 p$ chocolate

December, 1884 .

Same type, impression and paper as corresponding value of the issue of $1876-77$.

Watermarked a six rayed star with short broad points.

$I^{\circ}$ Perforated IOxII $1 / 2$.

2926 p pale ultramarine

$2^{\circ}$ Perforated Ioxi2 $1 / 2$.

2936 p pale ultramarine

$3^{\circ}$ Perforated Iox IOxI I $1 / 2 \times 121 / 2$.

294 6p pale ultramarine

Reprints.

$188 ?$

Watermarked Crown and $S A$, letters wide apart.

Perforated $111 / 2,111 / 2$ single and compound. 294a $6 p$ pale ultramarine

I885.

Same type, impression and paper as issue of September, 1876.

Watermarked a six rayed star with short broad points.

$I^{0}$ Perforated II $1 / 2$.

$2958 p$ on 9 p gray brown, black surcharge $2^{\circ}$ Perforated I IXI $21 / 2$.

$2968 \mathrm{p}$ on 9p gray brown, black surcharge I886.

Same type as corresponding values of the preceding issues; engraved on hard, thick, white wove paper varying in texture.

Watermarked a six rayed star with short broad points.

\section{$I^{\circ}$ Perforated IOxII $1 / 2$.}

2974 p reddish purple

2986 p pale ultramarine

$2^{0}$ Perforated Ioxi21/2.

2994 p reddish purple

$3006 \mathrm{p}$ pale ultramarine

$3^{\circ}$ Perforated II $1 / 2$.

$3014 \mathrm{p}$ reddish purple

302 Ish red brown

$4^{0}$ Perforated I I $1 / 2 \times 121 / 2$.

3034 p reddish purple

304 Ish red brown

Variety: Perforated $12 \mathrm{I} / 2$ on one side, II $1 / 2$ on the others.

3054 p reddish purple

$5^{\circ}$ Perforated I2 $1 / 2$.

$306^{5} \quad 4$ p reddish purple

\section{End of $\mathbf{I} 886$.}

Same type, impression and paper as the halfpenny stamps of the $188_{3}$ issue.

Watermarked Crown and SA, letters close together.

Perforated ro.

$307 \quad 1 / 2 \mathrm{p}$ red brown

$308 \quad 1 / 2 \mathrm{p}$ pale red brown

$3091 / 2 \mathrm{p}$ dark red brown

December, I886.

Typographed on soft white wove paper slightly surfaced. Size, $221 / 2 \times 3 \mathrm{gmm}$.

Watermarked Crown and SA, letters close together.
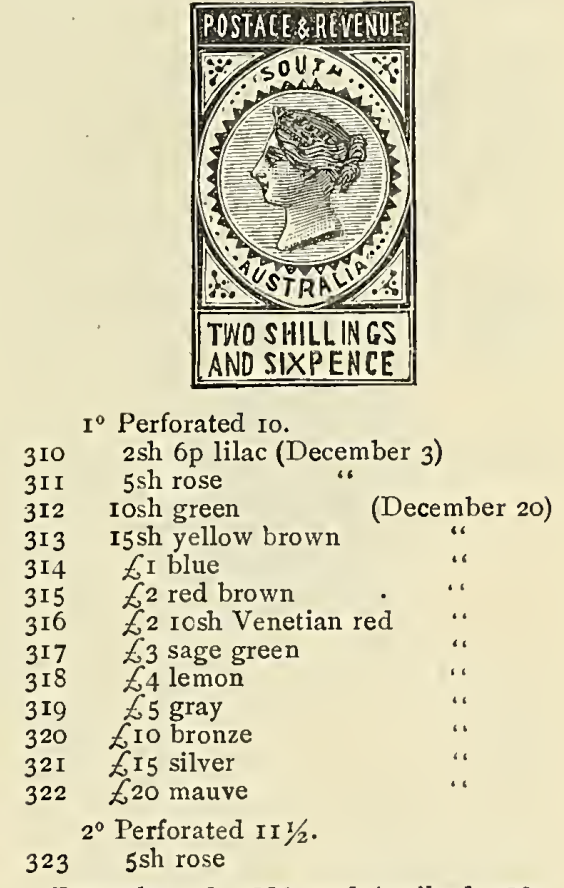

December 3d, I886, and April 2d, I887.

Typographed on soft white wove paper, slightly surfaced. Sizes: $3 p, 18 \times 22 \mathrm{~mm}, 6 \mathrm{p}$, $181 / 2 \times 22 \frac{1}{2} \mathrm{~mm}$

Watermarked Crown and SA, letters close together.
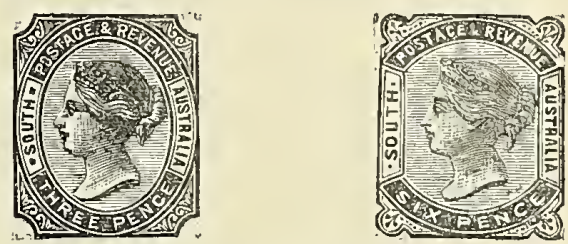

Perforated Io

$3243 \mathrm{p}$ light olive green (December $3 \mathrm{~d}$,

$3256 p$ blue (April 2nd, I887)

Reprints.

189?

Watermarked Crown and $S A$, letters wide apart.

Perforated 111/2.

326 3polive green

327 6p blue

I 890.

Same type, paper and impression as the halfpenny stamp of the 1886 issue.

Watermarked Crown and SA, letters close together.

$I^{\circ}$ Perforated Io.

$328 \quad 1 / 2 \mathrm{P}$ brown

$2^{\circ}$ Perforated II $1 / 2$.

$329 \quad 1 / 2 \mathrm{p}$ brown

$330 \quad 1 / 2 \mathrm{p}$ pale red brown

33 I $1 / 2 \mathrm{p}$ red brown

$332 \quad 1 / 2 \mathrm{p}$ bistre brown

$3^{\circ}$ Perforated II $1 / 2$ at one side, Io at the others.

$333 \quad 1 / 2 \mathrm{p}$ brown

$334 \quad 1 / 2 \mathrm{p}$ red brown

$335 \quad 1 / 2 \mathrm{p}$ pale red brown

$336 \quad 1 / 2 \mathrm{p}$ bistre brown 


\author{
$4^{\circ}$ Perforated I $21 / 2 \times$ II $1 / 2$. \\ $337 \quad \mathrm{t} / 2 \mathrm{p}$ pale red brown \\ Variety: Perforated horizontally I2 $1 / 2$ \\ across center of stamp. \\ $338 \quad 1 / 2 \mathrm{p}$ pale red brown \\ $5^{\circ}$ Perforated II $1 / 2 \times 121 / 2$. \\ $339 \quad \mathrm{r} / 2 \mathrm{p}$ pale red brown \\ June, I8go. \\ Typographed on soft white wove paper \\ slightly surfaced. Size, $181 / 2 \times 22 \mathrm{~mm}$. \\ Watermarked Crown and $\mathrm{SA}$, letters close \\ together.
}

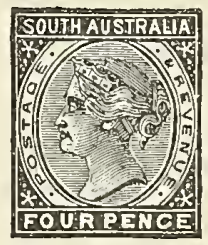

Perforated io.

$340 \quad 4 \mathrm{p}$ light violet

Reprints.

189 ?

Watermarked Crown and $S A$, letters wia'e apart.

Perforated $111 / 2$

341 4p violet

June Ist, I89I.

Provisional issue.

Fourpenny and sixpenny stamps of the issue of April 2nd, I887, and June, I89o, printed respectively in green and red brown and surcharged with new value, the original value being obliterated by a heavy line.

Watermarked Crown and SA, letters close together.
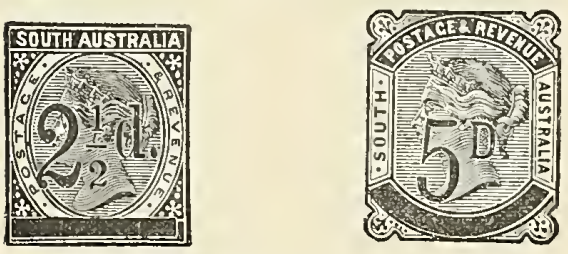

I ${ }^{\circ}$ Perforated Io.

$34221 / 2 \mathrm{p}$ on $4 \mathrm{p}$ green, brown surcharge

$3435 \mathrm{p}$.on $6 \mathrm{p}$ red brown, carmine surcharge $2^{\circ}$ Perforated II $1 / 2$.

$3442 \mathrm{t} / 2 \mathrm{p}$ on $4 \mathrm{p}$ green, brown surcharge $3^{\circ}$ Perforated II $\mathrm{x} / 2 \mathrm{xIO}$.

$34521 / 2 \mathrm{p}$ on $4 \mathrm{p}$ green, brown surcharge $4^{\circ}$ Perforated Ioxir $1 / 2$.

$34621 / 2 \mathrm{p}$ on $4 \mathrm{p}$ green, brown surcharge Variety: Perforated Io on three sides and I I $1 / 2$ on one side.

$3+721 / 2 \mathrm{p}$ on $4 \mathrm{p}$ green, brown surcharge $5^{\circ}$ Perforated Ioxi2 $1 / 2$.

$34^{8} 21 / 2 \mathrm{p}$ on $4 \mathrm{p}$ green, brown surcharge Reprints.

189 ?

Watermarked Crown and SA, letters wide apart.
Perforated 11 $1 / 2$.

349 21/2p on $4 p$ green, brown surcharge

$350 \quad 5 p$ on $6 p$ red brown, red surcharge

I 893 .

Same type, paper ana impression as corresponding values of preceding issue.

I. Watermarked Crown and SA, Ietters close together.

Io Perforated Io

35 I 3 P dull green

$2^{\circ}$ Perforated 15.

$352 \quad 1 / 2 \mathrm{p}$ brown

$353 \quad 1 / 2 \mathrm{p}$ pale brown

354 Ip green

$3552 \mathrm{p}$ orange red

$35621 / 2 \mathrm{p}$ on $4 \mathrm{p}$ green, brown surcharge

$357 \quad 3 \mathrm{p}$ dull green

$358 \quad 4 \mathrm{p}$ blue violet

$3596 \mathrm{p}$ bright blue

Varieties:

a. Double perforation vertically.

$3604 \mathrm{p}$ blue violet

b. Double perforation all round.

$36 \mathrm{I} 2 \mathrm{I} / 2 \mathrm{p}$ on $4 \mathrm{p}$ green, brown surcharge

II. Watermarked a six rayed star with short narrow points.

Perforated I5.

362 Ish brown

I894.

Typographed on soft white wove paper slightly surfaced. Size $181 / 2 \times 221 / 2 \mathrm{~mm}$.

Watermarked Crown and SA, letters close together.
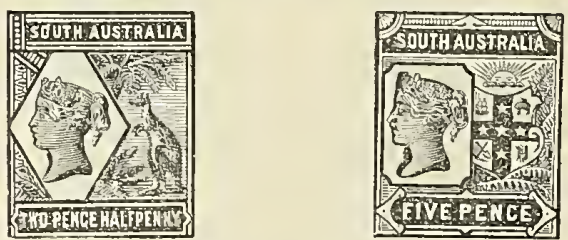

Perforated I 5

$363 \quad 21 / 2 \mathrm{p}$ violet blue

$364 \quad 5 \mathrm{p}$ dark violet

I 895.

Same type and impression as correspond ing values of preceding issues.

Watermarked Crown and SA, letters close together.

Perforated $\mathbf{3} 3$.

$365 \quad 1 / 2 \mathrm{p}$ brown

366 Ip green

$3672 \mathrm{p}$ red brown

$368 \quad 21 / 2 \mathrm{p}$ violet blue

$3694 \mathrm{p}$ deep mauve

$370 \quad 5 \mathrm{p}$ brown lilac

37 I $6 \mathrm{p}$ blue

I896.

Same type, impression and paper as I shilling of 1886 issue.

Watermarked a six rayed star with short broad points.

Perforated II $1 / 2$ clear cut.

$372 \quad$ Ish lake brown

\section{OFFICIAL STAMPS.}

$1868-74$.

Stamps of the regular issues surcharged in red, black or blue with one or more initials.

$$
\text { A. (Architect or Audit). }
$$

A. Red surcharge

Watermarked a large: $i \times$ rayed star with long narrow points.

\author{
I0 Roulettted. \\ 5 OI 2 p vermilion (No. 38 ) \\ 502 Ish brown (No. 49) \\ $2^{\circ}$ Perforated II $1 / 2$. \\ 5034 p dull purple (No. 73) \\ $3^{\circ}$ Perforated II $1 / 2 \times 121 / 2$ \\ $504 \quad 4$ p dull purple (No. 84 )
}


B. Black surcharge.

I. Watermarked a large six rayed star with long narrow points.

$$
I^{\circ} \text { Rouletted. }
$$

5052 2sh rose carmine (No. 52)

$2^{\circ}$ Perforated II $1 / 2$

$506 \quad 6 \mathrm{p}$ blue (No. 74 )

$3^{\circ}$ Perforated II $1 / 2 \times 121 / 2$.

$507 \quad 6 p$ blue (No 85)

$4^{\circ}$ Perforated to.

5084 p dull purple (No. 133)

II. Watermarked Crown and SA, letters wide apart.

Rouletted.

$5092 \mathrm{p}$ orange red (No. I05)

(without period).

A. Red surcharge.

Watermarked a large six rayed star with long narrow points.

Rouletted.

5 I0 Ip green (No. 35)

5 I I $6 \mathrm{p}$ blue (No. 40)

5 I2 Ish brown (No. 49)

B. Black surcharge.

Watermarked a large six rayed star with long narrow points.

$I^{\circ}$ Perforated II $1 / 2$

5I3 2sh deep carmine lake (No. I 76 )

2.) Perforated II $1 / 2 \times 121 / 2$.

5I4 2sh deep carmine lake (No. I86)

\section{A. C. (Attorney General).}

A. Red surcharge.

Watermarked a large six rayed star with long narrow points.

Rouletted.

5I5 Ip green (No. 35)

$5 \mathrm{I} 62 \mathrm{p}$ vermilion (No. 38$)$

$5 \mathrm{I7} 6 \mathrm{p}$ blue (No. 40)

5 I8 Ish brown (No. 49)

B. Blue surcharge.

I. Watermarked a large six rayed siar with long narrow points.

Rouletted.

5 I9 6 p blue (No. 40)

II. Watermarked Crown and SA, letters wide apart.

Rouletted.

$520 \quad 2 \mathrm{p}$ orange red (No. I05)

C. Black surcharge.

I. Watermarked a large six rayed s'ar with long narrow points.

$I^{\circ}$ Perforated II $1 / 2 \mathrm{x}$ roulet ted.

$521 \quad$ Ip green (No. 59)

$5226 \mathrm{p}$ blue (No. 62)

523 Ish brown (No. 64)

$2^{\circ}$ Perforated I I $1 / 2$.

524 Ip green (No. 70)

$525 \quad 4 \mathrm{p}$ dull purple (No. 73)

$5266 \mathrm{p}$ blue (No. 74 )

$3^{\circ}$ Perforated II $1 / 2 \times 121 / 2$

527 Ip green (No. 8I)

$528 \quad 4 \mathrm{p}$ dull purple (No. 84 )

$5296 \mathrm{p}$ blue (No. 85)

$4^{\circ}$ Perforated io.

$530 \quad 4 \mathrm{p}$ dull purple (No. I33)

$531 \quad$ Ish brown (No. I36)

II. Watermarked Crown and SA, letters wide apart.

I $^{\circ}$ Rouletted.

$2 p$ orange red (No. IO5) $2^{\circ}$ Perforated 10

$5332 \mathrm{p}$ orange red (No. 138 )

A. O. (Audit Office)

A. Red surcharge.

Watermarked a large six rayed star with long narrow points.

$I^{\circ}$ Rouletted.

$5346 p$ blue (No, 40)

$2^{\circ}$ Perforated II $1 / 2$.

$5354 \mathrm{p}$ dull purple (No. 73 )

$3^{\circ}$ Perforated II I $/ 2 \times 121 / 2$.

$536 \quad 4 p$ dull purple (No. 84 )

B. Blue surcharge.

I. Watermarked a large six rayed star with long narrow points.

$I^{\circ}$ Rouletted.

5376 blue (No. 40)

$2^{\circ}$ Perforated iा $1 / 2$.

538 Ip green (No. 70)

$3^{\circ}$ Perforated II $1 / 2 \times 121 / 2$.

539 Ip green (No. 8I)

II. Watermarked Crown and SA, letters wide apart.

Rouletted.

$540 \quad 2 \mathrm{p}$ orange red (No. I05)

C. Black surcharge.

I. Watermarked a large six rayed star with long narrow points.

$I^{\circ}$ Roulet ted.

$54 \mathrm{I} \quad 2 \mathrm{p}$ orange red (No. I26)

5426 p blue (No. 40)

$2^{\circ}$ Perforated i I $1 / 2 \times$ rouletted.

543 Ish brown (No. 64)

$3^{\circ}$ Perforated I I $1 / 2$.

544 Ip green (No. 70)

5454 p dull purple (No. 73)

5464 p dull purple (No. I 7 I)

5476 blue (No. 74)

548 Ish brown (No. 75)

$4^{0}$ Perforated II $1 / 2 \times 121 / 2$

549 Ip green (No. 8I)

$550 \quad 4$ p dull purple (No. 84)

55 I $4 \mathrm{p}$ dull purple (No. 182)

$5526 \mathrm{p}$ blue (No. 85 )

553 Ish brown (No. 87)

$5^{\circ}$ Perforated ro.

554 Ip green (No. I 31)

5554 p dull purple (No. I33)

556 Ish brown (No. I36)

$6^{\circ}$ Perforated Ioxit 1/2, I21/2 irregularly.

$5574 \mathrm{p}$ dull purple (No. I 58 )

II. Watermarked Crown and SA, letters wide apart.

Perforated ro.

$55^{8} \quad 2 p$ orange red (No. 138 )

III. Watermarked V over Crown.

Perforated ro.

$559 \quad 4 \mathrm{p}$ dull purple (No. 194)

B. Dirths and Deaths).

Red surcharge.

Watermarked a large six rayed star with long narrow points.

Rouletted.

$560 \quad 2 p$ vermilion (No. 38 )

$56 \mathrm{I} \quad 6 \mathrm{p}$ blue (No. 40)

562 Ish brown (No, 49)

B. C. (Bo'anical Gardens).

A. Red surcharge.

Watermarked a large six rayed star with long narrow points. 


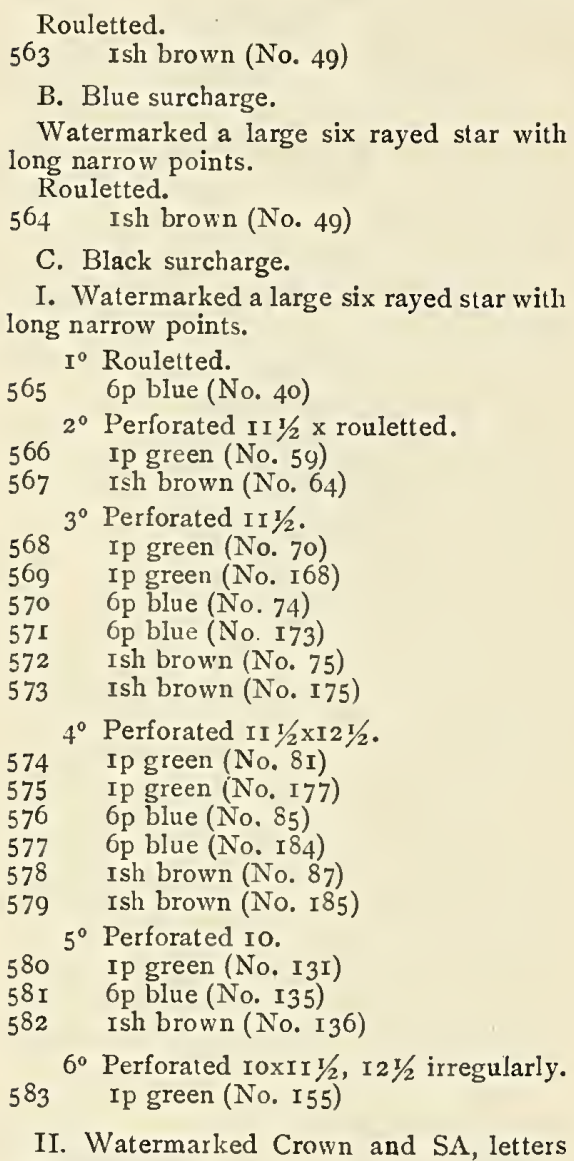
wide apart.

I $^{\circ}$ Rouletted.

$584 \quad 2 p$ orange red (No, IO5)

$2^{\circ}$ Perforated ro.

585 2p orange red (No I38)

III. Watermarked V over Crown.

Perforated Io.

$5862 p$ orange red (No. I93)

B. N. (Births and Marriages).

A. Red surcharge.

Watermarked a large six rayed star with long narrow points.

Rouletted.

$587 \quad 2 p$ vermilion (No. 38 )

B. Black surcharge.

Watermarked Crown and SA, letters wide apart.

Rouletted.

$588 \quad 2 \mathrm{p}$ orange red (No. ro5)

$$
\text { C. (Customs). }
$$

A. Red surcharge.

Watermarked a large six rayed star with long narrow points.

$I^{\circ}$ Rouletted.

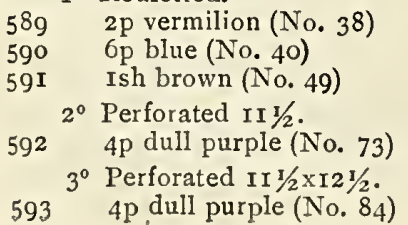

B. BIue surcharge.

I. Watermarked a large six rayed star with long narrow points.

Rouletted.

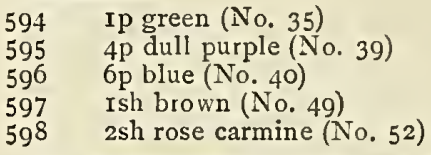

II. Watermarked Crown and SA, letters wide apart.

Rouletted.

$599 \quad 2 \mathrm{p}$ orange red (No. ro5)

C. Black surcharge.

I. Watermarked a large six rayed star with long narrow points.

$I^{\circ}$ Rouletted.

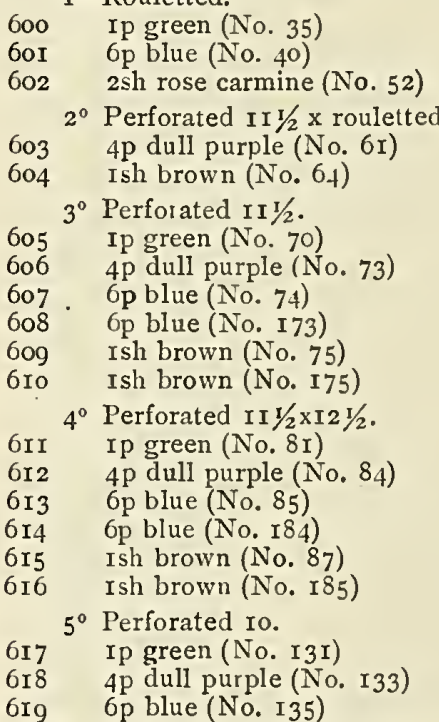

$6 r_{9} 6 \mathrm{p}$ blue (No. I35)

$6^{\circ}$ Perforated roxrI $1 / 2$, I $21 / 2$ irregularly. 620 Ip green (No, I 55)

$62 \mathrm{I} \quad 4 \mathrm{p}$ dull purple (No. I58)

Il. Watermarked Crown and SA, letters wide apart.

$\mathrm{I}^{\circ}$ Perforated io $x$ rouletted.

$6222 p$ orange red (No. I37)

$2^{\circ}$ Perforated ro.

$6232 \mathrm{p}$ orange red (No. $\mathrm{r}_{3} 8$ )

$3^{\circ}$ Perforated ro on three sides II $1 / 2$ on the other.

$6242 p$ orange red (No. I66)

III. Watermarked $\mathrm{V}$ over Crown.

Perforated 1o.

$625 \quad 2 \mathrm{p}$ orange red (No. I93)

C. D. (Commissariat Department).

A. Red surcharge.

Watermarked a large six rayed star with long narrow points.

$I^{\circ}$ Rouletted.

6262 p vermilion (No. 38 )

627 6p blue (No. 40 )

628 Ish brown (No. 49)

$2^{\circ}$ Perforated II $1 / 2$.

$629 \quad 4 p$ dull purple (No. 73)

$3^{\circ}$ Perforated II $1 / 2 \times 2_{2} 1 / 2$.

$630 \quad 4$ p dull purple (No. 84 )

$B$. Blue surcharge.

Watermarked a large six rayed star with long narrow points.

Rouletted.

63 I $6 \mathrm{p}$ blue (No. 40) 
C. Black surcharge.

I. Watermarked a large six rayed star with long narrow points.

$I^{\circ}$ Perforated II $1 / 2 \times$ rouletted.

632 Ip green (No. 59)

633 6p blue (No. 62)

634 Ish brown (No. 64)

$2^{\circ}$ Perforated II $1 / 2$.

6354 p dull purple (No. 73)

$3^{\circ}$ Perforated I I $1 / 2 \times 121 / 2$.

$636 \quad 4 \mathrm{p}$ dull purple (No. 84)

$4^{\circ}$ Rouletted.

$6372 \mathrm{p}$ orange red (No. I26)

$5^{\circ}$ Rouletted on four sides and perfora-

ted $I I \frac{1}{2}$ on four sides.

$638 \quad 2 p$ orange red (No. I 30 )

II. Watermarked Crown and SA, letters wide apart.

Rouletted.

$6392 \mathrm{p}$ orange red (No. I05)

C. (Crown Lands).

A. Red surcharge.

Watermarked a large six rayed star with long narrow points.

I' Rouletted.

$640 \quad 2 p$ vermilion $(\mathrm{No} .38)$

$64 \mathrm{I} \quad 6 \mathrm{p}$ blue (No. 40)

642 Ish brown (No. 49)

o Perforated I I $1 / 2$

$6434 \mathrm{p}$ dull purple (No. 73)

$3^{0}$ Perforated II $1 / 2 \times 121 / 2$.

$644 \quad 4 \mathrm{p}$ dull purple (No. 84 )

B. Blue surcharge.

I. Watermarked a large six rayed star with long narrow points.

Rouletted.

$645 \quad 4 \mathrm{p}$ dull purple (No. 39)

$6466 \mathrm{p}$ blue (No. 40)

II. Watermarked Crown and $S A$, letters wide apart.

Roulet ted.

647 2p orange red (No. 105)

C. Black surcharge.

I. Watermarked a large six rayed star with long narrow points.

$I^{\circ}$ Rouletted.

$648 \quad 2 \mathrm{p}$ orange red (No. I26)

$648 \mathrm{a}$ 6p blue (No. 40)

649 2sh rose carmine (No. 5.2)

$2^{\circ}$ Perforated II $1 / 2 \times$ rouletted.

650 Ish brown (No. 64)

$3^{\circ}$ Perforated II $1 / 2$.

65I 4 p dull purple (No. 73)

652 6p blue (No. 74)

653 6p blue (No. I73)

654 Ish brown (No. I75)

655 2sh pale rose carmine (No. 77)

$65^{6}$ 2sh deep carmine lake (No. I76)

$4^{0}$ Perforated II $1 / 2 \times 121 / 2$

6574 p dull purple (No. 84)

$658 \quad 6 p$ blue (No. 85)

659 6p blue (No. 184)

660 Ish brown (No. I85)

66 I 2sh pale rose carmine (No. 89)

662 2sh deep carmine lake (No. I86)

$5^{\circ}$ Perforated io

$6634 \mathrm{p}$ dull purple (No. I 33)

$6^{\circ}$ Perforated Ioxi I $1 / 2$, I2 $1 / 2$ irregularly. $6644 \mathrm{p}$ dull purple (No. I58)

II. Watermarked Crown and SA, letters wide apart.

$I^{\circ}$ Rouletled.

665 2p orange red (No. I05)
$2^{0}$ Perforated io.

$6662 p$ orange red (No. 138 )

$3^{\circ}$ Perforated Ioxi 1 1 $2,121 / 2$ irregularly.

667 2p orange red (No. I66)

III. Watermarked V over Crown.

Perforated Io.

$668 \quad 2 p$ orange red (No. I93)

$6694 \mathrm{p}$ dull purple (No. I94)

Variety: No watermark.

$670 \quad 4 \mathrm{p}$ dull purple

C. 6. (Census Office).

A. Red surcharge.

Watermarked a large six rayed star with long narrow points.

I $^{\circ}$ Rouletted.

$67 \mathrm{I} 2 \mathrm{p}$ vermilion (No. 38)

$6726 \mathrm{p}$ blue (No. 40)

673 Ish brown (No. 49)

$2^{\circ}$ Perforated II $1 / 2$.

$674 \quad 4 \mathrm{p}$ dull purple (No. 73)

$3^{\circ}$ Perforated II $1 / 2 \times 12 \frac{1}{2}$.

6754 p dull purple (No. 84 )

B. Black surcharge.

I. Watermarked a large six rayed star with long narrow points.

I $^{\circ}$ Rouletted.

$676 \quad 2 \mathrm{p}$ orange red (No. I26)

6772 sh rose carmine (No. 52 )

$2^{\circ}$ Perforated II $1 / 2$.

$678 \quad 4 \mathrm{p}$ dull purple (No. 73)

$679 \quad 6 p$ blue (No. 74.)

680 Ish brown (No. 75)

$3^{\circ}$ Perforated II $1 / 2 \times 121 / 2$

68I $4 \mathrm{p}$ dull purple (No. 84)

682 6p blue (No. 85)

683 Ish brown (No. 87)

$4^{\circ}$ Perforated Io.

$684 \quad 4$ p dull purple (No. I 44)

$5^{\circ}$ Perforated IOxI I $1 / 2,121 / 2$ irregularly.

$6854 \mathrm{p}$ dull purple (No. I58)

686 Ish brown (No. I62)

I1. Watermarked Crown \& SA, letters wide apart.

$$
\begin{aligned}
& I^{\circ} \text { Rouletted. } \\
& 687 \text { 2p orange red (No. I05) } \\
& 2^{\circ} \text { Perforated Io }
\end{aligned}
$$

$6882 \mathrm{p}$ orange red (No. 138 )

2. (No period after $O)$.

Black surcharge.

Watermarked a large six rayed star with long narrow points.

I0 Perforated II $1 / 2$.

$689 \quad 2$ sh pale rose carmine (No. 77 )

$2^{0}$ Perforated II $1 / 2 \times 121 / 2$.

$600 \quad 2$ sh pale rose carmine (No, 89)

$3^{\circ}$ Perforated roxi 1 $1 / 2$, I $21 / 2$ irregularly.

69I 2sh deep carmine lake (No. I64)

Q.P. (Commissioner of Police).

Red surcharge.

Watermarked a large six rayed star with long narrow points.

${ }^{\circ}$ Rouletted.

692 Ip green (No. 35)

$693 \quad 2 \mathrm{p}$ vermilion (No. 38)

6946 blue (No. 40)

695 Ish brown (No. 49)

$2^{\circ}$ Perforated II $1 / 2$.

$696 \quad 4 \mathrm{p}$ dull purple (No. 73)

$3^{0}$ Perforated II $1 / 2 \times 121 / 2$

6974 p dull purple (No. 84 ) 

C. $S_{\text {. (Chief Secretary or Colonial }}^{\text {Surgeon). }}$

A. Red surcharge.

Watermarked a large six rayed star with long narrow points.

$\mathrm{I}^{0}$ Rouletted.

$698 \quad 2 \mathrm{p}$ vermilion (No. 38 )

$6996 \mathrm{p}$ blue (No. 40)

700 Ish brown (No. 49)

$2^{\circ}$ Perforated I $1 / 2$.

$701 \quad 4 p$ dull purple (No. 73)

$3^{\circ}$ Perforated $\mathrm{r} \mathrm{I} / 2 \times 12 \mathrm{r} / 2$

7024 dull purple (No. 84)

B. Blue surcharge.

I. Watermarked a large six rayed star with long narrow points.

Rouletted.

7034 p dull purple (No. 39)

7046 blue (No. 40)

II. Watermarked Crown \& SA, letters wide apart.

Rouletted.

$7052 p$ orange red (No. ro5)

C. Black surcharge.

I. Watermarked a large six rayed star with long narrow points.

Io Rouletted.

$706 \quad 2 \mathrm{p}$ orange red (No. 126$)$

$7074 \mathrm{p}$ dull purple (No. 39)

$2^{\circ}$ Perforated I I $1 / 2 \times$ rouletted.

$708 \quad 4$ p dull purple (No. 6o)

709 6p blue (No. 6r)

$710 \quad$ Ish brown (No. 63)

Variety: Printed on both sides.

7 I $\quad 6 p$ blue (No. 65)

$3^{\circ}$ Perforated II $\mathrm{I} / 2$

7124 d dull purple (No. 73)

$7136 \mathrm{p}$ blue (No. 74)

714 rsh brown (No. 75)

$4^{\circ}$ Perforated II $1 / 2 \times 121 / 2$.

$7{ }_{5} \quad 4 \mathrm{p}$ dull purple (No. 84)

$716 \quad 6 \mathrm{p}$ blue (No. 85)

717 Ish brown (No.87)

$5^{\circ}$ Perforated ro.

7184 dull purple (No. r44)

$7 \mathrm{r}_{9} \quad 6 \mathrm{p}$ blue (No. 135)

720 rsh brown (No. 136)

$6^{\circ}$ Perforated roxir $1 / 2,121 / 2$ irregularly. $4 \mathrm{p}$ dull purple (No. I 58 )

$7226 \mathrm{p}$ blue (No. I6o)

723 Ish brown (No. I 62)

724 2sh pale rose carmine (No. 163)

II. Watermarked Crown and SA, letters wide apart.

I ${ }^{\circ}$ Rouletted.

$7252 p$ orange red (No. 105 )

$2^{\circ}$ Perforated ro.

$7262 p$ orange red (No. I38)

III. Watermarked V over Crown.

Perforated Io.

$727 \quad 4 \mathrm{p}$ dull purple (No I94)

Variety: Printed on both sides.

$727 a \quad 4 p$ dull purple

\section{Sgn. (Colonial Surgeon)}

A. Block type.

Black surcharge.

Watermarked Crown and SA, letters wide apart.
Roulet ted.

728 2p orange red (No. I05)

B. Roman type. C. Sgn.

A. Red surcharge.

I. Watermarked a large six rayed star with long narrow points.

$I^{\circ}$ Rouletted.

$7292 \mathrm{p}$ vermilion (No. 38 )

$730 \quad 6 p$ blue (No. 40)

$2^{\circ}$ Perforated in $1 / 2$

73I 4p dull purple (No. 73)

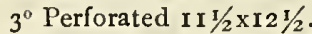

7324 p dull purple (No. 84 )

B. Black surcharge.

I. Watermarked a large six rayed star with long narrow points.

$I^{\circ}$ Perforated II $1 / 2$

7334 p dull purple (No. 73)

$7346 \mathrm{p}$ blue (No. 74)

$2^{\circ}$ Perforated II $1 / 2 \times 12 \mathrm{I} / 2$

$7354 \mathrm{p}$ dull purple (No. 84 )

736 6p blue (No. 85)

$3^{\circ}$ Perforated io.

7374 p dull purple (No. I33)

$4^{\circ}$ Perforated Ioxir 1 $12,{ }^{2} 1 / 2$ irregularly.

7384 p dull purple (No. 158)

II. Watermarked Crown \& SA, letters wide apart.

$r^{\circ}$ Rouletted.

$7392 \mathrm{p}$ orange red (No ro5)

$2^{\circ}$ Perforated ro.

$740 \quad 2 p$ orange red (No. 138 )

C. T. (Commissioner of Titles).

Red surcharge.

Watermarked a large six rayed star with long narrow points.

Rouletted.

$74 \mathrm{I} \quad$ Ish brown (No. 49)

D. B. (Destitute Board).

A. Red surcharge.

Watermarked a large six rayed star with long narrow points.

$I^{\circ}$ Rouletted.

742 Ip green (No. 35)

$743 \quad 2 \mathrm{p}$ vermilion (No. 38)

$744 \quad 6 \mathrm{p}$ blue (No. 40 )

745 rsh brown (No. 49)

$2^{0}$ Perforated Ir $1 / 2$.

7454 dull purple (No. 73)

$3^{\circ}$ Perforated II $1 / 2 \times 121 / 2$.

$747 \quad 4$ p dull purple (No. 84 )

B. Blue surcharge.

I. Watermarked a large six rayed star with long narrow points.

Rouletted.

$748 \quad 6 \mathrm{p}$ blue (No. 40)

II. Watermarked Crown \& SA, letters wide apart.

Rouletted.

$7492 p$ orange red (No. ro5)

C. Black surcharge.

I. Watermarked a large six rayed star with long narrow points.

$I^{\circ}$ Perforated II $1 / 2$.

$750 \quad$ Ip green (No. 69)

$75 \mathrm{I} \quad 4 \mathrm{p}$ dull purple (No. 73) 
$2^{\circ}$ Perforated II $1 / 2 \times 121 / 2$. Ip green (No. $8 \mathrm{I}$ )

753 Ip green (No. I 77)

$754 \quad 4$ p dull purple (No. 84)

$3^{\circ}$ Perforated $12 \mathrm{t} / 2$.

755 Ip green (No. 98)

$4^{\circ}$ Perforated Io.

$756 \quad 4$ p dull purple (No. I33)

757 Ish brown (No. I36)

$5^{\circ}$ Perforated IOxII $1 / 2$, I $21 / 2$ irregularly. $7586 \mathrm{p}$ blue (No. 158 )

II. Watermarked Crown \& SA, letters wide apart.

$I^{\circ}$ Rouletted.

759 2p orange red (No. IO5)

o Perforated Io.

$760 \quad 2 p$ orange red (No. I $3^{8}$ )

$3^{\circ}$ Perforated IOxII I $/ 2$, I $21 / 2$ irregularly.

7612 2p orange red (No. I66)

D. Pa (Deeds Registry).

Red surcharge.

Watermarked a large six rayed star with long narrow points.

Rouletted.

762 2p vermilion (No. 38)

763 6p blue (No. 40)

$763 a$ Islı brown (No. 49)

E. (Engineer).

A. Red surcharge.

Watermarked a large six rayed star with long narrow points.

$I^{\circ}$ Rouletted.

7642 p vermilion (No. 38)

765 6p blue (No. 40)

766 Ish brown (No. 49)

$2^{\circ}$ Perforated I I $1 / 2$.

$767 \quad 4 \mathrm{p}$ dull purple (No. 73)

$3^{\circ}$ Perforated II $1 / 2 \times 121 / 2$.

768 4p dull purple (No. 84)

B. Blue surcharge.

I. Watermarked a large six rayed star with long narrow points.

Rouletted.

$769 \quad 6 \mathrm{p}$ blue (No. 40)

769 a Ish brown (No. 49)

II. Watermarked Crown \& SA, letters wide apart.

Rouletted.

$7702 p$ orange red (No. I05)

C. Black surcharge.

I. Watermarked a large six rayed star with long narrow points.

$I^{\circ}$ Perforated I I $1 / 2 \mathrm{x}$ rouletted.

77I $4 \mathrm{p}$ dull purple (No. 6I)

$772 \quad 6 \mathrm{p}$ blue (No. 62)

773 Ish brown (No. 64)

$2^{\circ}$ Perforated II $1 / 2$.

$774 \quad 4 p$ dull purple (No. 73)

$775 \quad 6 \mathrm{p}$ blue (No. 74)

776 Ish brown (No. 75)

777 2sh deep carmine lake (No. 176$)$

$3^{\circ}$ Perforated I $1 / 2 \times 121 / 2$.

$778^{3} 4$ p dull purple (No. 84 )

$6 \mathrm{p}$ blue (No. 85 )

$\begin{array}{ll}779 & 6 \mathrm{p} \text { blue (No. 85) } \\ 780 & \text { Ish brown (No. 87) }\end{array}$

$78 \mathrm{I}$ 2sh deep carmine lake (No. I86)

$4^{\circ}$ Perforated Io.

7824 4p dull purple (No. I33)

783 Ish chest nut brown (No. I36)
$78+4$ p dull purple (No. I 58)

$784 \mathrm{a} \quad 6 \mathrm{p}$ blue (No. I6o)

785 Ish brown (No. I62)

II. Watermarked Crown \& SA, letters wide apart.

$I^{\circ}$ Rouletted.

786 2p orange red (No. I05)

$2^{\circ}$ Perforated ro.

787 2p orange red (No. I38)

E. B. (Education Board).

A. Red surcharge.

Watermarked a large six rayed star with long narrow points.

I $^{\circ}$ Rouletted.

$788 \quad 2 \mathrm{p}$ bright vermilion (No. 37)

788 a 6p blue (No. 40)

$2^{\circ}$ Perforated II $1 / 2$.

$789 \quad 4$ p dull purple (No. 73)

$3^{\circ}$ Perforated II $1 / 2 \times 121 / 2$.

7904 p dull purple (No. 84)

B. Blue surcharge.

I. Watermarked a large six rayed star with long narrow points.

Rouletted.

$79 \mathrm{I} \quad 4 \mathrm{p}$ dull purple (No. 39)

$792 \quad 6 p$ blue (No. 40)

II. Watermarked Crown \& SA, letters wide apart.

Rouletted.

793 2p orange red (No. I05)

C. Black surcharge.

I. Watermarked a large six rayed star with long narrow points.

I Rouletted.

7942 p orange red (No. I 26)

7954 4 dull purple (No. 39)

$2^{\circ}$ Perforated I I $1 / 2 \times$ rouletted.

$7966 \mathrm{p}$ blue (No. 6I)

$3^{\circ}$ Perforated ro.

7974 p dull purple (No. I33)

$4^{\circ}$ Perforated Ioxi I $1 / 2$, I2 $1 / 2$ irregularly.

7984 4p dull purple (No. I 58)

$5^{\circ}$ Perforated I I $1 / 2$.

$799 \quad 4 \mathrm{p}$ dull purple (No. I 7I)

$6^{\circ}$ Perforated I I $\mathrm{I} / 2 \times 12 \mathrm{I} / 2$.

8004 p dull purple (No. I82)

II. Watermarked Crown \& SA, letters wide apart.

I Rouletted.

$801 \quad 2 p$ orange red (No. 105)

$2^{\circ}$ Perforated Io.

$8022 p$ orange red (No. 138 )

$3^{\circ}$ Perforated IOxII $1 / 2$, I2 $1 / 2$ irregularly.

$8032 p$ orange red (No. I67)

III. Watermarked V over Crown.

Perforated Io.

804 2p orange red (No. I93)

Ga F. (Gold Fields).

Black surcharge.

I. Watermarked a large six rayed star with long narrow points.

Rouletted.

$8056 p$ blue (No. 40)

II. Watermarked Crown \& SA, letters wide apart. 
$I^{\circ}$ Perforated Iox rouletted. $2 p$ orange red (No. 137)

$2^{\circ}$ Perforated ro.

$8072 \mathrm{p}$ orange red (No. $\left.{ }_{3}{ }^{8}\right)$

G. $\because$ (Government Printer).

A. Red surcharge.

Watermarked a large six rayed star with long narrow points.

I. Rouletted.

$808 \quad$ Ip green (No. 35)

8096 p blue (No. 40)

8 ro Ish brown (No. 49)

$2^{\circ}$ Perforated I I $1 / 2$

8 I $\quad 4 p$ dull purple (No. 73)

$3^{0}$ Perforated II $1 / 2 \times 121 / 2$.

8I2 4p dull purple (No. 84)

B. Blue surcharge.

I. Watermarked a large six rayed star with long narrow points.

$I^{\circ}$ Rouletted.

8I3 Ip green (No. 35)

8 I 4 Ish brown (No. 49)

8 I 5 2sh rose carmine (No. 52)

$2^{\circ}$ Perforated I I $1 / 2 \times$ rouletted.

8 I6 Ip green (No. 59)

II. Watermarked Crown \& SA, letters wide apart.

8I 7 2p orange red (No. IO5)

C. Black surcharge.

I. Watermarked a large six rayed star with long narrow points.

$I^{\circ}$ Rouletted.

8 I 8 Ip green (No. 35 )

8 I9 Ish brown (No.49)

$820 \quad 2$ sh rose carmine (No. 52)

$2^{\circ}$ Perforated II $1 / 2 \times$ rouletted.

82 I Ip green (No. 59)

8226 p blue (No. 62)

$3^{\circ}$ Perforated II $1 / 2$.

823 Ip green (No. 70)

824 Ip green (No. I68)

825 2sh pale rose carmine (No. 77)

826 2sh deep carmine lake (No. I 76 )

$4^{\circ}$ Perforated I I $1 / 2 \times 121 / 2$.

827 Ip green (No. 82)

828 Ip green (No. I 77 )

829 2sh pale rose carmine (No. 80)

$830 \quad 2 s h$ deep carmine lake (No. I86)

$5^{\circ}$ Perforated ro.

83 I Ip green (No. I3I)

832 Ish brown (No. I36)

$6^{\circ}$ Perforated IOxi I $1 / 2$, I $21 / 2$ irregularly.

833 Ip green (No. I55)

834 Ish brown (No. I62)

835 2sh pale rose carmine (No. I63)

836 2sh deep carmine lake (No. I64)

II. Watermarked Crown \& SA, letters wide apart.

I $^{\circ}$ Rouletted.

837 2p orange red (No. I05)

2 o Perforated ro.

838 3p orange red (No. I38)

G.S. (Government Stores)

Red surcharge.

Watermarked a large six rayed star with long narrow points.

Rouletted.

$\begin{array}{ll}839 & \text { 2p vermilion (No. } 38 \text { ) } \\ 840 & 6 \mathrm{p} \text { blue (No. 40) }\end{array}$

$84 \mathrm{I}$ Ish brown (No. 49)
Q $:$ (Goolwa Tramway).

A. Red surcharge.

Watermarked a large six rayed star with long narrow points. $I^{\circ}$ Rouletted.

842 Ip green (No. 35)

843 2p vermilion (No. $3^{8}$ )

$8446 \mathrm{p}$ blue (No. 40)

845 Ish brown (No. 49)

Varieties: Without period after $\mathrm{T}$.

$846 \quad 2 \mathrm{p}$ vermilion (No. 38 )

$8476 \mathrm{p}$ blue (No. 40)

$2^{\circ}$ Perforated I I $1 / 2$.

$848 \quad 4$ p dull purple (No. 73)

$3^{\circ}$ Perforated II $1 / 2 \times 121 / 2$.

494 p dull purple (No. 84)

B. Black surcharge.

I. Watermarked a large six rayed star with long narrow points.

$I^{\circ}$ Perforated II $\mathrm{I} / 2$

850. 4 p dull purple (No. 73)

$2^{\circ}$ Perforated II $1 / 2 \times 121 / 2$.

$85 \mathrm{I} \quad 4 \mathrm{P}$ dull purple (No. 84)

$3^{\circ}$ Rouletted.

852 2p orange red (No. I 26)

II. Watermarked Crown \& SA, letters wide apart.

Rouletted.

8532 p orange red (No. IO5)

H. (Hospitals).

Black surcharge.

I. Watermarked Crown \& SA, letters wide apart.

$I^{\circ}$ Perforated ro.

$8542 p$ orange red (No. I 38 )

$2^{\circ}$ Perforated IOxiI $1 / 2$.

$8552 \mathrm{p}$ orange red (No. I66)

II. Watermarked $\mathrm{V}$ over Crown.

Perforated Io.

856 2p orange red (No. I993)

H. Assembly).

A. Red surcharge.

I. Watermarked a large six rayed star with long narrow points.

I ${ }^{\circ}$ Rouletted.

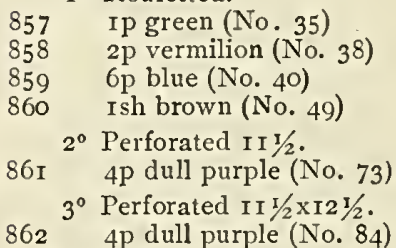

B. Black surcharge.

I. Watermarked a large six rayed star with long narrow points.

\begin{tabular}{|c|c|}
\hline $\begin{array}{l}863^{I^{0}} \\
864\end{array}$ & $\begin{array}{l}\text { Rouletted. } \\
6 \text { p blue (No. 40) } \\
\text { Ish brown (No. 49) }\end{array}$ \\
\hline $65^{2^{\circ}}$ & $\begin{array}{l}\text { Perforated I I } 1 / 2 \times \text { rouletted. } \\
\text { Ish dark brown (No. 64) }\end{array}$ \\
\hline $6^{3^{\circ}}$ & $\begin{array}{l}\text { Perforated I } 21 / 2 \times \text { rouletted. } \\
\text { Ish dark brown (No. } 68 \text { ) }\end{array}$ \\
\hline $\begin{array}{l}67 \\
68 \\
69 \\
70\end{array}$ & $\begin{array}{l}\text { Perforated I I } 1 / 2 \text {. } \\
\text { Ip green (No. } 70 \text { ) } \\
4 \mathrm{p} \text { dull purple (No. } 73 \text { ) } \\
6 \mathrm{p} \text { blue (No. } 74 \text { ) } \\
6 \mathrm{p} \text { blue (No. I 73) }\end{array}$ \\
\hline
\end{tabular}




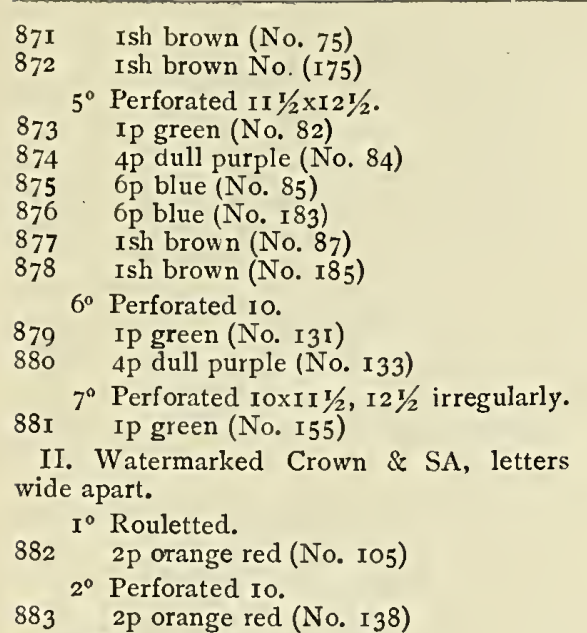

1. (Immigration Agent).

Red Surcharge.

Watermarked a large six rayed star with long narrow points.$$
I^{\circ} \text { Rouletted. }
$$

884 Ip green (No. 35)

885 2p vermilion (No. 38)

886 6p blue (No. 40)

$2^{\circ}$ Perforated I I $1 / 2$.

$887 \quad 4$ p dull purple (No. 73)

$3^{\circ}$ Perforated II $1 / 2 \times 121 / 2$.

$888 \quad 4$ p dull purple (No. 84)

. (Intestate Estates).

Black surcharge.

Watermarked Crown \& SA, letters wide apart.

Perforated Io.

$839 \quad 2 p$ orange red (No. I38)

. (Inspector of Sheep).

A. Red surcharge.

Watermarked a large six rayed star with long narrow points.

Rouletted.

$890 \quad 2 p$ vermilion (No. 38)

89 I $6 \mathrm{p}$ blue (No. 40)

B. Black surcharge.

I. Watermarked a large six rayed star with long narrow points.

$I^{\circ}$ Rouletted.

$892 \quad 2 p$ orange red (No. I26)

$2^{\circ}$ Perforated II $1 / 2 \times$ rouletted.

$8936 p$ blue (No. 62)

II. Watermarked Crown \& SA, letters wide apart.

Io Rouletted.

$894 \quad 2 p$ orange red (No. I05)

$2^{\circ}$ Perforated ro.

895 2p orange red (No. I38)

A. (Lunatic Asylum).

A. Red surcharge.

Watermarked a large six rayed star with long narrow points.

$$
I^{\circ} \text { Rouletted. }
$$

$896 \quad$ Ip green (No. 35)

8972 p vermilion (No. 38)

898 6p blue (No, 40)

899 Ish brown (No. 49) $2^{\circ}$ Perforated II $1 / 2$.

4 p dull purple (No. 73)

$3^{0}$ Perforated i I $\mathrm{t} / 2 \times 12 \mathrm{r} / 2$.

90I 4p dull purple (No. 84)

B. Black surcharge.

I. Watermarked a large six rayed star with long narrow points.

I $^{\circ}$ Rouletted.

$902 \quad 2$ sh rose carmine (No. 52)

$2^{\circ}$ Perforated I I $1 / 2 \times$ rouletted.

9036 blue (No. 62)

$3^{\circ}$ Perforated I I $1 / 2$.

$904 \quad 4 \mathrm{p}$ dull purple (No. 73)

$9056 \mathrm{p}$ blue (No. 74)

906 Ish brown (No. 75)

$4^{\circ}$ Perforated I I $1 / 2 \times 121 / 2$

907 4p dull purple (No. 84)

$908 \quad 6 \mathrm{p}$ blue (No. 85)

909 Ish brown (No. 87)

$5^{\circ}$ Perforated Io.

9 I0 4p dull purple (No. I33)

$6^{\circ}$ Perforated IOxI I $1 / 2$, I $2 \frac{1}{2}$ irregularly. 9I $\quad 4$ p dull purple (No. I 58)

II. Watermarked Crown \& SA, letters wide apart.

I ${ }^{\circ}$ Rouletted.

912 2p orange red (No. I05)

$2^{\circ}$ Perforated ro.

9132 p orange red (No. I38)

4. C. (Legislative Council).

A. Red surcharge.

Watermarked a large six rayed star with long narrow points.

Rouletted.

9I4 2p vermilion (No. 38)

$9156 \mathrm{p}$ blue (No. 40)

Varieties: Without period after C.

9I6 Ip green (No. 34)

9 I6a 2p vermilion (No. 38)

$9176 \mathrm{p}$ blue (No. 40)

B. Black surcharge.

I. Watermarked a large six rayed star with long narrow points.

${ }^{\circ}$ Rouletted.

9I8 6p blue (No. 40)

$2^{\circ}$ Perforated I I $1 / 2 \times$ rouletted.

$9196 \mathrm{p}$ blue (No. 62)

II. Watermarked Crown and SA, letters wide apart.

$I^{\circ}$ Rouletted.

$920 \quad 2 p$ orange red (No. I05)

$2^{\circ}$ Perforated roxrouletted.

$9212 \mathrm{p}$ orange red (No. 137)

L. (Legislative Librarian).

A. Red surcharge.

Watermarked a large six rayed star with long narrow points.

Io Rouletted.

922 2p vermilion (No. 38)

$9236 \mathrm{p}$ blue (No. 40)

Varieties: Without period after first I.

9242 p vermilion (No. 38)

$9256 \mathrm{p}$ blue (No. 40)

$2^{\circ}$ Perforated II $\pi / 2$

926 4P dull purple (No. 73)

$3^{\circ}$ Perforated II $1 / 2 \times 121 / 2$

9274 dull purple (No. 84)

B. Black surcharge.

Watermarked Crown and SA, letters wide apart. 
Perforated io.

928 2p orange red (No. 138)

L.

A. Red surcharge.

Watermarked a large six rayed star with long narrow points.

$I^{0}$ Rouletted.

$9292 \mathrm{p}$ vermilion (No. 38)

$9306 \mathrm{p}$ blue (No. 4o)

931 Ish brown (No. 49)

Varieties: Without period after $T$.

$932 \quad 2 p$ vermilion (No. 38 )

$9336 \mathrm{p}$ blue (No. 4o)

$2^{\circ}$ Perforated II $1 / 2$.

934 4p dull purple (No. 73)

$3^{\circ}$ Perforated I I $1 / 2 \times 121 / 2$.

9354 p dull purple (No. 84)

B. Blue surcharge.

I. Watermarked a large six rayed star with long narrow points.

Rouletted.

$936 \quad 6 \mathrm{p}$ blue (No. 40)

II. Watermarked Crown and SA, letters wide apart.

Rouletted.

$9372 p$ orange red (No. I05)

C. Black surcharge.

I. Watermarked a large six rayed star with long narrow points.

$r^{\circ}$ Rouletted.

938 2p orange red (No. I 26)

939 Ish brown (No. 49)

$2^{\circ}$ Perforated $\mathrm{r}$ I $1 / 2 \mathrm{x}$ rouletted.

9406 p blue (No. 62)

$3^{\circ}$ Perforated II $1 / 2$.

$94 \mathrm{I} \quad 4 \mathrm{p}$ dull purple (No. 73)

$9426 \mathrm{p}$ blue (No. 74)

943 6p dark blue (No. I 73)

$4^{0}$ Perforated I I $1 / 2 \times 121 / 2$.

$944 \quad 4 p$ dull purple (No. 84)

9456 plue (No. 85)

$9466 \mathrm{p}$ blue (No. I 84 )

$5^{\circ}$ Perforated 10.

$947 \quad 4$ dull purple (No. I33)

$9486 \mathrm{p}$ blue (No. I35)

$6^{\circ}$ Perforated Ioxi I $1 / 2$, I $2 \frac{1}{2}$ irregularly.

$9494 \mathrm{p}$ dull purple (No. I 58 )

$9506 \mathrm{p}$ blue (No. I6o)

95 I 2sh deep carmine lake (No. I64)

II. Watermarked Crown \& SA, letters wide apart.

Rouletted.

952 2p orange red (No. I05)

III. Watermarked V over Crown.

Perforated Io.

953

16. (Military).

A. Red surcharge.

Watermarked a large six rayed star with long narrow points.

Rouletted.

954 2p vermilion (No. 38)

$9556 \mathrm{p}$ blue (No. 40)

956 Ish brown (No. 49)

B. Black surcharge.

Watermarked a large six rayed star with long narrow points.

I 0 Rouletted.

9572 sh rose carmine (No. 52) $2^{\circ}$ Perforated I I $1 / 2 \times 121 / 2$.

958 Ish dark brown (No. 67)

1. B. (Marine Board).

A. Red surcharge.

Watermarked a large six rayed star with long narrow points.

$I^{\circ}$ Rouletted.

959 I p green (No. 35)

$960 \quad 2 \mathrm{p}$ vermilion (No. 38 )

$96 \mathrm{I} 6 \mathrm{p}$ blue (No. 40)

962 Ish brown (No. 49)

Variety: Perforated II $1 / 2$ at right side as well as rouletted.

962a $2 p$ vermilion

$2^{\circ}$ Perforated I I $1 / 2$

9634 4p dull purple (No. 73)

$3^{\circ}$ Perforated I I $1 / 2 \times 121 / 2$.

964 4p dull purple (No. 84 )

$4^{\circ}$ Perforated I I $1 / 2 \times$ rouletted.

$964 a \quad 4 p$ dull purple (No. 6r)

B. Black surcharge.

I. Watermarked a large six rayed star with long narrow points.

I0 Rouletted.

965 Ip green (No. 35)

9662 p orange red (No. I 26)

$967 \quad 6 \mathrm{p}$ blue (No. 40)

$2^{\circ}$ Perforated II $1 / 2$

968 Ip green (No. 7o)

$9694 \mathrm{p}$ dull purple (No. 73)

$970 \quad 6 p$ blue (No. 74)

97 Ish brown (No. 75)

$3^{\circ}$ Perforated II $1 / 2 \times 121 / 2$.

972 I p green (No. 8I)

973 4p dull purple (No. 84)

$9746 \mathrm{p}$ blue (No. 85)

975 Ish brown (No. 87)

$4^{\circ}$ Perforated ro.

$976 \quad 4$ p dull purple (No. I33)

$9776 \mathrm{p}$ blue (No. I 35)

978 Ish brown (No. I36)

$5^{\circ}$ Perforated IOxII $1 / 2, \times 21 / 2$ irregularly.

9794 p dull purple (No. I 58)

$980 \quad 6 \mathrm{p}$ blue (No. I6o)

$98 \mathrm{I}$ Ish brown (No. I62)

II. Watermarked Crown and SA, letters wide apart.

$\mathbf{I}^{\circ}$ Rouletted.

982 2p orange red (No. I05)

$2^{\circ}$ Perforated Io.

983 2p orange red (No. I38).

III. Watermarked V over Crown.

Perforated ro.

$984 \quad 4 p$ dull purple (No. I94)

19. (Manager of Railways).

A. Red surcharge.

Watermarked a large six rayed star with long narrow points.

Rouletted.

9852 p vermilion (No. 38 )

$986 \quad 6 \mathrm{p}$ blue (No. 40)

B. Black surcharge.

I. Watermarked a large six rayed star with long narrow points.

$r^{\circ}$ Rouletted.

987 2p orange red (No. I 26)

988 4p dull purple (No. 39)

$989 \quad 6 \mathrm{p}$ blue (No. 4o)

990 Ish brown (No. 49) 


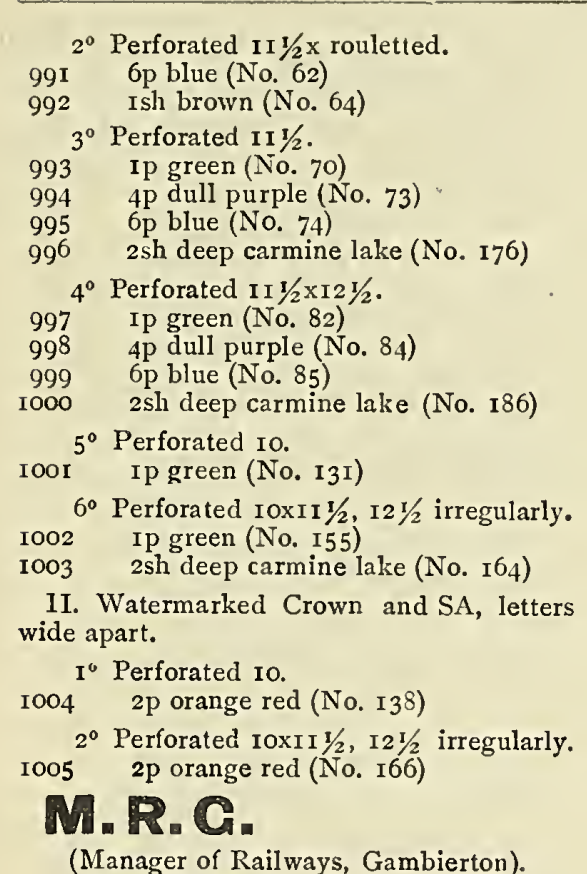

Railways, Gambierton)

A. Blue surcharge.

Watermarked Crown and SA, letters wide apart.

Rouletted.

I006 2p orange red (No. I05)

B. Black surcharge.

Watermarked Crown and SA, letters wide apart.

I Rouletted.

$10072 \mathrm{p}$ orange red (No. I05)

$2^{\circ}$ Perforated 10.

1008 2p orange red (No. I38)

10. (Northern Territory).

Black surcharge.

I. Watermarked a large six rayed star with long narrow points.

I ${ }^{\circ}$ Perforated II $1 / 2$.

I009 Ip green (No. 70)

Ioro 3p on $4 \mathrm{p}$ dark blue, black surcharge

(No. I 70)

ror I $4 \mathrm{p}$ dull purple (No. 73)

IOI2 $6 \mathrm{p}$ blue (No. 74)

IOI3 Ish brown (No. 75)

$2^{\circ}$ Perforated I2 $1 / 2$.

IOI3a Ip yellow green (No. 98)

$3^{\circ}$ Perforated I I $1 / 2 \times 121 / 2$.

IOI4 Ip green (No. 82)

IOI $5 \quad 3 \mathrm{p}$ on $4 \mathrm{p}$ dark blue, black surcharge (No. I 80 )

Ior6 4p dull purple (No. 84)

IOI7 $6 \mathrm{p}$ blue (No. 85 )

IOI8 Ish brown (No. 87)

II. Watermarked Ciown and SA, letters wide apart.

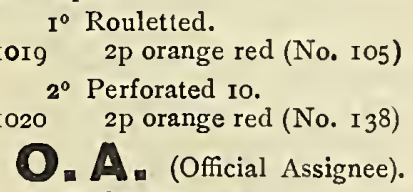

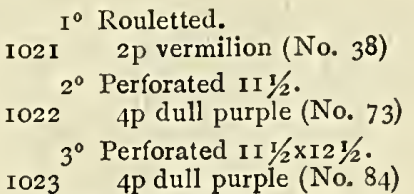

B. Blue surcharge.

Watermarked Crown and SA, Ietters wide apart.

Rouletted.

$10242 p$ orange red (No. I05)

C. Black surcharge.

I. Watermarked a large six rayed star with long narrow points.

$I^{\circ}$ Perforated $x \mathbf{I} / 2$.

$10254 \mathrm{p}$ dull purple (No. 73)

$2^{\circ}$ Perforated I $1 / 2 \times 121 / 2$.

I026 4p dull purple (No. 84)

$3^{\circ}$ Perforated Io.

I027 4p dull purple (No. I33)

II. Watermarked Crown and SA, letters wide apart.

I $^{\circ}$ Rouletted.

028 2p orange red (No. 105)

$2^{\circ}$ Perforated Io.

I029 2p orange red (No. 138 )

$3^{\circ}$ Perforated Iox rouletted.

I030 2p orange red (No. I37)

III. Watermarked V over Crown.

Perforated Io.

I03I 2p orange red (No. I93)

P. (Police)

A. Blue surcharge.

I. Watermarked a large six rayed star with long narrow points.

Rouletted.

I032 6p blue (No. 40)

II. Watermarked Crown and SA, letters wide apart.

Rouletted.

I033 2p orange red (No. I05)

B. Black surcharge.

I. Watermarked a large six rayed star with long narrow points.

I ${ }^{\circ}$ Rouletted.

I034 6p blue (No. 40)

$2^{\circ}$ Perforated I I $1 / 2 \mathrm{x}$ rouletted.

I035 6p blue (No. 62)

$3^{0}$ Perforated II $1 / 2$.

I036 6p blue (No. 74)

I037 6p blue (No. I73)

$4^{\circ}$ Perforated II $1 / 2 \times 121 / 2$.

I038 $6 \mathrm{p}$ blue (No. 85)

I039 6p blue (No. I84)

$5^{\circ}$ Perforated ro.

$1040 \quad 6 \mathrm{p}$ blue (No. 135)

II. Watermarked Crown and SA, letters wide apart.

${ }^{0}$ Rouletted.

I04I 2p orange red (No. I05)

$2^{\circ}$ Perforated I I $1 / 2 \times$ rouletted.

I042 2p orange red (No. II I)

$3^{\circ}$ Perforated II $1 / 2$.

I042a 2p orange red (No. IOg)

$4^{\circ}$ Perforated II $1 / 2 \times 121 / 2$.

I043 2p orange red (No. I Io)

$5^{\circ}$ Perforated Iox rouletted.

1044 2p orange red (No. I37) 


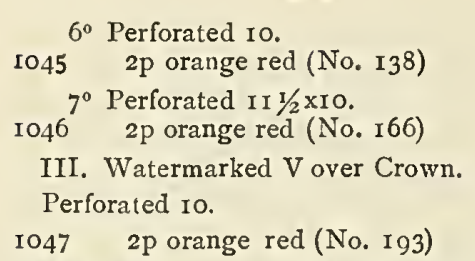

\section{A. (Protector of Aborigines).}

\section{A. Red surcharge.}

Watermarked a large six rayed star with long narrow points.

$$
\text { Rouletted. }
$$

I048 2p vermilion (No. 38 )

B. Black surcharge.

I. Watermarked a large six rayed star with long narrow points.

$$
\text { Rouletted, }
$$

I049 2p orange red (No. I 26)

II. Watermarked Crown and SA, letters wide apart.

I 0 Rouletted.

I05I 2p orange red (No. I05)

$2^{\circ}$ Perforated Io.

I052 2p orange red (No. I38)

D. (Post Office).

A. Red surcharge.

I. Watermarked a large six rayed star with long narrow points.

Rouletted.

$\begin{array}{ll}\text { I053 } & \text { Ip green (No. 35) } \\ \text { I054 } & \text { 2p vermilion (No. 38) } \\ \text { I055 } & \text { 6p blue (No. 40) } \\ \text { I056 } & \text { Ish brown (No. 49) }\end{array}$

I056 Ish brown (No. 49)

Variety: Two periods after $\mathrm{P}$ and none after $\mathrm{O}$.

I057 6p blue (No. 40)

B. Blue surcharge.

I. Watermarked a large six rayed star with long narrow points.

Rouletted.

I058 2p vermilion (No. 38)

II. Watermarked Crown and SA, letters wide apart.

Rouletted.

I059 2p orange red (No. IO5)

C. Black surcharge.

I. Watermarked a large six rayed star with long narrow points.

\begin{tabular}{|c|c|}
\hline $\begin{array}{l}1060 \\
1061 \\
1062\end{array}$ & $\begin{array}{l}\text { 2p orange red (No. I 26) } \\
6 \mathrm{p} \text { blue (No. } 40) \\
\text { I sh brown (No. } 49)\end{array}$ \\
\hline $063^{2^{0}}$ & $\begin{array}{l}\text { Perforated I I } 1 / 2 \times \text { rouletted } \\
\text { Ish brown (No. 64) }\end{array}$ \\
\hline $\begin{array}{l}063^{0} \\
065 \\
066\end{array}$ & $\begin{array}{l}\text { Perforated I I } 1 / 2 . \\
4 \mathrm{p} \text { dull purple (No. 73) } \\
6 \mathrm{p} \text { blue (No. } 74) \\
\text { Ish brown (No. } 75)\end{array}$ \\
\hline $\begin{array}{l}4^{0} \\
1067^{1068} \\
1069\end{array}$ & $\begin{array}{l}\text { Perforated I I I/2xI21/2. } \\
4 \mathrm{P} \text { dull purple (No. 84) } \\
\text { 6p blue (No. 85) } \\
\text { Ish brown (No. 87) }\end{array}$ \\
\hline & $\begin{array}{l}\text { Perforated Io. } \\
6 \mathrm{p} \text { blue (No. I35) } \\
\text { Ish brown (No. I36) }\end{array}$ \\
\hline
\end{tabular}

$I^{\circ}$ Rouletted. $6^{\circ}$ Perforated IOxII $1 / 2,121 / 2$ irregularly. Ip green (No. I 55)

I073 Ish brown (No. I62)

II. Watermarked Crown and SA, letters wide apart.

$$
\text { I }^{\circ} \text { Rouletted. }
$$

I074 2p orange red (No. I05)

$2^{\circ}$ Perforated Iox rouletted.

I075 2p orange red (No. I 37)

$3^{\circ}$ Perforated 10.

$1076 \quad 2 p$ orange red (No. 138 )

D. S. (Private Secretary).

A. Red surcharge.

Watermarkea a large six rayed star with long narrow points.

$$
\text { Io Rouletted. }
$$

$$
\begin{array}{cc}
\text { I077 } & \text { Ip green (No. 35) } \\
\text { I078 } & \text { 2p vermilion (No. 38) } \\
\text { I079 } & \text { 6p blue (No. 40) } \\
\text { I080 } & \text { Ish brown (No. 49) } \\
2^{\circ} & \text { Perforated I I } / 2 . \\
\text { I081 } & 4 \text { p dull purple (No. 73) } \\
3^{\circ} & \text { Perforated I I } / 2 \times 121 / 2 . \\
\text { I082 } & \text { 4p dull purple (No. 84) }
\end{array}
$$

B. Black surcharge.

I. Watermarked a large six rayed star with long narrow points,

$I^{\circ}$ Rouletted.

$\mathrm{IOS}_{3} 6 \mathrm{p}$ blue (No. 40)

I084 9p gray lilac (No. 45)

$2^{\circ}$ Perforated II $1 / 2 \times$ rouletted,

I085 Ip green (No. 59)

I086 6p blue (No.62)

I087 Ish brown (No. 64)

$3^{\circ}$ Perforated II $1 / 2$.

$1088^{3^{\circ}}$ Ip green (No. I 68)

I089 $3 \mathrm{p}$ on $4 \mathrm{p}$ sky blue, black surcharge (No. I 52)

Iogo $3 \mathrm{p}$ on $4 \mathrm{p}$ blue, black surcharge (No. I 70)

IOgI 4p dull purple (No. 73)

I092 $9 \mathrm{p}$ red lilac (No. 2or)

10932 sh pale rose carmine (No. 77)

$4^{\circ}$ Perforated I $1 / 2 \times 121 / 2$.

I094 Ip green (No. I77)

I095 $3 \mathrm{p}$ on $4 \mathrm{p}$ sky blue, black surcharge (No. I 53)

Iog6 $3 \mathrm{p}$ on $4 \mathrm{p}$ blue, black surcharge (No. I80)

I0974p dull purple (No. 84)

Io98 9p red lilac (No. 202)

I099 2sh pale rose carmine (No. 89)

$5^{\circ}$ Perforated Io.

I IOO Ip green (No. I $3 \mathrm{r}$ )

I IOI $3 \mathrm{p}$ on $4 \mathrm{p}$ slate blue, carmine surcharge (No. I48)

IIO2 3p on 4p blue, black surcharge (No. I 50)

I $0_{3} 4 \mathrm{p}$ dull purple (No. I33)

II04 6p blue (No. I35)

$6^{\circ}$ Perforated Ioxil $1 / 2,121 / 2$ irregularly.

I I05 4P dull purple (No. I 58 )

I 106 Iop on 9p orange yellow, black surcharge (No. I44)

II. Watermarked Crown and SA, letters wide apart.

Io Rouletted.

I107 2p orange red (No. I05)

$2^{\circ}$ Perforated ro.

1108 2p orange red (No. 138)

III. Watermarked V over Crown.

Perforated Io.

rog 2p orange red (No. 193) 
P.W (Public Works) (no period after W). Red surcharge.

Watermarked a large six rayed star with long narrow points.

Rouletted.

II IO $2 \mathrm{p}$ vermilion (No. 38 )

IIII 6p blue (No. 40)

I I 2 Ish brown (No. 49)

P. M. (with period after W).

Black surcharge.

I. Watermarked a large six rayed star with long narrow points.

$I^{\circ}$ Rouletted.

III3 2p orange red (No. I26)

III4 $6 \mathrm{p}$ blue (No. 40)

$2^{0}$ Perforated I I $1 / 2 \times$ rouletted.

III5 Ish brown (No. 49)

$3^{\circ}$ Perforated Io.

II 6 4p dull purple (No. I33)

II. Watermarked Crown and SA, letters wide apart.

$I^{\circ}$ Rouletted.

III 7 2p orange red (No. I05)

${ }^{\circ}$ Perforated Io.

I I 8 2p orange red (No. I38)

R. B. (Road Board).

Red surcharge.

Watermarked a large six rayed star with long narrow points.

$I^{\circ}$ Rouletted.

II I9 Ip green (No. 35)

II2O 6p blue (No. 40)

II2I Ish brown (No. 49)

$2^{\circ}$ Perforated II $1 / 2$

I 1224 p dull purple (No. 73). .

$3^{\circ}$ Perforated II $1 / 2 \times 121 / 2$.

II23 4p dull purple (No. 84 )

B. Blue surcharge.

Watermarked Crown \& SA, letters wide apart.

Rouletted.

I I24 2p orange red (No. ro5)

C. Black surcharge.

I. Watermarked a large six rayed star with long narrow points.

$\mathbf{I}^{\circ}$ Rouletted.

I 252 sh rose carmine (No. 52)

$2^{\circ}$ Perforated II $1 / 2$.

I 26 Ip green (No. I3I)

II 27 4p dull purple (No. I33)

$3^{\circ}$ Perforated I I $1 / 2 \times$ rouletted.

I I 27a Ip blue green (No. 59)

II. Watermarked Crown and SA, letters wide apart.

$I^{\circ}$ Rouletted.

I $128 \quad 2 \mathrm{p}$ orange red (No. IO5)

$2^{\circ}$ Perforated Io.

II 29 2p orange red (No. 138 )

III. Watermarked V over Crown.

Perforated Io.

II30 2p orange red (No. I93)

R.C. (Registrar General).

A. Red surcharge.

Watermarked a large six rayed star with long narrow points.

Rouletted.

$\begin{array}{ll}\text { I I3I } & \text { 2p vermilion (No. 38) } \\ \text { II32 } & \text { 6p blue (No. 40) } \\ \text { II33 } & \text { Ish brown (No. 49) }\end{array}$
B. Blue surcharge.

I. Watermarked a large six rayed star with long narrow points.

Perforated II $1 / 2 \mathrm{x}$ rouletted.

II34 6p blue (No. 62)

II. Watermarked Crown and SA, letters wide apart.

Rouletted.

I $352 \mathrm{p}$ orange red (No, 105)

C. Black surcharge.

I. Watermarked a large six rayed star with long narrow points.

$I^{\circ}$ Rouletted.

I $136 \quad 2 p$ orange red (No. I 26)

$2^{\circ}$ Perforated I I $1 / 2 \mathrm{x}$ rouletted.

II37 6p blue (No. 62)

II38 Ish brown (No. 64)

$3^{\circ}$ Perforated Io.

II 39 6p blue (No. I35)

II 40 Ish brown (No. I36)

$4^{\circ}$ Perforated IO, II $1 / 2$, I $21 / 2$ irregularly.

II4I $6 \mathrm{p}$ blue (No. I6o)

II. Watermarked Crown and SA, letters wide apart.

$I^{\circ}$ Rouletted.

Ir42 $2 p$ orange red (No. IO5)

$2^{\circ}$ Perforated Iox rouletted.

I $432 \mathrm{p}$ orange red (No. IO5)

$3^{\circ}$ Perforated ro

I $442 \mathrm{p}$ orange red (No. I38)

$4^{\circ}$ Perforated Io, II 1 12, I $21 / 2$ irreguiarly.

II45 2p orange red (No. I66)

III. Watermarked V over Crown.

Perforated Io.

I $46 \quad 2 p$ orange red (No. I93)

8. (Sheriff)

A. Red surcharge.

Watermarked a large six rayed star with long narrow points.

Rouletted.

II 47 2p vermilion (No. 38 )

I I47a 6p blue (No. 40)

B. Blue surcharge.

I. Watermarked a large six rayed star with long narrow points.

Perforated II $1 / 2 \times$ rouletted.

I I48 6p blue (No. 62)

II. Watermarked Crown and SA, letters wide apart.

Rouletted.

I I $492 \mathrm{p}$ orange red (No. I05)

C. Black surcharge.

I. Watermarked a large six rayed star with long narrow points.

$I^{\circ}$ Rouletted.

II50 6p blue (No. 40)

$2^{\circ}$ Perforated I I $1 / 2$.

II I 4p dull purple (No. 73)

II52 6p blue (No. 74)

II53 6p blue (No. I73)

$3^{\circ}$ Perforated II $1 / 2 \times 121 / 2$.

II $54 \quad 4 \mathrm{p}$ dull purple (No. 84)

II55 6p blue (No. 85)

II56 6p blue (No. I84)

$4^{\circ}$ Perforated Io.

II57 4p dull purple (No. I33)

II58 6p blue (No. I 35)

$5^{\circ}$ Perforated IO, II $1 / 2$, I $21 / 2$ irregularly.

II $594 \mathrm{p}$ dull purple (No. I58)

II. Watermarked Crown and SA, letters wide apart. 


\author{
$I^{\circ}$ Rouletted. \\ I $60 \quad 2 \mathrm{p}$ orange red (No. I05) \\ $2^{\circ}$ Perforated Iox rouletted. \\ II6I 2 p orange red (No. I37) \\ $3^{\circ}$ Perforated Io. \\ I 162 2p orange red (No. I38) \\ S. . . (Supreme Court). \\ A. Red surcharge. \\ Watermarked a large six rayed star with \\ long narrow points. \\ Rouletted. \\ I 63 2p vermilion (No. 38) \\ I 64 6p blue (No. 40) \\ B. Black surcharge. \\ I. Watermarked Crown \& SA, letters \\ wide apart. \\ Perforated Io. \\ II65 2p orange red (No. I38) \\ II. Watermarked V over Crown. \\ Perforated Io. \\ II66 2p orange red (No. I93) \\ S.G. (Surveyor General). \\ A. Red surcharge.
}

Watermarked a large six rayed star with long narrow points.

$I^{\circ}$ Rouletted.

I 672 p vermilion (No. 38 )

II68 6p blue (No. 40)

$2^{\circ}$ Perforated II $1 / 2$.

I $694 \mathrm{p}$ dull purple (No. 73)

$3^{\circ}$ Perforated II $1 / 2 \times 121 / 2$

I $704 \mathrm{p}$ dull purple (No. 84)

B. Blue surcharge.

Watermarked Crown and SA, letters wide apart.

Rouletted.

II7I 2p orange red (No. I05)

C. Black surcharge.

I. Watermarked a large six rayed star with long narrow points.

I $^{\circ}$ Rouletted.

I1 72 2p orange red (No. I26)

II73 4p dull purple (No. 39)

$2^{\circ}$ Perforated II $1 / 2 \times$ rouletted.

II $744 \mathrm{P}$ dull purple (No. 6I)

$3^{\circ}$ Perforated II $\%$

I $75 \quad 4 \mathrm{p}$ dull purple (No. 73 )

II $764 \mathrm{P}$ dull lilac (No. I7I)

$4^{\circ}$ Perforated II $1 / 2 \times 121 / 2$.

I $77 \quad 4 \mathrm{p}$ dull purple (No. 84)

I 78 4p dull lilac (No. I82)

$5^{\circ}$ Perforated IO

I $79 \quad 4 \mathrm{p}$ dull purple (No. I 33)

I $806 \mathrm{p}$ blue (No. I35)

$6^{\circ}$ Perforated 10, I1 $1 / 2,121 / 2$ irregularly.

I 8 I 4 p dull purple (No. I58)

I $82 \quad 6 \mathrm{p}$ blue (No. I35)

II. Watermarked Crown and $\mathrm{SA}$, letters wide apart.

I" Rouletted.

II 83 2p orange red (No. I05)

$2^{\circ}$ Perforated Iox rouletted.

I $84 \quad 2 p$ orange red (No. I 37 )

$3^{\circ}$ Perforated Io.

I $185^{3}$ 2p orange red (No. I38)

III. Watermarked V over Crown.

Perforated Io.

I 86 2p orange red (No. I93)

S. W. (Stipendiary Magistrate.)
A. Red surcharge.

Watermarked a large six rayed star with long narrow points.

$I^{\circ}$ Rouletted.

II 87 Ip green (No. 35$)$

I 188 2p vermilion (No. 38 )

I $89 \quad 4 \mathrm{p}$ dull purple (No. 39)

I I9o 6p blue (No. 40)

IIgI Ish brown (No. 49)

Varieties: Without period after M.

I $1922 \mathrm{p}$ vermilion (No. 38 )

I I93 4p dull purple (No. 39)

$2^{\circ}$ Perforated II $1 / 2 \times 121 / 2$.

I $194 \quad 4$ p dull purple (No. 84)

B. Blue surcharge.

I. Watermarked a large six rayed star with long narrow points.

Rouletted.

I $95 \quad$ 2P vermilion (No. 38)

I I96 4p dull purple (No. 39)

I $96 \mathrm{a} 6 \mathrm{p}$ dull blue No. (4I)

II. Watermarked Crown and SA, letters wide apart.

Rouletted.

II97 2p orange red (No. IO5)

C. Black surcharge.

I. Watermarked a large six rayed star with long narrow points.

$I^{\circ}$ Rouletted.

I $198 \quad 2 \mathrm{p}$ orange red (No. I26)

I 1994 4 dull purple (No. 39)

$2^{\circ}$ Perforated i I $1 / 2 \times$ rouletted.

I 2006 6russian blue (No. 63)

3" Perforated $121 / 2 x$ rouletted.

I 200a 6p Prussian blue (No. 67)

$4^{\circ}$ Perforated 1 I $1 / 2$.

I20I IP green (No. 7o)

I2O2 4p dull purple (No. 73)

I2034 4P dull lilac (No. I7I)

$4^{\circ}$ Perforated II $1 / 2 \times 121 / 2$.

I 204 Ip green (No. 82)

12054 p dull purple (No. 84)

I $2064 \mathrm{p}$ dull lilac (No. I82)

$5^{\circ}$ Perforated io.

1207 Ip green (No. I3I)

I $2084 \mathrm{p}$ dull purple (No. I33)

I 2096 6p blue (No. I35)

$6^{\circ}$ Perforated IOxII $1 / 2,12 \frac{1}{2}$ irregularly.

I2 Io $4 p$ dull purple (No. I 58 )

II. Watermarked Crown and SA, letters wide apart.

$I^{\circ}$ Rouletted.

I2II 2p orange red (No. I05)

$2^{\circ}$ Perforated Iox rouletted

I $2122 \mathrm{p}$ orange red (No. 137)

$3^{\circ}$ Perforated ro.

I213 2p orange red (No. 138 )

$4^{\circ}$ Perforated Ioxi I $1 / 2$, I $21 / 2$ irregularly

I2I4 2p orange red (No. I66)

III. Watermarked V over Crown.

Perforated IO.

I215 2p orange red (No. 193)

S.T. (Superintendent of Telegraphs). A. Red surcharge.

Watermarked a large six rayed star with long narrow points.

Rouletted.

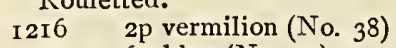

I $2176 \mathrm{p}$ blue (No. 40)

Varieties: Without period after $\mathrm{T}$.

I2I 8 2p vermilion (No. 38 )

I219 6p blue (No. 40) 
B. Blue surcharge.

III. Watermarked Crown and SA, letters wide apart.

$$
\text { I }^{0} \text { Rouletted. }
$$

I2 202 p orange red (No. I05)

$2^{\circ}$ Perforated I I $1 / 2$.

I22I 2p orange red (No. IOg)

C. Black surcharge.

I. Watermarked a large six rayed star with long narrow points.

Rouletted.

$12222 p$ orange red (No. 126)

12236 blue (No. 40)

1I. Watermarked Crown and SA, letters wide apart.

$I^{\circ}$ Rouletted.

$12242 \mathrm{p}$ orange red (No. I05)

$2^{\circ}$ Perforated Iox rouletted.

I 225 2p orange red (No. I37)

$3^{\circ}$ Perforated Io.

1226 2p orange red (No. I38)

III. Watermarked V over Crown.

Perforated Io.

I227 2p orange red (No. I93)

T. (Treasury).

A. Red surcharge.

Watermarked a large six rayed star with long narrow points.

I ${ }^{\circ}$ Rouletted.

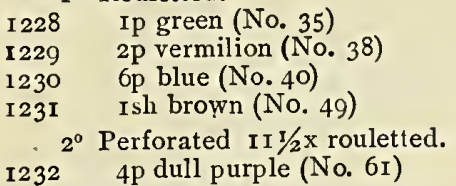

12324 p dull purple (No. 6I)

B. Blue surcharge,

I. Watermarked a large six rayed star with long narrow points.

Rouletted.

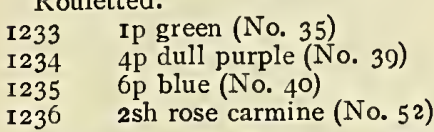

I236 2sh rose carmine (No. 52)

II. Watermarked Crown and SA, letters wide apart.

Rouletted.

I237 2p orange red (No. I05)

C. Black surcharge.

I. Watermarked a large six rayed star with long narrow points.

I $^{\circ}$ Rouletted.

\begin{tabular}{|c|c|}
\hline $\begin{array}{l}\text { I } 238 \\
\text { I } 239 \\
\text { I } 240\end{array}$ & $\begin{array}{l}2 \mathrm{p} \text { orange red (No. I } 26) \\
6 \mathrm{p} \text { blue (No. } 40) \\
2 \text { sh rose carmine (No. } 52 \text { ) }\end{array}$ \\
\hline $\begin{array}{l}241 \\
242\end{array}$ & $\begin{array}{l}\text { Perforated I I } 1 / 2 \times \text { rouletted. } \\
\text { 6p blue (No. 62) } \\
\text { Ish brown (No. 64) }\end{array}$ \\
\hline $\begin{array}{l}\text { I } 243^{3^{\circ}} \\
\text { I } 244 \\
\text { I } 245 \\
\text { I } 246 \\
\text { I247 } \\
\text { I248 }\end{array}$ & $\begin{array}{l}\text { Perforated I I } 1 / 2 \text {. } \\
4 \mathrm{p} \text { dull purple (No. 73) } \\
\text { 4p dull purple (No. I 7I) } \\
6 \mathrm{p} \text { blue (No. } 74 \text { ) } \\
6 \mathrm{p} \text { blue (No. I 73) } \\
\text { ish brown (No. } 75 \text { ) } \\
\text { 2sh pale rose carmine (No. 77) } \\
\text { 2sh deep carmine lake (No. I76) }\end{array}$ \\
\hline $\begin{array}{l}1254^{\circ} \\
\text { I } 251 \\
\text { I } 252 \\
\text { I } 253 \\
\text { I } 254 \\
\text { I } 255\end{array}$ & $\begin{array}{l}\text { Perforated I I } 1 / 2 \times 121 / 2 . \\
\text { 4p dull purple (No. } 84) \\
\text { 4p dull lilac (No. I82) } \\
6 \mathrm{p} \text { blue (No. } 85) \\
6 \mathrm{p} \text { blue (No. I 73) } \\
\text { Ish brown (No. 75) } \\
\text { 2sh pale rose carmine (No. 77) }\end{array}$ \\
\hline
\end{tabular}

$5^{\circ}$ Perforated I I $1 / 2 \times 121 / 2$

4 p dull purple (No. 84)

I258 4p dull lilac (No. I 82)

I $2596 \mathrm{p}$ blue (No. 85)

I260 $6 \mathrm{p}$ blue (No. I 84 )

I26I Ish brown (No. 87)

I262 2sh pale rose carmine (No. 89)

I 263 2sh deep carmine lake (No. I86)

$6^{\circ}$ Perforated ro.

I264 Ip green (No. I3r)

I265 6p blue (No. I35)

$7^{\circ}$ Perforated IOxII $1 / 2$, I $2 \mathrm{I} / 2$ irregularly.

I266 Ish brown (No. I62)

I 267 sh pale rose carmine (No. I63)

I268 2sh deep crimson lake (No. I64)

II. Watermarked Crown and SA, letters wide apart.

$I^{0}$ Rouletted.

I269 2p orange red (No. I05)

$2^{\circ}$ Perforated Io.

$2702 p$ orange red (No. I38)

Watermarked $\mathrm{V}$ over Crown.

$I^{\circ}$ Perforated Io.

I27I 2p orange red (No. I93)

T. (Titles Registry).

Black surcharge.

Watermarked a large six rayed star with long narrow points.

$I^{\circ}$ Perforated I I $1 / 2$

I272 4p dull lilac (No. I7 I)

I273 6p blue (No. I 73)

I274 Ish brown (No. I75)

$2^{\circ}$ Perforated II I $/ 2 \times 12 \frac{1}{2}$.

I275 4p dull lilac (No. I 82)

I $276 \quad 6 \mathrm{p}$ blue (No. I84)

I277 Ish brown (No. I85)

$3^{\circ}$ Perforated Ioxi I $1 / 2,12 \frac{1}{2}$ irregularly.

I 2784 dull purple (No. I 58 )

1279 6p blue (No. I60)

N. (Volunteers).

A. Red surcharge.

Watermarked a large six rayed star with long narrow points.

Rouletted.

I $280 \quad 2 \mathrm{p}$ vermilion (No. 38)

I28I 6p blue (No. 40)

I282 Ish brown (No. 49)

B. Black surcharge

I. Watermarked a large six rayed star with long narrow points.

Rouletted.

I $2836 \mathrm{p}$ blue (No. 40)

II. Watermarked Crown and SA, letters wide apart.

$I^{0}$ Rouletted

I 284 2p orange red (No. I05)

$2^{\circ}$ Perforated Io.

I $2852 p$ orange red (No. I 38 )

III. Watermarked V over Crown.

Perforated Io.

I 286 2p orange red (No. I93)

V. A (Valuator and Auctioneer). (no period after $\mathrm{A}$ ).

Black surcharge.

Watermarked Crown and SA, letters wide apart

Perforated Io.

I 287 2p orange red (No. I38)

V.N. (?)

Black surcharge.

Watermarked Crown and SA, letters wide apart. 
Perforated Io.

I 288 2p orange red (No. I38)

N. (Waterworks).

A. Red surcharge.

Watermarked a large six rayed star with long narrow points.

Rouletted.

$1289 \quad 2$ p vermilion (No. 38)

Variety: Printed on both sides.

I $290 \quad 2 \mathrm{p}$ vermilion
B. Black surcharge.

I. Watermarked a large six rayed star with long narrow points.

Perforated I I $1 / 2$

I29I 6p blue (No. 74)

II. Watermarked Crown and SA, letters wide apart.

I $^{\circ}$ Rouletted.

I 292 2p orange red (No. I05)

$2^{\circ}$ Perforated IO.

1293 2p orange red (No. I38)

OFFICIAL SERVICE STAMPS.

\section{A. Surcharged 0 in black.}

January, I874.

Surcharged on issues of I87o to July, I873.

I. Watermarked a large six rayed star with long narrow points.

I ${ }^{\circ}$ Perforated ro.

1294 4p dull purple (No. I33)

I 2954 P dull lilac (No. I34)

$2^{\circ}$ Perforated IOxI I $1 / 2$, I $21 / 2$ irregularly.

I296 Ip green (No. I 55)

12974 p dull purple (No. I 58)

I $2984 \mathrm{p}$ dull lilac (No. I 59)

12996 p Prussian blue (No. I60)

I300 6p dark blue (No. I6I)

I30I 2sh deep crimson lake (No. I64)

$3^{\circ}$ Perforated II $1 / 2$.

I302 IP green (No. I68)

1303 4p dull lilac (No. I 7 I)

I304 4P dull purple (No. I 72)

I 3056 p dark blue (No. I 73)

I306 6p Prussian blue (No. I 74)

$13079 \mathrm{p}$ violet (No. 203)

I308 Ish red brown (No. I 75)

I309 2sh deep carmine lake (No. I76)

Varieties : No period after S.

I3 I0 Ish red brown (No. I 75)

I3 Ioa 2sh deep carmine ake (No. I76)

I. Watermarked Crown and SA, letters wide apart.

I ${ }^{\circ}$ Perforated Io.

I3I I 2p deep orange red (No. I38)

I3I 2 p pale orange red (No. I39)

$2^{\circ}$ Perforated IOxII $1 / 2$, I $21 / 2$ irregularly.

I3I3 2p orange red (No. I66)

Variety: No period after S.

I3I $3 \mathrm{a}$ 2p deep orange red

January, $\leq 875$.

Watermarked Crown and SA, letters wide apart.

I $^{\circ}$ Perforated ro.

I3I4 Ip blue green

Variety: Surcharge inverted.

I3I5 Ip blue green

$2^{\circ}$ Perforated II $1 / 2 \times 10$.

I3I6 Ip blue green

$3^{\circ}$ Perforated II $1 / 2$

I3I7 Ip blue green

$4^{\circ}$ Perforated II $1 / 2 \times 121 / 2$.

I3I 8 Ip blue green

September, 1876 .

Watermarked a large six rayed star with short broad points.

I3I9 8p on 9p bistre brown, black surcharge

I $876-77$.

Watermarked a large six rayed star with short broad points.

$I^{\circ}$ Perforated Io.

I $320 \quad 6 \mathrm{p}$ dark blue $2^{\circ}$ Perforated IOXII $1 / 2,121 / 2$ irregularly.

I32I 4P dull purple

I322 4p dull lilac

I324 6p deep bright blue

I325 2sh bright crimson lake

Varieties: Surcharge inverted.

$1326 \quad 6 \mathrm{p}$ dark blue

I327 Ish red brown

I 328 2sh bright crimson lake

$3^{\circ}$ Perforated II $1 / 2$.

I 329 3p on $4 \mathrm{p}$ dark blue, black surcharge

I330 4p dull purple

I33I 4 P dull lilac

I332 6p dark blue

I333 6p deep bright blue

I334 Ish red brown

I 335 2sh bright crimson lake

arieties:

a. Surcharge inverted.

I336 Ish red brown

b. Double surcharge.

I337 6p deep bright blue

$4^{\circ}$ Perforated I I $1 / 2 \times 121 / 2$.

$1338^{4} \quad 3 \mathrm{p}$ on $4 \mathrm{p}$ dark blue, black surcharge

I $3394 \mathrm{p}$ dull purple

I $340 \quad 4 \mathrm{p}$ dull lilac

I34I $6 \mathrm{p}$ dark blue

$13426 \mathrm{p}$ deep bright blue

I343 Ish red brown

I344.2sh bright crimson lake

Varieties :

a. Surcharge inverted.

I 345 Ish red brown

I346 2sh bright crimson lake

b. Double surcharge.

I 347 2sh bright crimson lake

c. No period after $\mathrm{S}$.

I $347 \mathrm{a}$ 2sh bright crimson lake

$5^{\circ}$ Perforated I $21 / 2 \times 1$ I $1 / 2$.

I $348 \quad 6 \mathrm{p}$ dark blue

I349 Ish red brown

I350 2sh bright crimson lake

Varieties: Perforated $121 / 2$ on one side and $I I / 2$ on the others.

I35I 6p dark blue

I352 2sh bright crimson lake

$6^{\circ}$ Perforated $121 / 2$.

I353 Ish red brown

I 877 .

Watermarked Crown and SA,letters close togetlier.

$I^{\circ}$ Perforated Io.

I354 Ip blue green

I $354 \mathrm{a}$ IP dark yellow green

I355 2p pale orange red

I356 2p dark orange red

I357 2p dull pale yellow

I358 2p blood red

Varieties :

a. Surcharge inverted.

I359 Ip pale green

$1360 \quad 2 \mathrm{p}$ pale orange red

I36I 2p dark orange red 
b. Double surcharge

I362 Ip blue green

I 363 2p pale orange red

I364 $2 \mathrm{p}$ dark orange red

c. Triple surcharge.

I365 2p dark orange red

d. Without period after $O$.

I366 Ip blue green

I $3672 p$ orange red

e. Without period after S.

I368 Ip blue green

1369 2p orange red

f. Without periods.

I370 Ip blue green

I37I 2p orange red

g. Double surcharge, one inverted.

I372 Ip blue green

I $3732 \mathrm{p}$ orange red

h. Surcharged sideways.

I374 2p orange red

$2^{\circ}$ Perforated II $1 / 2 \times$ xIO.

I375 Ip blue green

I376 Ip dark yellow green

I377 2p dark orange red

$3^{\circ}$ Perforated Ioxi2 $1 / 2$.

$1378^{\circ}$ Ip dark yellow green

I379 2p dark orange red

$4^{0}$ Perforated II $1 / 2 \times 121 / 2$.

I $380 \quad 2 \mathrm{p}$ dark orange red I880.

A. Watermarked a large six rayed star with short broad points.

$I^{\circ}$ Perforated 10xiI $1 / 2$.

I 38 I 4P reddish purple

Varieties:

a. Surcharge inverted.

I382 $4 \mathrm{p}$ reddish purple

b. Double surcharge.

I $383 \quad 4 \mathrm{p}$ reddish purple

c. Without period after $O$.

I $3844 \mathrm{p}$ reddish purple

d. Without period after $S$.

I $3854 \mathrm{p}$ reddish purple

$\mathbf{2}^{\circ}$ Perforated Iox I $21 / 2$

I386 4p reddish purple

Varieties:

a. Surcharge inverted.

I $3874 \mathrm{p}$ reddish purple

b. Without period after $O$.

I388 4P reddish purple

c. Without period after $\mathrm{S}$.

I389 4P reddish purple

$3^{\circ}$ Perforated II $1 / 2$.

I390 4p reddish purple

I39I $8 \mathrm{p}$ on 9p yellow brown, black sur-

Varieties:

$$
\text { charge }
$$

a. Surcharge inverted.

I392 4P reddish purple

b. Double surcharge.

I393 8p on 9p yellow brown, black surcharge

$4^{\circ}$ Perforated I I $1 / 2 \times 121 / 2$

$1394 \quad 4 \mathrm{p}$ reddish purple

I 395 8p on 9p yellow brown. black surcharge

$5^{\circ}$ Perforated 1 I $1 / 2 \times$ io.

13964 4p reddish purple

$6^{\circ}$ Perforated IOxIOxII $1 / 2 \times 121 / 2$.

I $3974 \mathrm{P}$ reddish purple

$7^{0}$ Perforated IOxIOxI2 $1 / 2 \times 1$ I $1 / 2$

I398 4P reddish purple

B. Watermarked Crown and SA, letters close together.

Perforated Io.

I399 2p dark brown
January Ist, I 882 .

Watermarked Crown and SA, letters close together.

Perforated Io.

I $400 \quad 1 / 2 \mathrm{p}$ on Ip green, black surcharge

Variety:

I 4 I I $1 / 2 \mathrm{p}$ on IP green, black surcharge

December, 1884 .

Watermarked a large six rayed star with

short broad points.

$I^{\circ}$ Perforated Ioxir $1 / 2$.

I 402 6p pale ultramarine

Variety: Surcharge inverted.

I $4036 \mathrm{p}$ pale ultramarine

$2^{\circ}$ Perforated Ioxi $21 / 2$

I404 6p pale ultramarine

Varieties:

a. Surcharge inverted

I $4056 \mathrm{p}$ pale ultramarine

b. Double surcharge, one inverted.

I 406 6p pale ultramarine

$3^{\circ}$ Perforated IoxIoxI I 1 $/ 2 \times 121 / 2$.

$14076 \mathrm{p}$ pale ultramarine

$4^{\circ}$ Perforated Iox $\operatorname{IOx} 21 / 2 \times 121 / 2$.

I 408 6P pale ultramarine

I 886 .

Watermarked a large six rayed star with short broad points. Hard, thick, white wove paper.

I ${ }^{\circ}$ Perforated Ioxir $1 / 2$.

I $4094 \mathrm{p}$ reddish purple

I4IO 6p pale ultramarine

Varieties:

a. Surcharge inverted.

I4 I I 4P reddish purple

I4I2 6p pale ultramarine

b. No period after $S$.

I4I3 4p reddish purple

$2^{\circ}$ Perforated IOxI $21 / 2$.

I4I4 4P reddish purple

I4I5 6p pale ultramarine

arieties.

a. Surcharge inverted.

I4I6 $4 \mathrm{P}$ reddish purple

b. Without period after S.

I4I7 6p pale ultramarine

$3^{\circ}$ Perforated I I $1 / 2$.

Surcharge inverted.

I4I 8 4P reddish purple

$4^{0}$ Perforated IOxIOxI $21 / 2 \times 1$ I $1 / 2$.

I4I9 4p reddish purple

December, $\mathbf{I} 886$.

Watermarked Crown and SA, letters close together,

Perforated Io.

I $420 \quad 5 \mathrm{sh}$ rose

April 2d, I887.

Watermarked Crown and SA, letters close together.

Perforated ro.

I42I $6 \mathrm{p}$ blue

June, I 890 .

Watermarked Crown and SA, letters close together.

Perforated Io.

I $4224 \mathrm{p}$ light violet

June rst, r89r.

Watermarked Crown and SA, letters close together.

Io Perforated Io.

I423 $21 / 2 \mathrm{p}$ on $4 \mathrm{p}$ green, brown surcharge

$2^{\circ}$ Perforated II $1 / 2 \times$ IO.

$142421 / 2 \mathrm{p}$ on $4 \mathrm{p}$ green, brown surcharge

$3^{\circ}$ Perforated IOxII $\mathrm{J} / 2$.

$14252 \frac{1}{2} \mathrm{p}$ on $4 \mathrm{p}$ green, brown surcharge 
$4^{\circ}$ Perforated IOxI2 $1 / 2$

$14262 \mathrm{r} / 2 \mathrm{p}$ on $4 \mathrm{p}$ green, brown surcharge

$5^{\circ}$ Perforated II $1 / 2$.

$14272 \mathrm{r} / 2 \mathrm{p}$ on $4 \mathrm{p}$ green, brown surcharge

B. Surcharged $\mathrm{N}_{0}$ in black.

April, I89r.

I. Watermarked a large six rayed star with short broad points.

Perforated II $1 / 2 \times 121 / 2$.

I428 Ish red brown

II. Watermarked Crown and SA, letters close together.

I0 Perforated Io.

I $428 \mathrm{a} \quad \mathrm{r} / 2 \mathrm{p}$ brown

I429 Ip blue green

I430 $2 \mathrm{p}$ orange red

I43 I 4p light blue

1432 6p blue

Varieties:

a. Double surcharge.

I433 Ip blue green

I434 2p orange red

b. Surcharge inverted.

I435 Ip blue green

c. Without period after $\mathrm{O}$

$143^{6}$ Ip blue green

d. Without period after $\mathrm{S}$.

I437 Ip blue green

I438 2p orange red

e. Without periods.

I439 Ip blue green

$f$. With $O$ only.

I440 Ip blue green

g. Dark blue surcharge.

I44I Ip blue green

January IIth, I882.

Stamp typographed in upper right part of the wrapper. To the left ot the stamp is the inscription "sOUTH AUSTRALIA-NEWSPAPER ONLY" in two lines, separated by a dash, and with the coat of arms of Great Britain between SOUTH and AUSTRALIA.

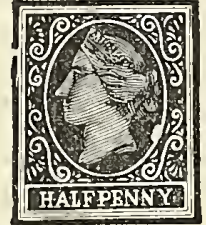

White wove paper.

$I^{\circ}$ Size I IOX285 $\mathrm{mm}$

I60I $\quad 1 / 2 \mathrm{p}$ purple

$2^{\circ}$ Size $\mathrm{r} 42 \times 445 \mathrm{~mm}$.

I $602 \quad \mathrm{r} / 2 \mathrm{p}$ purple

I 884 .

Stamp similar to the preceding issue, but re-engraved. The spandrels are more ornamented, the letters of HALFPENNY are more spaced and the lines forming the shading of the face are more horizontal. The inscriptions on the wrapper are the same as in the preceding issue, but in a somewhat larger type. $2^{\circ}$ Perforated II $1 \%$.

$1442 \quad 1 / 2 \mathrm{p}$ pale red brown

$3^{\circ}$ Perforated II $1 / 2$ at one side, Io at the others.

I443 $\mathrm{x} / 2 \mathrm{p}$ pale red brown

June Ist, I 89 I.

Watermarked Crown and SA, letters close together.

Perforated Io.

I $4442 \mathrm{r} / 2 \mathrm{p}$ on $4 \mathrm{p}$ green, brown surcharge

I445 $5 \mathrm{p}$ on $6 \mathrm{p}$ red brown, carmine surcharge

Variety: No period after S.

I 445a $5 \mathrm{p}$ on $6 \mathrm{p}$ red brown, carmine surI 893 . charge

Watermarked Crown and SA, letters close together.

Io Perforated Io.

I446 $3 \mathrm{p}$ dull green

$2^{\circ}$ Perforated 15.

I447 Ip green

I448 2p orange red

I449 $2 \mathrm{r} / 2 \mathrm{p}$ violet blue

r 450 3p dull green

I45I $4 \mathrm{p}$ blue violet

I452 5p dark violet I 896.

I. Watermarked Crown and SA, letters close together.

Perforated I 3 .

I453 Ip green

I454 2p red

II. Watermarked a large six rayed star with short broad points.

Perforated I I $1 / 2 \times 12 \mathrm{I} / 2$.

I 4552 sh carmine

WRAPPERS

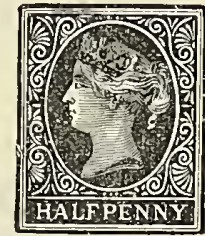

White wove paper.

Io Size IIOX $285 \mathrm{~mm}$.

$1603 \quad 1 / 2 \mathrm{p}$ purple

$2^{\circ}$ Size $142 \times 445 \mathrm{~mm}$.

I604 I/2p purple

I 885 .

Stamp and inscription same as in preceding issue.

Manila paper.

$I^{\circ}$ Size I I $3 \times 290 \mathrm{~mm}$

I605 $1 / 2 \mathrm{p}$ purple

$2^{\circ}$ Size $137 \times 442 \mathrm{~mm}$.

$1606 \quad 1 / 2 \mathrm{p}$ purple

r889.

Inscriptions same as in preceding issue, but stamp of the same type as one penny adhesive of corresponding date.

Manila paper.

Size $145 \times 283 \mathrm{~mm}$

I607 Ip green

OFFICIAL WRAPPERS.

I882.

Wrappers of corresponding date with stamp surcharged in black.

I. Surcharged. 0

White wove paper.

$I^{\circ}$ Size IIOX285 $\mathrm{mm}$

I 7oI $1 / 2 \mathrm{p}$ purple, black surcharge

$2^{\circ}$ Size $142 \times 445 \mathrm{~mm}$.

I702 1/2p purple, black surcharge

II. Surcharged

O.S. 
White wove paper.

$I^{\circ}$ Size I IOX $285 \mathrm{~mm}$

I 703 1 $/ 2 \mathrm{P}$ purple, black surcharge

$2^{\circ}$ Size $142 \times 445 \mathrm{~mm}$.

I $704 \quad 1 / 2 \mathrm{p}$ purple, black surcharge

r884.

Wrappers of corresponding issue sur-

\section{charged in black 0.}

White wove paper.

$I^{\circ}$ Size I rox $285 \mathrm{~mm}$.

I705 1/2p purple, black surcharge

$2^{\circ}$ Size I $42 \times 445 \mathrm{~mm}$.

I706 $1 / 2 \mathrm{p}$ purple, black surcharge
1885.

Wrappers of corresponding date surcharged as the wrappers of the preceding issue.

Manila paper.

$\mathrm{I}^{\circ}$ Size II $3 \times 290 \mathrm{~mm}$

I $707 \quad 1 / 2 \mathrm{p}$ purple, black surcharge

$2^{\circ}$ Size I $37 \times 442 \mathrm{~mm}$.

I708 1/2 $\mathrm{p}$ purple, black surcharge

1889.

Wrappers of corresponding date surcharged as in preceding issue.

Manila paper.

Size $145 \times 283 \mathrm{~mm}$.

r709 Ip green, black surcharge

COUNTERFEITS.

We do not know of any good forgeries of the stamps of this colony, with the exception of the surcharges of the official stamps. These forged surcharges can, however, be detected by the impression, which is not so clear and bold as that of the genuine, being generally made by hand instead of by press.

\section{SOUTH BULGARIA.}

Currency : 40 PARAS $=$ I PIASTRE $=\$ 0.05$ U. S. Currency.

\section{ADHESIVE STAMPS.}

September 22d, 1885 .

Adhesive stamps of Eastern Roumelia of 188I-I884, surcharged a lion in blue or black.

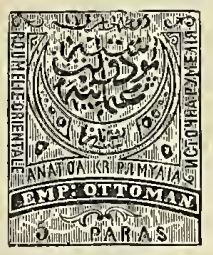

There are two types of this surcharge. In type I the second paw of the lion has four claws and the end of the tail is bushy. In type II the second paw has three claws, the end of the tail is pointed and the second and fourth paws have spurs.

A. Type I.

\section{Blue surcharge}

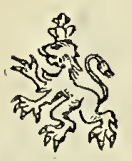

ro Perforated $131 / 2$

5pa black and olive, blue surcharge

2opa black and rose "“ "“

rpia black and blue " " "

5 pia rose and blue

Varieties:

a. Surcharge inverted.

5 2opa black and rose, blue surcharge

b. Double surcharge.

65 pa black and olive, blue surcharge

c. Pair, one without surcharge. Ipia black and blue, blue surcharge

$2^{\circ}$ Perforated II $1 / 2$.

$85 \mathrm{pa}$ violet, blue surcharge

9 ropa green "“ ".

ro zopa carmine "

Varieties:

a. Surcharge inverted.

II 5 pa violet, blue surcharge

I2 ropa green

Double surcharge.

5pa violet, blue surcharge

ropa green

Triple surcharge.

I5 Iopa green, blue surcharge d. Pair, one without surcharge.

I6 ropa green, blue surcharge

II. Black surcharge.

I 0 Perforated $13 \% / 2$.

7 2opa black and rose, black surcharge

I8 Ipia black and blue " "

I9 5pia rose and blue

Varieties :

a. Double surcharge.

2o Ipia black and blue, black surcharge

b. Triple surcharge.

2I Ipia black and blue, black surcharge

c. Pair, with a third surcharge between the first two.

22 Ipia black and blue, black surcharge

$2^{0}$ Perforated II $1 / 2$

235 pa violet, black surcharge

24 ropa green "“ ".

25 2opa carmine " "

Varieties :

a. Surcharge inverted.

265 pa violet, black surcharge

b. Double surcharge.

$27 \quad 5 \mathrm{pa}$ violet, black surcharge

B. Type II.

I. Blue surcharge.

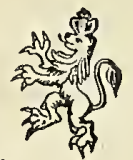

$I^{\circ}$ Perforated $\mathrm{r} 3 \mathrm{t} / 2$. 5pa black and olive, blue surcharge sopa black and rose

rpia black and blue " "“ 5 pia rose and blue

Varieties:

a. Surcharge inverted.

325 pa.black and olive, blue surcharge

33 2opa black and ros

b. Double surcharge.

2opa black and rose, blue surcharge

c. Pair, one without surcharge.

35 2opa black and rose, blue surcharge

$2^{\circ}$ Perforated I I $\mathbf{x} / 2$.

365 pa violet, blue surcharge

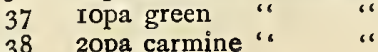




\section{Varieties:}

a. Surcharge inverted.

395 pa violet, blue surcharge

Double surcharge.

$40 \quad 5 \mathrm{pa}$ violet, blue surcharge

4 I 20 a carmine "

II. Black surcharge.

I0 Perforated I3 $1 / 2$.

42 2opa black and rose, black surcharge

43 Ipia black and blue, black surcharge

445 pia rose and blue

Variety: Pair, one without surcharge.

45 I pia black and blue, black surcharge

$2^{\circ}$ Perforated II $1 / 2$.

465 pa violet, black surcharge

47 Iopa green “" “"

Varieties:

a. Surcharge inverted.

$495 \mathrm{pa}$ violet, black surcharge

50 Iopa green

b. Double surcharge.

5 I 5 pa violet, black surcharge

52 2opa carmine

c. Tête bêche.

53 Iopa green, black surcharge

September 24 th, I 885 .

Adhesive stamps of Eastern Roumelia of the issue of $188 \mathrm{I}-\mathrm{I} 884$, surcharged with lion in frame in black or blue.

There are also two types of this surcharge. In type I the right part of the first Russian character Io in the inscription above the lion is a rounded $\mathrm{O}$ and the brush of the tail of the lion is open. In type II the right part of the first Russian character is an oval $\mathrm{O}$ and the brush of the tail of the lion appears solid.

A. Type $\mathrm{X}$.

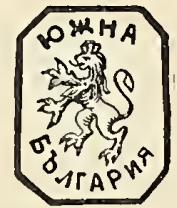

I. Blue surcharge.

Perforated I I $1 / 2$.

$545 \mathrm{pa}$ violet, blue surcharge

55 Iopa green

arieties:

a. Surcharge inverted.

$56 \quad 5 \mathrm{pa}$ violet, blue surcharge

57 Iopa green "“

b. Surcharge sideways.

$585 \mathrm{pa}$ violet, blue surcharge

59 ropa gree

c. Tête bêche.

6o $5 \mathrm{pa}$ violet, blue surcharge

6 I Iopa green “"

d. Double surcharge.

$625 \mathrm{pa}$ violet, blue surcharge

63 Iopa green “"

II. Black surcharge.

$I^{\circ}$ Perforated I $31 / 2$

645 pa black and blue, black surcharge

65 Iopa black and green "“ "

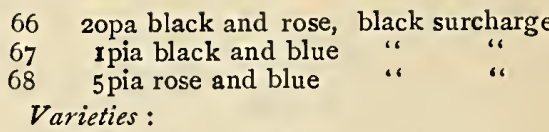

a. Surcharge inverted.

$695 \mathrm{pa}$ black and blue, black surcharge

70 2opa black and rose “ “ “

7 I I pia black and blu

b. Double surcharge.

72 2opa black and rose, black surcharge

c. Pair, one with type I with lion only and the other with lion with frame.

73 2opa black and rose

$2^{\circ}$ Perforated II $1 / 2$.

$74 \quad 5$ pa violet, black surcharge

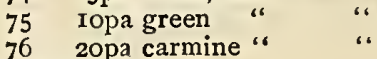

Varieties:

a. Surcharge inverted.

77 5pa violet, black surcharge

78 Iopa green " "

79 20pa carmine “

b. Surcharge sideways.

$80 \quad 5 \mathrm{pa}$ violet, black surcharge

c. Tête bếche.

825 pa violet, black surcharge

83 Iopa green “"

d. Double surcharge.

$84 \quad 5$ pa violet, black surcharge

85 Iopa green "“ " 86 "opa carmine "

e. Pair, with a third surcharge between the first two.

$87 \quad 5 \mathrm{pa}$ violet, black surcharge

B. Type II.

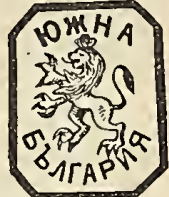

I. Blue surcharge

Perforated $1 \mathrm{I} 1 / 2$.

$88 \quad 5 \mathrm{pa}$ violet, blue surcharge

89 Iopa green "

II. Black surcharge.

$I^{\circ}$ Perforated I $^{1 / 2}$

go $5 \mathrm{pa}$ black and olive, black surcharge

9I 2opa black and rose "“ "“

92 Ipia black and blue "“ " "

935 pia rose and blue

Variety: Double surcharge.

94 Ipia black and blue, black surcharge

$2^{0}$ Perforated II $1 / 2$.

95 5pa violet, black surcharge

96 Iopa green "“ "“

97 2opa carmine

Varieties:

a. Surcharge inverted.

$98 \quad 5 \mathrm{pa}$ violet, black surcharge

99 Iopa green “،

b. Double surcharge.

Ioo $5 \mathrm{pa}$ violet, black surcharge

IOI IOpa green "، " "

IO2 2Opa carmine " "

\section{COUNTERFEITS.}

There are a good many forgeries of these stamps, but careful comparison with the various types, as given by us, will generally be sufficient to distinguish the bad from the good. 

